\title{
J(৫)
}

Received: 14.05 .2020

Accepted: 29.05 .2020

Published: 14.06 .2020

JOTS, 4/2, 2020: 546-731

\section{Die Lehre des Buddha und das Königshaus des Westuigurischen Reichs: Die vier Begegnungen}

\section{Buddha'nın Öğretisi ve Batı Uygur Kağanlı̆̆ Hanedanı: Dört Karşılaşma}

\author{
Peter ZIEME \\ Berlin/Germany \\ E-mail: ziemepet@gmail.com
}

In 2019 Abdurishid Yakup edited a significant old Uighur text from the National Library in Beijing in the journal "Turkic Languages", which is of importance for research into the Central Asian religious history of the Middle Ages beyond its turkological interest. Since in the meantime further copies have appeared, through which some difficult passages of the text can be interpreted in a new light, it is appropriate to dare to revise it, even if new problems come into the limelight again. This is a kind of religious memorandum, which was intended to encourage the royal house to turn to Buddhism. Uighur Buddhists bear witness to the colourful expressions of the classical literature of the Old Uighur period, although the manuscripts themselves probably date more from the Mongolian period of the 13th and 14th centuries.

Key Words: Buddhism, Four Encounters of the Legendary Buddha Biography, Western Uighur Royal Family, Old Uighur language. 


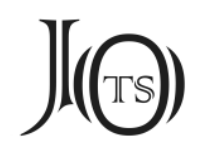

\section{Vorbemerkung}

Mit den Text- und Kunstfunden aus den Oasen-Regionen rund um die zentralasiatische Taklamakan seit dem letzten Drittel des XIX. Jahrhunderts begann für die Erforschung der Geschichte der Weltreligionen eine neue Etappe, nicht nur des Manichäismus und des Christentums, sondern insbesondere auch des Buddhismus. Mit seiner Ausbreitung von Gandhāra bis Dunhuang sind in den Stadtstaaten und Königreichen entlang der südlichen und nördlichen Seidenstraßen im I. Jahrtausend lokale Ausprägungen durch Übersetzungen aus der Gāndhārī-Sprache, aus dem Sanskrit, aus dem Chinesischen, aus dem Tibetischen in die Sprachen von Baktriern, Tocharern, Saken, Sogdern und seit dem IX.-X. Jahrhundert auch von Uiguren entstanden. Des weiteren gab es auch Übertragungen von einer Lokalsprache in eine andere wie beispielsweise aus dem Tocharischen ins Altuigurische. Für die Zeit seit dem 10. Jh. sind durch neuere Forschungen auch die Beziehungen $\mathrm{zu}$ den Kitan und Tanguten beleuchtet worden (Kitsudō 2013). Mit dem Mongolischen Kaiserreich einher ging eine Erhaltung und Verstärkung der buddhistischen Kulturen. Vielfältige Forschungen haben neue Erkenntnisse über die Buddhisten im Westuigurischen Königreich sowie im Mongolischen Reich erbracht, doch noch immer hat die Edition von bisher nicht erschlossenen Materialien einen hohen Stellenwert, weil neue Texte das in Umrissen schon erkennbare Bild über den altuigurischen Buddhismus im Detail ergänzen oder verändern. Da mit der Mission und Verbreitung zunächst ein riesiges Übersetzungswerk in Gang gesetzt werden mußte, basiert die Forschung in erster Linie auf vergleichenden Studien zwischen Geber- und Nehmersprachen. Doch ist diese nicht nur l'art pour l'art, denn sie resultiert über Betrachtungen, wie der Buddhismus adaptiert wurde, hinaus in neuen Erkenntnissen zum Wortschatz und zur Grammatik des Alttürkischen, meßbar in den bedeutenden Projekten der Grammar of Old Turkic, der Old Turkic Word Formation und des Uigurischen Wörterbuches.

Ein Nebenprodukt des genannten Übersetzungswerkes, das seit einigen Jahren in den Fokus gerückt werden konnte, ist die Betrachtung, ob man auch mit originalen altuigurischen Texten rechnen kann. An der Tatsache selbst bestehen kaum Zweifel, weil auch uigurische buddhistische Mönche oder 


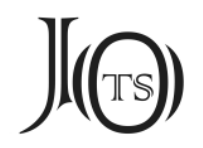

Nonnen sich bemüßigt fühlen konnten, Beiträge zur Verbreitung der Lehre des Erhabenen $\mathrm{zu}$ leisten. Es ist allerdings angesichts vieler unscheinbarer Fragmente oft nicht leicht, eindeutige Festlegungen zu treffen. Es ist hier nicht der Ort, alle diese Bemühungen vorzustellen. Doch der hier zu erörternde Text darf mit großer Sicherheit als ein wichtiges Beispiel eines Originaltextes gelten. Dieses Ergebnis möge durch die folgende Studie erhärtet werden, sie folgt damit dem Motto, mit dem J. P. LAUT und K. RöHRBORN einen Sammelband einleiteten: „Das älteste Schrifttum der Türken ist ein besonderes Anliegen der deutschen Turkologie“ $(1990)^{1}$.

Abdurishid YAKUP hat 2019 in der Zeitschrift Turkic Languages einen altuigurischen Text der Pekinger Nationalbibliothek ediert, der über das turkologische Interesse hinaus für die Erforschung der zentralasiatischen Religionsgeschichte des Mittelalters von Bedeutung ist. Zunächst ist hervorzuheben, daß es sich bei diesem Text nicht um ein Unikat handelt, denn außer dem von YAKUP edierten Fragment gibt es Reste von weiteren Handschriften ${ }^{2}$, von denen mindestens eine (Handschrift $G$ ) auch aus der Zeit stammen könnte, in welche der anzunehmende kulturelle und religiöse Hintergrund des Textes am ehesten passen könnte, also in die Milleniumswende ${ }^{3}$, als das Königshaus sich endgültig vom Manichäismus losgesagt hatte und den Buddhismus annahm. Der Text, von wem er auch immer verfaßt wurde, ist eine Art Memorandum, das in diese neue kulturell-religiöse Ausrichtung wirken sollte. Daß noch weitere Abschriften, die Kopien der Handschrift A oder eines anzunehmenden Urtexts darstellen, sowie einige Fragmente, die nicht sicher bestimmbar sind, erhalten sind, zeugt sicherlich von

1 Laut-Röhrborn 1990, VII. Die philologischen Studien zur altuigurischen Kultur haben auch in China, Japan, Rußland und in der Türkei in den letzten Jahrzehnten deutlich zugenommen, wodurch mehr und mehr ein das Fachgebiet fördernder Austausch von Forschungsergebnissen möglich sein wird.

Vgl. den Abschnitt "Handschriften".

3 V. HANSEN hat die globale Bedeutung dieser Zeit für die kulturellen und politischen Konstellationen zwischen China und den nördlich und nordwestlich gelegenen Staaten aufgezeigt. Sie nennt die religiösen Konversionen, die sich weltweit um das Jahr 1000 abspielten (2020: 120-121), und in diese Tabelle gehört durchaus auch die Hinwendung des uigurischen Königshauses zum Buddhismus, nicht zuletzt auch deshalb, weil damit die Glanzzeit des Manichäismus als Weltreligion dem Ende nahe war. 


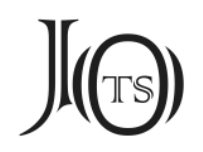

einer großen Beliebtheit und weiten Verbreitung dieses Themas bei den Uiguren. Wenn auch die meisten Abschriften wohl erst in der Yuan-Zeit entstanden sind, gehört der Text wegen des schon angedeuteten Hintergrunds in die Epoche der Konsolidierung des Westuigurischen Reichs mit einer eindeutigen Ausrichtung auf den Buddhismus als staatstragende Religion, also vermutlich in die Zeit vom Ende des X. zum Anfang des XI. Jahrhunderts.

An dieser Stelle drücke ich meinen Dank aus allen, die das Zustandekommen dieser Arbeit gefördert haben, den Kolleginnen und Kollegen der Langzeitprojekte Turfanforschung der Berlin-Brandenburgischen Akademie der Wissenschaften (BBAW) und Katalogisierung der Orientalischen Handschriften in Deutschland (KOHD) der Akademie der Wissenschaften zu Göttingen, insbesondere Simone-Christiane RASCHMANN, die eine frühere Version gelesen und mir wertvolle Hinweise $z u$ den Texten gegeben hat. Da die Fragmente der Berliner Turfan-Sammlung der BBAW leicht als Digitalisate zugänglich ${ }^{4}$ und in der Digitalversion der KOHD von Simone-Christiane RASCHMANN ${ }^{5}$ beschrieben sind, werden im Anhang nur Beispiele als Faksimiles beigefügt. Für die Möglichkeit, an den Texten der Serindia-Sammlung des Institute of Oriental Manuscripts (IOM) der Russischen Akademie der Wissenschaften zu arbeiten, danke ich Irina F. PopovA, der Direktorin des IOM, sowie den Betreuerinnen der Serindia-Sammlung. Die hier bearbeiteten Fragmente werden im Katalog der uigurischen Texte der Serindia-Sammlung ${ }^{6}$ beschrieben.

Besonderer Dank richtet sich an Dr. Liu Bo 劉波 von der Abteilung „Dunhuang and Turpan Literature Section“ der National Library of China 中國 國家圖書館古籍館敦煌文獻組 für die Fotos der Haupthandschrift.

\footnotetext{
Digitales Turfan-Archiv (DTA) der Berlin-Brandenburgischen Akademie der Wissenschaften.

5 Datenbank “KOHD Digital” der Akademie der Wissenschaften zu Göttingen.

6 Projekt einer Zusammenarbeit des IOM/St. Petersburg und des Toyo Bunko/Tokyo. Der 1. Band wird die publizierten altuigurischen Texte der Serindia-Sammlung umfassen und voraussichtlich 2021 erscheinen.
} 


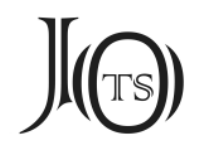

Herrn He HoNG 何鴻, dem Inhaber der Lujiang Caotang-Sammlung 盧江草 堂 in Hangzhou, danke ich für die freundliche Bereitstellung eines Textes wie auch für die Erlaubnis, diesen zu edieren.

\section{Einleitung}

\section{I.1. Zum Inhalt des Werkes und zur Textstruktur}

Dieser Text ist eine Abhandlung über Grundsätze des Buddhismus in einer der Laienschaft leicht verständlichen Sprache. Er ist klar strukturiert, und zwar derart, daß jeder Abschnitt mit einer Einleitung, einer Hinwendung an das Königshaus, beginnt, die allerdings in sehr allgemeiner Art gehalten ist. Dann folgen Passagen, deren Wortlaut jeweils einen der Grundsätze über Alter, Krankheit, Tod und Mönchtum exemplifizieren. Abgeleitet aus den vier Begegnungen des Prinzen mit einem Greis, einem Kranken, einem Leichenzug und einem Mönch, geben sie nach der Buddhalegende den Anstoß zu einem Nachdenken über die Welt und ihr Elend, das letztlich zum Umdenken und zur Erleuchtung führt. Am Ende eines jeden Abschnitts wendet sich der Autor wieder an täyrim ,meine Majestät‘.

Keine der Handschriften ist vollständig, weshalb auch kein originärer Titel angegeben werden kann. Sicher aber ist, daß es sich nicht um eine Übersetzung handelt. Da in Handschrift A der Kolophon direkt auf den Schluß des Textes folgt, ist der Umfang des Gesamttextes auf etwa 150 Textzeilen (nach der Handschrift A) zu schätzen. Aus dem Kolophon erfahren wir nur den Namen des Schreibers: Činqongdu Tutuy K(l)ya. Der erste Bestandteil ist ein typischer Mönchsname, der auf chinesische Zeichen zurückzuführen ist. Weil die Rekonstruktion nicht ganz unumstritten ist, verweise ich an dieser Stelle auf die ausführliche Diskussion im Kommentar zum Kolophon.

Inhaltlich geht es in den Abschnitten um eine Darstellung der vier Begegnungen des Buddha, die hier aber in verallgemeinerter Form vorgestellt werden. Die Abfolge, so wie sie hier auch vorliegt, ist ein fester Bestandteil der Buddhabiographie. Die umfangreichste Handschrift (A) beginnt mit den Ausführungen zum ,Alter', dem Thema der ersten der vier Begegnungen des 


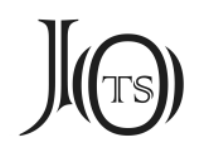

Prinzen Gautama, weshalb auch nicht sehr viel vom physischen Anfang der Handschrift fehlen dürfte, obwohl nach den Handschriften D und E zusätzliche Ausführungen anzusetzen sind.

Eine detaillierte und markante Schilderung der Vier Begegnungen enthält das sanskritische Mahāvadānasūtra, das durch E. WALDSCHMIDT erschlossen wurde (1953, 1956). Es ist eine Buddha-Biographie, die allerdings auf den Buddha Vipaśyin bezogen ist, aber die natürlich genauso auch auf Śākyamuni zutrifft. Aus dem Kapitel unter der Überschrift ,Vipaśyins Erlebnisse und Weltflucht seien hier einige Sätze zitiert, die von Interesse für den hier behandelten Text sind. Im Bericht des Wagenlenkers an den König Bandhumat ${ }^{7}$ heißt es über die zweite Ausfahrt: „Der Prinz, der zum Park hinausgefahren war, sah, Majestät, einen Mann, der totenblaß, dürr, ausgemergelt (und) von schlechter (Gesichts)farbe war, der abgestumpfte Sinne hatte und der abstoßend war für den Anblick vieler Menschen." (Weber 1999: 72) Zum König sagt er: „Auch Majestät haben die Eigenschaft der Krankheit und haben das Gesetz der Krankheit nicht überwunden." (Weber 1999: 73) Oder auch nach der Ausfahrt mit dem Anblick eines Toten: „Auch Majestät habe die Eigenschaft des Todes und haben das Gesetz des Todes nicht überwunden." (Weber 1999: 74)

Es ist klar, daß der Text auf buddhistischem Grundwissen und/oder möglicherweise auf bestimmten Texten basiert, dennoch darf man in diesem Fall wohl eine Neuschöpfung annehmen, denn die Struktur ist eindeutig nur im Milieu des Westuigurischen Königreichs vorstellbar. Es kam ja immer wieder darauf an, den Buddhismus nicht nur in den Klöstern anzunehmen und Texte zu übersetzen, sondern großer Wert mußte auch auf die Vermittlung an Laien, vor allem auch der adligen Gesellschaft, gelegt werden. Der vorliegende Text ist ein gutes Beispiel, wie das erfolgt sein könnte. Die klar strukturierte Abhandlung macht deutlich, wie sehr die Uiguren mit dem Buddhismus vertraut waren, was mutatis mutandis auch für andere buddhistische Texte gilt.

Dazu vgl. die altuigurische Version, wie sie u.a. in dem noch nicht edierten Fragment $\mathrm{Ch} / \mathrm{U} 6857$ vorliegt. 


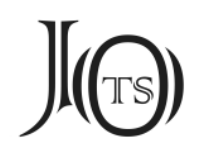

Trotz der Zuordnung zur Zeit des Westuigurischen Königreichs (X.-XI. Jh.) dürften die Handschriften spätere Abschriften repräsentieren, die eher in der Yuan-Zeit (XIII.-XIV. Jh.) geschrieben worden sind. Der einzige Kolophon nennt nur Monat und Tag, nicht einmal das Jahr des Zwölftierzyklus, wie es sonst oft der Fall ist.

YAKUP meint, daß der Text dazu auffordere, das säkulare Leben zu verlassen, oder konkreter sogar, daß eine Prinzessin den Weg einer Ordensschwester beschreiten solle (2019: 6). Doch erscheint es mir schwierig, aus dem Text diese Auffassung zu verifizieren, denn dieser richtet sich an das Königshaus, daß der Herrscher die Lehre des Buddha, ausgemalt an den vier Ausritten, beherzigen solle. Die Dichotomie von Reich und Religion wird eigentlich nicht angezweifelt. Wer oder was ist nun das Königshaus, wie ich in Ermangelung einer präziseren Formulierung die durch die Titelei Angesprochenen nenne? YAKUP gibt an einer Stelle der Annahme, es handele sich um eine weibliche Person ${ }^{8}$, den Vorzug, an anderer erwähnt er beide Geschlechter. Doch es gibt ausreichend Merkmale dafür, daß der König selbst angesprochen wird, nicht oder nicht nur die Königin. Von der darstellenden Kunst ist bekannt, daß königliche Spender meist oder oft als ein Paar präsentiert werden, und das betrifft sicher auch das Königshaus.

Wenn man den Adressaten Tägrikän Tegin Täyrim dahingehend interpretiert, daß er ein allgemeiner Repräsentant des Herrscherhauses ist, kann oder muß man in ihm den obersten Herrscher sehen, eher nicht eine konkrete Person, eventuell eben eine allgemeine Benennung des Königshauses annehmen.

Die angeredete Person, oder, wie aus dem Gesagten schon hervorgeht, die Personengruppe des Königshauses, trägt die Titelanhäufung: Tänrikän Tegin Täyrim mit folgenden Belegstellen: 007, 016, 028, 036/37, 049/50, 058, 064, 070,

\footnotetext{
So auch in der Editorial Note von L. JoHANSon, 1: “Abdurishid Yakup presents an edition of an old Uyghur text kept at the Beijing National Library, an appeal to a laywoman to give up her secular life and become a Buddhist nun. It is based on a similar Chinese text and even contains some characters used in that version. The edited text contains several words and expressions that are not found in previously known old Uyghur works, and it also displays a number of stylistically unique features."
} 


\section{J(৫)}

077/78, 087, 097/98, 104, 108, 121, 130, wobei in einem Fall (087) Täyrim fehlt. Das könnte allerdings durchaus ein Versehen sein.

In der Toyok-Inschrift (Imin 2020), die in die Zeit des Westuigurischen Königreichs zu datieren ist, kommen die drei Titel in verschiedenen konkreten Kombinationen vor. In der Punya-Weitergabe (Buyan ävirmäk) werden die vier höchsten Titel des Königshauses genannt:

1. t(ä)yri bügü tĐrikänim(i)z kut[lug] bügülüg ulug 1duk-kut kutına

2.t(ä)yrikän tegin kunčuy t(ä)yrim kutına

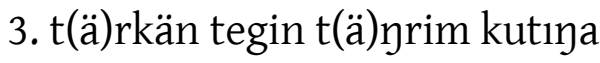

4. alp šingur tegin t(ä)yrim kutına. (Dazu vgl. Zieme 2020)

Durch kutıya ,der Majestät des/der XXX` werden die Titelgruppen klar abgegrenzt. Wenn man sie von oben nach unten betrachtet, so sieht man an erster Stelle den Idukkut, die ,Heilige Majestät', also quasi den König, gefolgt von seiner Gemahlin. Der dritte und der vierte Titel gehören vermutlich Prinzen. Es ist also zu vermuten, daß die Titelhäufung Täyrikän Tegin Tägrim nicht für eine konkrete Person gebraucht wurde, so daß er zur Verfügung stand, wenn man eine allgemeine Bezeichnung für die Herrschenden überhaupt brauchte. Doch in übersetzten Texten könnte es natürlich auch anders gewesen sein. In der altuigurischen Fassung der Xuanzang-Biographie wurde der Titel des Kronprinzen

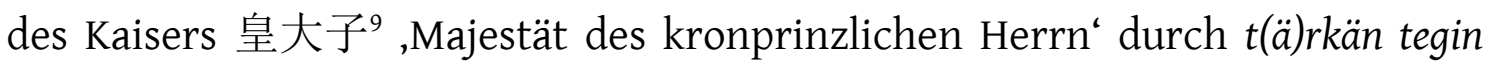
$t(\ddot{a})$ yrim kutı wiedergegeben ${ }^{10}$. Vergleicht man die Titel, dann ist es sehr unwahrscheinlich, daß eine Prinzessin gemeint sein könnte, auch wenn es Belege gibt, die für tärkän ,Prinzessin`sprechen (vgl. Sertkaya 2011).

Alle drei Bestandteile werden seit langer Zeit diskutiert, es gibt divergierende Ansichten. In einem Aufsatz habe ich versucht, die existierenden Fakten zusammenzutragen, doch ist auch diese Arbeit nicht abgeschlossen, weil durch neu erschlossene oder neu entdeckte Materialien die Sachlage sich ändert.

\footnotetext{
9 Wohl für 皇太子 'Common variant of Heir-Apparent (t'ai-tszu), normally the eldest son of a reigning Emperor' (Hucker 1985, Nr. 2863).

10 HT VII: Z. 1048. Das in der Übersetzung eingefügte, unseres‘ scheint überflüssig zu sein.
} 


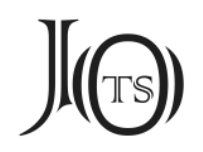

Erst 2008 wurde in Ix Tämir Sum im Arxangai Aimak in der Mongolei eine kurze Inschrift in Runen entdeckt, die deutlich $\mathrm{t}^{2} \mathrm{y} \mathrm{r}^{2} \mathrm{I} \mathrm{q} \mathrm{g}^{1} \mathrm{n} / \mathrm{O}^{2} \mathrm{O} \mathrm{k}$ nd A erkennen läßt: t(ä)gri k(a)g(a)n ötük(ä)ndä ,Der Täyri Kagan in Ötükän` (Magail et al. 2010). Dies zeigt, daß tägri kagan tatsächlich ein Vorläufer von tägrikän ist, auch wenn es denkbar ist, daß es selbst nach dem Entstehen von tägrikän immer mal wieder auch tägri kagan gebraucht werden konnte. Maḥmūd al-Kāšgarīs Aufzeichnung beleuchtet nur einen Aspekt, wenn er schreibt, daß man einen weisen Mann tägrikän nennt (Dankoff-Kelly 1984: 609 [343]; ED: 525). Das ,Memorandum ' nennt den Herrscher tägrikän und schreibt, daß der ,Heilige Täyrikän“ von allen Herrschern (han) der beste sei (Zhang-Zieme 2011).

Der zweite Begriff ist tegin, ein wahrscheinlich schon ,vortürkisches‘ Wort, das wohl einmütig als Prinz, als Sohn eines Hans, verstanden wird.

In tägrim nun steckt auch tägri ,Gott', aber ,mein Gott' hat dann ein Eigenleben geführt, wie es auch von europäischen Kulturkreisen bekannt ist bei ,Monsieur', ,Mylord' etc.

Alle drei Termini können auch Bestandteile des Repertoires von Personennamen sein. Dies kann hier aber nicht zutreffen, ebenso auch nicht, daß die Dreierkombination eine Person bezeichnet.

\section{I.2. Herrscher als Bodhisattva}

Mehrmals wird der Herrscher als ein aus dem Bodhisattva-Geschlecht Stammender angeredet. In dieser Hinsicht stellt der Text den uigurischen Herrscher in eine sehr alte Tradition, die in die vortürkische Zeit führt. Nach der jetzt durch die Dechiffrierung von Dieter Maue möglich gewordenen Interpretation der in Brāhmī geschriebenen Steininschriften von Bugut und Khüis Tolgoi stammen die Kagane aus dem ,Bodhisattva-Geschlecht' (Vovin 2019a) ${ }^{11}$. In anderen Zusammenhängen ist schon des öfteren auf die Bezugnahme

${ }_{11}$ Ursprünglich als unentzifferbar betrachtet, zeichnen sich jetzt Möglichkeiten der Interpretation ab, die natürlicherweise auch von Diskussionen begleitet sind, so will A. Vovin dar-pu and čim-pun auf den Balbals von Keregentas in Ostkazakstan als Verbformen für "sterben" interpretieren, während D. MAUE in ihnen Namen von Kaganen sieht. Selbst in später Zeit (Yuan) findet man Namen von Kaganen, die unbekannt scheinen: symy tymy kagan in U 5335, 16.2 (BT 34). 


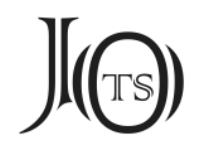

auch der uigurischen Herrscher auf die Bodhisattva-Herkunft hingewiesen worden (Zieme 1992: 76-77), und so wird es auch in mehreren Passagen in diesem Text deutlich.

\section{I.3. Zum Inhalt}

In der buddhistischen Literatur ist das Thema der Vergänglichkeit immanent. Ein sehr deutliches Beispiel findet sich im Pusaben yuan jing (T 153), wo so ähnlich wie in unserem altuigurischen Text ein König direkt angesprochen wird tilgen und auf die Vergänglichkeit hingewiesen wird. So heißt es nach der chinesischen Version T.III.153.52c-53a:

„Da sprach Velāma zum König [時毘羅摩c22:即白王言]: Nicht nur du, o König, mußt von dem lassen, was du gern hast. Die Trennung ist in jedem Fall ein Wesensmerkmal zusammengesetzter Erscheinungen (samskrttadharmāh). [夫愛別離非王獨有如此. 皆是 有 ${ }^{c 23}$ 爲法相也].

Hast du, großer König, davon bisher noch nie gehört? Götter, Nāgas, Asuras, Gandharvas, Garudas, Kimnnaras, Mahoragas, Asketen und Brahmanen, jung und alt, niemand vermag dem Tod zu entgehen. [大王昔來不曾聞耶. 若天·龍·鬼 ${ }^{24}$ 神·阿修羅·乾䦐婆·迦樓羅·緊

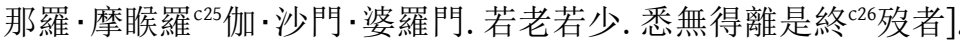

Alle Wesen, mein König, überwältigt er unweigerlich. [大王一切衆生決定有之].

Großer König! [大王] Wie das Wesen des Feuers derart beschaffen ist, daß es alle Dinge verbrennen kann, so auch das Gesetz der Vergänglichkeit: Es vermag alle Wesen zu vernichten. [譬如火 ${ }^{227}$ 性悉能燒然一切之物. 無常之法亦復如是. ${ }^{228}$ 悉能壞滅一切衆生].

Weißt du nicht, o König, daß Alter, Krankheit und Tod die Wesen ausrotten? [王不知耶. 是老病死. 能 ${ }^{29}$ 喪衆生].

Gleichwie an einer Wegkreuzung ein blüten- und früchtetragender Baum steht, den viele Menschen fortwährend schütteln; gleichwie, großer König, ein reißender Fluß in einem fort, unablässig dahinströmt, so auch das Leben der Wesen. [如四瞿道頭華果之樹. 常爲 多人之 ${ }^{53001}$ 所抖擻. 大王譬如駅河常流不停. 衆生壽 ${ }^{002}$ 命亦復如是].

Großer König! Wie ein Garuḍa in einen Nāgapalast einbricht, die Nāgas packt und sie frißt, oder wie ein Löwe in einer Herde von Hirschen wütet, irren alle Wesen in der Dreiwelt

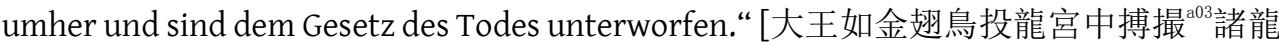
而食噉之. 亦如師子在麖鹿群威猛 ${ }^{204}$ 一切衆生在三界中流迴. 死法亦復如是] (Höke 1984: 126). 


\section{J(৫)}

Die aus der Daśakarmapathāvadānamālā bekannten Gespräche zwischen dem Meister und dem Schüler weisen auf die Gefahren hin, die entstehen, wenn man nicht den ethischen Regeln folgt. Auch in der Hami-Einleitung wird eindringlich darauf hingewiesen: (240-243) Schau, tolle Hunde reißen die Wirbelsäule seines Rückens auf, und er liegt nur als bloßer Rumpf da! (243-245) Und wen alles hatte der Jüngling wohl damals mit diesem seinem Körper erfreut? (245-246) Aber jetzt schau dir nur dies an, mein Sohn! (246-248) Mit eben diesem Körper erfreut er (jetzt nur noch) Hunde und (aasfressende) Vögel. (248-251) Da blickte jener kluge Schüler mit tränenerfüllten Augen auf jenen Jünglings-[Leichnam] und [sprach ergebenst [folgendermaßen] zum Lehrer: Mein Herr, [was] dieses G[esetz], das Tod genannt wird, [anbetrifft], so scheint es außerordentlich si[nn]los zu sein. (253-254) Es scheint absolut nicht auf das Ansehen irgendeiner Person zu achten. (254-255) Wie schlimm ist (doch) dieses Gesetz, Tod' namens anityatā (Geng et al. 2005: 96).

Wie bereits J. P. LAUT hervorgehoben hat, stellten die uigurischen Buddhisten Fragen von Leben und Tod oder von Werden und Vergehen in den Mittelpunkt ihrer Beschäftigung mit der Religion des Erwachten (2017: 84-85). In zahlreichen Texten haben sie diese Ansichten oftmals in sehr drastischen Szenen dargestellt, besonders in den beiden großen Werken des Maitrisimit nom bitig und der Daśakarmapathāvadānamālā, die in die Frühzeit des uigurischen Buddhismus gehören (Wilkens 2016), darüber hinaus auch in vielen anderen Werken, von denen nur Bruchstücke erhalten sind.

\section{Das Wort törü (törö)}

Ob das Wort törü (törö) immer als Gesetz übersetzt werden muß, fragt sich. Im vorliegenden Text scheint es sich vielmehr um ,Sache, Erscheinung, Tatsache` etc. zu handeln.

\section{Die Vier}

Buddhistische Gedankengebäude sind in der Regel klar strukturiert und nach von Zahlen bestimmten Systemen geordnet. Die Vier markiert große, wichtige Gruppen wie die hier im Fokus stehenden Begegnungen oder die 


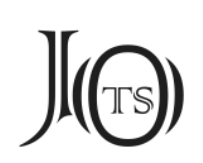

Wahrheiten, aber auch Formen der Geburt, Menschengruppen (varga), Weltkönige und viele mehr.

\section{Inhalt und Struktur des Textes nach der Handschrift A}

Folgt man der Handschrift A, hat der Text die folgende Makrostruktur:

Drei Abschnitte zum Thema Alter

Vier Abschnitte zum Thema Krankheit

Fünf Abschnitte zum Thema Tod

Zwei Abschnitte zum Thema Mönchtum

Ein Abschnitt Kolophon.

Berücksichtigt man die Ausführungen zur Handschrift D, muß man davon ausgehen, daß am Beginn des Textes mindestens noch zwei Alter-Abschnitte standen. Damit enthielte das erste Kapitel zum Thema Alter die zahlreichsten Abschnitte. Auch die Handschrift E ist der Kategorie Alter zuzuordnen. In diesem Fall scheint jedoch eine Variante zum Abschnitt Alter-2 vorzuliegen, was allerdings bedeutet, daß eine sehr große Variation möglich war.

\section{Alliteration}

Der Text ist kein durchgehend nach der strophischen Alliteration komponiertes Gedicht. Dennoch bezeugen zahlreiche Stellen, daß die Alliterationen wohl nicht ohne Intention eingebaut sind. Zur Übersetzung der hier angeführten Beispiele vergleiche man die entsprechenden Stellen in der Edition.

\section{Zweieralliterationen}

čakir bašlap 20 七 [yeti] ärdini-lär üzä ärklig türklüg .

čakiravart ıduk elig-(lär) han-lar ymä ::

oder

ilki-siztinbärü eritilmiš alku 34 kiši-lärkä aklatılmıš . 


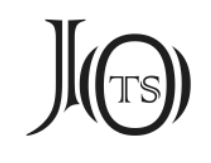

iglämäk atl(1)g äšidgäli yavız yel törü 35 bo täginür täyrim alku kamag tınl(1)g-lar-nıy arasınta .

36 ayaz-lı yagız-l1-ča yintmiš yegädmiš bodistv

küčüg küsün-üg kävip

küč<s>irätip olurgalı tur 39 -galı ärgäli 1dmatın

kapilavastu känt-lig m(a)hadakini yuul ičindä .

hansa-rača kaz-lar 49 han-1 törüyü b(ä)lgürü yarlıkamıš

arčuni toya-ta kunsar yašmaz

alp 61 ädräm-lig äninčig-lär ::

sorup suv-ug sugurdačı-lar .

sodup köl-üg tošgurdači-lar ::

tanču-lap tag 62 -1g ušattačı-lar ::

talačangini asure täg .

alku kamag kasıntın kadaš-ıntın adırılmıš .

ata ana kiši ogul kız-tın 73 öni ödrülmiš ::

yašaguluk-1 ärtmäk üzä yamadevi-ka yagumıš :

yalyuk 74 yertinčü-sindäki ädin tavar-1n .

töpür-ä tüü-lüg 77 tınl(1)g oglan-ları-nıy .

töyütgülüki bolu yarlıkamıš . 


\section{J(৫)}

bodistv uguš täyrikän tegin 78 täyrim kutı yarlıkasar :

bo ymä tıbolmıš törü tetir ::

生 [tugum] ažun 79 tutar-ča täylig ärsär :

九月十 [tokuz ay on] kün ög karın-ta solanıp olurur tuš-ta

äv-in bark-ın äd-in 84 tavar-in .

ärksizin türksüzin tidip ıdalap .

anityat-ka san-lig bolur 85 -lar ::

anın bo ölüm atl(1)g äšidgäli yavız yeel törü mundag bolu täginür täyrim

\section{Dreieralliteration}

ölmäz umug-lug mängü 92 sakınč-lıg :

öysüz täyri yerindäki täyri-lär ymä ::

üdi kün-i käldükdä adın 93 ažun-ka barır-lar.

Es besteht eine gewisse Tendenz, daß auch zusätzlich innerhalb der Verse Alliterationen beabsichtigt sind. Besonders deutlich tritt sie in den folgenden Beispielen hervor:

sorup suv-ug sugurdači-lar .

sodup köl-üg tošgurdačl-lar ::

oder

alku kamag tınl(1)g-lar-nıy arasınta .

36 ayaz-lı yagız-l1-ča yintmiš yegädmiš bodistv 


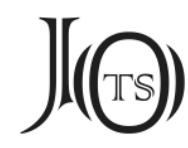

115 amrak ogul-1n ak yagi-sın . adırtsız tüz kördäči. ${ }^{12}$

Markant sind auch die Parallelismen, die den ganzen Text durchziehen. Hier soll nur eine Passage zitiert werden:

körünč-lüg orun-nuy körki küvänč-i .

toylašmıš bo tirin kuvrag-nıy 108 tokısı šobanı

109 yülitmiš tüšürmiš sač-lig sakal-lig .

yörgänmiš yaškınmıš kızıl sarıg 110 ton-lug kädimlig ::

tugmak karımak-ka korkup äymänip .

iglämäk ölmäk-ig erip 112 aklap

12 Diese Wendung gehört zu den Epitheta des Buddha. Eine besondere Epithetareihe enthält ein altuigurischer Text, von dem ein Blatt im IOM (SI 1465) erhalten ist: kim ol [ya]pata yadılmišyarlkančučı könüllüg [igi]n y[a]lhnayu ört[ä]nü turur ämgäklig tınl(1)glar üzä sačıр .. [...] tugmaksız bol[...]ların yašartu [...]

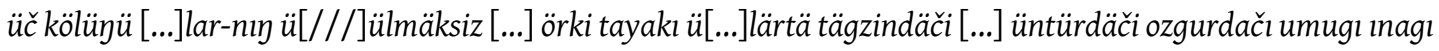
.. tört türlüg tözünlär käzigin bultukmakı üzä tört tugumlartakı [tınl(1)glar]nı tögidü yüküngülüki biligsiz bašlap nizvanilarıg tarkarmakı üzä .. beš ažun tınl(ı)glarnin amrangulukı ayagulukı amrak oglin ak yagısın adırtsı[z bir] täg tuta y(a)rlkadačı tar[...]lar tokısı toyın körklüg amrılmıšlar äržisi arslan hanı [ša]kimune t(ä)yri t(ä)yrisi [burhan]

"Śākyamuni, der Göttergott Buddha, der Löwen-König, der allerorts ausgedehnten barmherzigen Sinnes für die in [Krankheit] flammenden und brennenden leidvollen Lebewesen ist, der die ohne Geburt [... Wesen] ergrünen läßt, der nicht-reißendes [...] Seil und Stütze der [...] der Drei Fahrzeuge ist, der Hoffnung und Zuflucht der [im Samsāra] wirbelnden [Wesen] ist, sie herauszieht und erlöst, der durch das Erlangenlassen der Reihe der Vier Edlen [d. i. Vier Edle Wahrheiten] der Verehrte der [Wesen] in den vier Geburten ist, der durch das Entfernen der Kleśas beginnend mit dem Nichtwissen der Geliebte und Hochgeschätzte der Lebewesen in den fünf Existenzformen ist, der als MönchGestalteter, der seinen geliebten Sohn und seinen bösen Feind unterschiedslos wie eins zu betrachten geruht, der die Zierde der [...] ist, der der R̦si der Beruhigten ist". Das Fragment stammt aus einer Handschrift, von welcher weitere Blätter in mehreren Sammlungen vorliegen, meist aber noch unbearbeitet sind. Ein anderes Blatt wurde von A. YAKUP publiziert, das ein Zitat aus dem AYS enthält (2015). Zu dessen Einordnung vgl. meine vorläufigen Bemerkungen in Zieme 2021. Da nunmehr weitere Blätter aus der Nationalbibliothek Beijing (vgl. Mirkamal-Zieme [in Vorbereitung]), als Faksimiles bereits publizierte Blätter aus dem Tianjin Arts Museum 1996 sowie Blätter der Dunhuang Akademie hinzukommen, ist eine umfassende Bearbeitung dieses Textes eine dringende Aufgabe. 


\section{J(৫)}

aklančıg sansar-tın ozup kutrulup .

abayapur nirvan mägi-sin bulgalı 113 tapgalı

äv-in bark-1n kodup kämišip ::

ög-in kay-in yıglatu sıgtatu

114 ogul-ın kız-ı örlätü čärlätü ::

tag aryatan orun-larıg sävä taplayu

115 amrak ogul-ın ak yagı-sın . adırtsız tüz kördäči ::

kıy käzä kapıg sanayu 116 bulmıš-ča k(1)y-a

aš üzä kanımlig bolup.

Im übrigen ist der Text in Prosa abgefaßt, in die aber, wie dargelegt, metrische Partien eingestreut sind, die von einem sehr stilisierten Konzept ausgehen. Die Darstellung der Sachverhalte ist von einem ausgesprochenen Hang nach bildhaften Ausdrücken oder Wendungen geprägt.

Auch andere Werke des uigurischen Buddhismus weisen ähnliche Strukturen auf, die man als Mischung aus Prosa und Poesie bezeichnen kann, oder einfach auch als Texte mit eingestreuten Versen.

Eine Einleitung zur umfangreichen Daśakarmapathāvadānamālā weist solche Textteile mit Verscharakter auf, worauf J. WILKENS bereits hingewiesen hat (BT 37: 134-135). Des weiteren bietet auch die Tömürti-Einleitung, deren Sponsoren, Tükätmiš Totok und (seine Frau) Alkatmıš, die vornehme, adlige Uiguren um das Jahrtausendmillenium im Westuigurischen Königreich waren, hierfür beeindruckende Beispiele, die als solche in der Edition (BT 37) nicht herausgestellt wurden. Allerdings weisen die Verse nicht immer Merkmale der strophischen Alliteration auf.

Es ist offensichtlich, daß die Einleitung nach den drei Grundvoraussetzungen des Gelübdes zur Buddhagesinnung, dem sogenannten 


\section{$J(\Theta)$}

Triratna, aufgebaut ist: Buddha - Dharma - Samgha ,Der Erleuchtete - die Lehre die Gemeinde‘. Die erhaltene Handschrift setzt mit dem Ereignis der Erleuchtung ein, quasi die Lebensgeschichte des Buddha nach den vier Begegnungen, die Thema der hier edierten Texte sind, weiterführend. Und die genannten Sponsoren bringen ihre Triratna-Verehrung zur Sprache, indem sie zum Buddha gewendet sagen:

[tizi]mizni čökütip

älgimizni kavšurup

äyitä ätözin

tönitä töpün

[a]gır ulug süzök kertgünč köyülin

ayayu agırlayu yinčürü yükünü täginür-män (BT 37: 00019-00023).

Unsere Kniee beugend, unsere Hände faltend, mit gebeugtem Körper, mit geneigtem Scheitel, mit sehr starkem reinem Glauben, verneige(n) ich (= wir) uns ehrfürchtig und verehrungsvoll.

Mit ikinti ,Zweitens' geht der Text zum zweiten Juwel, dem dharma, über:

öylüg mäyizlig tavarlar üzä ukıtgul[u]k :

ulug küč[lü]g üč törlüg öčmäk tözlärin

üč üdlärtä iš išlämäkin körüp

ülgüsüz üküš törlüg adrok-ların ukup (BT 37: 00028-00033) (13 $^{13}$

Betrachtet man die durch gestalthafte Substanzen zu lehrenden großmächtigen dreierlei Wurzeln des Verlöschens und das Wirken in den drei Zeiten, erkennt man ihre zahllos vielen Vorzüge.

alku nizvanilıg ootlarıg kalısız öčürdäči :

alku tugum a[žun]larıg t[1d]dačı b(ä)klädäči ..

alku törlüg ädgüläri üzä adınlar idi egišmägü ..

13 Als Beispiel strophischer Alliteration auch in BT 37: 135 genannt. 


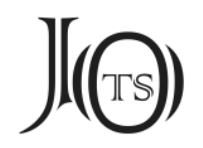

Die Feuer aller kleśas restlos verlöschend, alle Geburtsexistenzen versperrend und verschließend über alle ihre Vorzüge sollen andere nicht widersprechen.

üzmälämäk tarkarmakda ulatı

ulug ulug ataguluk atlar üzä atagu ..

üksüz terkinsiz etigsiz akıgsız

üč törlüg irulug üčünč kertü nom ärdini (BT 37: 00028-00042) ..

Das mit Ausrotten und Vernichten, mit solchen groß zu nennenden Namen zu nennende, das ohne Anhäufung, ohne Ansammlung und nicht-zusammengesetzt, diese dreierlei Merkmale habende dritte ${ }^{14}$ wahrhaftige Dharma-Juwel.

Dann folgt die Einteilung des dharma in die drei Teile, den sogenannten Dreikorb (tripițaka): sūtra, vinaya und abhidharma, denen als viertes und fünftes die Dogmen des Achtfältigen Weges und des Nirvāṇa hinzugefügt werden. Zum Abschluß des zweiten Juwels werden Tripițaka und Dharma nochmals zusammenfassend genannt.

Die Nennung der Sponsoren, dieses Mal trägt die Gattin auch den Ehrentitel Täyrim, leitet dann zum dritten Juwel (BT 37: 00087-00133) über.

Auch in weiteren Blättern der Tömürti-Handschrift, die dem I. Karmapatha zugehörig sind, gibt es längere Passagen mit Verscharakter oder, vorsichtiger gesagt, Passagen, in die alliterierende Verse eingestreut sind.

Im nachfolgenden bringe ich einige Beispiele aus der Edition von J. Wilkens, wobei ich seine durchaus stimmige Übersetzung nur dahingehend verändert habe, daß die deutsche Version der altuigurischen Reihenfolge näher kommt.

\section{Schilderung einer Frauenleiche auf dem Leichenacker (BT 37: 00257- 00304)}

tozmıš tooz toprak üzä öysiräp bozarıp ..

${ }_{14}$ Im Text steht üčünč ,dritter‘, vermutlich ein Fehler für ikinti ,zweiter‘. 


\section{$J(\Theta)$}

yagız (BT 37: 00259) ${ }^{15}$ yavgan sävigsiz taplagsız bolup turur ..

Vom aufgewirbelten Staub verlor (der Körper der Frau) Farbe und ist grau geworden. Scheußlich und schlecht, unlieblich und ungefällig ist er geworden!

bo ok tišläri ärti munuy ..

ulugsuz kičigsiz tükäy ${ }^{16}$ tüp tüz .. k(a)lt1

uvšak yinčü salkımına ogšatı yüp yürün ..

Das waren ihre Zähne: Nicht (zu) groß, nicht (zu) klein, vollständig und ganz eben, ganz weiß einer zierlichen Perlenkette gleich.

bo ok munuy erni ärti ..

kıp kızıl sıta-ka ogšatı ärtä körklä ..

ol ok bo munuy tišlärin erinlärin körgil ..

Das waren ihre Lippen! Einer knallroten Koralle gleich sehr schön! Doch nun, schau ihre Zähne und Lippen an!

käpirä ${ }^{17}$ čokrayu t(a)šllu ünmiš

kap kara boksıg yıdıg kanı üzä ürtülüp

kara kagač bolup ärtinü artak yavız bolup yatur ..

Von ihrem - anschwellend und brodelnd - ausfließenden pechschwarzen stinkenden Blut bedeckt, (wie) schwarzer Dreck geworden, überaus verfault und scheußlich geworden liegt sie da.

bo ok munuy iki ämigläri ärti .. inčä kaltı

lenhua tovurčukına ohšatı katıg tıgrak bürtügi yumšak ..

nä bürtükdä ök amranmaklıg tuzakda tutunturdačı

15 J. WILKENS setzt im Text yavız statt yagız, wie die Handschrift hat. Beruft man sich auf andere -g-//-vVariationen, könnte aber auch yagız eine richtige Sprachform sein.

${ }^{16}$ In der Handschrift 00261 twyk'y. J. WiLKENS emendiert zu tükäl.

17 BT 37: 00266-00267: ((bo)) äbirä, dazu Zieme 2016. 


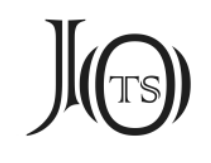

soymıš kumut čǎčăkkä ohšatı yipün čögšik öylüg ..

ol ok bo munun amtı ämigin körgil ..

Das waren ihre zwei Brüste! So wie einer Lotosknospe gleich waren sie fest und kompakt, (doch) bei Berührung weich. Sobald jemand sie berührte, wurden sie, denjenigen in die Liebesfalle geraten lassend, einer entfalteten Kumudablume gleich rosigfarben. Doch sieh jetzt ihre Brüste!

ätläri kırtıšları togrulup yarılıp ..

kap kara boksıg yıdıg kanları tökülür

arıgsız ičintä kurtlar kovšašu közünür

yap yašıl yıdıg yirinlär kan-lar turur..

Ihr Fleisch und ihre Haut platzen und reißen auf, ihr pechschwarzes stinkendes Blut strömt aus. In den Exkrementen erscheinen Würmer einander jagend. Da sind grasgrüner stinkender Eiter und Blut.

bo ok munuy beli ärt[i :] inčä k(a)ltı

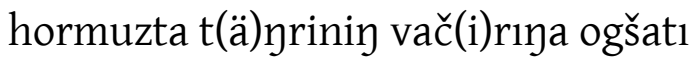

yıgvı yinčgä ol antag yinčgä beli birlä yörgänü tolganu ..

169 etmiš yaratınmıš etig yaratıglıg yükläri üzä

akrušl(a)nu nä yorıyu t(ä)pä barsar :

k(a)ltı yutik sögütnün čäčäklig butıkı t[ä]g közünür ärti ..

kördäči erkäk äränlärnị

köyüllärin kögüzlärin tıgratır ärti ..

Und das waren ihre Hüften! So wie dem Vajra des Gottes Indra gleich: fest und zart; wenn sie, mit einer solchen zarten Hüfte sich windend und schlängelnd, geschmückt und geziert mit Schmuck-und Zierlasten, - obwohl sie schreitet und auftritt ${ }^{18}$ - ruhig daherkommt, erschien sie wie ein Blütenzweig des yūthikā-Baums. Der sie sehenden männlichen Helden Herzen und Sinne ließ sie erstarren.

18 BT 37: 00287. J. WILKENs liest tapa, entgegen', doch wäre auch täp-ä ,auftretend 'möglich. 


\section{$J(\Theta)$}

bo ok munuy beli ärt[i :]

karnı ičinä isig kirip ürišip kepärip

ičintä bagırsukları kıs kus ätä

örü kudı agtar(1)lu toytar(1)lu .

taštın sınarkı äti kırtıšı kül birlä bulgašı .

kayuta ärti munuy yinčgä beli tep bilmägü täg turur ..

kör amtı munı oglum ..

Doch nun, sieh ihre Hüften! In ihren Bauch trat Hitze ein, und er blähte sich auf, darin machten die Gedärme schmatzende (Geräusche). Nach oben und unten wirbelten sie hin und her, ihr äußeres Fleisch und ihre Haut vermischten sich mit Asche. Wo sind ihren zarten Hüften? Man kann es nicht wissen. Sieh jetzt dies, mein Sohn!

bo sansarnıy utunı yavizı.

ätöznün artamak tözlügi ..

bo yaylig ol tep..

Die Abscheulichkeit und Schlechtigkeit des Samsāra sowie das Wesen des Körperverfalls sind eben so.

(...)

ötrü ol kunčuylar ölüginin karnı

ürišip kepärip tänizip yarılıp bardı ..

da (geschah es), daß der Bauch der Frauenleiche sich blähte und anschwoll und schließlich aufplatzte.

2. Doch auch die nachfolgende Schilderung einer Jünglingsleiche (BT 37: 00313-00379) ist nicht minder drastisch.

azk(1)y-a inaru barip :

anta y(e)mä bir yigit urı ölügin kördilär ..

anı y(e)mä körüp ulug tına inčıklayu .. 


\section{$J(\Theta)$}

bilgä bahšıka ötünti ..

Als sie (Meister und Schüler) ein wenig weiter gegangen waren, sahen sie dort auch die Leiche eines jungen Mannes.

Als (der Schüler) sie sah, seufzte er tief und sprach zum weisen Meister:

t(ä)yrim munı kör[ü] y(a)rlıkazun ..

bo yigit urı ölügi

alku ädgülärintä adrılıp üdrülüp

anityatlıg elig han älgintä kirip ..

k(ä)ntü ätözin bulganur bus-anur osuglug töpön tüšüp yatur .

Ehrwürdiger, seht dies! Die Leiche dieses jungen Mannes, aller Vorzüge bar und bloß, ist in die Hände des Anityatā-Königs geraten. Er liegt da, mit dem Scheitel nach unten, als ob er sich selbst betrauere und bekümmere.

topraklıg yukug türtüg yüzinä <<mäyizinä>> yukurup türtüp ..

ädgülärin amrakların kučugsayurča

iki kolların uzatı ıdıp kučumsınu yat[u]r ..

inčip öskintä kim ärsär ädgüläri amrakları yok ..

Sich sein mit Staub verschmiertes und geriebenes Gesicht einschmierend und -reibend liegt er da, und als ob er seine Guten und Lieben umarmen wollte, breitet er seine Arme aus und versucht, sie zu umarmen. Jedoch vor ihm sind gar keine Guten und Lieben.

bilgä bahšı sözlädi ..

Der weise Meister sprach:

atayım oglum sansarnıy törösi muntag ok ol

alku yalyok oglanı bir ikinti[kä]

amranmaklıg bagın näčä käd katıg basarlar ymä

’äy kenki künintä munı täg ök sın suburgan ara

amrakıntın adrılıp kuš käyik birlä turu kalırlar .. 


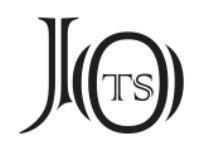

Mein Kleiner, mein Sohn! Das Gesetz des Saṃsāra ist eben so! Alle Menschensöhne, wie fest und stark sie sich einander auch mit dem Band der Liebe binden, an ihrem letzten Tag trennen sie sich wie dieser hier im Grab von ihren Lieben und bleiben nur mit Vögeln und Wild zurück.

\section{(...)}

kaylıčıs amtı munčulayu kamılıp yatur ..

kaylı etigi sünöklüg yantarları säšilmiš turur ..

kaylıčısı nämän munuy kanča baryuk ol :

kạlısı munčulayu i(y)äsiz yatur ..

Jetzt liegt sein Kutscher ${ }^{19}$ gleichermaßen zusammengebrochen da. Die Wagenausstattung - seine Knochenmaschinerie - ist aufgelöst. Wohin mag wohl sein Kutscher gegangen sein? Sein Wagen liegt ebenso herrenlos da. ${ }^{20}$
(...)

antag ol oglum .. bo ölüm tegli törö :

alkunı bir täg yüz körmädin ölürdäči yetürdäči ärür .. amtı äšid anı amrak oglum ..

So ist es, mein Sohn, das Gesetz, das Tod heißt. Alle gleichermaßen ohne Ansehen des Gesichts tötet und vernichtet es. Jetzt hör das, mein lieber Sohn:

bo (ölüm) tegli törönüy yüü körmämäki ..

bo ok ärki söki bo yertinčü yer suv törügäli ....

purvantak(a)lp üdtin bärü ötgürü

bökünki künkätägi

19 J. WILKENS weist auf das Wagengleichnis im Milindapañha und anderen buddhistischen Texten hin, denen zufolge das Skelett des Menschen mit einer Maschinerie vergleichen wird, BT 37: 221, Anm. zu (00338 ff.). Aus einer vorangehenden Stelle wird der Verstand mit dem Kutscher gleichgesetzt (BT 37: 00342): tuymak biliglig kaylıč ,Kutscher, (d. i.) Einsichts-Wissen (= Verstand)'.

20 Diese Strophe wird auch in BT 37: 135 als metrisch vorgestellt. 


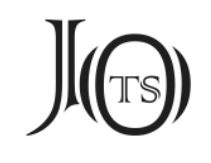

Das Nicht-Gewahrwerden des Gesetzes des Todes: das ist seit ewig so, seit diese Welt entstanden ist. Von der pūrvantakalpa-Zeit an bis zum heutigen Tage.

Diese längeren Zitate aus der DKPAM-Edition sollen zeigen, wie diese beliebten buddhistischen Themen bei den Uiguren behandelt wurden. Inhaltlich finden wir auch in dem hier zur Debatte stehenden Text ähnliche Schilderungen, aber doch auch mit sprachlich verschiedenen Passagen und Wendungen.

\section{Zitate aus dem Udānavarga und aus Āgama-sūtras}

Der Udānavarga ist ein Werk, das auch in den lokalen Kulturen Zentralasiens verbreitet war. In altuigurischer Version liegen nur Zitate oder Auszüge vor. In seiner Bearbeitung von Āgama-Auszügen vergleicht J. WiLKENS (2017: 221) die entsprechenden Gāthās mit Uv 1, 29. Da diese Verse sehr gut in das Thema passen, seien einige Passagen aus M. HAHNS Übersetzung (2007: 14-17) zitiert.

\section{(I.27)}

Als er einen Alten sah und einen Kranken,

dann einen Toten, den sein Geist verlassen hatte,

verließ der Weise das Gefängnis >Haus<;

schwer nur kann man auf die Sinnenlust verzichten.

\section{(I.28)}

Die bunten königlichen Wagen werden brüchig, und auch der Leib wird alt und schwach;

die Lehre edler Menschen aber altert nie, die Edlen geben sie an Edle weiter.

\section{(I.29)}

O du gemeines Alter, pfui über dich -

du machst den Menschen alt und häßlich!

Als erstes hat das Alter 


\section{$\mathrm{J}(\Theta)$}

diese wunderbare Form zerstört.

\section{(I.30)}

Auch wer einhundert Jahre lebt,

fällt schließlich doch dem Tod anheim;

nacheinander treffen ihn

Alter, Krankheit, dann der Tod.

\section{(I. 42)}

Daher sollt ihr stets gesammelt sein, euch mühen

und an der Versenkung Freude finden,

den Tod als Abschluß von Geburt und Alter stets im Blick.

Den Todesgott samt seinem Heer bezwingend

überwindet dann Geburt und Tod als Mönche!

Die altuigurischen Entsprechungen nach den Auszügen aus dem Bieyi za ahanjing hat J. WILKENS (2017: 221.) zusammengestellt. Der Wortlaut ist völlig anders als im Memorandum, aber ebenfalls sehr drastisch:

aya karımaklıg utun y(a)vlak yagı

tokılıg körklä säčä taylančıg öylärig

s(ä)n uyur s(ä)n buzgalı artatgalı

birök yašasar ymä yüz yıl tolgınča

odgurak kirür ölümlüg iz orukka

iglämäk kälip kunar ol küčüg küsünüg

karımak uduzup tutuzu berür ölmäkkä

[
咄哉老賊惡

端正殊妙色

汝能壞敗也

設壽滿百年

必入于死徑

病來奪其力

老將付與死

是故常樂禪

撿心勤精進

bilgä biligi üzä bilip tugmaknıy uučın kıdıgın 了知生邊際 


\section{J(৫)}

［］］＼cjkstart勝彼魔軍衆

ärtär tugmak ölmäklig intın kıdıgka 度有生死岸

O verfluchter, schlechter Alter-Feind! Ziemliche und schöne, erwählte und wunderbare Formen kannst du zerstören und vernichten. Selbst wenn man lebte, bis sich auch hundert Jahre erfüllen, geht man sicher in den Pfad des Todes. Krankheit kommt und raubt seine Kräfte. Alter führt und überantwortet (ihn) zum Tod. [...] Den Sinn sammelnd soll man sich heiß und emsig bemühen. Durch Weisheit soll man erkennen das Ende und die Grenze der Geburt. [...] (Dann) passiert man zum jenseitigen Ufer von Geburt und Tod (= saṃsāra).

Diesmal direkt nach dem Sanskritttext liegen weitere Strophen aus dem Anityatā-Kapitel des Udānavarga in einer bilingualen (Skt./uig.) Handschrift vor, die J. Oda (2003: 33) ediert hat. Die Ślokas sind anders als im Original arrangiert.

\section{$(\mathrm{I} .22)^{21}$}

alku yıgmıš termiš äd tavarlar alkınmak tüplüg ärürlär

tüšmäk yimrilmäk tüplüg ärürlär ediz tikvi ${ }^{22}$ taglı bašgoklı

amrašmıš eltišmiš ka kadaš adırılmak tüplüg ärürlär

ölüm tüplüg ärür inčip isig öz

Alle angehäuften und gesammelten Güter haben die Wurzel des Dahinschwindens. Die Wurzel des Fallens und Einstürzens haben hohe, spitze Berge und Gipfel. Geliebte, einander zugetane Familien und Verwandte haben die Wurzel der Trennung. Mit der Wurzel des Todes ist nun mal das Leben.

\section{(I.22)}

Alles, was man angehäuft hat, schwindet endlich wieder hin;

alles, was errichtet wurde, stürzt am Ende wieder ein;

alles, was verbunden wurde, trennt sich schließlich wieder.

${ }^{21}$ Für diese Strophe liegen weitere Varianten vor, die aus verschiedenen Textzusammenhängen stammen, vgl. J. WILKENS in BT 37: 62-65. D. MAUE hat eine Parallele nach dem Fragment Ch/U 7174 veröffentlicht (2016).

22 So auch in Ch/U $7174 \mathrm{v}$, vgl. Maue 2016. 


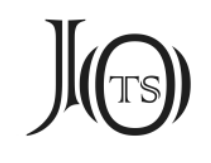

Und ein jedes Leben endet mit dem Tod (Hahn 2007: 14).

(I.18)

ärtärlär inčip tünli künli

isig özi ymä bäklänür

özi yašı alkınur yalıuklarnı

kaltı kičig ögüztäki suvk(1)yalar täg

Es verstreichen Nacht und Tag. Das Leben auch wird begrenzt. ${ }^{23}$ Der Geschöpfe Lebenszeit schwindet. Wie die kleinen Wasser im Fluß.

\section{(I.18)}

Tag und Nacht verstreichen;

und das Leben schwindet;

wie das Wasser seichter Flüsse,

so versiegt das Menschenleben (Hahn 2007: 13).

\section{(I.8)}

anta nä atl(1)g yalyuk ögürlär

kičig yigit ärürmän isig öztä

kičig yigit ymä inčip ölürlär

äränlär kunčularlı ymä ülgüsüz üküš

Weshalb preisen Geschöpfe über das Leben: Ich bin ein junger Held! Auch junge Helden sterben. Ob Mann, ob Frau auch zahllos viele.

\section{(I.8)}

Wie können Sterbliche auf das Leben vertrauen,

23 Das Verb bäklän- hat viele Nuancen, hier wohl in der Bedeutung, fixiert, begrenzt seinc, vgl. OTWF: 593-594. 


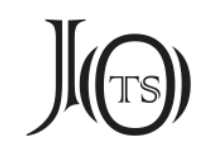

indem sie denken: »Ich bin jung and habe alles vor mir«?

Auch die jungen Menschen sterben -

egal ob Mann, ob Frau - in großer Zahl (Hahn 2007: 12).

\section{(I.25)}

näy ök kök kalık yüüzintä näy taluy ögüz otrasınta

tag kısıl aralarına kirip

näy bultukmaz antag osuglug yer orun

kayuta nä turup ölümlüg yagıka basıtmasar

Nicht im Himmels- und Luftraum oder inmitten des Meeres, noch wenn man hineingeht in die Berge und Täler, nirgends gibt es einen solchen Ort, an dem man, wo immer man ist, nicht vom Tod-Feind betroffen wäre.

\section{(I.25)}

Nicht im Luftraum, auch nicht mitten auf dem Meer,

nicht in der tiefsten Bergeshöhle

gibt es einen Ort auf Erden,

wo man dem Tod entrinnen könnte (Hahn 2007: 14).

Eine Variante von I.22 kommt, wie J. WILKENS gezeigt hat, auch in der DKPAM (BT 37: 63-64) vor:

alku yıgılmıš äd $\mathrm{t}(\mathrm{a})$ var barča alkınmak tözlüg ol

ätöz ulatı ediz etmiš etig yaratıg tüšmäk kamılmak tüplüg tetir

birlä kavıšmıš kakadaš y(e)gän tagay adaș böšük ädgü ögli kim bar ärsär

äy kenintä öyi öni adrıltačllar üstün [bav]agr altın aviš tamukatägi kim özlüglär bar ärsär

äy kenintä ölmäginčä ozmaklar[1] yok 


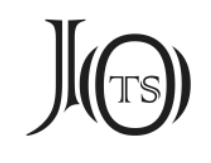

Auf den Beleg im Maitrisimit nom bitig hatte bereits G. EHLERS (1990) hingewiesen. Die Strophe ist nicht vollständig erhalten, auf Blatt 3 der Einleitung steht:

[...] ärtimlig ärür

öz yaš k(ä)ntü ürlüksü[z] mänüsüz ärür

äd t(a)var k(ä)ntü artayur buzulur

yok kurug ämgäk tözlüg adal(1)g turur

[...] ist vergänglich. Das Leben selbst ist unbeständig und nicht ewig. Hab und Gut selbst verderben und werden zerstört, sie sind nichtig, vom Wesen des Leids und notbringend.

Diese Strophe oder ein anderer genereller Śloka, leider ist er im Wortlaut nicht gegeben, war auch der Bezugspunkt für eine Vorrede zum altuigurischen Altun Yaruk Sudur (Zieme 1989).

\section{Die Handschriften}

Der Text ist in Fragmenten mehrerer Sammlungen von zentralasiatischen Materialien belegt. Die umfangreichste Version besitzt die Nationalbibliothek in Beijing. Weitere Bruchstücke sind in der Serindia Sammlung des IOM der Russischen Akademie der Wissenschaften sowie in der Turfan-Sammlung der Berlin-Brandenburgischen Akademie der Wissenschaften aufbewahrt. Ein Fragment stammt aus der Lujiang Caotang-Sammlung in Hangzhou.

\section{Konkordanzen}

\begin{tabular}{||c|c||}
\hline \multicolumn{2}{|c||}{ Konkordanz der Fragmente nach den Handschriften } \\
\hline \hline Handschrift A & BD 14941, BD BD 14940 \\
\hline \hline Handschrift B & SI 3902 (4bKr 124) \\
& SI 4756 (O 96) \\
& SI 4745 (O 84) \\
& SI $3992(4 \mathrm{bKr} 163)$ \\
& SI $3996(4 \mathrm{bKr} 169)$ \\
& SI $3968(4 \mathrm{bKr} 82)$ \\
& SI $3875(4 \mathrm{bKr} 54)$ \\
& SI 3877 (4bKr 86) \\
\hline \hline
\end{tabular}




\begin{tabular}{||c|c||}
\hline & SI $3869(4 \mathrm{bKr} 45)$ \\
& SI $4072(4 \mathrm{bKr} 81)$ \\
& SI $3928(4 \mathrm{bKr} 159)$ \\
& SI 3981 (4bKr 129) \\
& SI 3870 (4bKr 146) \\
\hline \hline Handschrift C & Ch/U 7161 (T II T 512) \\
& SI 4319 (Kr I 242) \\
& SI $4210(\mathrm{Kr}$ I 123) \\
& SI 4457 (Kr I 372) \\
& SI 4996 (Kr I 421) \\
& SI 4956 (Kr I 10) \\
\hline \hline Handschrift D & SI 5594 (Kr IV 267) \\
\hline \hline Handschrift E & SI 4762 (O 102) + SI 5803 (3Kr 20/5) \\
\hline \hline Handschrift F & Ch/U 8187 + Ch/ U 8199 + Ch/U 6023 (Lücke) Ch/U 6205 \\
& + Ch/U 6446 + Ch/U 6353 \\
\hline \hline Handschrift G & Ch/U 6834 + Ch/U 6087 + Ch/U 6864 \\
\hline \hline Handschrift H & Ch/U 6769 \\
\hline \hline Handschrift I & SI 5671 (2Kr 49) \\
\hline \hline AppA & U 1824 \\
\hline \hline AppB & \\
\hline \hline
\end{tabular}

\begin{tabular}{||c||c||c||}
\hline \multicolumn{3}{|c|}{ Konkordanz der Fragmente nach dem Standort } \\
\hline \hline Standortsignatur & alte Signatur & Handschrift \\
\hline \hline BD 14941 (BD 14940) & & A \\
\hline \hline Ch/U 6023 & T II 4080 & F \\
\hline \hline Ch/U 6087 & T II Y 39 & G \\
\hline \hline Ch/U 6154 & & Anm. 121 \\
\hline \hline Ch/U 6205 & T I x 559 & F \\
\hline \hline Ch/U 6353 & T I x 544 & F \\
\hline \hline Ch/U 6446 & T I x 554 & F \\
\hline \hline Ch/U 6511 & & Anm. 121 \\
\hline \hline Ch/U 6769 & T II S 510 & H \\
\hline \hline Ch/U 6834 & & G \\
\hline \hline Ch/U 6864 & T II 740 & C \\
\hline \hline Ch/U 7161 & T II T 512 & Anm. 121 \\
\hline Ch/U 7363 & & \\
\hline \hline
\end{tabular}




\section{$J(\Theta)$}

\begin{tabular}{|c|c|c|}
\hline $\mathrm{Ch} / \mathrm{U} 7511$ & & Anm. 121 \\
\hline Ch/U 8187 & & $\mathrm{~F}$ \\
\hline Ch/U 8199 & & $\mathrm{~F}$ \\
\hline U 1824 & & AppB \\
\hline SI 3869 & & B \\
\hline SI 3870 & $4 \mathrm{bKr} 46$ & B \\
\hline SI 3874 & $4 \mathrm{bKr} 52$ & B \\
\hline SI 3875 & $4 \mathrm{bKr} 53$ & B \\
\hline SI 3877 & $4 \mathrm{bKr} 86$ & B \\
\hline SI 3902 & $4 \mathrm{bKr} 124$ & B \\
\hline SI 3928 & $4 \mathrm{bKr} 159$ & B \\
\hline SI 3968 & $4 \mathrm{bKr} 82$ & B \\
\hline SI 3981 & $4 \mathrm{bKr} 129$ & B \\
\hline SI 3992 & $4 \mathrm{bKr} 163$ & B \\
\hline SI 3996 & $4 \mathrm{bKr} 169$ & B \\
\hline SI 4072 & $4 \mathrm{bKr} 81$ & B \\
\hline SI 4210 & Kr I 123 & C \\
\hline SI 4319 & Kr I 242 & C \\
\hline SI 4457 & Kr I 372 & C \\
\hline SI 4745 & 084 & B \\
\hline SI 4756 & 096 & B \\
\hline SI 4762 & O 102 & $\mathrm{E}$ \\
\hline SI 4956 & Kr I 10 & $C$ \\
\hline SI 4996 & Kr I 421 & C \\
\hline SI 5594 & Kr IV 267 & $\mathrm{D}$ \\
\hline SI 5671 & $2 \mathrm{Kr} 49$ & AppA \\
\hline SI 5803 & $3 \mathrm{Kr} 20 / 5$ & E \\
\hline Lujiang Caotang & & $\mathrm{I}$ \\
\hline
\end{tabular}

Einige unpublizierte Fragmente sind als Belege für besondere Probleme benutzt worden: (DTA) Ch/U 6154, Ch/U 6511, Ch/U 6857, Ch/U 7363, Ch/U 7511, U 4451, U 4891, U 5342, U 5657, Mainz 299, Mainz 419, Mainz 735; (IOM) SI 1465, SI 1656, SI 2617, SI 4089, SI 4958, SI 4984; (Istanbul) Bibliothek der İstanbul Üniversitesi No. 20. 


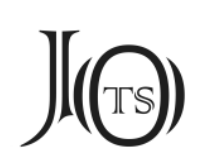

\section{Handschrift A}

Die Handschrift A wurde im Band 135 der Faksimileausgabe der DunhuangHandschriften der Nationalbibliothek Beijing veröffentlicht: BD $14941 .{ }^{24}$ Die Vorderseite ist Teil einer Abschrift eines chinesischen Vinaya-Texts ${ }^{25}$.

Die Erstedition des altuigurischen Texts auf der Rückseite liegt seit kurzem als Aufsatz von A. YAKUP vor (2019). Für die hier beabsichtigte vergleichende Studie benutze ich diese Handschrift A als Haupttext, weil sie am vollständigsten erhalten ist. Den Text gebe ich nur in Transkription wieder, in die einige neue Lesungen und Vorschläge einfließen, wobei ich mich auf solche Stellen beschränke, die mir für das Textverständnis wichtig oder notwendig erscheinen. Durch die Parallelhandschriften ergeben sich für einige unklare Stellen Anhaltspunkte für ein besseres Textverständnis, doch bieten die neuen Bruchstücke ihrerseits auch selbst viele Probleme, gerade wenn Varianten oder abweichende Passagen vorliegen.

\section{Gedicht der Vorderseite}

In seiner Einleitung ediert A. YAKUP das Gedicht, das auf der Vorderseite am Ende des chinesischen Textes (BD 14940) steht, das ich mit einigen Modifizierungen wie folgt interpretieren möchte:

özüm ädrämsiz bolmaktın

özök-k(i)yäm ädgü bolmadı

ötsär küsüš bo bitig

ünär ärki abipirayaka tayansar

Weil ich selbst ohne Tugend bin / ist mein Innerstes nicht gut. / Wenn man zum Wunsch vordringt, kommt diese Schrift / wohl hervor, wenn man sich auf abhiprāya stützt.

${ }^{24}$ Nach S. 21 dieser Ausgabe handelt es sich um einen uigurischen Text von der Größe 134,5 x 25,2 cm, er soll aus der Zeit des IX.-X. Jh. stammen. Diese Schriftrolle stammt aus Dunhuang, alle anderen Abschriften aus der Turfanoase.

25 Das Fragment BD 14940 ist auch in IDP zugänglich. Zu Einzelheiten vgl. Yakup 2019: 6-7. 


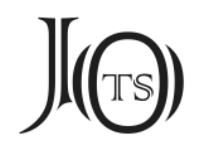

A. YAKUP möchte in der Niederschrift dieses Gedichts am Ende des chinesischen Vinaya-Texts ein Verbindungsglied zur Rückseite mit dem uigurischen Text sehen, weil letzterer eine Aufforderung an Laien sein soll, die sie auf den Mönchs/Nonnenweg führen soll (2019: 7, 10). Diese Annahme ist möglich, jedoch nicht wirklich gesichert.

\section{Text der Rückseite}

Der Text ist in einer recht deutlichen Kursivschrift geschrieben. Die Schreibweise der Dentale und Sibilanten weist auf die Erscheinungen hin, die G. DOERFER als Dentalkonfusion bezeichnet hat (1993: 115-119).

\section{Chinesische Schriftzeichen}

Die ganze Handschrift ist durchzogen mit chinesischen Zeichen, die sicherlich als uigurische Wörter gelesen wurden. A. YAKUP vermutet in in diesem Verfahren, daß ein chinesischer Text als Vorlage gedient haben könnte (2019: 10), doch ist in diesem Fall diese Annahme nicht gesichert, weil den Uiguren jener Zeit das komplette buddhistische Tableau der chinesischen Buddhisten zur Verfügung stand. Die chinesischen Zeichen werden als integrale Bestandteile verwendet, die zweifellos altuigurisch gelesen wurden (werden sollten). Unter den parallelen Handschriften gibt es einige, die an den entsprechenden Stellen die türkischen Wörter verwenden. Beispiele dafür sind:

\begin{tabular}{||l||l||}
\hline \multicolumn{1}{|c|}{ A } & \multicolumn{1}{c|}{ B } \\
\hline \hline 029 三 & 02+03: 22 üč \\
\hline \hline 029 四大 & 02+03: 22 tört mahabutlar \\
\hline \hline 043 四 yüz 四 & 02+03: 39 tört yüz tört \\
\hline \hline 101 九十八 & 09+10+11: 13 tokuz on säkiz \\
\hline
\end{tabular}

In der Regel wurden Suffixe in uigurischer Schrift angefügt. A. YAKUP meint, daß „characters had different readings in different contexts“ (2019: 8). Für das angeführte Beispiel 上 tägrikä下人 $k a$ in Zeile 129 schlägt er die Lesung ÜSTÜNKI t(ä)ngrikä AlTÏNQÏI YALNGUQqa vor (Yakup 2019: 8) ${ }^{26}$, doch die Handschrift B 13: 07

${ }^{26}$ Die Wiedergabe mit Großbuchstaben bedeutet hier, daß chinesische Zeichen vorliegen, die allerdings uigurisch gelesen wurden. 


\section{J(৫)}

lautet üstün t(ä)yrikä altın ya[lyuk-ka], wie es zu erwarten ist. Ähnlich ist auch in seinem zweiten Beispiel nicht AlTÏNQÏ, sondern altın zu lesen.

\section{Zur Lesung von 'ylyn}

In den meisten Fällen endet ein Abschnitt (Passus) mit der finalen Anrede täyrim ,Majestät!' (005, 015, 026, 036, 047, 056, 068, 076, 085, 096, 120, 133). Viermal $(026,068,106,133)$ steht stattdessen oder als weitere Anrede * $y^{\prime} l y n$ tägrim. Das vor diesem tägrim stehende Wort liest A. YAKUP yalin oder alin (Yakup 2019: 25). In seiner Erklärung bietet er zwei Erklärungsmöglichkeiten. Zum einen setzt er das türkische Wort yalın mit der Übersetzung ,my splendid Lady' oder ,Her Majesty, My Lady an. Da yalin bisher nur in substantivischer Verwendung bekannt ist, müßte für ,splendid' yalınlıg oder yalınčıg stehen. Beide Adjektive sind belegt, aber nicht hier. Ohne einen eindeutigen Nachweis für yaln in adjektivischer Verwendung ist es schwer, eine solche Deutung zu unterstützen. Zum anderen hat die zweite Lesung alin und deren Herleitung aus skt. alina ,nothing low', ,a reference to the akanisțhadevas, the eighth of the eight (or nine) heavens included in the fourth dhyāna in the form realm ' (Yakup 2019: 25) ein semantisches Problem. Das Negativum von PPP lina $(<\sqrt{l i})$, liegend, steckend, verborgen' scheint mir als eine besonders positive Eigenschaft nicht sehr geeignet zu sein, auch wenn es einen Buddha namens Alīnaghoșa ,der, dessen Verkündung nicht verborgen (oder gehemmt) ist' gibt (SWTF I: 154a). In der Textübersetzung gibt er seiner ersteren Lösung den Vorzug: ,My Lady!‘. Der prinzipiellen Lösung, einen Titel anzunehmen, ist zuzustimmen, doch nicht den Erklärungsversuchen, weshalb ich hier einen alternativen Vorschlag unterbreite.

Wenn man diese vier Belege vergleicht, muß man feststellen, daß der erste Buchstabe nur als Alif gelesen werden kann, während für die drei folgenden Zeichen in allen vier Stellen yly recht eindeutig ist. Der letzte Buchstabe gleicht in drei Fällen $(026,068,106)$ einem finalen $<n>$, doch in 133 kann man finales $<k>$ lesen. 


\section{J(G)}

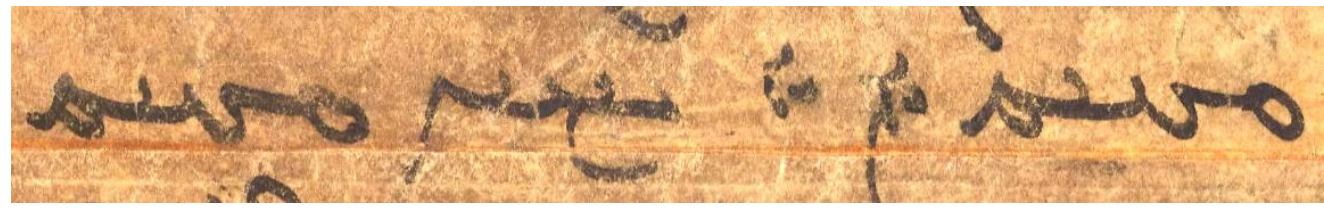

026

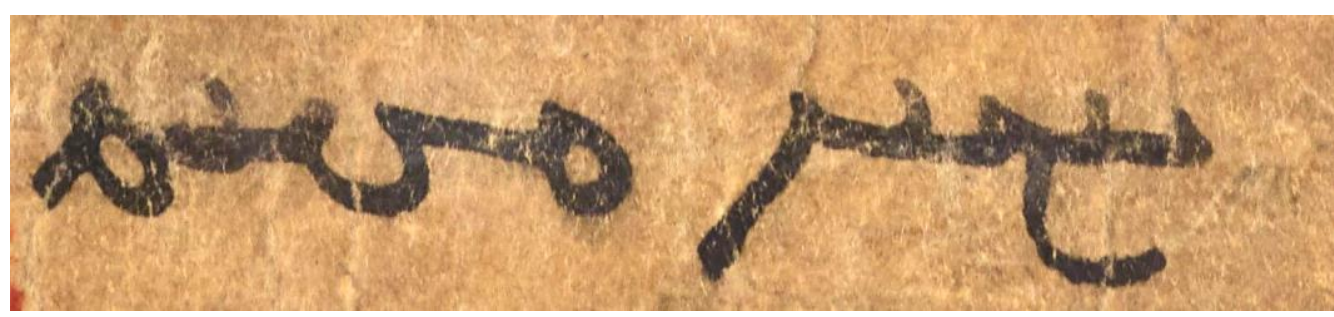

068

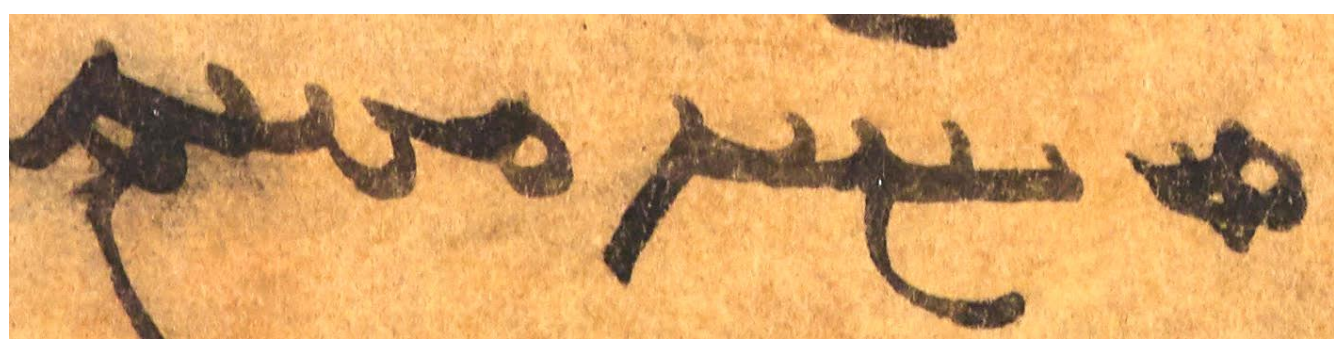

106

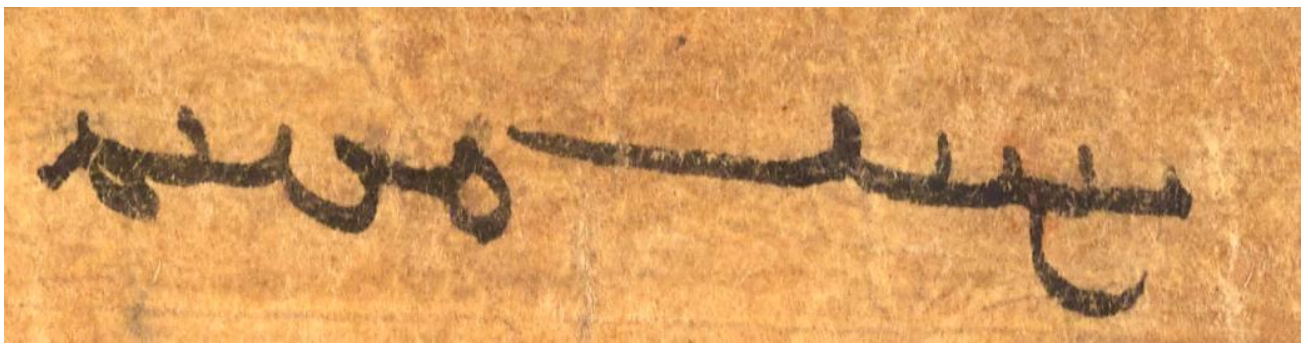

133

Zusammenfassend ergibt die Analyse, daß man in drei Fällen 'ylyn und in einem Fall (133) 'ylyk transliterieren muß. Vom Kontext her kann nur die letztere Variante, nämlich elig ,König', in Frage kommen, die durch einen eindeutigen Beleg in der Handschrift $\mathrm{C}^{27}$ verstärkt wird. So gesehen, handelt es sich also um die Anrede elig tägrim ,König-Majestät!

27 Handschrift C

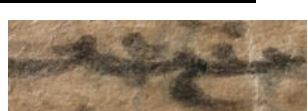




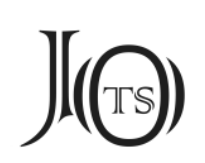

\section{Zur Struktur}

Die von mir vorgenommene Einteilung in Sinnabschnitte erfolgt nach der Struktur der Handschrift. Jeder neue Abschnitt beginnt mit $y$ - $a$,oh! als Interjektion. Als Hervorhebung erscheint dieses Wort $y$ - $a$, wenn es am Anfang der Zeile steht, bereits auf dem oberen Rand, vgl. Zeilen 006, 057, 069 und 107. A. Yakup hat in allen Fällen ymä ,und' gelesen. Mit letzterem beginnen zwar sehr oft altuigurische Texte, ja, es scheint sogar ein Charakteristikum für einen genuinen uigurischen Text zu sein, doch hier ist es anders, die Interjektion $y$ - $a$ ,oh!' dient wohl sogar der Verstärkung des beabsichtigten Tenors des Textes als Aufforderung.

\section{Passagen über Alter}

Von zahlreichen Aussagen sei hier ein Abschnitt aus AN V.78 zitiert:

„There is the case where a monk reminds himself of this: At present I am young, blackhaired, endowed with the blessings of youth in the first stage of life. The time will come, though, when this body is beset by old age. When one is overcome with old age \& decay, it is not easy to pay attention to the Buddha's teachings. It is not easy to reside in isolated forest or wilderness dwellings. Before this unwelcome, disagreeable, displeasing thing happens, let me first make an effort for the attaining of the as-yet-unattained, the reaching of the as-yet-unreached, the realization of the as-yet-unrealized, so that - endowed with that Dhamma - I will live in peace even when old. ${ }^{\text {"28 }}$

Wieviele Abschnitte dem Thema Alter gewidmet waren, ist nicht sicher. Vom Textbestand ausgehend nehme ich an, daß man mit Alter-1 nahezu an den Beginn des Textes heranreicht, wenn man noch einige Zeilen für Alter-1 sowie kurze Abschnitte für Titel und Einleitung voraussetzt, die jedoch nicht erhalten sind. Es könnten aber auch weitere Alter-Passagen vorangehen.

\section{Abschnitt Alter-1}

$001 \mathrm{k}(\mathrm{a}) \mathrm{y}^{29}[$

] miš $\check{c} \mathrm{~W}^{\prime} \mathrm{k}^{330}$

\footnotetext{
28 AN 5.7 Anagata-bhayani Sutta.

29 Unklar.

30 Unklar.
} 


\section{$J(\Theta)$}

002 täg · ig-kä ${ }^{31}$ är $[k s i z$

] bolmak-1 ärür :: 二者 [ikinti ärsär]

köyül-nün karımakı ärsär

003 kim $^{32}$ bo köyül kšan kšan sayu . tünärip kararıp čöküp batıp ${ }^{33}$ :: ädgüli ay1g

004 -lı iki türlüg nom-larıg adırtlayu ${ }^{34}$ umatın . bulıt-lıg tün-däki

005 satıg-čı-lar ${ }^{35}$ täg bilmäksiz kıldačı täginür täyrim :: ... ::

[Erstens: Was das Altern des Körpers betrifft,] weit (?) [...] wie [...] č č' $k^{\prime}$, ist sein $\mathrm{Ma}[\mathrm{chtlos}$ und Ohnmächtig]-Sein gegen die Krankheit. Zweitens: Was das Altern des Sinnes betrifft, ist es so, daß der Sinn von Moment zu Moment ${ }^{36}$ dunkler und schwärzer wird, versinkt und abtaucht. Die zwei Dinge, ob (etwas) gut oder schlecht (ist), kann er nicht unterscheiden. Das macht unwissend wie (es für) Kaufleute in bewölkter Nacht (gilt).

Mein Fürst!

\section{Kommentar}

Inhaltlich geht es in diesem ersten Abschnitt um die körperlichen und geistigen Gebrechen, die jedermann treffen können. Von den körperlichen Schwächen ist zunächst wegen des Erhaltungsstandes nichts erhalten. Interessant ist der Vergleich mit den Kaufleuten, die in bewölkter Nacht den Weg nicht finden können. Auch wenn dieser auf einem Sprichwort oder einer fremden Vorlage beruht, so paßt diese Anspielung auf die Kaufleute sehr schön zu einem volksnahen Text, denn die Händler hatten eine eminente Bedeutung in Wirtschaft und Kultur so wie schon in Indien, vielleicht aber noch mehr in Zentralasien dank der Handelswege, die gemeinhin ,Seidenstraßen' benannt wurden. Der Vergleich gibt dem Text ein zweifellos zu erwartendes Lokalkolorit.

\footnotetext{
$31 \quad$ Unklar, vielleicht auch ärk-kä?

32 Fehlt bei Yakup 2019: 12.

33 Geschrieben: $p^{2} d y p$.

34 Geschrieben: "'tyrdl'yw.

35 Geschrieben: s'dyq-cy-l'r.

36 Der Ausdruck kšan kšan ist häufig belegt, vgl. u. a. Suv. 55/8; 123/20.
} 


\section{$J(\Theta)$}

\section{Abschnitt Alter-2}

006 y-a ${ }^{37}$ alku kamag tınl(1)g oglan-ları-nıy . bulunčsuz čintamani ${ }^{38}$ ärdinisi bolu

007 yarlıkamıš täyrikän tegin t(ä)yrim kut ${ }^{39}$ yarlıkasar :: kim bo karımak tegli utun ${ }^{40}$

008 törü yana : kamag tınl(1)g oglan-ları-nıy . kašınčıg körklä ätözlärin

009 kamıš-layu yančdačı :: kuzgun ${ }^{41}$ täg kara sač-ların : kugu-layu yürünärttäčí ${ }^{42}$ :

010 yürüy yinčü tizmiš ${ }^{43}$ täg : tiš-lärin azıg-ların ${ }^{44}$ : altun-(layu) sargartdačı $\because:$

011 tülüg ärük čäčäki täg . öylärin kırtıš-ların . šäpgün ${ }^{45}$ kar-a kıldačı ::

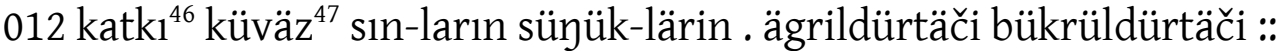

013 tıgrak katıg türk yigit ärän-lär-kä . ergülük yarsı(gu)luk ${ }^{48}$ bolmıš :: karımak

37 Yakup 2019: 13 liest ymä.

38 Geschrieben: cynd'm'ny.

39 Geschrieben: qwdy.

40 Geschrieben 'wdwn.

41 Geschrieben: qwsqwn.

${ }^{42}$ Geschrieben: ywrwnk ${ }^{3} r d t^{3} c y$.

43 Geschrieben: tysmys. Yakup 2019: 13 liest tïqmï̌s.

${ }^{44}$ Geschrieben: "syq l'ryn.

45 Geschrieben: s'pkwl.

46 Geschrieben: $q^{3}$ dqy.

47 Yakup 2019: 13 liest küvän und übersetzt ,arrogant', doch könnte küvän nur ein Imperativ des Verbs küvän- ,to be proud' (ED: 690a) sein, was allerdings nicht in den Kontext paßt. Nach der Parallele der Handschrift F ist küväz zu lesen.

48 Yakup 2019: 13 liest yarsilyuluq. 


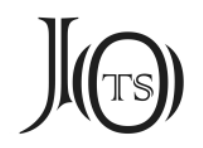

014 tegli kargatmıš ${ }^{49}$ utun $^{50}$ törü . kamag tınl(1)g oglan-larına tüzü-kä ${ }^{51}$ bir täg

015 käldäči täginür täyrim ::

Wenn Mein Gnädiger Prinz-Fürst, der das unauffindbare cintāmaṇi-Juwel aller, sämtlicher Lebewesenkinder zu sein geruht, (es anzunehmen geruht), dann ist es so: Die verruchte Sache, die Alter genannt wird, nun läßt die anziehenden, schönen Körper aller Lebewesenkinder wie Schilf ${ }^{52}$ zerknicken $^{53}$, läßt die schwarz wie Raben seienden Haare weiß wie ein Schwan werden, läßt die wie weiße Perlen aufgereihten Zähne und Backenzähne gelb wie Gold erscheinen, macht ihre der Blüte eines Pfirsichs ${ }^{54}$ (gleichende) Gesichts- und Teintfarbe nacht-schwarz ${ }^{55}$, läßt ihre festen ${ }^{56}$ und stolzen Gebeine und Knochen krumm und gebückt werden ${ }^{57}$; sie ist von allen festen und stabilen, kräftigen und

49 Geschrieben: q'rq'dmys. Yakup 2019: 13 liest qayïndamï̌s, das er zusammen mit utun ,unfortunate übersetzt, allerdings ohne einen Nachweis für erstere Lesung anzugeben.

50 Geschrieben: 'wdwn.

51 Geschrieben: twysw k'.

52 In dem Text U 4891 heißt es ähnlich: (Z. 05) kamıš čöpi täg a kk[ura ...], wie ein Schilfhalm [umknickend ...] ' (Z. 07) ... bo karrmak törü mund $[a$...] ,... diese Sache 'Alter' hier ...'.

53 In einer Beschreibung, wie der Körper in der Hölle zerbricht, heißt es: ät’öz 03 [pa]r(a)manu kog kıčmık bolup kum 04 sačllip kamišlayu yančlsar "wenn der Körper zu parāmaṇu-Staub und als Sand zerstreut wird oder wie Schilf umknickt” (Mainz 419 v2-4). Hier wird dieselbe Metapher verwendet.

54 tülüg ärük ist wohl eine Bezeichnung für den ,Pfirsich`oder die ,Aprikose', vgl. Maue 2002: 104. Ein neuer Beleg im Katalog Raschmann-Sertkaya, Nr. 032 (ohne Übersetzung). Yakup 2019: 25 ,prunus siberica'. Hauenschild 1994: 36 sieht in ärük eine generelle Bezeichnung für Pfirsiche, Aprikosen und Pflaumen, weshalb Adjektive zur Spezifizierung vorgesetzt werden. Demgemäß meint tülüg ärük den „Pfirsich', obwohl Hauenschild auch Belege für ,Aprikose‘ zitiert. Eine ganz eindeutige Festlegung bleibt schwierig.

55 Das Wort s'pkwl liest Yakup säpgül ,spotted', wobei er wohl an MK 242/14 (سَنَكِل) (ED: 839a sengil ,freckles') denkt, das DLT I: 359 säpgil liest. Da Sommersprossen meist braun sind, könnte man auch šäpgül vorschlagen, herzuleiten aus np. šab-e gol 'The night of roses (when people visit the rosegardens to celebrate the event of spring)' (Steingass: 729b). Passender wäre jedoch (شبكَون) 'the colour of night, i.e. black' (Steingass: 732a), vgl. u. a. Burhân-1 Katı: 714a şeb-gûn 'Efsûn vezninde şeb-renk manasındadır ki gece renkli demektir. Murat, reng-i siyâhtır'. Lugat-1 Remzi: (سياه قرهبكون). Bei dieser Deutung stört das finale $<\mathrm{l}>$ für $<\mathrm{n}>$.

56 Vgl. ED: 598b katkı, harsh, hard hearted', wie beispielsweise ymä küväz katkı köyül(l)üg (Geng-Klimkeit 1988/I: 16), hier aber eher im Sinne von ,fest, stabilk. Die Reihenfolge der Glieder wäre auch umgekehrt.

57 Zum Verbstamm ägril- vgl. UWV/1: 132 (nur ein Beispiel). 


\section{J(৫)}

starken Männern verachtet und verhaßt. Die Alter genannte verfluchte und verhaßte Sache kommt zu allen Lebewesenkindern, zu allen gleichermaßen.

Mein Fürst!

\section{Kommentar}

Den Körper, Haare, Zähne und den Teint betreffende Merkmale des Zerfalls werden mit drastischen Vergleichen vorgestellt und erläutert. War in Alter-1 allgemein von den körperlichen und geistigen Gebrechen die Rede, nimmt sich der Autor hier einzelne Symptome vor, um den Verfall zu veranschaulichen. Ähnliche Vergleiche benutzt auch der Meister in der Daśakarmapathāvadānamā $\bar{a}^{58}$.

\section{Abschnitt Alter-3}

015 y-a ${ }^{59}$ sansar-a pramandal yertinčü yer suv

016 ičindäki tınl(1)g-lar-(nı)) ayaguluk-1 bolu yarlıkamıš täyrikän tegin tänrim kut-1

017 yarlıkasar : bo karımak tegli utun törü ärsär :: alkıču üdtäki ${ }^{60}$ oot täg .

018 ädgüg yavızıg adırtlamatın ${ }^{61}$ alku-ka - [bir] täg käldäči täginür :: äymintın 三十

019 二 [otuz iki] lakšan-lar üzä etiglig62 . 八十 [säkiz on] nayrag-lar yaratıg$\operatorname{lig}::$ čakir bašlap

20 七 [yeti] ärdini-lär üzä ärklig türklüg ${ }^{63}$. čakiravart ${ }^{64}{ }^{1}$ duk elig-(lär) hanlar ymä ::

$58 \quad$ BT 37.

59 Yakup 2019: 13 liest ymä.

60 Yakup 2019: 13 liest ügdürgü.

61 Geschrieben: 'tyrdl'mtyn.

62 Geschrieben: 'ydyklyk.

63 Yakup 2019: 13 tuүulup.

64 Yakup 2019: 13 čakravart. 


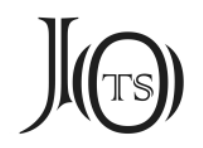

21 äy tüpindä karımak üzlünčü-lüg ${ }^{65}$ bolur-lar :: täyrikän tegin täyrim kutı 022 -nı̣ . anča ${ }^{66}$ ol anı täg köz äsri . köyül arvı bolgu täg ärki türki mäyi 023 -si tona-s1 . näčä üküš tälim bar ärsär ymä :: tugmak törü-tin ozma 024 -tuk ${ }^{67}$ üčün . karımak törü-tin ymä ozmıš ${ }^{68}$ kutrulmıšs $^{69}$ täginmäz :: 025 otgurak $^{70}$ karımak törü-lüg yarlıkar ${ }^{71}$. $\operatorname{arıt1}^{72}$ karımagay ärki män tep 026 s[özläyü] ${ }^{73}$ yarlıkamazun täyrim :: :: elig täyrim tegül šakimuni kılgu ol $\because:$

Wenn Mein Gnädiger Prinz-Fürst, der von allen Lebewesenkindern in der saṃsārapramandala irdischen Welt ${ }^{74}$ verehrt wird, (es anzunehmen geruht), dann ist es so: Die Alter genannte verruchte Sache ist wie das Feuer in der Endzeit. ${ }^{75}$ Ohne gut und böse zu unterscheiden kommt sie zu allen gleichermaßen. Selbst die mit den 32 lakșanas ausgestatteten, mit den 80 anuvyañjanas versehenen und durch die mit cakra ${ }^{76}$ beginnenden sieben Juwelen herrschenden heiligen cakravartin-Könige und Herrscher werden am letzten Ende alter-endlich sein. Wenn auch der Majestät des Gnädigen Prinz-Fürsten Kraft

65 Geschrieben: 'wyslwncw lwk.

66 Yakup 2019: 14 näčä.

67 Geschrieben: 'wsm'twq.

68 Geschrieben: 'wsmys.

69 Geschrieben: qwdrwlmys.

70 Yakup 2019: 14 ärür muntay. Nach der Handschrift C eindeutig otgurak.

71 Yakup 2019: 14 y(a)rlïyï.

72 Geschrieben: "'rydy.

73 Yakup 2019: 14 ergänzt zu s[aqïn]u.

74 Das Wort sansar-a-pramandal ist ein skt. Rekonstrukt: *samsāra-pramaṇdala, das sich so nicht belegen läßt. Die nachfolgende altuig. Übersetzung yertinčü yer suv macht aber deutlich, daß die, irdische Welt‘ gemeint ist, also wohl saṃsāramaṇdala, das wohl dieselbe Bedeutung hat wie samsāracakra (vgl. ZinSchlingloff 2007). MONIER-WILLIAMs gibt als Bedeutung von pramandala ,felly of a wheel' (685a) an, was hier sicher nicht zutrifft.

75 'Feuer der Endzeit', vgl. 'The conflagration in the kalpa of destruction that consumes the physical universe. All existences below the first meditation heaven 初禪天 are said to be annihilated (Skt. yuga-anta-agni).' (DDB).

76 Hier steht nur das skt. Wort cakra, Rad' in seiner altuig. Lautung čakir, ohne die altuig. Entsprechung tilgän, weil es sich um einen Terminus handelt. Zu der Liste der 7 Juwelen vgl. BT 7: 57 mit Anm. zu A 669. 


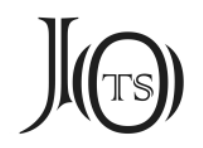

und Stärke, Seligkeit und Freude zahlreich und viel - als ob sie den Augen vielfältig und dem Sinn unbegreiflich wären ${ }^{77}$ - sein mögen, so wird (Seine Majestät), weil sie von der Sache der Geburt nicht erlöst ist, auch nicht von der Sache des Alters erlöst und befreit sein, (ganz) sicher ist sie von der Sache des Alters betroffen. Man sollte niemals sagen: „Ich werde nicht altern“.

Mein Fürst! Mein König-Fürst soll sagen ${ }^{78}$ : „Śākyamuni soll wirken!“

\section{Kommentar}

In diesem letzten Abschnitt über das Alter nimmt der Autor auf die Herrschenden Bezug, zunächst allgemein auf die Könige und Herrscher aller Welten und dann speziell auf die Königliche Majestät der Uiguren, möchte man hinzusetzen. Mit der Mahnung, daß es keine Ausnahme vom Altern geben kann, schließt dieses Kapitel mit der eindeutigen Aufforderung, sich dem Wirken des Śākyamuni hinzugeben und nach seiner Lehre zu leben.

\section{Passagen über Krankheit}

Von zahlreichen Aussagen sei hier aus AN V.78 zitiert:

„Furthermore, the monk reminds himself of this: At present I am free from illness \& discomfort, endowed with good digestion: not too cold, not too hot, of medium strength \& tolerance. The time will come, though, when this body is beset with illness. When one is overcome with illness, it is not easy to pay attention to the Buddha's teachings. It is not easy to reside in isolated forest or wilderness dwellings. Before this unwelcome, disagreeable, displeasing thing happens, let me first make an effort for the attaining of the as-yet-unattained, the reaching of the as-yet-unreached, the realization of the as-yetunrealized, so that -- endowed with that Dhamma -- I will live in peace even when ill.“

\section{Abschnitt Krankheit-1}

027 [bodist]v uguš tözlüg kinšuk ärdini . gavdam bag-lıg kumut 028 lenhu-a törüyü bälgürü yarlıkamıš täyrikän tegin täyrim kutı yarlı

77 Hier vermute ich wieder ein zugrundeliegendes Sprichwort: köz äsri köjül arvı bolgu täg.

78 tegül,man soll sagen', eine kontrahierte Form von tegü ol. 


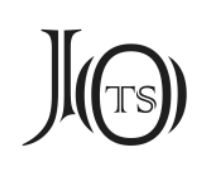

029 -[ka]sar :: bo ärsär 三 [üč] tooš-lar bulganmak-ıntın 四大 [tört mahabut] ${ }^{79}$-lar tüzüksirämäkintin ${ }^{80}$.

030 [五 beš ag1]lık-lar ${ }^{81}$ bımsıramak-ıntın ${ }^{82}$ 六 [altı] ordu-lar artamak-ıntın ${ }^{83}$ . aš ičgü

031 [si]りmämäkintin :: azuča ${ }^{84}$ ärsär ymä butii ${ }^{85}$ amanuš-i-lar buu sigšil almak

032 -ıntın . yäk ičgäk-lär üzä yelpikmäkintin ${ }^{86}$. grah ${ }^{87}$ tokımak-ıntın $^{88}$

033 boguz igitmäk üzä ilgünmiš ${ }^{89}$ :: ilki-siztinbärü eritilmiš ${ }^{90}$ alku

034 kiši-lärkä aklatılmıš ${ }^{91}$. iglämäk atl(1)g äšidgäli yavız yel törü

035 bo täginür täyrim :: ::

79 Yakup 2019: 14 ersetzt naheliegenderweise 大 durch ulug, doch die Handschriften B und C haben mahabut.

80 Geschrieben: twyswksyr'm'kyntyn.

81 Ergänzt nach der Parallele SI 4956 (Handschrift C) beš agllk-lar. Yakup 2019: 14 hat keine Ergänzung.

82 Geschrieben: pymsyr'm'q lesen (so auch Yakup 2019: 14), bestätigt durch Handschrift C.

83 Geschrieben: 'rd'm'q yntyn, so auch in Handschrift C.

84 Geschrieben: "swc'.

85 Geschrieben: $p w d y$.

86 Yakup 2019: 14, liest yelpünmäkintin. MK hat zwar das Verb yelpin-, und yelpün- könnte eine labialisierte Form sein, aber der $<\mathrm{n}>$ gelesene Buchstabe ist eher $<\mathrm{k}>$, so daß das Verbalnomen vom Verb yelpik- vorzuliegen scheint, wie es auch im Suv. vorkommt: yelpikmäk agukmak (Suv. 472/15; das Verb aguk- wurde in das UWV/1: 31, aufgenommen, doch die mAK-Ableitung nicht, sicherlich ein Ergebnis der ungerechtfertigten Aufsplittung des Wortschatzes in Nomina und Verba, auf die A. Vovin in seiner Rezension aufmerksam gemacht hat, vgl. Vovin 2019b: 169-170).

87 Geschrieben: k'rä. Entsprechend liest Yakup 2019: 14 garh.

${ }^{88}$ Geschrieben: $k^{2} d^{2}$ n, mit Yakup 2019: 14 zu tokımakındın zu emendieren, wie auch Handschrift C zeigt.

${ }^{89}$ Handschrift C: iglämiš. Vielleicht liegt in A ein Kopistenfehler vor.

90 Geschrieben: 'yrydylmys. Yakup 2019: 14 liest allerdings yarațilmiš und übersetzt dementsprechend "was created".

91 Geschrieben: "ql'dylmys. 


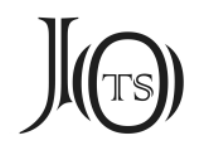

Wenn die Majestät der Fürstlichen Prinz-Hoheit von [Bodhisatt]va-Natur, die (als) kumudaLotos des kimśuka $a^{92}$-Juwel(haltigen) Gautama-Stammes aufzugehen und aufzutauchen geruht, (es anzunehmen geruht), dann ist es so: Was dies betrifft, so ist es die - aus der Vermischung der 3 doșas $^{93}$, aus der Unordnung ${ }^{94}$ der 4 mahābhütas, aus dem Verlustiggehen der Klassifikation ${ }^{95}$ der 5 Schätze $^{96}$, aus der Verderbnis der 6 Paläste $^{97}$, aus dem Nichtverdauen ${ }^{98}$ von Speisen und Getränken, oder auch (aus den Umständen), daß bhütas und amanusyas ${ }^{99}$ die Seelen und Sinne ${ }^{100}$ geraubt haben, oder daß man von Dämonen

92 Geschrieben: kynswq. Yakup 2019: 14 liest kinšoq und übersetzt (p. 22) ,Kiṃśuka-Jewel‘. Der botanische Name ist nach SWTF II: 74b ,Butea frondosa Roxb'. Dieser Baum ist seiner roten Blüten wegen berühmt (vgl. auch BSJT, Nr. 152); SH 425b, Nakamura 328b. Die Wiedergabe von -ka durch /q/ist auch in einem unpublizierten Gedicht belegt: IOM SI 4958 r08 kiši körklüg kynswq ärdini. Skt. /k/ ist in der Regel durch vorderes / $\mathrm{k} /$ wiedergegeben und es wäre die Schreibung kynswk zu erwarten (vgl. Röhrborn 1988: 235: "Solche abweichenden Transkriptionen fehlen aber fast völlig" mit Verweis auf die "Ausnahmen" in BT VII: 7). Diese ist in anderen altuigurischen Texten belegt: Guanjing [ZiemeKudara 1985: Z. 243 nebst Anm.] 243 [ETŞ: 20/184]; U 5342 IIr 03, 09. Für den vorliegenden Fall jedenfalls waren sich die Uiguren nicht sicher, denn von den 4 Belegen haben 2 /k/, 2 /q/. Merkwürdig ist BT 7: A153 kynksw = kiyšu (dazu Anm. in BT 7: A 153).

93 Yakup 2019: 14 liest tuušlar und übersetzt (22) ,THREE equals` als Wiedergabe des buddhistischen Terminus 三平等, three karmic agents are equal'. Eher kommt jedoch die Herleitung aus skt. tridoșa ,drei Körpersäfte‘ (Maue 1996: 130 üč došlarıg für skt. tridoșa) in Frage, eines der Grundprinzipien der indischen Medizin, das im Suvarnaprabhāsasūtra einen wichtigen Platz einnimmt.

94 Das Wort tüzüksirä- ist hier zum ersten Mal belegt, abgeleitet von tüzük ,ordentlich, geordnet etc. (OTWF 251-252).

95 Bisher liegt keine Deutung vor. Wenn man von dem denominalen Verbalsuffix $\{+$ sIrA $\}$ ausgeht, ist das zugrundeliegende Nomen brm, das vielleicht auf chin. 品 pin (Pulleyblank 240: $p^{h} i m$ ) zurückgeht. Die 5 Skandhas unterliegen einem genauen Regelwerk, und wenn sie dieser Kategorisierung verlustig gehen, entstehen ebenfalls Krankheiten.

96 Nach den Handschriften B und C ist die Ergänzung sicher. Es handelt sich wahrscheinlich um die fünf Skandhas, 五蓝 wuyun, die fünf Anhäufungen, die Elemente der menschlichen Existenz, sonst meist als bešyükmäk belegt (TT VI: 157). Die Verwendung von agıllk,Schatzkammer für diesen Terminus ist unerwartet und bisher nicht belegt.

97 Yakup 2019: 22 ,SIX palaces', ohne Erklärung. Vielleicht identisch mit 六處 liuchu = skt. șadāyatana ,6 Sinnesorgane‘ (UWN/1: 112).

98 Yakup 2019: 14 ärkmämäkintin. Aus der Übersetzung, because food and drink are not sufficient' (Yakup 2019: 22) müßte man auf ein Verb ärk- genügend sein' schließen, doch finde ich dafür keinen Nachweis. Nach der Parallele SI 4956 (Handschrift C) ašı ičgüsi sigmämäkintin liegt das Verb sin,hineingehen', hier speziell, verdauen' vor.

99 Skt. bhūta und amanuşya sind Klassen von Dämonen.

${ }^{100}$ Altuig. buu sigšil (andere Lesungen sind möglich), vgl. Zieme-Kara 1978: Anm. 233 (77-78). 


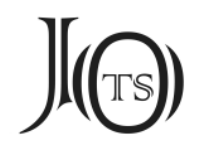

besessen ist, oder daß man von Schlägen von grahas ${ }^{101}$ betroffen ist, der mit dem Füttern der Kehlen ${ }^{102}$ beschäftigt ${ }^{103}$ ist, - entstehende und seit der Anfangslosigkeit an ${ }^{104}$ verachtete ${ }^{105}$ und von allen Menschen verhaßte Krankheit genannte und schlecht anzuhörende Sache ${ }^{106}$.

Mein Fürst!

\section{Kommentar}

Der Autor nennt hier summarisch und in enzyklopädischer Weise, möglicherweise auf besonderem Wissen basierend, viele Ursachen von Krankheiten. Die wesentlichen Verursacher werden auch in den medizinischen Teilen des Suvarnaprabhāsasūtra erörtert. Sie umfassen auf dem Āyurveda beruhende Theoreme, die Verdauung betreffende praktische Dinge sowie übernatürliche von Dämonen ausgeübte Einflußnahmen. Besonders hervorzuheben wäre das ,Füttern der Kehlen“, ein Ausdruck, der sich wohl auf die Nahrungsaufnahme bezieht ${ }^{107}$. Während hier boguz mit der ursprünglichen Bedeutung ,Kehle‘ zu sehen ist, hat das Wort nach BT 43, 68 in den Dokumenten des Postwesens als erster Bestandteil von boguz at auch die Bedeutung von ,Futter', sofern die Bedeutungsannahme von ,fodder horse, led horse, horse to carry fodder' zutrifft.

${ }^{101}$ Skt. graha (,greifend'),Krankheitsdämon'.

${ }^{102}$ boguz igidmäk. Vgl. U 5657 verso (Schreibübungen) 04/06 ertä bir čıay kiši [...] 06/07 boguz igitip yorır är[kän]. Die genaue Bedeutung ist nicht klar: "während ein sehr armer Mann [...] (seine) Kehle zu füttern geht”. Man dürfte an gewisse Schwierigkeiten denken, um Leute zu sättigen.

103 Yakup 2019: 14 liest irgürmiš und übersetzt (22), activated'.

104 ,seit der Anfangslosigkeit an' ist ein feststehender Begriff für ,von Anfang an'. Yakup 2019: 14 transliteriert 'ylky syn tynp'rw und liest ilkisitinbärü, ohne die Form zu erklären, doch trifft seine Übersetzung (22), from the very beginning' $z u$.

105 Vgl. UWV/2: 31.

106 Yakup 2019: 22 interpretiert das vor törü ,Sache' stehende Wort yyl im Sinne von ,the rule of years of life', doch scheint mir eher ein Binomen vorzuliegen, wie aus der Handschrift C [ön]dün törü (dazu Anm. unter C) hervorgeht. Doch welches Wort mit yyl gemeint ist, bleibt unklar, möglicherweise meint der Schreiber el törü (ED: 122).

107 In UWV/2 so noch nicht belegt. 


\section{$J(\Theta)$}

\section{Abschnitt Krankheit-2}

035 y-a alku kamag tınl(1)g-lar-nıy arasınta .

036 ayaz-l1 yagiz-l1-ča yintmiš ${ }^{108}$ yegädmiš bodistv uguš-lug täyrikän

037 tegin täyrim kut ${ }^{109}$ yarlıkasar :: kim bo eritilmiš ${ }^{110}$ yavız . iglämäk tegli utun ${ }^{111}$

038 törü ärsär :: küčüg küsün-üg kävip küč<s>irätip ${ }^{112}$ olurgalı tur

039 -galı ärgäli ${ }^{113}$ 1dmatın . aš-ka ičgü-kä sav-ka sözkä tapsız kıl

040 -tačc täginür :: bo iglämäk ymä 三 [üč] türlüg bolu täginür :: 一者 [änilki ärsär $]^{114}$ tadu .

$041 \mathrm{~m}(\mathrm{a})$ ha[but]-lar bulganmakıntın t[ur]mı̌̌ ig : 二者 [ikinti ärsär] učık yelpik ${ }^{115}$ tözlüg :

042 [ig] 三者 [üčünč ärsär] kılınč tözlüg ig bolar ärür-lär 三 [üč] türlüg iglär ::

${ }^{108}$ Yakup 2019: 14 liest yertmiš yegädmiš und übersetzt (22), surpasses'. Das ginge aber nur, wenn man eine ungewöhnliche Form yert- von ärt- voraussetzt, zu Belegen für das Biverb ärt-yegäd-vgl. UWV/1: 189, obwohl RÖHRBORN eine Schreibung yyrt- nicht verzeichnet. Zum Ausdruck vgl. UWN/2: 78: statt ärtmiš ašunmıš hier yintmiš yegädmiš. Für yintmiš wurde in BT 8: B 154 ,Schnitzfehler für utmıš vermutet, doch sollte man angesichts der Belege (OTWF 704: ETŞ 13/26 [wegen Alliteration wurde die Wendung kamag šmnularıg yintip utmiš zu yintip kamag šmnularıg utmiš umgestellt]; Blockdruck IOM SI 1656, Z. 20; U 4451, A 04; Ch/U 8126 v 05 [= BT 38 Ic05 fälschlich y(e)gätmiš gelesen]) und vor allem wegen des Doppel-Paarworts in B038 ein Verb yint- oder yent- mit der Bedeutung ,besiegen' (ED: 946b nur ,to search' oder ,to seek') akzeptieren.

${ }^{109}$ Geschrieben: qwdy.

${ }^{110}$ Geschrieben: 'yydylmys.

${ }^{111}$ Geschrieben: 'wdwn.

${ }^{112}$ Geschrieben: kwycyr'dyp. Wie die Handschrift C zeigt, hat der Schreiber den Buchstaben -s- vergessen. Yakup 2019: 15 übersetzt zwar, wie der Kontext erfordert, ,weakens', gibt aber keine Erklärung der Form/yp kü̈̌̈̈nädip.

${ }^{113}$ Yakup 2019: 15 liest ärkli. Wohl an ärk ,Macht' denkend übersetzt er (22): ,enables one neither to sit nor stand', ohne Erklärung.

114 Yakup 2019: 15 BAŠTÏNQÏI.

115 Yakup 2019: 15 yelpig. 


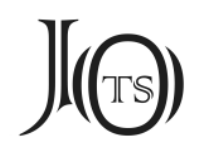

043 [tadu maha]but-lar bulganmakıntın turmıš ig yana 四 [tört] yüz 四 [tört] türlüg

044 [bol]u täginür :: bo 四 [tört] yüz 四 [tört] türlüg ig-lärdä . kayu ärsär igig iglägü

045 -čä täylig ärsär :: arada ymä ot äm tusulur ${ }^{116}$. arada ymä ot äm tusulmaz

$046 \operatorname{adın}^{117}$ ažun-ka sanlıg bolur-lar :: bo munı täg osug-lug eritilmišs ${ }^{118}$ yavız 047 iglämäk törü muntag bolu täginür täyrim :: ::

Wenn die Majestät der Fürstlichen Prinz-Hoheit, die unter allen Lebewesen im Himmel und auf der braunen (Erde) ${ }^{119}$ vom Geschlecht des siegreichen und unübertrefflichen Bodhisattva ist, (es anzunehmen geruht), dann ist es so: Was diese besagte ${ }^{120}$ schlimme Krankheit ${ }^{121}$ genannte verruchte Sache betrifft, so schwächt sie Kraft und Stärke ${ }^{122}$ und macht kraftlos, sie läßt nicht zu, daß man sitzen, stehen, existieren kann, sie macht ${ }^{123}$ appetitlos auf Speisen und Getränke, Wörter und Rede. Diese Krankheit ist von dreierlei Art. Erstens: die durch das Verwirrtsein der dhātus und mahābhūtas entstehende Krankheit. Zweitens: die [Krankheit], die von Dämonen und Geistern ${ }^{124}$ (verursacht ist). Drittens: die vom Karma verursachte Krankheit. Dies sind die drei Arten von Krankheiten. Von der

116 Yakup 2019: 15 tušulur. Er geht offenbar von einem Passivverb tušul- ,gefunden werden', für das auch ERDAL (OTWF: 680) plädierte, doch schreibt Erdal: "our suggestion [tušul-für tusul-] can only be proven to be correct if some exs. of tuşul- with dotted Ş turn up". Im vorliegenden Fall paßt tusul- ,nützen“ jedenfalls besser.

${ }^{117}$ Geschrieben: 'tyn.

${ }^{118}$ Geschrieben: 'yrydylmys.

119 Hier nur durch yagız ausgedrückt. Ähnlich auch in dem Blockdruck U 4846, wo K. RöHRBORN für eliglärtä hanlarta ayazh yagızlı̌̌a ärtmiš ašunmiš die Übersetzung, den Königen und Kaisern himmelhoch überlegen ${ }_{2}{ }^{\prime}$ (UWN/2: 78) vorschlägt, doch scheint mir eine Dichotomie von Königen im Himmel und auf der Erde eher zuzutreffen.

${ }^{120}$ Das Verb ayttl- kommt in UWV/1 nicht vor, ist aber bei MK belegt (vgl. ED: 269b).

${ }^{121}$ Die Wendung yavız iglämäk kommt auf dem Fragment $\mathrm{Ch} / \mathrm{U}$ 6154v in einer alleinständigen Zeile vor, gefolgt von ymä ämgäk. Es diente neben weiteren ähnlichen Stücken (Ch/U 6511, Ch/U 7511, Ch/U 7363) zur Reparatur eines lädierten Blockdrucks des chinesischen Lotos-sūtra T. 262. Ob der Text aber hierher gehört, bleibt unklar.

${ }^{122}$ Parallele SI 4956 (Handschrift C): küčüg küsünüg kävip küsän[ ].

${ }^{123}$ Yakup 2019: 15 til-țaï.

${ }^{124}$ učk yelpik, zu diesem Paarwort vgl. BT 23: I Amulett XXX; Suv. 475/7; Yüsüp 2004: 413; BT 47: 18. 


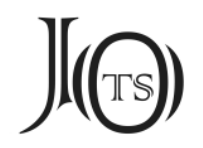

durch das Verwirrtsein der dhātus und mahābhütas entstandenen Krankheit gibt es nun 404 Arten. Wie sehr man auch von diesen 404 Arten von Krankheiten eine Krankheit heilen will, so nützt manchmal ein Heilmittel, manchmal nützt ein Heilmittel nicht. So sind (Betroffene) der anderen Welt angehörig. Die solcherart verachtete schlechte Krankheit (genannte) Sache ist so.

Mein Fürst!

\section{Kommentar}

Die 404 Arten von Krankheiten sind ein Topos der chinesischen Medizin, der auch in Übersetzungen buddhistischer Texte belegt ist, u.a. im Kšanti kilguluk nom: (1656-1558) birök yalyok ažuninta ärsär m(ä)n tört yüz tört törlüg iglär ätöziyä bür<t>ülmäklig ämgäklärkä tägmälim „Was ferner (Wesen) in der MenschenExistenzform anbetrifft, so wollen wir nicht auf diejenigen Leiden treffen, (die darin bestehen, daß unsere) Körper von den 404 Krankheiten berührt werden.". ${ }^{125}$ Auch in medizinischen Abhandlungen ist von den 404 Arten von Krankheiten (chin. 四百四病) die Rede. Die Zahl 404 ergibt sich daraus, daß jedes der vier Elemente für 101 Arten von Körperzuständen verantwortlich gemacht wird ${ }^{126}$ und damit quasi als Topos für ,alle Krankheiten ${ }^{127}$ gilt. Ein altuigurischer Text, für den keine Vorlage ausfindig gemacht werden konnte, setzt die 404 Krankheiten in Bezug zu 404 Heilkräutern: (120-125)

azu-ča ymä 四 [tört] bölük oot äm bölük-lärinä tükäl-lig otačl-lar 王 [han]-ı gandamadan tag-ta b(ä)lgülüg bolmıš 四 [tört] yüz 四 [tört] türlüg ig-lärkä 應 [yarašs] öyi nä äsrinü ot-larıg katıp kavišturup

«Or ainsi parce que quand le Roi des médecins, parfaits dans les quatre détachements des remèdes, apparaissait sur la montagne appelée Gandhamadana il a mélangé et assemblé tous les différents remèdes contre les 404 types de maladies» (Zieme 2017a.).

\footnotetext{
125 BT 25: 161, mit Verweis auf SH: $178 b$.

${ }^{126}$ SH: 178b; Salguero et al. 2017b: 282. Vgl. auch Index zu Salguero 2017a.

127 DDB.
} 


\section{J(৫)}

\section{Abschnitt Krankheit-3}

048 y-a kapilavastu känt-lig m(a)ndakini yuul ičindä . hansa-rača ${ }^{128}$ kaz-lar

049 han-1 törüyü b(ä)lgürü yarlıkamıš . bodistv uguš-lug tänrikän tegin

050 täyrim kutı yarlıkasar :: kim bo iglämäk atl(1)g utun törü yalりuz $<>>129$

051 tınl(1)g-ka ok kälmiš täginmäz ${ }^{130}::$ kaltı nätäg öydün yınak-tın 大 [ulug] bädük

052 kay-a ${ }^{131}$ tag yorıyu kälsär :: üstün kapıg1 ${ }^{132}$ kök kalık bilä ${ }^{133}$ tutč1 ${ }^{134}$ 下 [altın]

053 tüpi yagız bilä tutčı ${ }^{135}$. üstün učugma 下 [altın] bagır-ın yorıgma

054 tınl(1)g-larıg - [bir] kalısız yančar yumurur ${ }^{136}$ ärsär . ančulayu ok ymä bo iglämäk

055 atl(1)g utun törü :: ädgü yavız bay čıgay temätin . alku-ka barča bir

056 kalısız - [bir] täg kältäči täginür täyrim :

${ }^{128}$ Geschrieben: $q^{\prime} n z^{\prime} r^{\prime} c^{\prime}$. Ob der letzte Buchstabe wirklich ein $<^{\prime}>$ ist, bleibt unsicher, es ist wohl eher ein finales < $<$ c mit einem Abstrich, denn erstens hat die Hs. C klar -rřc, zweitens wäre die Aussprache hansarač zu erwarten wie auch bei $m(a)$ harač < Skt. mahārāja. Vgl. BT 37: 1010b.

129 Das Wort soll getilgt sein. Yakup 2019: 15 bo.

130 Yakup 2019: 15 täginmäsär.

131 Yakup 2019: 15 qara.

132 Vgl. Yakup 2019: 15 qapïyi(?). Offenbar soll das Wort nicht getilgt sein, wie es nach dem Foto den Anschein hat. Vielleicht liegt aber auch eine Korrektur zu učı vor, wie das Wort in der Handschrift C geschrieben ist.

${ }^{133}$ Yakup 2019: 15 birlä, doch entweder hat der Schreiber hier wie auch in der folgenden Zeile den Buchstaben $<r>$ vergessen, oder es liegt tatsächlich die neuere Form bilä vor.

134 Geschrieben: twdcy.

135 Geschrieben: twdcy.

${ }^{136}$ Yakup 2019: 15 yemürür. 


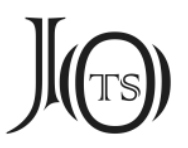

Wenn die Majestät der Fürstlichen Prinz-Hoheit, die vom Geschlecht des Bodhisattva ist, der in dem See Mandākinīin der Stadt Kapilavastu ${ }^{138}$ als König der Gänse ${ }^{139}$ hervorzukommen und zu erscheinen geruht hat, (es anzunehmen geruht), dann ist es so:

Diese Krankheit genannte verruchte Sache kommt nicht nur zu den Lebewesen. So wie aus dem Osten ein großer Fels-Berg - dessen obere Spitze ${ }^{140}$ an den Himmel reicht ${ }^{141}$, dessen unterer Boden an die braune (Erde) ${ }^{142}$ reicht - wandernd daherkommt und die oben fliegenden und die unten auf dem Bauch kriechenden Lebewesen alle restlos vernichtet und zertrümmert, ebenso ist auch die Krankheit genannte verruchte Sache. Gut und Böse, Reich und Arm nicht unterscheidend, kommt sie zu allen gleichermaßen.

Mein Fürst!

\section{Kommentar}

In diesem Abschnitt fällt insbesondere der Vergleich der Vernichtung durch Krankheit mit dem Fels-Berg ins Auge, der die Wucht verdeutlichen soll. Ob eine direkte Vorlage anzunehmen ist, bleibt unklar. Aber immerhin kann man

137 Yakup 2019: 15 m(a)hadagiri ,(fountain) Mahādagari', ohne Nachweise. Es handelt sich aber wohl um einen Fluß (oder Bach), mit Sicherheit nicht um den Fluß Rohinī in der Nähe von Kapilavastu. Atü. yul bezeichnet meist einen ,Bach', aber Mandākinī ist der Name eines Sees, auch in der Maitrisimit wird dafür das Wort yul benutzt, cf. Laut 1986: 57. Nach Dietz 2004: 60 war M. ein ,pond'. Zum Namen M. vgl. Laut 1986: 56-57 sowie 57 n. 5 nach Zitaten aus der Maitrisimit. Am Ufer des Mandākinī-See predigte Buddha den Vier Mahārājadevas. Vgl. Malalasekera 1960: 443-444 (Mandākinī). Zu Belegen in verschiedenen Umschriften wie 曼陀耆泥 mantuoqini im Taishō Tripițaka vgl. Akanuma 405-406. Nach MW: 788b war M. Name eines Nebenflusses des Ganges im Tal Kedāranātha oder auch anderer Flüsse. Ein weiterer Beleg liegt in dem Lobpreis Laut-Zieme 1990, 23 vor. Dort wird auch das Land genannt, wo der M. sich befindet. Unsere damalige Lesung [...]suz vermittelte den Eindruck eines altuigurischen Wortes, doch sind die erhaltenen Buchstaben eher [...]py zu lesen (in der Lücke sind 1-2 Buchstaben als fehlend anzunehmen).

${ }^{138}$ Kapilavastu, vgl. Deeg 2003.

139 Der Skt.-Bezeichnung ( $q^{\prime} \dot{n} z^{\prime} r^{\prime} c^{\prime}=$ hamısarāja) folgt die altuig. Übersetzung kazlar hanı ,Gänsekönig', ,king of the swans (haṃsaräja) (Cicuzza 2011: 184), vgl. BT 13: 9.20 (nebst Anm.). Ähnlich auch in der Maitrisimit (Geng-Klimkeit 1988/I: Z. 1656), kazlar eligi (Suv. 450/21), kazlar bägi (TT X, BT 37: 06557; in BT 37: 565 und 637 als räjahamsa rekonstruiert).

${ }^{140}$ Nach Handschrift C.

${ }^{141}$ Mit Yakup 2019: 27, ist tutčl als verkürzte Form von tutdačl zu erklären.

${ }^{142}$ Wohl ein Vergleich, um die Größe des Berges auszumalen. 


\section{J(G)}

auf das Pabbatopama Sutta („The Simile of the Mountains“) verweisen, wo wir lesen:

„What do you think, great king? Suppose a man, trustworthy and reliable, were to come to you from the east and on arrival would say: 'If it please your majesty, you should know that I come from the east. There I saw a great mountain, as high as the clouds, coming this way, crushing all living beings [in its path]. Do whatever you think should be done.' Then a second man were to come to you from the west ... Then a third man were to come to you from the north ... Then a fourth man were to come to you from the south and on arrival would say: 'If it please your majesty, you should know that I come from the south. There I saw a great mountain, as high as the clouds, coming this way, crushing all living beings. Do whatever you think should be done.' If, great king, such a great peril should arise, such a terrible destruction of human life - the human state being so hard to obtain - what should be done?" Und noch eindringlicher in den Versen:

"Like massive boulders,

mountains pressing against the sky,

moving in from all sides,

crushing the four directions,

so aging and death

come rolling over living beings:

noble warriors, brahmans, merchants,

workers, outcastes, \& scavengers.

They spare nothing.

They trample everything." (Thanissaro Bhikkhu 1997)

,König der Gänse‘. Der Pāli-Text Buddhapādamañgala interpretiert den Terminus hamsarāja in einer sehr plastischen und deutlichen Art:

"The king of swans: since the Blessed One does not take delight in worldly values reckoned as gold and money and consisting of the seven jewels and so on." (Cicuzza 2011: 184) 


\section{J(৫)}

\section{Abschnitt Krankheit-4}

057 y-a kšatirik tözlüg käyik-lär kuvrag-1 arasınta . kesari arslan hanın058 -ča yintmiš ${ }^{143}$ yegädmiš bodistv uguš-lug täyrikän tegin täyrim kut1 yarli<ka>

059 -sar :: kim bo purvanandiniklp bašlag-1ndakı . čaru upačaru varu kalyani-ta

060 ulatı agır 大 [ulug] elig-lär han-lar :: arčune tona-ta atsar yašmaz ${ }^{144}$ alp

061 ädräm-lig äninčig-lär ${ }^{145}$ :: (sorup suv-ug sugurdačı-lar ${ }^{146}$. sodup ${ }^{147}$ kölüg tošgurdačı-lar :: $)^{148}$

tägip ök tag-1g yimirdäči-lär . tanču-lap tag

062 -1g ušattačı-lar ${ }^{149}::$ talačangini asure täg . ulug bädük ät’özlüg-lär

063 dartaraštiri bäg täg küč-lüg küsün-lüg-lär ymä : näy inčip bo

064 iglämäk (lig utun) törü-tin ozmat1-lar ${ }^{150}$. täyrikän tegin täyrim kutı-nıy . näčä ök

065 anı täg . köz äsri köyül arvı bolgu täg . ärki türki mäyi-si toya

066 -s1 näčä üküš tälim ärsär ymä :: iglämäk-lig utun (törü) sok-a yakın kälmiš-tä

067 karamuk-ča ymä ymä tusulmaz . näy inčip ${ }^{151}$ iglämägäy ärki m(ä)n tep sakınu

\footnotetext{
${ }^{143}$ Wie schon an anderer Stelle liest Yakup 2019: 15 yertmiš.

144 Yakup 2019: 16 ärtsär yaqmaz.

${ }^{145}$ Yakup 2019: 16 ärkinčiglär.

${ }^{146}$ Yakup 2019: 16 turyurdačllar.

147 Yakup 2019: 16 qudup.

${ }^{148}$ In der Handschrift B folgt dieser Satz erst nach ušattačı-lar.

${ }^{149}$ Geschrieben: 'wș' $d t^{2} c y$ l'r.

${ }^{150}$ Geschrieben 'wsm'ty l'r.

151 Yakup 2019: 15 igig.
} 


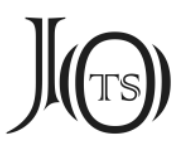

068 yarlıkamazun täyrim :: elig täyrim tegül :: ::: : ::

Wenn die Majestät der Fürstlichen Prinz-Hoheit, die vom Geschlecht des siegreichen und unübertrefflichen Bodhisattva ist, der vom kșatriya-Stamm unter der Schar der wilden Tiere wie der Löwenkönig ist, (es anzunehmen geruht), dann ist es so: Die sehr großen Könige und Herrscher des Anfangs des purvāntakalpa ${ }^{152}$ wie Cāru, Upacāru, Varu-Kalyāṇi ${ }^{153}$; die von dem Helden Arjuna angeführten sehr Tapferen ${ }^{154}$ und Wunderbaren ${ }^{155}$, die sich nicht verstecken, selbst wenn sie schießen ${ }^{156}$; die schlürfend ${ }^{157}$ das Wasser (eines Sees) Austrinkenden und spuckend einen See Auffüllenden ${ }^{158}$; die Angreifenden und den Berg Einstürzenden, die den Berg Zerstückelnden und Verkleinernden; die wie Asura Tālajangha ${ }^{159}$ große, gewaltige Körper Habende; und auch die Mächtigen und Starken wie Dhṛtirāșțra ${ }^{160}$, (sie alle) haben sich auch nicht vor der verruchten Sache der Krankheit gerettet. Wenn der Majestät des Gnädigen Prinz-Fürsten - so bunt den Augen und so zweifelhaft dem Sinn erscheinenden ${ }^{161}$ - Kraft und Stärke, Seligkeit und Freude zahlreich und viel sein mögen, so wird die verruchte Sache der Krankheit, wenn sie ganz nahe

${ }^{152}$ Geschrieben: pwrv'ग3 dyn'kl. In der Einleitung der DKPAM-H kommt das Wort wie folgt vor: purvantak(a)lp üdtin bärü ,seit pūrvāntakalpa-Zeiten' (Geng et al. 2005: 98-99: Z. 262; 107, Z. 366). Aber die hier geschriebene Form läßt sich nicht so einfach als purvantaklp lesen. Da die DKPAM aber mindestens einen deutlichen Beleg hat, könnte es sich hier vielleicht auch um eine unklare Schreibung handeln.

${ }^{153}$ In der Einleitung der DKPAM-H werden einige dieser Könige als cakravartin-Herrscher erwähnt: Mah[āsamṃmat]a, Roca, Kalyāṇa, Varakalyāṇa, Upoṣadha, Tāyin, Aśva, Gajāśva, Dhundhumāra, Cāru, Upacāru etc., vgl. Geng et al. 2005: 107. Der Name varu dürfte mit Vara(kalyāṇa) identisch sein.

${ }^{154} \mathrm{UWN} / 2: 236$.

${ }^{155} \mathrm{UWN} / 2: 212$.

${ }^{156}$ Das könnte eine populäre Redewendung sein: atsar yašmaz ,wer schießt, verbirgt sich nicht', doch Vergleichbares habe ich nicht gefunden.

157 Vgl. Geng et al. 2005, DKPAM-H I-IV: 057-058: säkiz türlüg ämgäk-lig ögüzlärig kugurdačı sugurdačl.

${ }^{158}$ Ein Beispiel für alliterierende Verse mit geichmäßiger Silbenzahl $(4+5 / / 4+5)$ und mit innerer Alliteration im ersten Vers (so- // su- // su-): sorup suvug sugurdačllar // sodup kölüg tošgurdačlar.

159 Geschrieben: t'l’’̌’nkkyny. Obwohl Yakup 2019: 15 talačanguhi (?) liest, gibt er als Äquivalent den Namen ,Talājangha (?)؛. In der Anm. verweist der Autor auf MW: 445a, wo richtig Tālajangha steht.

160 Den Namen rekonstruiert YAKUP als Dhṛtirāșțra, doch fügt er keine Erklärung hinzu, vgl. BT 37: drtiraštre < tochA dhṛdhirāșțre dhräḍhirāșțre / tochB dhṛtirāșțre < skt. dhṛtirāșțra n. pr. 06660.

161 Die Wendung, die Yakup 2019: 23 "her eyes would be blurred and the mind would be confused" übersetzt, lautet: köz äsri kögül arvı bolgu täg "so bunt den Augen und so zweifelhaft dem Sinn erscheinend", sie könnte einem volkstümlichen Text entnommen sein. 


\section{$\mathrm{J}(\Theta)$}

kommt, ihr auch nicht einmal wie ein Körnchen ${ }^{162}$ nützen. Auf keinen Fall soll man denken:

„Ich werde wohl nicht erkranken“.

Mein Fürst! Mein König-Fürst soll (es) sagen!

\section{Kommentar}

Die größten Helden längst vergangener Zeiten wie auch die kontemporären Mächtigen unterliegen Krankheiten, so wie schon in den vorangegangenen Abschnitten. Hier wird noch einmal eindringlich gesagt, daß niemand sagen könne, er werde nicht krank.

Das Ende des Abschnittes nennt die Asuras.

talačangini asure täg . ulug bädük ät'özlüg-lär ,Die große, riesige KörperHabenden wie der Asura Tālajanghha'. Informationen über Asuras, die im Buddhismus eher ein Schattendasein führen, sind generell gering, doch sind sie meist als Gegenspieler der Götter genannt. In der Reihe der erweiterten Liste der Existenzformen (gati) nehmen die Asuras nach Göttern und Menschen den dritten Platz der drei guten gati ein ${ }^{163}$, doch bisweilen werden sie den drei schlechten gati vorangestellt (Mus 1939). In der Kunst sind sie oft sehr phantasievoll dargestellt. Im altuigurischen Kontext kommen Asuras nicht nur in den übersetzten Texten (Altun Yaruk Sudur, Āgama-Texte, Maitrisimit etc. vgl. UWN/1: 306-307) vor, sondern auch in eigenständigen Dichtungen (BT 13: 134, Neujahr).

Zwar nennt U. WOGIHARA Tālajangha als Namen eines rākșasa oder eines bhūta (Wogihara 1979: 537a), doch ist vorstellbar, zumindest im Verständnis der uigurischen Buddhisten, daß er (auch) als ein Asura galt, auch wenn er nicht in

${ }^{162}$ Das Wort karamuk bedeutet ,tares, corn-cockle‘ (ED: 660b), wie auch Yakup 2019: 23 übersetzt. In Vergleichen dient es wie hier dazu, etwas Winziges anzudeuten. So auch in einem volkstümlichen Gedicht (SI 4089, ZZ. 73-76): kan yolın ogul tilär/kagl yolın tilgän tilär tep / kamıg türlüg ämgäklär/kalısız sana salsar ymä / kanımıznı nomınta / karamukča yıkma "Der Vater wünscht sich als sein Glück einen Sohn / der Wagen wünscht wünscht sich für seinen Weg ein Rad/Selbst wenn allerlei Leiden / restlos auf dich stürzen / zerstöre dennoch nicht ein Körnchen von der Lehre unseres Vaters (Śākyamuni)!" In den beiden ersten Versen spielt der Autor vermutlich mit der unterschiedlichen Semantik von yol als ,Weg' und ,Glück'.

${ }^{163}$ Vgl. DDB. 


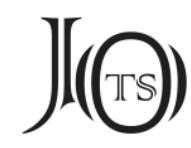

der Liste der namentlich bekannten Asuras steht, so jedenfalls nach einem unpublizierten Text der Serindia-Sammlung: talačani bašlap asurelar-nıı ,der Asuras beginnend mit Tālajangha ${ }^{164}$ Auch im altindischen Mahābharata ist er ausdrücklich ein Asura: „Wegen der tugendhaften Praxis der Brahmanen scheint die Sonne am Himmel. Weil die mächtigen Asuras Vatapi und Talajangha die ehrbaren Brahmanen mißachteten, wurden sie von deren Fluch vernichtet." (Weltsch 2011: 424.)

Neben der häufigen Form asure ("swry) gibt es in einigen Texten auch die ältere Form ("swr) asur (UWN/2: 306). Wie die Asuras gesehen wurden, beschreibt sehr anschaulich ein Fragment eines Codexblattes aus einer Sammelhandschrift ${ }^{165}$ :

01 birär bölük asur-lar yana ägirdi-lär 02 bükürdi-lär. birär bölük asur-lar baš-lar 03 -ınta müyüz üntürdi . birär bölük 04 asurlar äšgäk ät'öz kılıp äšgäk ünin 05 üntädi-lär . birär bölük asur-lar ada[k] 06 -inta tävä tapanı kıltı-lar . b[irär] 07 bölük asur-lar it ünin üntädilär . 08 birär bölük asur-lar kök kara sarıg 09 kızıl ätöz tägšürdi-lär . birär bölük asur 10 -lar ät'özlärintä ot [yalı]n üntürdi 11 -[lär . ] birär bölük [asur-lar] boguzlarıntın 12 []kä tüt[ün ]. birär 13 [bölük asurlar ] yalın

„Einige Gruppen von Asuras stürmten voran und spitzten ${ }^{166}$ (Wasser) (wie) Elefanten. Einige Gruppen von Asuras ließen aus ihren Köpfen Hörner sprießen. Einige Gruppen von Asuras machten ihre Körper zu Eseln und schrien mit Eselsstimmen. Einige Gruppen von Asuras machten ihre Füße zu Kamelsohlen. Einige Gruppen von Asuras schrien mit Hundegeheul. Einige Gruppen von Asuras veränderten sich in blaue, schwarze, gelbe und rote Körper. Einige Gruppen von Asuras ließen aus den Körpern Flammen hervor. Einige Gruppen von Asuras [brachten] aus ihren Kehlen Rau[ch hervor]. Einige Gruppen von Asuras [brachten] Flammen [...].“

Wie Lin Li-Kouang schreibt, findet sich der umfangreichste Bericht über Asuras im [Saddharma]-smrtyupasthānasūtra (T 721, T 722), obwohl der Text diese Existenz-Kategorie nicht als eine eigene gati betrachtet, sondern, ausgehend von

164 SI 4984 (Kr I 116) verso, Z. 21.

165 Mainz 299 (vgl. KOHD Digital), Blatt II.

166 OTWF: 466 bükür- ,to spurt out, spray ‘ mit Verweis auf Beispiele aus dem AYS, zu AYS X 479 vgl. Gulcalı 2013: 193. Als Zweitbestandteil des Paarworts sač- bükür- in dem Satz Suv. 640/1-2 čından suvın sogıtıp bükürtilär sačdılar elig bägkä hatunka „Die Minister besprengten, nachdem sie es gekühlt hatten, den König und die Königin mit Sandelwasser“. (Nobel 1958: 349) chin. 454a16 臣以梅檀水灑王及夫人. 
der pañcagati-Theorie, zwischen der Preta- und der Tier-Existenz ansiedelt (Lin 1949: 24). Doch gibt es auch in dieser Version keine Hinweise auf die vielfältigen Gestalten, wie sie in der obigen Passage genannt werden.

\section{Passagen über Tod}

Von genereller Aussagekraft sind sehr viele Stellen in den alten buddhistischen Texten wie auch in Mahāyāna-Texten zu finden. Hier sei zur Einstimmung aus dem Maranasatti sutta (AN VI.20) zitiert:

„Monks, mindfulness of death -- when developed and pursued -- is of great fruit and great benefit. It plunges into the Deathless, has the Deathless as its final end. And how is mindfulness of death developed and pursued so that it is of great fruit and great benefit, plunges into the Deathless, and has the Deathless as its final end?

There is the case where a monk, as day departs and night returns, reflects: 'Many are the [possible] causes of my death. A snake might bite me, a scorpion might sting me, a centipede might bite me. That would be how my death would come about. That would be an obstruction for me. Stumbling, I might fall; my food, digested, might trouble me; my bile might be provoked, my phlegm... piercing wind forces [in the body] might be provoked. That would be how my death would come about. That would be an obstruction for me.' Then the monk should investigate: 'Are there any evil, unskillful mental qualities unabandoned by me that would be an obstruction for me were I to die in the night?' If, on reflecting, he realizes that there are evil, unskillful mental qualities un-abandoned by him that would be an obstruction for him were he to die in the night, then he should put forth extra desire, effort, diligence, endeavour, undivided mindfulness, and alertness for the abandoning of those very same evil, unskillful qualities. Just as when a person whose turban or head was on fire would put forth extra desire, effort, diligence, endeavour, undivided mindfulness, and alertness to put out the fire on his turban or head, in the same way the monk should put forth extra desire, effort, diligence, endeavour, undivided mindfulness, and alertness for the abandoning of those very same evil, unskillful qualities. But if, on reflecting, he realizes that there are no evil, unskillful mental qualities unabandoned by him that would be an obstruction for him were he to die in the night, then for that very reason he should dwell in joy and rapture, training himself day and night in skilful qualities.

Further, there is the case where a monk, as night departs and day returns, reflects: 'Many are the [possible] causes of my death. A snake might bite me, a scorpion might sting me, a centipede might bite me. That would be how my death would come about. That would be an obstruction for me. Stumbling, I might fall; my food, digested, might trouble me; my bile might be provoked, my phlegm... piercing wind forces [in the body] might be provoked. That would be how my death would come about. That would be an obstruction for me.' 


\section{$J(\Theta)$}

Then the monk should investigate: 'Are there any evil, unskillful mental qualities unabandoned by me that would be an obstruction for me were I to die during the day?' If, on reflecting, he realizes that there are evil, unskillful mental qualities un-abandoned by him that would be an obstruction for him were he to die during the day, then he should put forth extra desire, effort, diligence, endeavour, undivided mindfulness, and alertness for the abandoning of those very same evil, unskillful qualities. Just as when a person whose turban or head was on fire would put forth extra desire, effort, diligence, endeavour, undivided mindfulness, and alertness to put out the fire on his turban or head, in the same way the monk should put forth extra desire, effort, diligence, endeavour, undivided mindfulness, and alertness for the abandoning of those very same evil, unskillful qualities. But if, on reflecting, he realizes that there are no evil, unskillful mental qualities unabandoned by him that would be an obstruction for him were he to die during the day, then for that very reason he should dwell in joy and rapture, training himself day and night in skilful qualities.

This, monks, is how mindfulness of death is developed and pursued so that it is of great fruit and great benefit, plunges into the Deathless, and has the Deathless as its final end. ${ }^{\text {“167 }}$

\section{Abschnitt Tod-1}

069 y-a ikšivaku ${ }^{168}$ uguš-nuy etigi ${ }^{169}$ yaratıg-1 kšatrik tözlüg kinšuk ${ }^{170}$

070 ärdini . törüyü b(ä)lgürü yarlıkamıš. täyrikän tegin täyrim kutı yarlıkasar ::

071 kim bo 四 [tört] kiši-lärkä kötürtmiš ${ }^{171}$. tınsız diravi-ka okšatı äd ärsär $\because:$

072 alku kamag kasıntın kadaš-ıntın adırılmıš $\check{s}^{172}$, ata ana kiši ogul kız-tın

073 öni ödrülmiš :: yašaguluk-1 ärtmäk üzä yamadevi-ka yagumıš :: yalıuk

074 yertinčü-sindäki ädin tavar-ın . ärkin türkin ärksizin titip ıdalap ::

\footnotetext{
167 AN (Thanissaro Bhikkhus Internet version).

168 Yakup 2019: 16 liest ikšavaku.

169 Geschrieben: 'ydyky.

170 Geschrieben: kyn்șwä.

171 Geschrieben: kwydwrtmys.

172 Geschrieben: 'tyrylmys.
} 


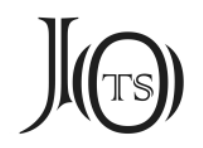

075 alku nom-lar-nı ürlügsüzin ukıttač1 ${ }^{173}$. ölüm atl(1)g ülügsüz < > törü 076 bo täginür täyrim ::

Wenn die Majestät der Fürstlichen Prinz-Hoheit, Zierde und Ausstattung des ikṣvākuStammes als kiṃśuka-Juwel vom kṣatriya-Wesen zu erscheinen und sich zu zeigen geruht, (es anzunehmen geruht), dann ist es so:

Was die von vier Menschen hochgehobene ${ }^{174}$, einem leblosen $\mathrm{Klotz}^{175}$ ähnelnde Sache betrifft, so lehrt sie, daß man von allen Verwandten und Familienangehörigen getrennt, von Vater und Mutter, von Frau und Kindern separiert, durch das Vergehen des Lebens Yamadeva nahe kommt, die der Menschenwelt angehörigen Güter und Dinge, Macht und Stärke willenlos aufgibt und verläßt, (in einem Wort), daß alle Dinge vergänglich sind. Die unglückliche Sache namens Tod ist das!

Mein Fürst!

\section{Kommentar}

Es ist bemerkenswert, daß selbst in dieser späten Zeit dem uigurischen König derselbe Stammbaum wie dem Buddha Gautama zugeschrieben wird. ,Zum ikșvāku-Stamm gehörig' ist eines der zahlreichen Epitheta des Buddha, wie beispielsweise das altuigurische Garbaparimančani sudur (BT 23: 165, H013) belegt. Im ,Sūtra der Fragen des Mañjuśrī‘ 文殊師利問經 (T 468) wird eine Beziehung zwischen den Ikșvākus ${ }^{176}$ und Śākyas hergestellt (nach DDB: T.XIV.468.494b19). Nicht jedoch gehört es zu den ,zehn Epitheta des Buddha' (十佛名 shi foming) (Nattier 2003).

173 Geschrieben: 'wqydt'cy.

174 Vergleich für das Schwerwiegende der Sache.

175 Altuig. diravi < Skt. dravya 'substance, thing, object' (MW: 501a).

176 Salomon-Baums 2007. Das dem Namen zugrundeliegende Wort Skt. ikșu ,Zuckerrohr‘ ist auch in einem vermutlich zur DKPAM gehörigen altuigurischen Fragment (SI 2617) belegt: ikšu kamıš täg ,wie ikṣuZuckerrohr'. Im Brahmanadhammika sutta (SI 5709 + SI 3901) findet sich folgender Satz als Übersetzung von T.I.26.678c18-b 我等從彼來, Wir kamen zu ihm‘: (ZZ. 24-25) 我 ikšivaku han-ka yakın kälti-lär ,Sie kamen dem König Ikṣvāku nahe“. Sn. 301 (II/7): „Da machten sie zurecht sich Sprüche und suchten dann Okkāka auf". (Okkāka ist die Pāliform für Ikṣvāku). Interessant, daß in diesem chinesischen Āgama-Auszug, der Name des Königs nicht genannt wird, doch der uigurische Übersetzer setzt ihn hinzu. 


\section{J(৫)}

Vergleiche für die Unabänderlichkeit des Todes finden sich in den buddhistischen Texten, wie schon dargelegt, besonders zahlreich. Um die Schwere des Todes zu vermitteln, wird hier der aus dem Sanskrit entlehnte Begriff dravya verwendet, der generell einen Gegenstand, ein Ding bedeutet (MW: 501a), hier so schwer, daß vier Personen ihn nicht hochheben können. Vielleicht denkt der Autor auch an den bewegungslosen Leichnam. Ob diese Ausdrucksweise einer indischen Vorlage entspringt, ist nicht klar, es könnte sich auch um eine ad hoc Bildung handeln.

Die Anspielung auf Yamadeva, den Gott des Todes in der Unterwelt, paßt zu diesem Szenario.

\section{Abschnitt Tod-2}

y-a 二 [iki] adak-lar-nıy ayaguluk-1 . töpür-ä tüü-lüg

077 tınl(1)g oglan-ları-nı . tönütgülükii ${ }^{177}$ bolu yarlıkamıš . bodistv uguš ${ }^{178}$ täyrikän tegin

078 täyrim kut $1^{179}$ yarlıkasar :: bo ymä tı bolmıš törü tetir :: näčä-tä birök 生 [tugum] ažun

079 tutgu-ča ${ }^{180}$ täylig ärsär : 九月十 [tokuz ay on] kün ög karın-ta ${ }^{181}$ solanıp olurur tuš-ta - [bir]är

080 -läri . ög karın-ta ok ölür-lär :: näčä-tä birök ada-sızın äsän tuggu-ča

081 täylig ärsär :: yag yedürmäk süt ämizmäk-tä182 ulat1-lar üzä . tirig öz ilgün

082 -türür :: bo tınl(1)g yana öydün sözlägüči karımak-lıg kar tolı üzä bašıra

\footnotetext{
177 Geschrieben: twynkwdkwlwky.

178 Hier fehlt das Suffix $\{+\mathrm{lXg}\}$, das auch Yakup 2019 einsetzt.

179 Geschrieben: qwdy.

180 Geschrieben: $t w d^{2} r c^{\prime}$.

181 Yakup 2019: 17 qarnïnta.

182 Geschrieben: 'mysm'k t'.
} 


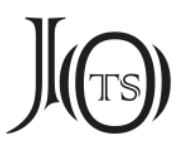

083 tokıtılıp ${ }^{183}::$ iglämäk ${ }^{184}$ isig yeel üzä in lan ${ }^{185}$ bolup :: äv-in bark-ın äd-in 084 tavar-1n . ärksizin türksüzin titip ${ }^{186} 1$ dalap . anityat-ka san-lıg bolur 085 -lar :: anın bo ölüm atl(1)g äšidgäli yavız yeel törü mundag bolu täginür täyrim ::

Wenn die vom Geschlecht der - Verehrter der Zweifüßigen ${ }^{187}$ und der, vor dem sich die bis zum Scheitel behaarten Lebewesenkinder verbeugen ${ }^{188}$, seienden - Bodhisattva-Majestät der Fürstlichen Prinz-Hoheit (es anzunehmen geruht), dann ist es so: Das nun ist eine immerwährende ${ }^{189}$ Sache. In welchem Maße man auch eine Geburt und Existenz erhält, sterben zu der Zeit, nachdem man neun Monate und zehn Tage im Mutterleib eingeschlossen gesessen hatte, einige (schon) im Mutterleib. Wenn man aber ohne Schaden gesund geboren wird, läßt man durch Fütterung mit Fettem und Säugung mit Milch usw. das Leben ${ }^{190}$ fördern ${ }^{191}$. (Und doch) werden auch diesem Lebewesen Schnee und Hagel des oben erwähnten Alters auf seinen Kopf ${ }^{192}$ niederprasseln ${ }^{193}$; durch den heißen Wind der Krankheit wird es inlan ${ }^{194}$. Willenlos gibt es auf und läßt ab von Haus und Hof, Hab und Gut,

${ }^{183}$ Geschrieben: twqydylyp, vielleicht hat der Schreiber eine Korrektur vorgenommen.

${ }^{184}$ Analog zu karımaklig der Zeile 082 ist hier zu iglämäklig zu emendieren.

185 Yakup 2019: 083 anlan.

186 Geschrieben: tydyp.

187 Yakup 2019: 17 liest adaq barnïng. Wenn das Suffix $\{+\mid \mathrm{Xg}\}$ vergessen sein sollte, kann man zu adak(lig)lar emendieren (zu Beispielen vgl. UWN/1: 19), wie dies hier andere Handschriften bezeugen. In der Übersetzung richtig: Yakup 2019: 23 ,two-legged'.

${ }^{188}$ Das Verb töyüt-, vgl. tönit- ED: 517b.

189 Geschrieben: ty, Yakup 2019: 17 liest täv und übersetzt, deceitful‘. Da alle finalen <v> einen nach links führenden Abstrich haben, kann hier nur ein finales <y> vorliegen. $\mathrm{Zu} t \mathrm{t}$,immerwährend' vgl. ED: 433a. Das Wort ist allerdings in den späteren Texten selten.

190 tirig öz,Leben`, wörtlich: ,Lebendes Selbst' ist ein manichäischer Terminus, der sekundär auch in buddhistischen Texten auftritt.

191 ilgündür- ,unterhalten lassen, fördern lassen', vgl. UWV/2: 117-118.

${ }_{192}$ Die Form bašra ist selten belegt, vgl. hier auch Handschrift F Ch/U 8199.

${ }^{193}$ Vgl. tokıttl- ED: 468a.

194 Yakup 2019: 27, liest anlan und schlägt Herleitung von chin. 安瀾 anlan, calm, peaceful‘ vor, doch ist eher inlan zu lesen, und ,friedlich“ paßt schwerlich in den Kontext. Für die zweite Silbe lan kann man an 闌 lan ,erschöpft' denken, doch fehlt mir eine Erklärung für die erste Silbe in. 


\section{$J(\Theta)$}

es wird der anityatā zugeordnet sein. Deshalb ist diese Tod genannte (vom) Wind (verursachte) ${ }^{195}$ Sache, die man (nur) schlecht hören (will) ${ }^{196}$, so beschaffen.

Mein Fürst!

\section{Kommentar}

Als besonders tragisch wird seit jeher ein Tod im Mutterleib gesehen, doch in diesem Abschnitt wird herausgestrichen, daß der Tod unweigerlich auch alle Wohlgeborenen erwischt. Am Ende gibt es nichts anderes als anityatā.

\section{Abschnitt Tod-3}

086 y-a alku kamag šaki-lıg-lar-nıy arasınta . kut buyan čog yalın-(lar) üzä kudulu

087 turur kutlug buyan-lıg :: täyrikän tegin täyrim kutı yarlıkasar :: kim bo ölüm

088 atl(1)g ülügsüz törü yalnuz bo ok tınl(1)g-ka kälmiš täginmäz :: tugmıš $\operatorname{tinl}(1) g$

089 oglan-larına tüzü-kä197 bir täg käldäči täginür :: äymıntın kök kalık-ka

090 tayak-lıg-ın yorıdačı : yam t(ä)yri yer-indäki . dyan t(ä)yri yer-indäki 天 [täyri]-lär ymä .

091 säkiz tümän m(a)hak(a)lp ${ }^{198}$ uzun ${ }^{199}<>^{200}$ özlüg yaš-lıg . ölmäz umuglug mäygü

\footnotetext{
195 ,vom Wind verursacht' paßt besser in den vorigen Abschnitt über die Krankheit, vielleicht liegt eine Unachtsamkeit des Schreibers vor.

196 Dieselbe Wendung in Z. 034.

197 Geschrieben: twysw k'.

198 Yakup 2019: 18 maylap.

199 Geschrieben: 'wswn.

200 Ein Wort getilgt.
} 


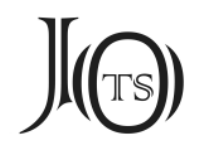

\author{
092 sakınč-lıg : öysüz ${ }^{201}$ täyri yerindäki täyri-lär ymä :: üdi ${ }^{202}$ kün-i käldükdä \\ $\operatorname{adin}^{203}$
}

093 ažun-ka barır-lar :: bo munı täg üstünki 天 [täyri]-lär ymä adın ${ }^{204}$ ažunka

094 sanlıg bolgu-ča täylig ärsär : takı nä ayıtmıš adın ${ }^{205}$ tınl(1)g-lar . adın ${ }^{206}$ ažun

095 -ka sanlıg bolmagay mu :: anın ölüm atl(1)g . ülügsüz törü alku-ka bir täg 096 käldäči täginür täyrim ::

\begin{abstract}
Wenn die Majestät der Fürstlichen Prinz-Hoheit, die unter allen Śākyahaften so gesegnet und verdienstreich ist, daß sie von Segen und Verdienst, von Pracht und Glanz überquillt, (es anzunehmen geruht), dann ist es so: Die unglückliche Sache namens Tod kommt nicht allein zu diesen (genannten) Lebewesen. Sie kommt zu den geborenen Lebewesenkindern, zu allen gleichermaßen. Sogar (zu) den auf das Firmament gestützt laufenden, bis zu den im yāma-Himmelsland und bis zu den im dhyāna-Himmelsland seienden Göttern. (Sogar) zu den 80000 mahākalpas langes Leben habenden, (zu den) unsterblich zu sein hoffenden, (zu den) ewig sich dünkenden Göttern des arūpya-Himmelslandes, auch sie gehen, wenn Stunde und Tag gekommen sind, in eine andere Existenz. Wenn sogar auch diese derartigen obigen Götter einer anderen Existenz zugehörig sein mögen, was soll man da noch sagen von anderen Lebewesen: sollten sie einer anderen Existenz nicht angehören? Deshalb kommt die Tod genannte unglückliche Sache zu allen gleichermaßen.
\end{abstract}

Mein Fürst!

\title{
Kommentar
}

Hier nun wird betont, daß der Tod nicht nur die Menschenwelt ergreift, sondern auch alle Götterwelten. Es werden Götter des zur Sinnenwelt (skt. kāmadhātu) gehörigen Yāma, Götter der Versenkungsstufen (skt. dhyāna) und Götter der Nichtform (skt. arūpyadhātu) genannt.

\footnotetext{
201 Yakup 2019: 18 örksüz.

202 Yakup 2019: 18 uday.

203 Geschrieben: 'tyn.

204 Geschrieben: "tyn.

205 Geschrieben: "tyn.

206 Geschrieben: 'tyn.
} 


\section{$J(\Theta)$}

\section{Abschnitt Tod-4}

(096) y-a küsüš-lüg yertinčü-nüy körki küvänč

097 -i . ediš yertinčü-nün etigi ${ }^{207}$ yaratıg-1 : bolu yarlıkamıš tänrikän tegin

098 täyrim kutı yarlıkasar :: nä antag yalıuk bolgay ölüm-kä san-lıg bolma

099 -tačı :: äymıntın kadgi gunačari 二 [iki] türlüg praty(e)kasanbud-lar : ridi $^{208}$ küü kälig

100 ädräm tašgarıp kök kalık yüüzintä učdačı-lar :: 上 [üstün] ät’özin-tin 火 $[$ ot $]<>$

101 ündürüp 下 [altın] ät’özintin suv akıttačı-lar ${ }^{209}$ : 九十八 [tokuz on säkiz] nizvani-larig

102 tarkarıp bavagir-lıg ediz artıg ašıp. arhant kutı-lıg čog-ka yalın

103 -ka tägmiš ${ }^{210} \operatorname{tınl(1)g-lar~ymä~::~anityat-lıg~}{ }^{211}$ az tag-ta ornandı-lar battı$\operatorname{lar}^{212}::$

104 täyrikän tegin tänrim kutı bir-k(i)y-ä nizvani ${ }^{213}$ tarkarmatuk ärip nätägin ${ }^{214}$ ölüm

105 törü-tin ozgalı ${ }^{215}$ ugay :: adırtlıg ${ }^{216}$ otgurak ölmäk törülüg yarlıkar ${ }^{217}::$

\footnotetext{
207 Geschrieben: 'ydyky.

208 Yakup 2019: 18 ațï.

${ }^{209}$ Geschrieben: "qydt'cy l'r.

210 Yakup 2019: 19 täginmiš.

${ }^{211}$ Geschrieben: "nydy't lyq.

212 Geschrieben: $p^{2} d t y$ l'r.

213 Geschrieben: nysv'ny.

214 Yakup 2019: 19 ärtgin.

${ }^{215}$ Geschrieben: 'wsq'ly.

${ }^{216}$ Geschrieben: "'tyrtlyq.

217 Yakup 2019: 19 y(a)rliqayay.
} 


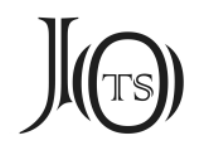

106 arıtı ölmägäy ärki män tep sakınu ${ }^{218}$ yarlıkamazun täyrim :: elig täyrim $\because:$

Wenn die Majestät der Fürstlichen Prinz-Hoheit, die Schönheit und Stolz der kāma-Welt und Zierde und Schmuck der Gefäß-Welt ${ }^{219}$ zu sein geruht, (es anzunehmen geruht), dann ist es so:

Wie sollte es ein solches Geschöpf geben, das nicht vom Tod befallen wäre! Sogar die zwei Arten von Pratyekasaṃbuddhas, i.e. khadga(vișānakalpa) und gunacāri ${ }^{220}$, die ṛddhiZauberkräfte demonstrierenden an der Oberfläche des Himmels Fliegenden, die oben von ihrem Körper Feuer Herauslassenden und unten von ihrem Körper Wasser Fließenlassenden ${ }^{221}$, die 98 kleśas aufgegeben, den hohen Paß des bhavāgra überquert habenden und so zu Pracht und Glanz der arhat-Würde gelangten Lebewesen, (alle diese) haben sich auf dem Gier-Berg ${ }^{222}$ der anityatā niedergelassen und sind dort versunken. Wenn die Majestät der Fürstlichen Prinz-Hoheit nicht einmal ein kleśa aufgegeben hat ${ }^{223}$, wie sollte sie dann der Tod-Sache entkommen können? Sie wird sicher und gewiß von der TodSache betroffen sein. Sie soll auf keinen Fall meinen: Ich werde wohl nicht sterben!

Mein Fürst! Mein König-Fürst!

\section{Kommentar}

Auch in diesem letzten Abschnitt über den Tod werden besondere über Zauberkräfte verfügende Gruppen genannt, die dem Tod nicht entkommen

${ }^{218}$ Trotz der recht deutlichen Schreibung s’ayyw, lese ich mit Yakup 2019: 19 saqïnu.

${ }^{219}$ Vgl. Dietz 2003: 218 Gefäßwelt (bhājanaloka).

220 Yakup 2019: 18: kanačare, gaṇacāra'.

${ }^{221}$ Kurze Zusammenfassung der Zauberkräfte, die eigentlich nur dem Buddha eigen waren, die jedoch auch von Mönchen während der Meditation entwickelt werden können. Vgl. dazu Schlingloff 2015, worin entsprechende Texte aus dem berühmten Yogalehrbuch mit bildlichen Darstellungen in Zentralasien verglichen werden. Den ersten hier genannten Zustand behandelt der Autor in seinem Kapitel „Der Zustand der Levitation“. Das Zwillingswunder lautet: „Dann zeigt man das Zwillingswunder: unten flammt der Körper, nach oben entströmen dem Körper kühle Wasserströme; oben flammt der Körper, nach unten entströmen dem Körper kühle Wasserströme.“ (Schlingloff 1962-1963/II: 52).

${ }^{222}$ az tag,Gier (skt. rāga)-Berg'. Dabei liegt wohl eine ad hoc-Bildung vor. Es handelt sich nicht um einen gängigen Terminus. Den einzigen Nachweis finde ich in T.LII.2103.346a04 虎踞貪山, Ein 〈inaccessible terrain ist der Gier-Berg'.

${ }^{223}$ Das muß wohl nicht gleich als Majestätsbeleidigung verstanden werden. 


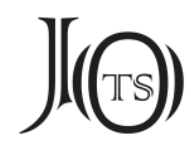

können. Des weiteren geht es um die Kleśas, deren Überwindung allerdings zwar förderlich ist, aber keinen Ausweg aus dem Sterben bedeutet.

\section{Pratyekasambuddha}

Diese Form für pratyekabuddha kommt auch in einer Saddharmapundarikasūtra-Handschrift vor (Oda 1996). Der zweite Anpassungskörper Avalokiteśvaras ist der Pratyekabuddha, so auch in allen alttürkischen Handschriften bis auf die Handschrift Oda, wo die Form pr'tyk's'npwt lautet, die von Oda richtig auf pratyekasambuddha zurückgeführt wird. Merkwürdig ist, daß sich diese Form anderswo nicht nachweisen läßt. Wahrscheinlich ist es eine Kontamination aus pratyekabuddha und samyaksambuddha. Sie fußt möglicherweise auf einer Resanskritisierung des chinesischen Ausdrucks. Die Handschrift setzt noch hinzu: „wenn sie sich Übungen in den Dharmas, die aus den 12 nidānas entstanden sind, unterzogen haben“. In einem anderen altuigurischen Fragment ${ }^{224}$, die Vorzüge der Heiligkeitsstufen elaborierend, liegt die umgekehrte Reihenfolge der beiden Pratyekabuddhas vor. Auf die nur im Schluß erhaltene Passage über die Vorzüge der Arhat-Stufe (ZZ. 1-5) folgt eine Darlegung über die Pratyekabuddhas (Kloppenborg 1974):

(05) yana anta basa (06) [anta]g ävdin barkdın ünmäk-nin ikinti pr(a)ty(e)kabud kutı-lıg (07) ulug tüši ärür : ol ymä nätäg < > osuglug ärki tep tesär (08) kim [k]ayu : birök bıšrunmı̌s köyül-lüg yıgınmıš ädgü yıltızlıg (09) 1duk tınl(1)g-lar ärtär-lär inčip olar ut-karš yertinčünüy (10) yokaru ükliyü barır arasınta uzatı butanatpat tegmä bügü (11) biliglig burhan-lar yertinčü-tä b(ä)lgürmäyük üd kolu bolg[u är]mäz (12) ol üdtä tözindäbärü münsüz katagsız tört türlüg simarti (13) [up]astan ög turug-ları bašlap alku (nizvanilar)-nıy yüründägi bolmıš (14) [ar]y-a aštangomarg säkiz bölük-lüg tözün köni yol-ka (15) [täg]i yintäm bir täg kirsiz < > tapčasız yeti kırk türlüg (16) [tuy]mak arkalıg nom-larıg bahšısızın (17) nom-čısızın k(ä)ntün tuyup tanuklap bügü bilig-lig burhan (18) -lar-ta basa ok bütün yertinčü-nüy ikinti takšanki dentar (19) törüyür b(ä)lgürär-lär : inčip ol ıduk tınl(1)g-lar : yana iki türlüg (20) [bar : ] än’ilki gunačari tegmä säkiz on k(a)lp-ta yıgmı̌̌ (21) [ädg]ü kılınč-lıg kuvragın yorıtačı atl(1)g pr(a)ty(e)kasanbud-lar ikinti (22) yüz k(a)lp-ta yıgmıš kazganmı̌ buyan ädgü kılınč-lıg katga (23) -višana klpi tegmä katgi käyik-niy müyüsinä okšatı yal(1)yuzın (24) yorıdačı pr(a)ty(e)kasanbud-lar : inčip yana bo iki türlüg pr(a)ty(e)kasan- (25) -bud dentar-lar : näčä tört kirtü nomug keyürü nomlamasar-lar (26) ymä tüü türlüg irdi küü

${ }^{224}$ Mainz 735 (T II Y 59). 


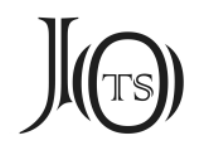

kälig ädräm-lärig kör- (27) -kitmäk üzä tın(1)g-lar-ka asıg tusu kılgu-luk (28) išin küčin tükäl bütürüp tözkärinčsiz ıduk (29) burhan-lıg dakšanki dentar-lar birlä otgurak (30) tuš tulum bolup sansar-tın ozgu-ka anuk kılur-lar (31) munı munčulayu [...] sansar-ka korkınč (32) köyüli bilgä biligi küčlüg ärip y(a)rlıkančučı köyüli (33) küčsüz yogačare-lıg tözün kutlug tınl(1)g ikinti pr(a)ty(e)-(34) -kabud kutı-lıg ortun kölük üzä sansar-lıg arkug (35) ärdär-lär kečär-lär

„Ferner danach gibt es zweitens die große Frucht der Pratyekabuddhaschaft, die vom Hinausziehen aus dem Haus kommt. Von welcher Art ist diese? Wenn heilige Wesen, die ein reifes Herz und gesammelte gute Wurzeln haben, sterben, so utkarșa ${ }^{225}$ gehen sie hoch über die Welt. Dazwischen erscheinen sie lange nicht in der buddhānām utpādah ${ }^{226}$ genannten Welt der weisen Buddhas. Es ist nicht die Zeit dazu. Dann verstehen und bezeugen sie die 37 dharmas ${ }^{227}$, angefangen mit den von der Wurzel her sündlos seienden viererlei smṛti-upāsthāna Bewußtseinszuständen bis zum ārya-aștangamārga achtteiligen edlen, wahren Weg, der Heilmittel für alle kleśas ist, völlig und auf einmal ohne Lehrer und Prediger, und nach den weisen Buddhas erscheinen zweitens die dakșaṇika Priester auf der ganzen Welt. Es gibt wieder zwei Arten: Erstens die guṇa-ācārya ${ }^{228}$ genannten Pratyekasambuddhas, die mit der in 80 kalpas angesammelten Schar von guten Taten Wandelnde genannt werden. Zweitens die mit den in 100 Kalpas gesammelten und erworbenen guten Taten allein wandelnden Pratyekasaṃbuddhas, die khaḍgavișanạa genannt werden, dem Horn des khadga-Tiers gleichend. Wenn nun diese zweierlei Pratyekasaṃbuddha-Mönche die Lehre der Vier Wahrheiten ausgiebig predigen, vollführen sie vollständig die Tat des Nutzen-Schaffens für die Lebewesen durch das Zeigen von allerlei ṛddhi-Zauberkräften und treffen sich mit den dakșanika Mönchen, die die unergründliche heilige Buddhaschaft erlangt haben, und schaffen so die Bereitschaft, sich aus dem samsāra zu befreien. Auf solche Weise werden die Furcht vor dem saṃsāra und die Weisheit mächtig. Die edlen und würdigen Yogacārin-Wesen, deren Barmherzigkeit kraftlos ist, passieren und überwinden durch das mittlere Gefährt der zweiten Pratyekasambuddhaschaft das saṃsāra-Tal.“

Die zwei Arten von Pratyekabuddhas sind (1) khaḍaviṣānakalpa (jemand, der wie das Horn des Rhinozeros ist ${ }^{229}$, (2) pratyekajina = gunacāri ${ }^{230}$.

\footnotetext{
${ }^{225}$ Skt. utkarșa $=$ 上生 shangsheng (DDB).

226 諸佛出世 (DDB).

${ }^{227}$ Vgl. Zieme 2013.

${ }^{228}$ Mahāvyutpatti: varga-cārī.

229 Die altuig. Form ist eine Verkürzung des genannten Terminus, vgl. auch BT 3: 69.

${ }^{230}$ So erklärt sich nunmehr auch BT 3: 69 k’nč̀ry, über das V. RYBATZKI spekuliert hat (2008: 199).
} 


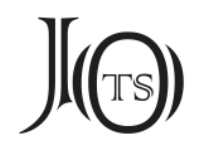

Der Gedanke durchzieht natürlich das ganze buddhistische Schrifttum, aber interessanterweise wird darauf auch Bezug genommen in einem Begräbnissermon für eine Laienschwester (Sri Lanka im Jahre 1998): „Maranodhammo 'mhi [means] 'I, too, am prey to the nature of death'; I can never escape death. Everyone of us must cultivate that feeling." (Langer 2013: 143)

\section{Passagen über die Begegnung mit einem Asketen}

In der Buddhabiographie nimmt diese Episode einen Wendepunkt ein, insofern als nach den drei negativen Begegnungen nun ein positives Ereignis mit dem Zusammentreffen mit Asketen eingeleitet wird.

\section{Abschnitt Mönch-1}

107 y-a körünč-lüg orun-nuy körki küvänč-i . toylašmıš bo tirin kuvrag-nıy

108 tokısı šobanı bolu yarlıkamıš ${ }^{231}$ täyrikän tegin täyrim kutı yarlıkasar :: kim bo ${ }^{232}$

109 yülitmišs ${ }^{233}$ tüšürmiš ${ }^{234}$ sač-lig sakal-lıg · yörgänmiš ${ }^{235}$ yaškınmıš ${ }^{236}$ $k_{1 z 1}{ }^{237}$ sarig

110 ton-lug kädimlig :: yölänmiš tayanmıš čıpratgu ${ }^{238}$ tayak-lıg . dentar $\operatorname{atl}(1) g$

111 yalıuk ärsär :: tugmak karımak-ka korkup äymänip . iglämäk ölmäk-ig erip

\footnotetext{
231 Yakup 2019: 19 täginmiš.

232 Yakup 2019: 19 bo kim.

233 Geschrieben: ywlydmys.

${ }^{234}$ Der Schrift nach müßte man eher tüšünmiš lesen.

${ }^{235}$ Geschrieben: ywrk’nmys. Yakup 2019: 19 yasan\{ïn\}mïš.

236 Geschrieben: y’sqynmys.

237 Geschrieben: qysyl.

${ }^{238}$ Geschrieben: cynkr'dqw.
} 


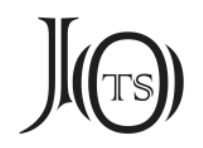

112 aklap $^{239}$ aklančıg sansar-tın ozup ${ }^{240}$ kutrulup $^{241}$. abayapur nirvan ${ }^{242}$ mäyi-sin bulgalı

113 tapgalı äv-in bark-1n kodup kämišip :: ög-in kay-1n yıglatu ${ }^{243}$ sıgtatu

114 ogul-ın kız-ın örlätü čärlätü ${ }^{24}$ :: tag aryatan orun-larıg ${ }^{245}$ sävä taplayu

115 amrak ogul-ın ak ${ }^{246}$ yagı-sın . adırtsız ${ }^{247}$ tüz kördäči :: kıy käzä ${ }^{248}$ kapıg sanayu

116 bulmıš-ča $\mathrm{k}(1)$ ya aš üzä kanımlıg bolup . sögüt tüpindä uč kıdıg yer

117 orun-larta . olurup . 十 [on] türlüg orun-lartın öyi ödrülüp 八 [säkiz] tözün

118 köni yol-ta yorıdačı ::: 三 [üč] agu nizvani-larıg alkıp tarkarıp 三 [üč] bitig $^{249}$ nom-lar

119 -ta yaratındačı :: alku-ta adruk ${ }^{250}$ kamag-ta kutlug ayag-ka tägimlig dentar atl(1)g

120 yalyuk bo täginür tänrim ::

${ }^{239}$ Geschrieben: '’̈̈lp $p$.

${ }^{240}$ Geschrieben: 'wswp.

${ }^{241}$ Geschrieben: qwdrwlwp.

${ }^{242}$ Yakup 2019: 19 arïy.

${ }^{243}$ Geschrieben: yyql'dw.

${ }^{244}$ Geschrieben: 'wrl'dw cyrl'dw. Yakup 2019: 19 orlațu čarlatu.

245 Yakup 2019: 19 orunlarïn.

${ }^{246}$ Yakup 2019: 19 anaz. Wenngleich das Wort auch so gelesen werden könnte, scheint mir ak, verhaßt (UWN/1: 76 mit der Herleitung aus chin. 惡 e) naheliegender zu sein, denn wenn man von ,hoffnungslosen Feinden' spricht, wird der Gegensatz weniger stark.

${ }^{247}$ Geschrieben: 'tyrtsyz.

${ }^{248}$ Geschrieben: $k^{\prime} s^{\prime}$.

${ }^{249}$ Geschrieben: pytyq. Yakup 2019: 20 pitaq.

${ }^{250}$ Geschrieben: 'trwq. 


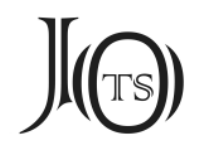

Wenn die Majestät der Fürstlichen Prinz-Hoheit, die Schönheit und Stolz des AussichtsOrtes ${ }^{251}$ und Schönheit und Zierde dieser festlich versammelten ${ }^{252}$ Schar zu sein geruht, (es anzunehmen geruht), dann ist es so: Was das Mönch genannte Geschöpf, mit abrasiertem und fallengelassenem Bart und Haar, in umhüllende ${ }^{253}$ und lockere (?) ${ }^{254}$ rot-gelbe Gewänder ${ }^{255}$ gekleidet, mit einem khakkara-Stock ${ }^{256}$ zum Anlehnen und Aufstützen, betrifft, so fürchtet es sich vor Geburt und Alter, verachtet und haßt Krankheit und Tod, verläßt und gibt auf Haus und Hof, um dem verhaßten Samsāra zu entkommen und sich aus ihm zu befreien, um die Freude des Nirvāṇa (im) Abhayapura zu erlangen und zu erreichen, läßt Mutter und Vater wehklagen und weinen, quält und verletzt Sohn und Tochter, liebt und schätzt die Orte der Berg-Klöster, betrachtet seinen geliebten Sohn und seinen verhaßten Feind unterschiedslos; mit dem, was es Straßen ${ }^{257}$ durchschneidend ${ }^{258}$ und Tore abklappernd ${ }^{259}$ durchwandert und da gerade ${ }^{260}$ an Bettelspeise erlangt, ist es zufrieden, setzt sich am Fuß des Baumes an Grenz-Orten nieder und trennt sich von den zehn Orten ${ }^{261}$ und wandelt auf dem Edlen und Ebenen Weg; es vernichtet und vertreibt die drei Gift-

251 Was genau unter körünčlüg orun zu verstehen ist, ist mir nicht klar.

252 Vgl. Geng-Klimkeit 1988/I: 2306 yıgılıp toylap.

$253 \mathrm{Zu}$ yörgän- ,umhüllt, eingewickelt sein`vgl. ED: 966a.

254 YAKUP liest yasanınmiš ,dressed with` ohne Erklärung. Ein entsprechendes Verb kann ich im Alttürkischen nicht finden. Die Schreibung y'sqynmys kann als eine metathetische Form für y’qsynmys = yakšınmıš erklärt werden. MK (ED: 908a) hat yaxsın- (yaksın-) mit dem Beispiel er kaftan yaxsindl "the man threw the cloak over his shoulders but did not fasten it in the middle or insert his arms”. Dieses Verb ist belegt in Suv. 664/7-9 y(a)rlıkančučl könüllüg b(ä)k yarık [Pet: y(a)rlı] yagsınmı̌ [Pet: yazgınmıš] ärür ät'özüyüzdä 'der feste Panzer der Barmherzigkeit ist um Euren Körper geworfen' (chin. T.XVI.665.555c29 大悲爲甲㫣 dabei wei jiazhou, die große Barmherzigkeit zum Panzer machend', Nobel 1958: 362). Während dieses Beispiel wegen der fehlerhaften Lesung fehlt, diskutiert M. ERDAL (OTWF: 625-626) die anderen drei Beispiele aus der Maitrisimit, aus der Xuanzang-Biographie und aus Shōgaito 1988: 126 mit der Lösung, daß yakšın- als Ableitung von yak-, to approach, to touch“ zu lesen ist. Vgl. ausführlich Gulcalı 2019: 81-82.

255 Das kāṣāya-Mönchsgewand sollte von mattroter oder gelbbrauner Farbe sein (DDB). Im mongolischen Lalitavistara ist das Gewand fol. 10r16 al, was PopPE durch ,red-yellow' übersetzt (1967: 117).

256 čırratgu bedeutet nicht ,bell`, wie Yakup (2019:24) meint, sondern eines der unabdingbaren Utensilien des Mönches, den khakkara.

257 Statt qïr (Yakup 2019: 19) ist kly ,Straße (< chin. 街 jie) zu lesen, denn der letzte Buchstabe ist ein eindeutiges finales $<y>$. Auch scheint mir ,Berg'vom Kontext her nicht zu passen, denn zum Erlangen von Almosen muß man in bewohnte Viertel gehen. Vgl. Zhang-Zieme 2019: 191: kıy käzä kapıg sanayu bušl pinvat kolu yorırsiz, Almosen erbettelnd geht Ihr die Straßen entlang, die Häuser zählend‘

258 käsä von käs- schneiden, oder käzä mit Dentalkonfusion von käz- ,passieren, durchgehen“.

259 kapıg sanayu ,Tore abzählend‘ = ,von Tor zu Tor`, gehört zur Aktivität des Bettelgangs eines Mönches.

260 Für $k(l) y a$.

261 ,zehn Orte‘ = Skt. daśabhūmi (?). 


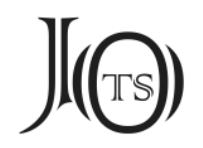

Leidenschaften und vervollkommnet sich nach den drei Büchern ${ }^{262}$. Das Geschöpf mit dem Namen des allerausgezeichneten, des allergesegneten und der Verehrung würdigen Mönches ${ }^{263}$ ist das.

Mein Fürst!

\section{Kommentar}

Dieser Passus ist eine generelle Beschreibung eines Mönches. Nach den äußeren Merkmalen wie Tonsur, Gewand und Bettelstab, den wichtigsten Charakteristika eines Mönches, wird kurz der Werdegang vom Auszug aus dem Haus bis zu den Einsiedlerorten skizziert, um dann auch die spirituelle Schulung anzusprechen.

\section{Abschnitt Mönch-2}

(120) y-a ${ }^{264}$ ögüp alkınčsiz ädgülüg ${ }^{265}$ küläp tükätinčsiz ${ }^{266}$

121 (adruk-lug) täyrikän tegin täyrim kutı yarlıkasar :: kim bo dendar ${ }^{267}$ lar-nıy törügülük tıltag-1

122 antag täginür :: äybašlayu bo yertinčü-tä kšatrik braman bayagut uz bo tört

123 türlüg tözlüg uguš-lug-lar törüdi-lär bälgürdi-lär :: bo 四 [tört] türlüg tözlüg ${ }^{268}$ uguš

${ }^{262}$ Gemeint ist sicher der Tripitaka ,die drei Schriften'. Doch suggeriert YAKUPs Lesung pyt' $q$ auch die Möglichkeit, daß der Schreiber mit der ungewöhnlichen Schreibung pytyq an sanskritisches pitaka ,Korb' dachte, dem steht allerdings entgegen, daß in der Regel skt. /ka/ durch uig. /k/ wiedergegeben wird. Der genaue Grund für das finale /q/ erschließt sich nicht so leicht.

${ }^{263}$ Hier ist das altererbte Wort dentar gebraucht wie übrigens auch bei Zhang-Zieme 2019: 190: bilgä tendara ,O weiser Mönch!'.

${ }^{264}$ Zwischen $\langle y>$ und $<>>$ gibt es noch einen kleinen Kreis, der wie ein $w$ aussieht. Es liegt eine besondere Gestaltung der Interjektion vor.

${ }^{265}$ Statt y-a ögüp aginčsiz ädgülüg liest Yakup 2019: 20, ymä ögüp küläp tükädinčsiz ädgüläp.

${ }^{266}$ Geschrieben: twyk'dyncsyz.

${ }^{267}$ Geschrieben: tynd'r.

${ }^{268}$ Yakup 2019: 20 liest ätözlüg. 


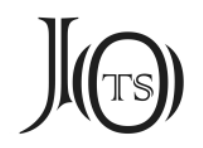

124 -lug-larda ${ }^{269}$ yan-a kayu ärsär birär uguš-takı tınl(1)g-lar tugmak karımak-ka korkup

125 äymänip . iglämäk ölmäkig erip alkap :: äv-in bark-ın ädin tavar-ın kodup

126 kämišip :: sač-ların sakal-ların yülitip ${ }^{270}$ karaš-a ${ }^{271}$ ton kädär-lär :: braman bayagut

127 uz bo 三 [üč] uguš-dakı-lar : kšatrik uguš-lug-larıg tapıg udug agır ayag

128 kılur-lar :: kšatrik uguš-lug-lar yana toyın-lar-ka dentar-larka tapıg udug

129 agır ayag kılur-lar :: 上 [üstün] täyri-kä 下人 [altın yalyuk]-ka alku-ka ayaguluk bolur-lar ::

130 täyrikän tegin täyrim kutı ymä . ol ${ }^{272}$ ayag-ka tägimlig-kä yakın barıp .

131 öndün körgüči 三 [üč] türlüg sav-larıg . ol ayag-ka tägimlig-nin äv-tin

132 bark-tın üngülük tıltagıg sor(u) $p^{273}$ özi ök barıp ayıtsar ${ }^{274} \mathrm{uz}$ bolu

133 tägingäy ärti täyrim :: :: elig täyrim tegü ol šakimuni kılgu ol ::

Wenn die Majestät der Fürstlichen Prinz-Hoheit, deren Güte zu loben unerschöpflich, deren Vorzüge zu preisen unendlich ist, (es anzunehmen geruht), dann ist es so: Was ist der Grund, daß diese Mönche entstehen? Zuerst sind auf dieser Welt die den viererlei Kasten Angehörigen, Kṣatriyas, Brāhmaṇas, Śreșthins und Handwerker, entstanden und erschienen. Von den diesen viererlei Kasten Angehörigen haben dann, wie auch immer, Lebewesen einzelner Gruppen, sich vor Geburt und Alter fürchtend und ängstigend, Krankheit und Tod hassend und verachtend Haus und Hof, Hab und Gut aufgegeben und verlassen, haben sich Haar und Bart abrasiert und sich in kāṣāya-Gewänder gekleidet. Die drei Kasten von Brahmanen, Śreșthins und Handwerkern dienen den der kșatriya-Kaste Angehörigen und verehren sie. Die der kșatriya-Kaste Angehörigen wiederum dienen den Mönchen und verehren sie. Diese werden von allen, von oben den Göttern bis hinunter zu

\footnotetext{
269 Yakup 2019: 20 liest uguš-larda.

270 Geschrieben: ywlydyp.

271 Mit der ungewöhnlichen Schreibung k'rys '.

272 ol fehlt bei Yakup 2019: 20.

273 Unsicher. Aber für die Lesung qorp (Yakup 2019: 21) ist die S. 28 gegebene Deutung nicht ausreichend.

${ }^{274}$ Geschrieben: '’yyds'r.
} 


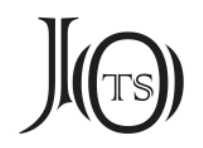

den Menschen, verehrt. Wenn die Majestät der Fürstlichen Prinz-Hoheit nun dem Verehrungswürdigen sich nähert und nach den oben gesehenen dreierlei Worten (= Schriften) und nach dem Grund, warum der Verehrungswürdige aus Haus und Hof fortgezogen ist, fragt, und wenn er (dann) selbst geht und fragt, würde es nicht gut sein? Mein König-Fürst soll sagen: Śākyamuni soll es machen!

\section{Kommentar}

Im letzten Abschnitt wird beschrieben, wie und warum aus den vier Kasten heraus sich eine Gruppe von Asketen gebildet haben. Obwohl ja grundsätzlich die Kasten als abgeschafft galten, wird hier gewissermaßen in einem historischen Rückblick die Hierarchie der Kasten vorgestellt, wenn der Text besagt, daß die Brahmanen, die Śresthins und die Handwerker die kșatriya-Kaste verehren, während letztere wiederum die Mönche hochschätzt.

In BT 3: 119-123 werden die 4 Kasten den 4 großen Flüssen verglichen, die in das Meer einströmen: kištirik braman uz tarıčč bö tört ugušluglar takı gay sit sindu vakšu ögüzlär atı kötrülmiš kayımazlıg mahasamudar ulug taluy ögüzkä aka kudulu bašlatı „Die den vier Kasten der Krieger, Brahmanen, Handwerker und Bauern Angehörigen begannen so wie die Flüsse Gañāā, Sītā, Sindhu und Vākșu in das Mahāsāmudra genannte große Meer, (d.h.) zu unserem Vater, dessen Name erhaben ist, einzufließen."

Namen der vier Kasten in den altuigurischen Texten

\begin{tabular}{|c|c|c|c|c|c|}
\hline & a & $\mathrm{b}$ & c & $\mathrm{d}$ & e \\
\hline & Skt./Chin. & Text & BT 3 & SI 4028 & Hedin 12v04-09 \\
\hline 1 & brāhmana/婆羅門 & braman (II) & braman (II) & & - \\
\hline 2 & kṣatriya/刹利 & kšatrik (I) & kšatrik (I) & kšatrik & kišatirya \\
\hline 3 & vaiśya/毘舍 & bayagut (III) & uz (III) & & uz \\
\hline 4 & śūdra/首陀羅 & $\mathrm{uz}(\mathrm{IV})$ & tarıgčı (IV) & & tarıgčı \\
\hline
\end{tabular}

\section{Anmerkungen ${ }^{275}$}

Alle Termini erscheinen in vielen Texten ohne Bezug auf das Kastensystem.

${ }^{275}$ b ist der vorliegende Text, c der obige Abschnitt aus BT 3, dist ediert in Zieme 2016, e in Wilkens 2017. 


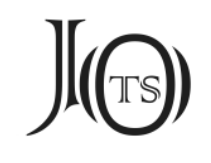

Für 1a und 2a werden in allen Quellen die Skt. Termini verwendet.

Für 3a gibt es unterschiedliche Übersetzungen (3b vs. $3 c$ und $3 e$ ).

Für $4 \mathrm{a}$ gibt es unterschiedliche Übersetzungen ( $4 \mathrm{~b}$ vs. $4 \mathrm{c}$ und $4 \mathrm{e}$ ). Aus Punkt 4 und 5 ergibt sich, daß die Terminologie nicht fixiert war, denn uz ,Handwerker ${ }^{\star}$ und tarıgčl ,Bauer ${ }^{\text {2276 }}$ präsentieren unterschiedliche Kasten oder Sozialschichten.

Die chin. Transkription ist in $2 \mathrm{~d}$ auch als Umschrift in uig. Schrift überliefert: črrly.

In 1e fehlt 1a nicht nur in der uig. Übersetzung, sondern auch in der chin. Vorlage.

Aus dieser Übersicht geht hervor, daß nach den Texten, in denen die Kasten komplett genannt werden (b und c), die kșatriya-Kaste an die erste Stelle gerückt ist.

\section{Abschluß und Kolophon}

Hier endet der Memorandum-Text, dem ein Kolophon nachgestellt ist.

\section{Abschnitt Kolophon}

134 sadu bolzun ädgülüg kälzün ::

135 kulut čnnkondu tutun $\mathrm{k}(1) \mathrm{y}-\mathrm{a}$ čahšapt ay altı

136 y(i)g(i)rmi-kä kodurup tükätü ${ }^{277} \mathrm{k}(\mathrm{i}) \mathrm{y}$-ä tägintim ::

Es sei sādhu! Es möge Gutes kommen! Ergebenst habe ich (der Sklave), Činkongdu Tutuy K(1)ya, am Sechsten des 12. Monats (dies) aufzuzeichnen beendet!

Die Lesung des Namens ${ }^{278}$ ist unsicher. Auf jeden Fall ist die letzte Silbe ( $\left.d u\right)$ das Element, das auf chinesisch 奴 $n u$,Sklave zurückgeht und sehr häufig in den buddhistischen Namen vorkommt. Vermutlich handelt es sich beim

\footnotetext{
276 Gül 2016.

277 Geschrieben: twyk'dw. 


\section{J(৫)}

vorangehenden Teil um zwei chinesische Silben, die einen Bodhisattva, einen buddhistischen Terminus oder ähnliches wiedergeben. Vielleicht kommt der Begriff 真空 zhenkong ,Wahre Leere' in Betracht. Der ganze Name 真空奴 bedeutet dann ,Sklave der Wahren Leere'. A. MiRKAMAL hatte bereits diesen Namen in der Handschrift B128: 18 von den Nördlichen Mogao-Grotten gefunden, wo die uigurische Wiedergabe ebenfalls Činkondu ist. ${ }^{279}$ Die Strophe lautet wie folgt:

[ü]zlünčüsintä yana yinkokke sudurug

ötvi süzük könülin

ötünüp čınkondu tu-n1 ${ }^{280}$

üzäläyü yana ok nomlatmıš

Am Ende nun ließ er Čınkoydu Tu[tuy] das Sūtra yinkokke ${ }^{281}$ mit scharfem und klarem Sinn überprüfend predigen.

Wenn beide Texte aus Mogao/Dunhuang stammen, besteht eine hohe Wahrscheinlichkeit, daß es sich um dieselbe Person handelt. Dies würde bedeuten, daß Činkoydu nicht nur Schreiber, sondern auch Prediger war.

Das besagte Sūtra, das Sūtra der Vollkommenen Erkenntnis - ein wichtiger Text des Chan-Buddhismus - liegt in altuigurischer Fassung zu Teilen in einer Vielzahl von Fragmenten vor. Auch ein Kommentartext wurde übersetzt oder vielleicht sogar von einem Uiguren verfaßt, der bezeugt, daß der ChanBuddhismus stark ausgeprägt war, wobei eine genaue Zeiteingrenzung für diese Aktivitäten zu geben unmöglich ist.

279 Mirkamal 2015: $195 \mathrm{Fußn}$.

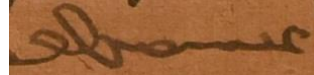

${ }^{280}$ Dabei dürfte dw, tu gelesen, die verkürzte Form des Titels tutuך sein. Das Suffix ny $\{+$ nı $\}$ drückt den Akkusativ aus.

281 圓覺經. Zahlreiche Fragmente von Übersetzungen des Sūtras wie auch von Kommentaren sind aus verschiedenen Sammlungen bekannt. 


\section{J(৫)}

\section{Weitere Handschriften}

Eine Reihe von Handschriften, die im Gegensatz zur Handschrift A nur selten integrale chinesische Zeichen haben, bezeugen, daß der Text sich einer großen Beliebtheit erfreute. Das weist natürlich auch auf die Bedeutung des Textes hin. Zwar stehen die meisten Kopien auf Rückseiten chinesischer Rollen, doch gibt es auch Nachweise, daß eigenständige Buchrollen (ein Beleg könnte die Handschrift $\mathrm{H}$ sein) angefertigt wurden, deren Herstellung eher für die frühe Zeit uigurischen Schrifttums (X.-XI. Jh.) anzusetzen ist. Dennoch bleibt es ein Problem, warum die meisten Handschriften in die späte Phase (XIII.-XIV. Jh.) gehören und zu der Zeit auch eine gewisse Überarbeitung erfahren haben. Die Titel für das Herrscherhaus weisen jedoch eher in die frühere Periode.

Die Handschriften unterscheiden sich von A in unterschiedlichen Maßen. So gibt es in einigen Fällen und einigen Passagen recht divergierende Formulierungen oder komplett andere Sätze, was wohl bedeutet, daß dieser Text einer großen Variationsbreite unterlag. Daraus ergibt sich, daß man nicht in allen Fällen von wirklichen Abschriften eines Urtextes sprechen kann. Die Reihenfolge der Handschriften bestimmt sich durch den Umfang sowie den zunehmenden textlichen Abstand zu A.

Während die Handschrift A aus Dunhuang stammt, vielleicht auch die Lujia Caotang-Handschrift, kommen alle anderen Manuskripte aus Orten der TurfanOase, doch in nur wenigen Fällen offenbaren die alten Fundortsignaturen eindeutige Hinweise: Sängim (Ch/U 6769), Yarxoto (Ch/U 6087) und Toyok (Ch/U 7161). Hinzu kommt ein direkter Leserhinweis in der Handschrift B. ${ }^{282}$

\section{Textvergleich der Handschriften}

Um Übereinstimmungen und Divergenzen zu verdeutlichen, füge ich hier eine Tabelle ${ }^{283}$ ein, in der die Syntagmen aus den drei Handschriften A, B und C verglichen werden.

\footnotetext{
${ }^{282}$ Vgl. Fragmente 04+05, Z. 21.

${ }^{283} \mathrm{~S}$ in der ersten Spalte bedeutet S[yntagma]. A, B und C die Handschriften A, B und C.
} 


\begin{tabular}{|c|c|c|c|}
\hline & A & B & C \\
\hline S 01 & [bodist]v uguš tözlüg & 20 [/// k]šatrik [uguš tözlüg] & 09 [y]-a kišatirik tözlüg \\
\hline S 02 & kinšuk ärdini & [kinšuk] ärdini & kinšuk ärdini \\
\hline S 02 & gavdam bag-lig & gödam baglig & gödam baglig \\
\hline $\mathrm{S} 03$ & kumut lenhu-a & kumut lenhu-[a] & kümüt lenhu-a \\
\hline S 04 & törüyü bälgürü yarlıkamıš & tö[rüy]ü b(ä)lgürä yarlı[kamıš] & törüyü bälgürä yarlıkamıš \\
\hline S 05 & täyrikän tegin täyrim & [tä]yrikän tegin t(ä)yrim & täyrikän tegin täyrim \\
\hline S 06 & kut1 yarlı-[ka]sar & kutı yarlıkasar & kutı yarlıkasar \\
\hline S 07 & bo ärsär 三 [üč] tooš-lar & [bo ärsär] üč toš-[la]r & bo ärsär üč toš-lar \\
\hline S 08 & bulganmak-ıntın & bulg[anmakın]tın & bulganmakıntın \\
\hline S 09 & 四大 [tört ulug]-lar & tört mahabut-lar & tört mahabut-lar \\
\hline S 10 & tüzüksirämäkintin & tüz[-üksirämäkintin] & tüzü[ksi]-rämäkintin \\
\hline S 11 & [五 beš ag1]llk-lar & [b]eš agılık & beš agılık-lar \\
\hline $\mathrm{S} 12$ & bımsıramak-ıntın & [bımsıramakıntın] & bırtınmakıntın \\
\hline $\mathrm{S} 13$ & 六 [alt1] ordu-lar & [alt1] [ordu-lar & alt1 ordu-lar \\
\hline $\mathrm{S} 14$ & artamak-intın & [arta]mak-ıntın & artamakıntın \\
\hline S 15 & aš ičgü & aš [ičgü] & aši ičgüsi \\
\hline $\mathrm{S} 16$ & [si]ymämäkintin & [siymämäkintin] & sinmämäkintin \\
\hline S 17 & azuča ärsär ymä & [azuča] [ärsär ymä] & azuča ärsär ymä \\
\hline S 18 & buti amanuš-i-lar & [buti] amanuši-lar & bute amanuše-lar \\
\hline S 19 & buu sigšil & buu [sigšil] & buu sigšil \\
\hline S 20 & almak-ıntın & [almakıntın] & almakıntın \\
\hline S 21 & yäk ičgäk-lär üzä & [yäk] [ičgäklär üzä] & yäk ičgäk-lär üzä \\
\hline S 22 & yelpikmäk-tin & [yelpi]kmäk-tin & yelpikmäkdin \\
\hline S 23 & grah tokımak-ıntın & gr[ah tokımakıntın] & grah [tokı]-[mak]ıntın \\
\hline S 24 & boguz igitmäk üzä ilgünmiš & [boguz] [igitmäk üzä ilgünmiš] & boguz yigitmäk üzä iglämiš \\
\hline S 25 & ilki-siztinbärü eridilmiš & 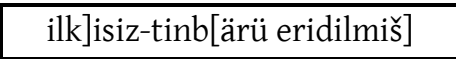 & 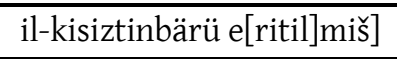 \\
\hline S 26 & alku kiši-lärkä & alku kišilär-[kä] & [alku] kiši-kä \\
\hline S 27 & aklatılmı̌̌ iglämäk atl(1)g & [aklatıl]-mıš ig[lä]mäk atl(1)g & aklatılmıš iglämäk atlıg \\
\hline S 28 & äšidgäli yavız yel törü & äšidgäli y[avız yel törü] & išitgäli [yavız u] tun törü \\
\hline S 29 & bo täginür täyrim & [bo täginür täyrim] & bo täginür täyrim :: \\
\hline
\end{tabular}




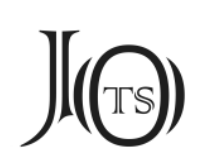

\section{Handschrift B}

\section{Vorderseite}

Der Text der chinesischen Vorderseite ist ein Abschnitt aus dem 妙法蓮花 經 Miaofa lianhua jing (T. 262). Aus Zusammensetzungen wird deutlich, daß die Rückseite in voller Höhe der Rolle zur Niederschrift der altuigurischen BuddhaProklamation benutzt wurde, erhalten ist mal nur die untere Hälfte (SI 4756), mal nur die obere Hälfte (SI 4745). Möglicherweise lassen sich noch weitere Bruchstücke dieser sehr markant und flüssig geschriebenen Handschrift finden. Die uigurische Schrift ist kursiv, aber recht deutlich geschrieben. Wie aus den Zeilen 3 und $19 \mathrm{zu}$ ersehen ist, ließ der Schreiber vor einem neuen Abschnitt einen Abstand zu dessen Verdeutlichung, in Z. 19 wurde der Rest der Zeile mit einzelnen Punkten ausgefüllt. Zur Markierung der Syntagmen innerhalb eines Abschnitts dient ein einzelner Punkt.

Bisher konnten die folgenden Fragmente dieser Buchrolle des Lotos-Sūtra dem Text zugeordnet werden. Wenn auch zuweilen bruchstückhaft, so umfassen die Fragmente aber quasi den gesamten Textumfang wie auch die Handschrift A, die allerdings wesentlich besser bewahrt ist.

Fragment 01: SI 3902 (4bKr 124) ist ein Bruchstück vom unteren Teil der Rolle mit 8 Zeichen einer Kolumne. Ein Teil des unteren Randes ist erhalten. Es entspricht T.IX.262.16c20-25.

Fragment 02: Direkt schließt sich SI 4756 (O 96) an, ebenfalls vom unteren Teil der Rolle mit etwa 10 vorhandenen Zeichen pro Kolumne. Auf dem Rand unter Kol. 07 findet sich gegenläufig ein Eintrag in uigurischer Schrift kwypw ohne offensichtlichen Bezug zum Text. Es entspricht T.IX.262.16c24-17a06.

Fragment 03: Nach einer geringen Lücke folgt SI 4745 (O 84), ein Fragment vom oberen Teil der Rolle mit 11 Zeichen pro Kolumne. Die Zeilen 11-12 des Fragments 02 sind mit den Zeilen 01-02 des Fragments 03 zu vereinen, wobei drei 


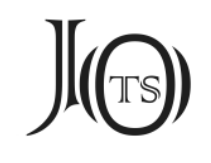

(in 11+01) bzw. zwei $(12+02)$ chinesische Zeichen fehlen. Es entspricht T.IX.262.17a06-17a17 ${ }^{284}$.

Fragment 04: Direkt folgt SI 3992 (4bKr 163) vom oberen Teil der Rolle mit 11 Zeichen pro Kolumne. Es entspricht T.IX.262.17a18-17a27.

Fragment 05: SI 3996 (4bKr 169) vom oberen Teil der Rolle mit 11 Zeichen pro Kolumne. Es entspricht T.IX.262.17a27-17b04.

Fragment 06: SI 3968 (4bKr 82) ebenfalls vom oberen Teil der Rolle mit der Entsprechung T.IX.262.17b04-17b11.

(Lücke von 3 chinesischen Kolumnen)

Fragment 07: SI 3875 (4bKr 54). Es ist nicht eindeutig, aus welchem Teil der Rolle das Fragment stammt. Es entspricht T.IX.262.17b15-20.

(Lücke von 17 chinesischen Kolumnen)

Fragment 08: SI 3877 (4bKr 86) vom unteren Teil der Rolle. Es entspricht T.IX.262.17c07-10.

Fragment 09: SI 3869 (4bKr 45) vom oberen Teil der Rolle. Es entspricht T.IX.262.17c08-12..$^{285}$

Fragment 10: SI 4072 ( $4 \mathrm{bKr} 81$ ) vom oberen Teil der Rolle. Es entspricht T.IX.262.17c18-18a04.

Fragment 11: SI 3928 (4bKr 159) vom unteren Teil der Rolle. Es entspricht T.IX.262.18a02-03.

Fragment 12: SI 3874 (4bKr 52). T.IX.262.17c29-18a06.

Fragment 13: SI 3981 (4bKr 128) T.IX.262.18c13-c19.

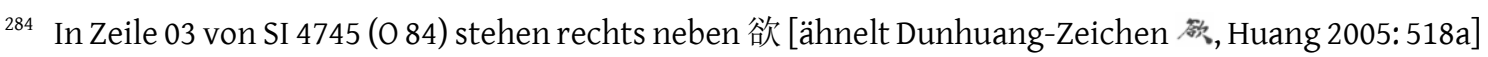
誘 yuyou zwei kleiner geschriebene Zeichen: ? (nur ein Bruchteil ist erhalten) 長 chang, lang. Das folgende 引 yin ähnelt dem Dunhuang-Zeichen 32 (Huang 2005: 501b).

${ }^{285}$ Ein weiteres Fragment mit einer ähnlichen Stelle aus T. 262 ist SI 3869 (4bKr 45) stammt aus einer anderen Kopie, denn die am Ende der Zeile 03 von SI 3877 stehenden Zeichen 爾時 (T.IX.262.17c10.01+02) kommen am Anfang der Zeile 04 von SI 3869 wieder vor. SI 3869 verso ist ein Fragment eines Kolophons mit dem Namen Taybodu (? < 大寶奴). 


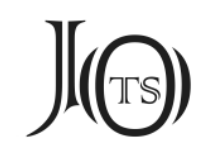

Fragment 14: SI 3870 (4bKr 46) T.IX.262.18c18-c24.

\section{Rückseite}

Hier erfolgt die Lesung der Rückseiten der Handschrift B in der oben aufgestellten Anordnung der Fragmente. Die Entsprechungen zu A werden in der folgenden Zeile angeführt. $Z$ bedeutet hier wie auch in den anderen Parallelhandschriften Zusatz, Var. Variante, ? unklare Zuordnung oder unklarer Inhalt.

\section{Fragment 01: SI 3902}

001[

] $\mathrm{t}(\ddot{\mathrm{a}}) \mathrm{y}[\mathrm{r}] \mathrm{i}[/ /] \mathrm{m}[/ / / /] \mathrm{t}[\quad]$

?

$002[\quad] m a k-\operatorname{lig}$ iš-lär $[$ ]

?

003[

] bolmak-1n ${ }^{286}$ bulmıš-1n . yws//

?

004[

] köšikig ${ }^{287}$ kolunu "y

?

005 [ ] arıgın amrilmak-ta adırt[lig ]

?

$006[\quad] / / \mathrm{s} / / / / / . / / \mathrm{k}$ bolmıs $/ / /[\quad]$

?

007 [ ]-lar . inčä kaltı elig [ ]

?

008[

] $\mathrm{t}[$

]

\footnotetext{
${ }^{286}$ Der $<$ l> Haken ist fast nicht sichtbar.

287 Geschrieben: kwșykyk.
} 


\section{J(৫)}

?

\section{Fragmente 02+03: SI 4756 + SI 4745}

009 [tıgrak katıg türk yigit äränlärkä ergülük] yarsı(gu)luk [bolmıš :: karımak]

013/014

010 [tegli kargatmıš utun törü kamag tınlıg ogla]n-ları-na bir täg' ${ }^{288}$ käldäči

014

011 [täginür täyrim :: ] ((frei))

015

012 [y-a sansar-a pramandal yertinčü yer] suv-nuy ičintäki tınl(1)g oglan ${ }^{289}$ 015/016

013 [-larnıy ayagulukı bolu yarlıka]mıš t(ä)yrikän tegin t(ä)yrim ku[t]1

016

014 [yarlıkasar bo karımak tegli udu]n törü ärsär . alkınču üdtäki oot

017

015 [täg ädgüg yavız]ıg adırtlamatın ${ }^{290}$ alku-ka bir täg

018

016 [käldäči täginür : äymıntın o]tuz iki 1(a)kšan-lar üzä etiglig ${ }^{291}$ 018/019

017 [säkiz on nayrag-lar ü]zä ${ }^{292}$ yaratıglıg č(a)kir bašlap yeti

019

A014 hat vor bir täg zusätzlich tüzükä.

289 A016 ohne oglan.

290 Geschrieben: '"tyrdl'm'tyn wie in A018.

291 Geschrieben: 'ydyklyk wie in A019.

${ }^{292}$ Das [ü]zä ist ein Zusatz gegenüber A019, wo es vergessen sein dürfte. 


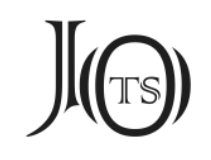

018 [ärdinilär üzä . ärklig türklü]g . min tona küčlüg oglan $019 / Z$

$019[$ ]nč1-lig . tört divip yertinčü

Z

020 [-lärig čcakr]av(a)rt iduk han-lar ${ }^{293}$ ymä äy

020

021 [tüpindä karımak üzlünčü]lüg bolur-lar . t(ä)yrikän tegin

021

022 [tänrim kutının anča ol anta]g osuglug ${ }^{294}$ köz äsri köyül

022

023 [arvı bolgu täg mäyisi tonas]ı čogı yalını ärki türki adı

022

024 [maygal1 ${ }^{295}$ näčä üküš tälim b]ar ärsär ymä . tugmak törü-tin

023

025 [ozmatuk üčün karımak tö]rü-tin ymä ozmıš kutrulmı̌̌

024

026 [täginmäz : otgurak karımak tö]rü-lüg yarlıkar [a]rıtı ${ }^{296}$ karımagay $\mathrm{m}(\mathrm{ä}) \mathrm{n}$

025

027 [tep sözläyü yarlıkamazun täyri]m . elig t(ä)yrim ${ }^{297}:$ :

026

${ }^{293}$ A020 hat vor hanlar noch eliglär.

294 A022 anča ol anı täg, ohne osuglug.

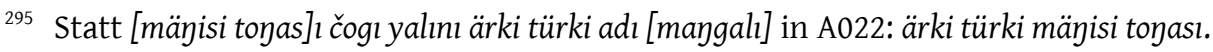

${ }^{296}$ Geschrieben:[ ]rydy.

${ }^{297}$ Geschrieben: Verkürzt (?) für A026 elig tänrim tegül šakimuni kılgu ol. 


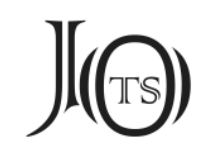

028 [y-a k] šatrik [uguš tözlüg kinšuk] ärdini gödam baglıg kumut lenhu 027/028

029 -[a] tö[rüy]ü b(ä)lgürä yarlı[kamıš tä]prikän tegin t(ä)yrim kutı yarlikasar

028/029

030 [bo ärsär] üč toš-[la]r bulg[anmakın]tın tört mahabut-lar tüz

029

031 [-üksirämäkintin b]eš agılık [bımsıramakıntın altı]

029/030

032 [ordu-lar arta]mak-ıntın . aš [ičgü sinmämäkintin azuča]

030/031

033 [ärsär ymä buti] amanuši-lar buu [sigšil almakıntın yäk]

031/032

034 [ičgäklär üzä yelpi]kmäk-tin . gr[ah tokımakıntın boguz]

032/033

035 [igitmäk üzä ilgünmiš ilk]isiz-tinb[ärü eritilmiš² ${ }^{29}$ alku kišilär aklatıl] 033/034

036 -mıš ig[lä]mäk atl(1)g äšidgäli y[avız yel törü bo täginür täyrim]

034/035

037 [y]a alku kamag tınl(1)g oglan-lar-[nıy arasınta ayazlı yagızlı]

035/036

038 -ča ärtmiš ašunmıš yintmiš yegä[d]m[iš 299 bodistv ugušlug] 036/037

${ }^{298}$ Geschrieben: 'yrydylmys.

299 Statt ärtmiš ašunmıš yintmiš yegädmiš hat A036 nur yintmiš yegädmiš. 


\section{J(৫)}

039 [täyri]kän t(ä)Đrim kutı ${ }^{300}$ yarlıkasar . kim bo erit[ilmıšs ${ }^{301}$ yavız iglämäk tegli]

037

$040[u] t[u] n^{302}$ törü [är]sär . küčüg küsünüg k[ävip küčsirätip]

037/038

041 [o]lurgalı yatgalı turgalı ärgäli ${ }^{303} 1$ dmatın . [aška ičgükä sav]

038/039

042 -ka sözkä tapsız kıldačı täginür . bo i[glämäk ymä]

039/040

043 üč türlüg bolu täginür . äy’ilki tad[u mahabutlar bulganmak]

040/041

044 -intın . tugm[1]š ig . ikinti učık yel[pik tözlüg ig]

$041 / 042$

045 üčünč k1lınč tözlüg ig . bolar är[ürlär üč türlüg iglär]

042

046 tadu mahabut-lar bulganmak-ıntın . tu[r]mı̌̌ ig yana tört yüz tört]

043

047 türlüg bolu täginür . bo tört yüz tört [türlüg iglärdä]

043/044

048 kayu ärsär . igig iglägüčä ärsär ${ }^{304}$. arat[a ymä ot äm tusulur]

$044 / 045$

300 Geschrieben: qwdy.

301 Geschrieben: 'yryd[ ].

302 Geschrieben: [ ]d[ ]n.

303 Statt [o]lurgalı yatgalı turgalı ärgäli hat A038-039 nur olurgalı turgalı ärgäli.

304 Vor ärsär hat A045 noch täylig. 


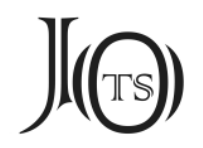

049 arata ymä ot äm tusulmaz . adın [ažunka sanlıg bolur]

045/046

050 -lar [b]o mun1 [täg] osug-lug eritmiš ${ }^{305}$ [yavız iglämäk]

046/047

Fragmente 04+05: SI 3992 + SI 3996

051 törü alku t[1nl(1)]g $\mathrm{g}^{306}$ oglan-[1]ya [muntag bolu täginür]

047

$052 \mathrm{t}(\text { ä)yrim .....t(ä)yrim .. čini[k ] }]^{307}$

$047 / \mathrm{Z}$

053 činik ol ${ }^{308}$

Z

054 [y]-a kapiva ${ }^{309} \mathrm{~m}(\ddot{)}) \mathrm{n}$ sivtsuin/sintsuin ${ }^{310}$

055 [y]-a kapilavasdu känt-lig [mahakadini yuul ičindä]

048

056 hansarača kaz-lar hanı [törüyü bälgürü yarlıkamıš bodistv ugušlug]

305 Geschrieben: 'yrydmys, in A046 eritilmiš.

306 Erhalten ist nur t-----Schlußstrich, aber wegen folgendem oglan ist sicher tınlıg zu lesen, auch wenn der l-Haken komplett fehlt.

307 Nach dem Schluß des Abschnitts mit t(ä)yrim folgt das Wort čini[k], das in der folgenden Zeile zwischenzeilig wiederholt wird, allerdings in der Verbindung mit ol: čynyk ywl = činik ol. Von einer ähnlichen Konstellation her ist činik aus einer Yogaśataka-Handschrift bekannt (Rachmati 1932: 402 činik bitig bo ärür yüz bir türlüg bitiglärdä talkmı̌̌ ulug türlüg činik bo ärür „Das ist ein činik Buch. Aus hundertundeins Büchern zusammengeheftetes [OTWF: 360 talk- ,top twist'] großartiges činik ist es." Vermutlich geht činik auf Skt. cinaka, Chinese‘ zurück, denn die Handschrift wurde ja aus einer chinesischen Schriftrolle gefertigt.

308 Es folgen zwei mit dünner Feder geschriebene Wörter: sivtso nomčı. Zu den Namen vgl. Matsui 2004.

309 Der Schreiber wollte hier schon mit dem neuen Abschnitt einsetzen, denn kapiva ist der Anfang von kapilavastu der folgenden Zeile.

310 Name eines Benutzers: syvtswyn/syntswyn = sivtsuin/sintsuin oder ähnlich, sicher chin. Ursprungs. 


\section{$J(\Theta)$}

048/049

057 täyrikän tegin täyrim [kutı yarlıkasar kim bo]

049/050

058 iglämäk-lig yavız ${ }^{311}$ ya[lyuz bo tınl(1)g-ka ok]

050/051

059 kältäči täginmäz ${ }^{312} \cdot$ kaltı nä[täg üstün]

051/Var.

060 t(ä)yri yer-in-täki alt[ın yertinčü-täki ]

Var.

061 alku tınl(1)g-lar oglan-ları [

Var.

062 iglämäk-lig yavız törü [

Var.

063 täginmäz . alku tınl(1)g oglan-[ları

Var.

064 törü-kä tägdäči täginür [ kaltı nätäg öydün yııak]

Var./051

065 -tın ulug kay ${ }^{313}$ tag yorı[yu kälsär üstün kapıgı kök]

052

066 kalık birlä tutčı altın [tüpi yagız birlä tutč1] ${ }^{314}$

052/053

${ }^{311}$ Es scheint ein korrigierter Schreibfehler vorzuliegen, denn der letzte Buchstabe könnte ein $/ \mathrm{m} / \mathrm{sein}$.

${ }^{312}$ A051 kälmiš täginmäz.

${ }^{313} q^{3} y=\operatorname{kay}(a)$,Fels'.

${ }^{314}$ Von Z. 09 bis Z. 16 scheint der Text durcheinander gekommen zu sein, denn 11 alku tinl( ( )g-lar oglanlarl kommt in Z. 13 erneut vor. 


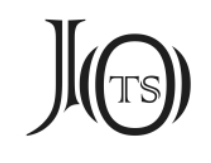

067 üstün učugma altın ${ }^{315}$ [bagırın yorıgma tınlıglarıg bir] 053/054

068 kalısız yančar yumirtur [ärsär ančulayu ok ymä bo] 054

069 iglämäk-lig utun ${ }^{316}$ törü bay [čıgay]

054/055

070 adırtlamatın ${ }^{317}$ alku-ka bir täg [kältäči täginür ..]

055/056

$071 \mathrm{t}(\text { ä)yrim : turur-ta sözlämäk y(a)vız s(a)v tu[rur }]^{318}$

$056 / \mathrm{Z}$

072 [y]-a alku kamag bodun bokun-lug k[šatrik tözlüg käyiklär kuvragi] 057

073 arasın-ta yalyuz arslan hanı tü[käl ${ }^{319}$ yegädmiš bodistv ugušlug] 057/058

074 täyrikän tegin täyrim kutı yarlıkas[ar kim bo purvanandanakalp] 058/059

075 bašlag-1ntakı čaru upačaru var[u kalyani-ta ulatı]

059

076 uzun özlüg yaš-lıg ${ }^{320}$ agır [ulug elig-lär han] $\mathrm{Z} / 060$

\footnotetext{
${ }^{315}$ Von den ersten vier Buchstaben sind nur die linken Bestandteile erhalten.

316 Geschrieben: 'wdwn.

317 Geschrieben: 'tyrdl'matyn. In A055 temätin.

318 Zusatz in zierlicher Schrift: „Stehend sprechen ist eine schlechte Sache.“(?)

319 Zusatz, Lesung nicht sicher.

320 Zusatz uzun özlüg yaš-lıg ,langlebig‘.
} 


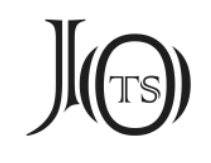

077 -lar arčuni t[oya-ta] ärtsär yaš[maz alp ]

060

Fragment 06: SI 3968

078 tägip ök tag-1g yimirdäči-lär . [tanču-lap tag-1g]

061

079 ušattač ${ }^{321}$-lar . sorup suv-ug su[gurdačı-lar . sodup]

061/062

080 kölüg tošgurdačı-lar . talačangi[ri asure täg · ulug]

061/062

081 bädük ${ }^{322}$ ät’özlüg-lär . dandarasati[ri' ${ }^{323}$ bäg täg küč-lüg]

062/063

082 küsünlüg-lär . näy inčip bo i[glämäk-lig utun törü-tin ozmatı]

063/064

083 -lar . täyrikän tegin täyrim kut[1 ${ }^{324}-n ı \eta$ näčä ök]

064

084 üstün-ki aš-ları ičgü-1[äri

]$^{325}$

Z

085 -či-läri'326 näčä öztä nätäg ärsä[r ]

Z/066

321 Geschrieben: ' $w s^{2} d t^{3} c y$.

322 Papier ist verkrunkelt, aber da ein großes - $d$ - nicht zu sehen ist, war das Wort sicher $p^{2}$ twk geschrieben gewesen.

323 Geschrieben: d'nd'sty[ ].

324 Geschrieben: qwd[ ].

${ }^{325}$ Unklar, was die ,oberen Speisen und Getränke` bedeutet. Eine Entsprechung zu A065 ist nicht auszumachen.

326 Es ist unklar, welches Wort vor -či angenommen werden kann. 


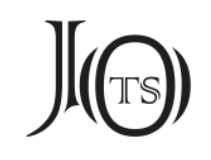

086 utun törü soka yakın kälmi[š-tä karamuk-ča]

066/067

087 ymä tusulmaz . näy inčip iglä[mägäy ärki m(ä)n tep sakınu]

067

088 yarlıkamaz $^{327}$ täyrim .... . elig [täyrim tegül] $]^{328}$

068

(Lücke)

Fragment 07: SI 3875

089 ürük 329

?

(Lücke)

Fragment 08: SI 3877

090[

] $\mathrm{l}[\mathrm{k}[\mathrm{]}[\mathrm{]}] \mathrm{n}[\mathrm{]}$

$?$

091[

a]din $\operatorname{tinl}(1) g-l a r \operatorname{adin}$

094

092 [ažunka sanlıg bolmagay mu] . anın bo ölüm

095

093 [atlıg ülügsüz törü alkuka] bir täg käldäči

095/096

094 [täginür täyrim .. ] kulutı ligui tutuy ärki tudtum

096/Z

\footnotetext{
327 Vielleicht falsch für yarlıkamazun?

328 Emendation nach A068.

${ }^{329}$ Fraglich, das Papier ist an dieser Stelle verkrunkelt: / $w / r w k$.
} 


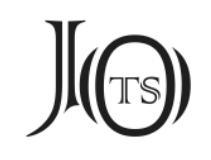

095 [y-a küsüšlüg yertinčünüy k]örki küvänči ediš 096/097

096 [yertinčünüy etigi yaratıgı b]olu y(a)rlıkamıš t(ä)yri 097

097 [-kän tegin t(ä)yrim kutı yarlıkasar nä antag y]alyuk tınl(1)g bolgay 097/098

Fragmente 09 + 10 + 11: SI 3986 + SI 4072 + SI 3928

098 [ölümkä sanlıg bolmatačı äy]mıntın kadgi

098/099

099 [gunačare iki türlüg praty(e)kasan]bud-lar . küü kälig

099

100 [ädräm tašgarıp kök kal1]k yüüzintä učdačı-lar .

100

101 [üstünki ät’özintin oot ] üntürüp altın $100 / 101$

102 [ät'özintin suv akıtdačılar] tokuz on säkiz

101

103 [nizvanilarıg tarkarıp bavagir]-lıg ediz artıg ašıp $101 / 102$

104 [arhant kutılıg čogka yalınka] tägmiš tınl(1)g-lar $102 / 103$

105 [ymä anityatlıg az] tag-ta ornan-tı-lar batt $1^{330}$ 103

${ }^{330}$ Geschrieben: $p^{2} d t y$. 


\section{$J(\Theta)$}

106 [-lar täyrikän tegin täy]rim ymä bir-ky-ä ymä ${ }^{311}$ nizvani $103 / 104$

107 [tarkar]matın ${ }^{332}$ ärip näčükin ${ }^{33}$ ölüm törü-tin ozgalı $104 / 105$

108 ugay . adırtlıg $g^{334}$ ölmäk törü-lüg yarlıkar ölmägäy ${ }^{335}$

$105 / 106$

109 män tep sezinü ${ }^{336}$ yarlıkamazun . täyrim :: elig tngrim ${ }^{337}$..

106

110 [y]-a bo ${ }^{338}$ körünčlüg orun-nuy körki [küvän]č-i . toylašmı̌̌ 107

111 bo tirin kuvrag-nıy tokısı [šobanı bolu yarlıkamıš] $107 / 108$

112 täyrikän tegin täyrim kut1 ${ }^{339}$ yarlık[asar kim bo yülitmiš] $108 / 109$

113 tüšürmiš sač-lıg sakal-lıg yö[rgänmiš yakšınmıš kızıl sarıg] 109

114 karža ton-lug kädim-lig yölän[miš tıgmıš

110

\footnotetext{
${ }^{331}$ Das Wort ymä nicht in A104.

${ }^{332}$ A104 tarkarmatuk.

${ }^{333}$ A104 nätägin.

${ }^{334}$ Geschrieben: 'tyrtlyq. In A105 folgt noch otgurak.

335 A106 fügt die Verneinungsverstärkung arttı ein.

336 Geschrieben: sysynw. A106 sakıyu.

${ }^{337}$ Im frei gebliebenen Raum der Zeile: burhan bolayın ,Ich möchte Buddha werden.

${ }^{338}$ In A107 ohne bo.

339 Geschrieben: qwdy.
} 


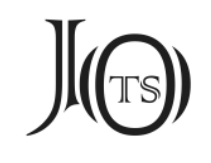

115 karımak-ka korkup äymänip . i[glämäk ölmäk-ig]

\section{1}

116 erip aklap aklančig sansar-tın [ozup kutrulup . abayapur]

$111 / 112$

117 nirvan-lıg enč orun-ta kä[

$112 / Z$

118 -in äd-in tavar-in yarıp ya[

Z

119 ög-in kay-ın yıglatu ${ }^{340}$ sıgtatu [ogul-ın kız-1n]

$113 / 114$

120 örlätü ${ }^{341}$ čärlätü . tag aryatan or[un-larıg sävä]

114

121 taplayu . amrak ogul-ın ak ya[gi-sın . adırtsız]

$114 / 115$

122 bir täg ${ }^{342}$ kördäči . kıy käzä [kapıg sanayu bulmıš]

$115 / 116$

123 -ča k(1)y-a pinvat aš ${ }^{343}$ üzä [kanımlıg bolup]

116

124 sögüt altın-ınta ${ }^{344}$. uč k1dıg orun-larta ${ }^{345}$

116/117

\footnotetext{
340 Geschrieben: yyql'dw.

341 Geschrieben: 'wyrl'dw.

342 Statt bir täg in A115 tüz.

343 Statt pinvat aš in A116 nur aš.

344 Statt altın-ınta in A116 tüpindä.

${ }^{345}$ A116 hat zusätzlich yer.
} 


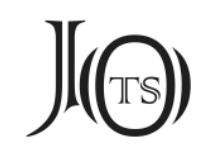

125 olurup on türlüg ayıg-lartın ${ }^{346}$ öni ödrülüp

117

126 on karmap(a)t yolın-ta ${ }^{347}$ yorıdačı . az övkä

$117 / 118$

127 biligsiz üč agu ${ }^{348}$ nizvani-larıg tarkarıp ${ }^{349} \check{c}(a) h s ̌ a p(a) t^{350}$

118

128 [üč bitig nom-lar-ta yaratın]d[ačı ... $] \mathrm{d}[\ldots .$.

$118 / 119$

\section{Fragment 12: SI 3874}

129[

]

$\mathrm{Z} /$ ?

$130[\quad] \mathrm{t}[\mathrm{]}$ ] bäg kutı sw//

$\mathrm{Z} /$ ?

$131[\quad] z y(a) r l i g$ bitig anta

$\mathrm{Z} /$ ?

132 (frei)

133 [ ] ] ]

Z

$134[$ ] bitidim

Z

346 A117 orun-lartin.

347 Statt on krmap(a)t in A 117/118 tözün köni yol-ta.

348 In dieser Version werden die ,drei Gifte‘ aufgezählt.

349 A118 alkıp tarkarip.

350 Nicht in A118. 


\section{J(G)}

\section{Fragment 13: SI 3981}

135[

ä] vin [

125

136[

y]ülitip ${ }^{351} \mathrm{k}[$

]

126

137 [bayagut] uz üč ug[ušdakılar kšatrik

]

127

138 uguš-1[u]g-larka agır ayag [kılur-lar :: kšatrik]

127

139 uguš-lug-lar yana t[o]yın-[lar-ka dentar-larka tapıg udug]

128

140 agir ayag kilip tapınur-la[r

129

141 üstün $^{352}$ täyri-kä altın ya[lyuk-ka

129

142 barča ayaguluk bolur . täy[rikän tegin täyrim] $129 / 130$

143[

\section{Fragment 14: SI $3870^{353}$}

144 [täyr]isi b[urhan

$145-\operatorname{lig}$ y(a)rlik[

351 Geschrieben: [ ]wlydyp.

352 Geschrieben: 'wyztwn.

353 Dieses Fragment könnte aus einem Kolophon stammen. 


\section{J(G)}

146 kutına ' w[

]

Der somit erschlossene Text der Handschrift B stimmt weitestgehend mit dem von A überein, so daß keine Übersetzung notwendig ist, doch sollen im folgenden Abweichungen von der Handschrift A erörtert und übersetzt werden.

\section{Abweichende Passagen der Handschrift B}

\section{Fragment 01: SI 3902}

\begin{tabular}{|c|c|c|}
\hline 001[ & ] $\mathrm{t}(\ddot{a}) \mathrm{n}[\mathrm{r}] \mathrm{i}[/ /] \mathrm{m}[/ / / /] \mathrm{t}[$ & ] \\
\hline & & \\
\hline 002[ & ]mak-lıg iš-lär [ & ] \\
\hline$?$ & & \\
\hline 003[ & ] bolmak-ın bulmıš-ın . y & yws/ \\
\hline$?$ & & \\
\hline 004[ & ] köšikig kolunu '? & \\
\hline$?$ & & \\
\hline 005[ & ] arıgın amrilmak-ta adırt[lig & ] \\
\hline$?$ & & \\
\hline 006[ & ]$/ / \mathrm{s} / / / / / . / / \mathrm{k}$ bolmıš $/ / /[$ & ] \\
\hline$?$ & & \\
\hline 007[ & ]-lar . inčä kaltı elig [ & ] \\
\hline$?$ & & \\
\hline 008[ & ] $\mathrm{t}[$ & \\
\hline
\end{tabular}

?

Obwohl der zitierte Abschnitt den parallelen Zeilen von A013 an vorangeht, lassen sich für diesen keine Übereinstimmungen $\mathrm{zu}$ A feststellen. Möglicherweise liegt dies daran, daß SI 3902 sehr schlecht erhalten ist, weshalb auch eine zusammenhängende Übersetzung keinen Sinn ergibt. Erwähnt seien 


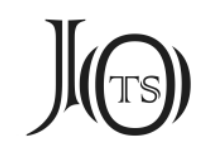

004 ,eine Bedeckung erbittend' und 005 ,im Friedlichsein in Reinheit deutlich (?)', aber auch diese Deutungen sind nicht sicher, auch wenn der Anschluß zum nachfolgenden Text 02 feststeht.

\section{Epitheta der Cakravartin-Könige}

018 [ärdinilär üzä . ärklig türklü]g . min tona küčlüg oglan $019 / Z$

$019[$ tapi]gči-lig . tört divip yertinčü

Z

020 [-lärig čakr]av(a)rt iduk han-lar ymä äy

020

„Auch die [ mächtigen Cakr]avartin heiligen Könige, die tausend stark wie Helden seiende Söhne [und ... Dien]er(?) haben, die die Welten der vier Kontinente (dvīpa) [beherrschen].“

A020 erwähnt nicht alle Attribute eines Raddrehenden Königs. Da in B nur die Hälften der Zeilen erhalten sind, ist eine volle Emendation nicht möglich. Ein Cakravartinrāja besitzt die schon erwähnten 7 Juwelen sowie 1000 Söhne. Vgl. T.I.1.39b09 千子具足勇健雄猛 „He had one thousand sons, courageous and valiant.“ (Ichimura 2015: 226)

\section{In dem folgenden Abschnitt gibt es einige Textabweichungen.}

057 täyrikän tegin täyrim [kutı yarlıkasar kim bo]

049/050

058 iglämäk-lig yavız ${ }^{354}$ ya[lyuz bo tınl(1)g-ka ok]

050/051

059 kältäči täginmäz $z^{355}$. kaltı nä[täg üstün]

Var.

354 Es scheint ein korrigierter Schreibfehler vorzuliegen, denn der letzte Buchstabe könnte ein /m/ sein.

355 A051 kälmiš täginmäz. 


\section{$J(\Theta)$}

060 t(ä)yri yer-in-täki alt[ın yagız yerintäki

Var.

061 alku tınl(1)g-lar oglan-ları [

Var.

062 iglämäk-lig yavız törü [

Var.

063 täginmäz . alku tınl(1)g oglan-[ları

Var.

064 törü-kä tägdäči täginür [ kaltı nätäg öndün yınak] 051/052

Es scheint, daß der mit [kim bo] iglämäklig beginnende Abschnitt B057-064 eine Erweiterung von A050-051 kim bo iglämäk atl(1)g utun törü yalyuz < > 051 tınl(l)g-ka ok kälmiš täginmäz :: darstellt.

\begin{tabular}{|c||c||}
\hline Handschrift A & Handschrift B \\
\hline \hline 50 utun & 058 yavız \\
\hline \hline 051 kälmiš täginmäz & 059 kältäči täginmäz \\
\hline
\end{tabular}

B059-064 So wie alle Lebewesenkinder [oben] im Himmelsland und unt[en auf der Erde gleichermaßen betroffen sind, trifft] die schlechte Sache der Krankheit nicht [einen allein], alle Lebewesenkinder gelangen [zu der schlechten Sache der Krankheit].

IV.

In Zeile B071 steht ein Zusatz in zierlicher Schrift: turur-ta sözlämäk $y(a)_{v l z}$ $s(a) v$ tu[rur] „Stehend sprechen ist eine schlechte Sache.“(?) Das sieht fast wie eine Anweisung bei einer möglichen Rezitation aus. 
V.

B076 hat gegenüber A vor den ,sehr verehrten“ den Zusatz ,die langlebigen‘. A060 agır 大 [ulug] elig-lär] B071 uzun özlüg yaš-lıg agır [ulug elig-lär]

VI.

Während der Text der Zeilen A065-066 köz äsri ... näčä üküš tälim ärsär ymä fehlt, hat B die folgende Variante: B084 üstün-ki aš-ları ičgü-l[äri ] B085 -či-läri näčä öztä nätäg ärsä[r ] „die obigen Speisen und Getränke [...], die [...] wie es bei ihm selbst ist (?)“. Wie dieser Text ergänzt werden kann, bleibt wegen der großen Lücken unklar.

VII.

Ein Zusatz eines Nutzers in B094: kulutı ${ }^{356}$ ligui tutuy ärki tudtum ${ }^{357}$ (A096).

\section{VIII.}

Auf nirvan in A112 folgt in B117-118 eine Ergänzung nirvan-lıg enč orun-ta kä[ ] -in äd-in tavar-in yarıp ya[...] ,an dem friedlichen Ort des Nirvāṇa [...] Hab und Gut spaltend (?)“.

\section{Fragment 12: SI 3874}

129[

Z/?

$130[\quad] \mathrm{t}[$ ] bäg kutı sw//

$\mathrm{Z} /$ ?

$131[\quad] z y(a) r l i g$ bitig anta

$\mathrm{Z} /$ ?

356 Geschrieben: qwlwdy.

357 Späterer Eintrag in der frei gebliebenen Zeile: „Ich, Ligui Tutuy, habe wohl (daran) festgehalten.“ Lesung und Funktion von ärki sind nicht klar. 


\section{J(৫)}

132 (frei)

$133[$ ] ] $\quad$ ]

Z

$134[$ ] bitidim

Z

Es handelt sich bei diesem Abschnitt um eine Art Kolophon, vielleicht auch einfach um einen späteren Eintrag.

\section{Handschrift C}

Der alten Fundortsignatur (T II T 512) zufolge stammt das Fragment Ch/U 7161 aus Toyok. Entsprechend dürften dann die anderen Fragmente dieser Handschrift aus der Serindia-Sammlung ebenfalls aus Toyok kommen, doch gibt es dafür keinen Beleg.

\section{Vorderseite}

Die sechs Fragmente lassen sich einer chinesischen Schriftrolle zuordnen, die eine Abschrift des Weimojie suoshou jing 維摩詰所設經 （T. 475 Vimalakīrtinirdeśasūtra) enthält.

Fragment 01: Ch/U 7161 (T II T 512) = T.XIV.475.545c07-17.

Fragment 02: SI 4319 (Kr I 242) = T.XIV.475.545c14-21.

Lücke

Fragment 03: SI 4210 (Kr I 123) = T.XIV.475.546a06-13

Fragment 04: SI 4457 (Kr I 372) = T.XIV.475.546a05-12.

Fragment 05: SI 4996 (Kr I 421) = T.XIV.475.546a05-12.

Lücke

Fragment 06: SI 4956 (Kr I 10) Fragment in voller Höhe der Buchrolle. Es entspricht T.XIV.475.546a17-28. 


\section{J(৫)}

\section{Rückseite}

In umgekehrter Reihenfolge enthält die Rückseite eine mit wenigen Varianten abweichende Abschrift des altuigurischen Textes von A. Die Schrift auch dieser Handschrift ist kursiv, doch ebenfalls recht deutlich geschrieben.

\section{Fragment 06: SI 4956 (Kr I 10)}

01[

019

02[

020

03 [-lar äy tüpindä karımak üzlünčülüg bolurlar täy]rikän tegin yaratıg]l[1]g

čakiravart] 1duk han ${ }^{358}$

\section{1}

04 [täyrim kutınıท näčä ol anı täg köz äsri könül arv1] bolgu täg mänis ${ }^{359}$ 021/022

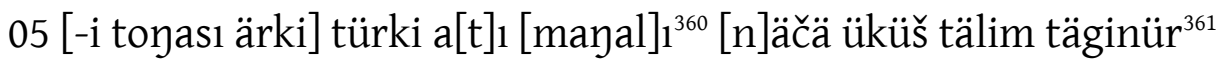
022/023

06 [ärsär ymä tugmak t]örütin ozmamıš üčün karımak törü-tin ymä $023 / 024$

07 [ozmıš kutrulmı̌̌] täginmäz otgurak karımak törü-lüg yarlıkar arıtı karı $024 / 025$ 08 -mayın ${ }^{362}$ tep s[ö]zlä[yü] yarlıkamazun täyrim \{bügü $\}^{363}$ elig täyrim .. ..

\footnotetext{
358 A hat davor noch eliglär.

359 Geschrieben: m’nkyz.

360 A022 ärki türki mäyisi toyası. Vom Platz her sind in B noch weitere fehlende Wörter anzusetzen.

361 In A023 bar ärsär.

362 A025 karımagay ärki män.

${ }^{363}$ Durch Umkreisung wurde der Fehler markiert, denn bügü gehört nicht hierher.
} 


\section{J(৫)}

025/026

09 [y]-a kišatirik tözlüg kinšuk ${ }^{364}$ ärdini gödam ${ }^{365}$ baglıg kümüt lenhu-a $027 / 028$

10 törüyü bälgürä yarlıkamı̌s täyrikän tegin täyrim kutı yarlıkasar 028/029

11 bo ärsär üč toš-lar ${ }^{366}$ bulganmakıntın tört m(a)habut-lar tüzü[ksi] 029

12 -rämäkintin beš agılık-lar bımsıramakıntın altı ordu-lar artamakı[ntın] $]^{367}$ 029/030

13 aš $1^{368}$ ičgüsi ${ }^{369}$ sinmämäkintin azuča ärsär ymä bute ${ }^{370}$ amanuše $e^{371}-l a r$ buu 030/031

14 sigšil almakıntın yäk ičgäk-lär üzä yelpikmäkdin gra[h tokı] 031/032

15 -[mak]tın b[o]guz yigitmäk üzä iglämiš il-kisiztinbärü e[ritil] 032/033

16 -[miš alku] kiši-kä aklatılmıš iglämäk atlıg ${ }^{372}$ išitgäli 033/034

\footnotetext{
364 Geschrieben: kynș̌wq.

365 Geschrieben: kwyd'm.

366 Es folgen zwei getilgte Buchstaben.

367 Geschrieben: " $r d{ }^{\prime} m$ 'qy[ ].

368 Geschrieben: "šyy.

369 A030 aš ičgü.

370 Geschrieben: pwty.

371 Geschrieben: "'m'nwș̌y.

372 Das folgende Wort wurde vom Schreiber getilgt.
} 


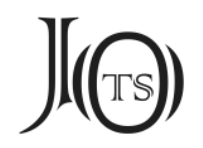

17 [yavız u] tun ${ }^{373}$ törü bo täginür täyrim : :.374

034/035

18 [y-a alku kamag t]ınl(1)g oglan-ları-nıy arasınt[a ayazlı] 035/036

19 [yagızlıča y]intmiš yegädmišs ${ }^{375}$ bodisvt [ugušlug täyrikän tegin] 036/037

20 [täyrim kutı y]arlıkasar . kim bo eritmiš376 [yavız iglämäk] 037

21 [tegli utun törü ärsär] küčüg küsünüg kävip kü<č>sirä[tip ${ }^{377}$ olurgal1] 037/038

22 [turgalı ärgäli 1d]matın aš[ka ičg]ü-kä sa[vka sözkä tapsız] 038/039

$23\left[\right.$ kiltačl $\left._{1}\right] \operatorname{turur}^{378}[\quad]$ 039/040

(Lücke)

\section{Fragmente 05+04+03: SI 4210 + SI 4457 + SI 4996}

24 [arada ymä oot äm tusulmaz adın] až[un]-ka sanlı[g] 045/046

25 [bolur-lar :: bo munı täg osuglug eritilmiš iglä]mäk tegli utun ${ }^{379}$

\footnotetext{
373 Geschrieben: [ ]dwn. Handschrift A034 yavız yel törü.

374 Rest der Zeile frei geblieben.

375 Geschrieben: yyk'tmys.

376 A037 eritilmiš.

377 Hier fehlt der Buchstabe -č-, in der Handschrift A das mediale -s-. In B besteht eine Lücke.

378 A040 täginür.

379 Geschrieben: 'wdwn. In A046 yavı.
} 


\section{$J(\Theta)$}

046

26 [törü muntag bolu täginür tänrim] 僧奴羅 $\mathrm{m}(\ddot{a}) n$ sivtso $^{380}$ 046/047

27 [y-a kapilavastu käntlig mandakini yuuln]uy ičintä hansarač kaz 048

28 [-lar hanı törüyü bälgürü yarlıka]mıš täyrikän tegin ${ }^{381}$ kutı yarlıkasar 049/050

29 [kim bo iglämäk atl(1)g udun] törü yalıuz bo ok tınl(1)g-ka kälmiš 050/051

30 [täginmäz ${ }^{382}$.. alku kamag kiši]lär-kä tüzü-kä bir täg kältäči 051/Z

31 [täginür ${ }^{383}$.. kaltı nätäg] öydün yınak-tın ulug kay-a ta[g yorıyu] 051/052

32 [kälsär] üstün ${ }^{384}$ uč $1^{385}$ kök [kalık] birlä tutč1 [altın] 052

33 [tüpi yag]1z bilä tutčı . [üstün] učugma altın [bagırın] 053 34 [yorıgma tınlıg]larıg bir kalısız yančar yum[urur ärsär]

380 Dieser Eintrag im freigebliebenen Raum dieser Zeile umfaßt einen Namen in chin. Zeichen 僧奴羅 sengnu luo ,Luo, Sklave des Samgha‘ sowie einen in uig. Schrift: Sivtso, vgl. Matsui 2004.

381 Auf dem Foto sieht es aus, als ob ein zwischenzeiliger Eintrag $t^{`}$ vorliegt. Dies ist aber durchscheinend von der Vorderseite chin. 欲.

382 Nachfolgender Satz ist Zusatz gegenüber A 051.

383 Der Satz [alku kamag kiši]lär-kä tüzü-kä bir täg kältäči [täginür] ab dieser Stelle steht nicht in der Handschrift A.

384 Geschrieben: [ ]ysdwn.

385 A052 kapigl. 


\section{J(৫)}

$053 / 054$

35 [ančulayu ok ymä] bo iglämäk atl(1)g utun ${ }^{386}$ törü ädg[ü yavız]

054/055

36 [bay čıgay temätin alkuka barča bir kalısız bir täg käl]däči täginü[r tänrim]

055/056

(Lücke)

\section{Fragmente 02+01: SI $4319+\mathrm{Ch} / \mathrm{U} 7161$}

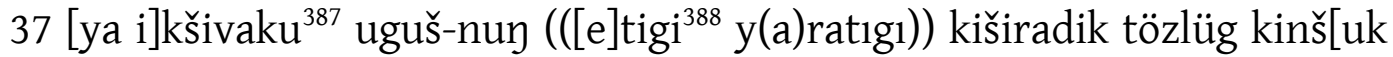
ärdini törüyü]

069/070

38 [b(ä)l]gürä yarlıkamıš t(ä)yrikän tegin t(ä)yrim kutı y[arlıkasar kim bo]

070/071

39 [kim bo tört] kiši-lärkä kötürtmiš ${ }^{389} \mathrm{t}[1 \mathrm{~ns}$ sz] d[iravi-ka okšat1]

071

40 [äd ärsär alku] kamag kasıntın ${ }^{390}$ kadaš-1ntın ${ }^{391}$ [adı]rılmıš a[ta ana]

071/072

41 [kiši ogul kıztın] öni ${ }^{392}$ ödrülmiš . [yašagul]uk-1 yitmäk ${ }^{393}$ üz[ä]

386 Geschrieben: 'wdwn.

387 Die Schreibung in A69 ist ' $y k s y v^{\prime} k w$, hier jedoch ['y] $k$ šy $y v^{\prime} q w$. Da auch in anderen Fällen die Schreibung mit <k>, nicht <q> überwiegt, sollte man hier einen Fehler annehmen. Zur generellen Repräsentanz vgl. Röhrborn 1988.

388 Geschrieben: [ ]dyky.

389 Geschrieben: kwytwrdmys.

390 Geschrieben: q'zyntyn.

391 Lesung etwas undeutlich wegen Zerstörung des Papiers.

392 Geschrieben: 'wynky (der Abstrich des k kreuzt sich mit einem finalen y).

393 Handschrift A: ärtmäk. 


\section{J(৫)}

$072 / 073$

$42[\quad] y^{`}$ sw [ ]mak üzä anityat ${ }^{394}$

?/Z

43 [ yalyuk yertinčüsindäk]i ädin tvar-1n ärkin

074

44 [türkin ärksizin titip ıdalap alku nomlar]nıy ürlügsüzin ukıtdačı 074/075

45 [ölüm atlıg ülügsüz törü bo tägin]ür tᄁrim ::

075/076

46 [y-a iki adaklıglarnıy ayaguluk]ı töpürä tülüg tınl(1)g 076/077

47 [oglanlarınıy tönütgülüki bolu yarlıkamıš y(a)r]lıkamıš t(ä)Đrikän tegin 077

48 [täyrim kutı yarlıkasar bo ymä tı bolmı]š törü täginür . näčä

078

49[]$^{395}$-tä tugum ažun tutsar ${ }^{396}$

078/079

50 [tokuz ay on kün ög karınta] solanıp olurur . birär 079

51 [-läri ög karınta ok ölürlär . näčä]dä adasızın [äsä]n 080

\footnotetext{
394 Geschrieben: "nydy't.

395 Unklar, wie die Lücke gefüllt werden kann.

396 Geschrieben: $t w d s^{3} r$.
} 


\section{J(৫)}

\section{Handschrift D}

Es liegt aus dieser Handschrift nur ein Fragment aus der SerindiaSammlung vor: SI 5594 (Kr IV 267).

\section{Vorderseite}

Die chinesische Vorderseite enthält einen Abschnitt aus dem 妙法蓮花經 Miaofa lianhua jing (T. 262) mit der Entsprechung T.IX.262.43c01-43c22. Diese chinesische Handschrift unterscheidet sich sehr deutlich von dem unter B zusammengestellten Manuskript, weshalb anzunehmen ist, daß es sich um zwei verschiedene Buchrollen handelt. Für einen Großteil der Kolumnen ist die volle Buchrollenhöhe erhalten.

\section{Rückseite}

Die Zeilen des Textes auf der Rückseite sind, zumindest an den Stellen, wo die volle Buchrollenhöhe vorliegt, fast vollständig erhalten. Die Übereinstimmungen mit der Handschrift A betreffen nur den Rahmen, nicht aber die Expositionen in den drei Alter-Abschnitten von A. Deshalb sollte man annehmen, daß also mindestens noch zwei Alter-Abschnitte, die in dieser Handschrift D dokumentiert sind, vor den Beginn der Handschrift A zu stellen sind. Dem steht allerdings entgegen, daß mit Z. 26 ein Abschnitt beginnt, der in der Handschrift A der Z. 069 gleicht: $y$-a ikšivaku uguš-nuy etigi yaratıg-ı, mit welcher der Abschnitt Tod-1 beginnt. Da die Reihenfolge Alter - Krankheit - Tod jedoch kaum veränderbar sein dürfte, ist wohl anzunehmen, daß der Abschnittsanfang sich auch wiederholen konnte.

\section{Text}

$01 / /$ kämiš sävinč-lig akm[1] šs s[uv]-1[ar] baš-1[ar] y[uu]l-1[ar ]

$02 / / y^{397}$ tökünü tökünü üšütü ${ }^{398}$ turur $^{399}$ kar kır(a)gu buz boran

\footnotetext{
${ }^{397}$ Das finale $<y>$ könnte das Possessivsuffix zu den voranstehenden Nomina sein.

${ }^{398}$ Geschrieben: 'wyswdw.

399 Lesung unklar.
} 


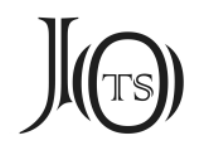

03 -[la]r üzä iki otuz intiri-lıg hu-a-ların čǎčäk-lärin

04 säkiz türlüg yertinčü-lüg nom-lug yap-ların yavıšgu-ların 05 kurıttač ${ }^{400}$ bo karımak tegli utun ${ }^{401}$ törü bo bir tınl(1)g-ka

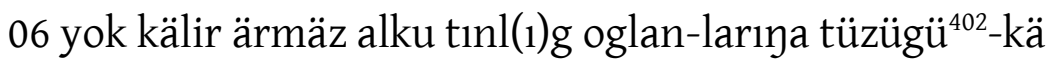
07 [bir] täg kälü̈ ${ }^{403}$ täginür t(ä)yrim m(ä)n b[ ] ] 08 [ü]č uguš yertinčü-lüg karangu ič[intä ] 09 [ ]n kišadirik tözlüg yaruk yula törü-yü [bälgürä ] ] 10 [tän]grikän tegin $\mathrm{t}(a ̈) \eta n r i m ~ k u t{ }^{405} \mathrm{y}(\mathrm{a})$ rlıkasar kim inči[p ] $]^{406}$ 11 kar(1)tmıš kavrılu sın-mıš kamag-ta yavız kan-lıg yin-li[g] 12 ärip ${ }^{407}$ karak-nıり kart1 ${ }^{408}$ bolmıš körgäli körksüz kad kadalur ${ }^{409}$ 13 ///sav bolmıš ön-lüg mäyiz-lig adınsız čerlig äninčig ya/// 14 [yap]ranmıš oprak ton-lug kädim-lig akarıp a[ ] 15 [//]y yar yagmakı üzä ölitilmiš šılatılmıš [ 16 [ä]mgänü sıkılu öttürmäki (?) [üz]ä ärkälänü (?) titrü 17 [ ]ıgu tugrı sav-lıg sözlüg ärip ägilmiš bükrilmiš sın 18 -lıg sünük-lüg yakın elintä (?) almıš tayak-lıg kamč[1] 19 [-1] Ig t(a)šarati ((tona)) bälgürü tašıkaru közünü ${ }^{410}$ tälmirip tugu///

\footnotetext{
400 Geschrieben: qwrydt'̌xy.

${ }^{401}$ Geschrieben: 'wtwn.

402 Gedschrieben: twyswkw.

403 In Z. 25 mit deutlicherer Schreibung: kälü.

404 In Z. 07 steht im frei gebliebenen Raum ein Eintrag eines Lesers: $m(\ddot{a}) n b[$ ],Ich, B[ ]’.

405 Geschrieben: $q w d y$.

${ }^{406}$ Hier ist die Zeile nicht vollständig, mindestens ein Wort ist in der Lücke anzusetzen.

407 Oder akıp?

${ }^{408}$ Geschrieben: $q^{\prime \prime} d y$.

409 Unklar, vielleicht, geschichtet" mit einer unklaren Herleitung von kat ,Schicht‘.

${ }^{410}$ Geschrieben: kwyswnw.
} 
20 /// sinir-lig ärip täy-tä ädgü tartıg-lig s[ ] ]

21 [ya]d sav-larıg äš(i)dmäk-tin tartmıš ${ }^{411}$ ramıš kulgak kačig

22 [b]olmak-ta ulatı ${ }^{412}$ kamag-ta körksüz ämgäk-lär-nin b[ ]

23 bolmıs . bo munı täg osuglug asıgs[1z karımak tegli]

$24[\mathrm{u}]$ tun törü täyrikän tegin t[änrim ]

25 [ ] kälü täginür sezinü ${ }^{413}$ yarl[1kamazun täyrim ]

[?]

26 [ya ikš]ivaku uguš-lug [ ]

\section{Übersetzung}

[Alter]

(01-07) Diese Alter genannte verruchte Sache, die durch Schnee, Reif, Eis und Kropf - die die fließenden Wasser und Bäche [und Seen] der Freude gleich sprudelnd kühlen ${ }^{414}$ - die Blumen und Blüten der 22 indriyas ${ }^{415}$ sowie Blätter und Zweige der achtfachen weltlichen Dinge ${ }^{416}$ vertrocknen läßt, ist nicht etwas, das zu einem Lebewesen kommt, sie kommt zu allen Lebewesen gleichermaßen. Mein Fürst!

[Alter]

(08-25) Wenn die Majestät der Fürstlichen Prinz-Hoheit, die in der Dunkelheit der dreifachen Welt [...] als helle Leuchte aus dem kșatriya-Stamm entsteht und hervorkommt, es anzunehmen geruht, dann ist es so: Diese derartige unnütze Sache des Alters, (11) die verursacht, daß man alt wird, gepreßt und zerbrochen, allerschlimmst blutig und

${ }^{411}$ Geschrieben: t'rdmys (?).

${ }^{412}$ Geschrieben: 'wl'dy.

${ }^{413}$ Geschrieben: sysynw.

${ }^{414}$ ED: 258b.

${ }^{415}$ Vgl. SH: 21-22: (二十二品)二十二根 The twenty-two roots, organs or powers [indriya, vgl. DDB]: Auge, Ohr, Nase, Zunge, Körper, Geist (=6), männlich, weiblich Leben (=3); Freude, Leid, Vergnügen, Sorge, Freiheit (=5); Glaube, Anstrengung, Bedachtsamkeit, Konzentration, Weisheit (=5); Was zu wissen ist, was gewußt wird, Wissen von beidem (=3). Vgl. Dayal 1932: 141-145; Skilling 2012.

${ }^{416}$ Das sind die acht weltlichen Dinge (Skt. aștalokadharmāh, vgl. DDB); T.XXVI.1536.0442c28-0443a01: 八 世法者云何爲八. 答一得二不得三毀四譽五稱六譏七苦八樂. 云何名得. 答若於可愛色聲香味觸. 衣服飲食臥具病縁. 


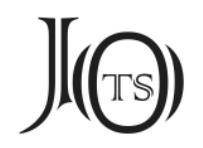

schleimig, (durch) ein Geschwür des Augapfels häßlich anzusehen, geschichtetes (= faltiges) Antlitz und Gesicht, besonders schwachsichtig ${ }^{417}$, mit erschreckend ${ }^{418}$ (14) zerrissenen Kleidern, weiß gewordenen [...], (15) durch das Regnen von //y Speichel befeuchtet und genäßt $\mathrm{t}^{419}$, [...] durch das Leiden und Gequält-Sein ${ }^{420}$ beherrscht, (selbst der) mit genauen (17) [...] korrekten Worten und Aussprüchen habende, mit gebeugten und gebückten Gliedern und Knochen, (18) Daśaratha Held ${ }^{421}$ mitgenommene Stöcke und Peitschen habend erscheinend und nach außen präsent seiend, blickend ... (20) mit [...] Sehnen seiend, in der Waage mit guten Gewichten, (21) vom Hören der s[ ] und [fremd]en Worte gezogen und entfernt, mit dem Ohr-Organ beginnend (22) der allerhäßlichsten Leiden [Ursache] geworden ist, kommt zum Täyrikän Tegin [wie auch zu allen anderen]. Er möge nicht daran zweifeln, Täyrim!

[?]

(26) [0] aus dem Ikșvāku-Stamm [seiender ...]

Kommentar zu 02 boran ,Schneesturm ‘ ${ }^{422}$

(a)

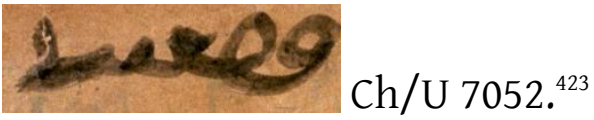

(b)

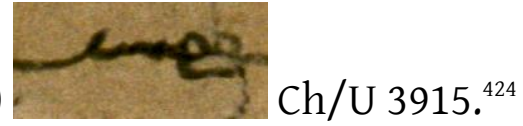

${ }^{417}$ ED 429b čärlig,with weak sight‘.

${ }^{418}$ Meist im übertragenen Sinn gebraucht, erstaunlich, frappierend', Vgl. UWN II: 212.

${ }^{419}$ Angesichts von ölitilmiš šlatıllmıš scheint Hedin 1953.52.0013v40 šllalıp (Wilkens 2017, 218) ein alter Fehler für šllatilıp zu sein (vgl. Hedin 1953.52.0013v48 ölitilmäk šllatılmak), doch Passiv vom transitiven Verb šlla- ist šlla-l-. Da öli- aber intransitiv ist, ist das Passiv öli-t-il- notwendig, während neben šllalfakultativ auch šllatıl- möglich ist, vgl. Hedin 1953.52.0013v48 ölitmäk šlamak.

${ }^{420}$ Eine Lesung wie ötüntünmäk ist unmöglich.

${ }^{421}$ Vgl. BT 37: (00469-00471) „(Aber) es kam der Dämon des Todes und der Zeit herbei und unterwarf sie selbst.“ (00471-00479) „Unter den [ver]blendeten Helden Rāma, Lakșmaṇa, Bharata und Śatrughna, Söhne des Königs Daśaratha, vereinigten sich Rāma und Lakșmaṇa mit ihren Leuten, und als sie das zehnköpfige Oberhaupt der Dämonen, Daśa[grīva], Herr der Stadt Lan̉kā, augenblicklich am Himmel fliegend erblickten, da töteten sie die Dämonen, rākșasas und Titanen wie Nikumbha, Kumbhakarṇa, *Prahasta und Indra[jit] und andere."

${ }^{422}$ Für das Osmanische/Türkeitürkische vgl. TETTL I: 762 borağan/boran/buran ,kasırga, sağanak, sis;; nach Stachowski 2019: 90b bedeutet osm. boran ,Sturm, Gewitter', doch wird auch trkm. bora- ,stark schneien` zitiert, womit sich die Bedeutung ,Schneesturm` rechtfertigen läßt.

${ }^{423}$ Tezcan-Zieme 1994.

424 Zieme 2013: 676. 
(c)

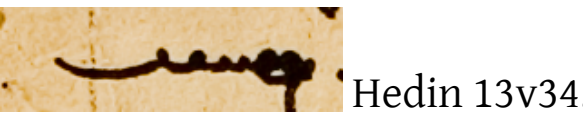

(d)

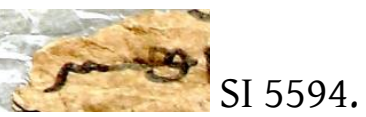

Nach Prüfung dieser Belege erscheint es mir angebracht zu sein, für alle Fälle das Wort "Schneesturm" anzunehmen, das in den alttürkischen Wörterbüchern noch nicht vorkommt. Am deutlichsten ist in (a) und (d) pwr’n zu lesen, während für (b) und (c) auch pwqr’ möglich wäre.

\section{Handschrift E}

\section{Vorderseite}

SI $4762(0$ 102) + SI 5803 (3Kr 20/5), zwei direkt zusammengesetzte Fragmente aus einer chinesischen Schriftrolle des Suvarnaprabhāsasūtras in der Dharmakșema-Version (T 663) ${ }^{425}$.

\section{Rückseite}

Die Rückseite enthält einen altuigurischen Text, der dem Abschnitt Alter-2 vergleichbar ist. Man könnte meinen, es handele sich um eine Variante, in die ein Beispiel eines Wandels vom starken Jüngling zum Greis eingeflochten ist. Wenn man von den Zeilen 15-16 ausgeht, muß man annehmen, daß für die Niederschrift die volle Höhe der Schriftrolle auch auf der Rückseite verwendet wurde. Dieser Umstand macht es unmöglich, eine zusammenhängende Übersetzung zu geben.

\section{Text}

SI $4762+$ SI 5803

01[ ]-1[1]g sävi[

$02[$ ] ] kara] sačlıg sakallıg yımrak [

009

03 yipün čivšig yüüz mäniz-lärin [

${ }^{425}$ T.XVI.663.338c12-24+c25-339a4. 


\section{J(৫)}

011

$04[\mathrm{k}]$ esari arslan hanı täg sünük-lü[g ]

05 bo är yonamat tegmä türk yigi[t

06 yayılmak-ın yayılip yamakalyan[ ]

07 [ ]yk adınčig muyaddınčıg ${ }^{426}$ ya[ ]

08 yakturu uz 1 dilmak $^{427}$ yavilu b[ ]

09 yag1lig yigit kičig ${ }^{428}$ iš tuš [ ]

10 yenik korku k1lık ärig-lig yi[ ]

11 kenki mänilig yitgünäyin $\mathrm{t}[$ ]

12 barčanı ok m(ä)n täginäyin temiš [ ]

13 öyingä mänizinä küvänü kö[ ]

$14[. .$.$] bal[1] \mathrm{km}$ š $^{429}$ iš tuš-lar bil[

15 [k1l]ınmagu-larıg k1lınu kılınmak kılık-1[ı ]

16 üdüg ${ }^{430}$ kolug ärtürü täginür ärti ärig-lig bo [ ]

17 törü bo är-nin türk igit bolma[k1 ]

18 tözintin ${ }^{431}$-bärü kitip katk1 [ ]

19 -ta yüp yürün tiš-lärin azıg[ların ]

010

20 agulug karımak-lig [ ]

$013 / 014$

\footnotetext{
${ }^{426}$ Geschrieben: 'tynčyq mwnk'tdynčyq.

${ }^{427}$ Geschrieben: 'ytylm'q.

428 Oder: käčig?

429 Unklar.

430 Geschrieben: 'wytwk.

${ }^{431}$ Geschrieben: twysyntyn.
} 


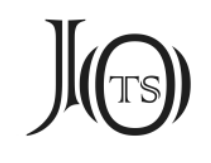

Wegen karımak ,Alter' kann man eine Variante zu einem Abschnitt dieser Kategorie annehmen. Da es abgesehen von den Zeilen um 009-014 so gut wie keine direkten Übereinstimmungen mit der Handschrift A gibt, könnte es sich auch um einen vorangehenden Passus über das Alter handeln, der in der Handschrift A fehlt.

\section{Übersetzung}

(01-05) [...] der [...], beliebte [...], [schwarze] Haare und Bart tragende, liebliche [...], einen einem violetten Pfirsich gleichenden Teint und Gesichtsfarbe [habende einem kesarin Löwen gleichende Knochen habende [...] Yonamat (?) genannte kräftige Jüngling [...] (06) wird durch Irrtümer irrend wie Yamakalyan[i von besonderen und erstaunlichen [...] (08) betroffen, das Geschick verlierend ${ }^{432}$ schwach werdend [...] (09) feindlich kräftig kleine Freunde [...] (10) Leichtfertigkeit ${ }^{433}$-Charakter habend [...] ,,ich will Freude verlieren“ [...] (12) „das alles will ich erlangen“ [...], (13) auf Farbe und Teint vertrauend [...].

(014) mit verwundeten (?) $)^{434}$ Freunden und Kameraden [...] (15) das Nicht-Zu-Verrichtende tuend und das Zu-Verrichtende Charakter [...] (16) die Zeit verbringend hat er schwer [ ist ] (17) das Gesetz (die Sache).

(17-18) Dieses Mannes Jugendlich- und Kraftvoll-Sein [...] (18) ist von Grund auf vergangen, stark [ seine] schlohweißen Zähne [ gelb werden lassend] ist des giftigen Alters [Sache].

\section{Kommentar}

Hier sind zwei Bezeichnungen für kräftige Jünglinge aus indischem Milieu belegt. Obwohl die Lesung im ersten Fall klar ist, bleibt die Etymologie unsicher. Es gibt mindestens zwei Lösungswege. Der erste wäre wie folgt: Wenn man den ersten Teil $y w n^{\prime}$ als yona ${ }^{435}$, den zweiten $m^{2} t$ als Suffix annimmt, käme man auf Yonamat < *Yauvanama(n)t < *Yavanamat, sofern yona für yauvana stehen

\footnotetext{
${ }^{432}$ Eine noch unklare Bildung verbirgt sich unter uz ıdılmak.

${ }^{433}$ Vgl. Zieme 2020a: 157.

434 ED: 337 a.

${ }^{435}$ Eine umfangreiche Studie zum Problem ist Karttunen 2015: bes. 325 ff.
} 


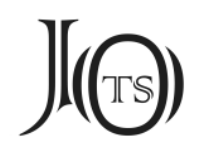

könnte. Läßt man einen yavanamund $a^{436}$ für einen jungen Griechen ohne Bart außer Betracht, wäre * Yauvanamat als Pendant zu belegtem Yauvanava(n)t ${ }^{437}$ eine passable Möglichkeit. ${ }^{438}$ Der zweite Weg geht von skt. yoni ,Geburt' aus, wobei das mittlere Aliph in $y w^{\prime} n^{\prime} m^{\prime} t$ im Wege steht, denn man sollte eine Schreibung *ywnym't erwarten. Der zweite Teil indes paßt gut zum Suffix \{-mat\}. Sanskrit yonimat bezeichnet jemanden, der aus einem guten Mutterleib gekommen ist ${ }^{439}$.

Es scheint, daß mit dem zweiten Namen das Gegenteil zum Ausdruck gebracht werden soll, zumindest wenn man von yama ,Tod ${ }^{440}$ ausgeht. Eine zufriedenstellende Lesung dieses Namens steht aber noch aus.

\section{Handschrift F}

\section{Vorderseite}

Die sechs Bruchstücke Ch/U $8187+\mathrm{Ch} / \mathrm{U} 8199+\mathrm{Ch} / \mathrm{U} 6023$ (T II 4080) (Lücke) Ch/U 6446 (T I x 554) + Ch/U 6205 (T I x 559) + Ch/U 6353 (T I x 544) ${ }^{441}$ entstammen einer Rolle mit der Abschrift der chinesischen Version des Mahāyāna Mahāparinirvānasūtra. ${ }^{442}$

\section{Rückseite}

Der chinesischen Vorderseite folgend ist es möglich, die Reihenfolge der Fragmente zu etablieren. Weil alle Fragmente von der unteren Hälfte der chinesischen Buchrolle stammen, ist anzunehmen, daß zur Niederschrift der Rückseite nicht die volle Höhe der Buchrolle genutzt wurde, sondern nur die

\footnotetext{
${ }^{436}$ Skt. Yavanamunda, bald Y[avana], one with a shaven head' (MW: 848a).

${ }^{437}$ MW: 859b: possessing youth, young, youthful'.

${ }^{438}$ Nach einem Vorschlag, den mir freundlich Dieter Maue übermittelt hat.

${ }^{439} \mathrm{MW}: 858 \mathrm{c}$, connected with the womb, sprung from a womb; descended from a good racec.

${ }^{440}$ MW: $846 a$, rein, curb, bridle؛.

${ }^{441}$ Für die Hilfe bei der Zusammenstellung dieser Bruchstücke danke ich Simone-Christiane RASCHMANN. Vgl. auch ihre Eintragungen in KOHD Digital.

${ }_{442}$ Die ersten drei Fragmente entsprechen der Passage T.XII.374.381c08-c25 // T.XII.375.621b20-c09, nach einer Lücke von 14 Kolumnen bilden die folgenden drei Fragmente einen weiteren zusammenhängenden Teil: T.XII.374.382.a12-a26 // T.XII.375.621c23-622a08.
} 


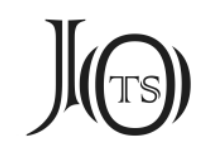

untere Hälfte. Da jedoch keine zusammenhängenden Zeilen herzustellen sind, bleibt die Lokalisierung schwierig. Möglicherweise liegt eine verkürzte Variante vor. Immerhin ist zweimal (17 und 22) vom Alter die Rede, woraus hervorgeht, daß der erste Teil der Handschrift zu dieser Kategorie gehört, wahrscheinlich aber in anderer Abfolge als in der Handschrift A. Für den zweiten Teil (24-44) ist dann eine Parallele zu einem Passus über Krankheit anzunehmen.

\section{Erste Passage}

\begin{tabular}{|c|c|c|}
\hline \multicolumn{3}{|c|}{$\mathrm{Ch} / \mathrm{U} 8187+\mathrm{Ch} / \mathrm{U} 8199+\mathrm{Ch} / \mathrm{U} 6023$} \\
\hline 01[ & ] kılınč-nıy öz yat [ & ] \\
\hline 02[ & \multicolumn{2}{|c|}{ t]örüyü b(ä)lgürü y(a)rl[1kamıš] } \\
\hline 03[ & ]guluksuz ädgü-lüg [ & ] \\
\hline 04[ & ] sansar $-\mathrm{n} 1[\mathrm{y}$ & ] \\
\hline 05[ & ] küč-lärin [ & ] \\
\hline 06[ & ]ıg bäg-kä a[ & ] \\
\hline 07[ & ]durtačı. ka[ & ] \\
\hline 08[ & ]n sıgtaturtačı k[ & ] \\
\hline 09[ & ] ünä kälmiš qw[ ] t & g küp ediz \\
\hline 10[ & ]y yürünädtürtäči kar & g yürüy \\
\hline 11[ & ]si tüšürdäči . katk1 ${ }^{443}$ & väz sın-ların \\
\hline
\end{tabular}

012

12 [sünüklärin ägril]dürtäči kamag-ka säviglig asıg-lıg 012

${ }^{443}$ Geschrieben: q'dqy. 


\section{$J(\Theta)$}

13 [

]ürüldürtäči . katuru ${ }^{44}$ ग[ [ ] $]^{445}$ kördäči

14[

]miš täg körür kıldačı adrok tılayu

15[

] ičintä ${ }^{446} \mathrm{a}$ [ ]ndäči kälmädük üd

$16[$-tä

k]arımak-lıg kar kıragu üzä baș̆ıra

17[

] yavız karımak tegli utun ${ }^{447}$ törü bo

014

$18[\text { täginür täyrim ..] }]^{448}$

19[

]k-1 üzä ${ }^{449}$ sörpp $^{450}$ kadıg (šaki-lıg) sünüšč[i]

20[

]v bahšı bolu y(a)rlıkamıš t(ä)yrikän tegin

21 [täyrim

] bo yal(a)yuk ymä iki türlüg bolu täginür

22[

] köyül-nüy karımak-1 . ätöznüy

23 [karımakı ärsär

]gu turur küči-nin küsüni

(Vorderseite: Lücke von 14 chinesischen Kolumnen)

\section{Zweite Passage}

Ch/U $6446+\mathrm{Ch} / \mathrm{U} 6205+\mathrm{Ch} / \mathrm{U} 6353$

24[

] tarıkmıš . [

${ }^{444}$ Geschrieben: $q^{\prime} d w r w$.

${ }^{445}$ Unklar.

446 Unklar.

447 Geschrieben: 'wdwn.

${ }^{448}$ Rest der Zeile frei geblieben.

449 Unklar.

450 Oder sürp (wie in HT V: 1911). MK hat ein Verb sörplä- in dem Beispiel ol ärnäk bilä sörplädi „he drew a lot with his finger“ (ED: 845a). Clauson writes: ,the basis otherwise unknown“. In HT V: 1911 gibt es die Wendung ärtinü kadır bil[gä] sürp alplanmaklı, Attribute, die den Chan von Khotan charakterisieren: „Der Chan von Chotan ist sehr kriegerisch, weise und tapfer “" (HT V: 207) = chin. T.L.2053.0251a13 其王雄智勇武 wo xiongzhi, outstandingly wise‘ wurde durch ärtigü kadır bil[gä] , sehr mächtig weise‘ wiedergegeben, während yongwu ,tapfer und martialisch' sürp alplanmaklıg , *tapfer und heldenhaft' entspricht. 


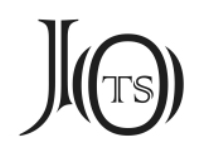

\begin{tabular}{|c|c|c|}
\hline 25[ & \multicolumn{2}{|c|}{ kü]süš-lüg · /[ } \\
\hline 26[ & \multicolumn{2}{|c|}{ ] ätözlüg . [ } \\
\hline 27[ & \multicolumn{2}{|c|}{ ] turur sav [ ] -1[ig] } \\
\hline 28[ & \multicolumn{2}{|c|}{ ] yarsınčıg yavız köyli .. } \\
\hline 29[ & \multicolumn{2}{|c|}{ a]dak-1 . ayupa ${ }^{451}$ tegmä isig } \\
\hline 30 [öz berdäči & \multicolumn{2}{|c|}{ ] čivake-[d]a ulat $1^{452}$ otačs ${ }^{453}$-lar } \\
\hline 31[ & \multicolumn{2}{|c|}{ ]K y(a)lyuk bo täginür $\mathrm{t}(\ddot{a})$ yrim } \\
\hline 32[ & \multicolumn{2}{|r|}{ ]/d' siti-lig } \\
\hline 33[ & \multicolumn{2}{|r|}{ yarlıka]mı̌̌ t(ä)yrikän } \\
\hline 34 [tegin täyrim & yarlıkasar & b]olu täginür-1[är] \\
\hline 35[ & & ] ičtin sınark1 \\
\hline 36[ & & ]/-nynk : ikinti taštın \\
\hline $37[$ sinark1 & & ]/d’ nynk . yaz üd \\
\hline 38 [-lärtä & & ]/ : k[ü]z üd-lär-tä \\
\hline 39[ & & üdlär]tä törčiyür \\
\hline 40[ & & ] bulganur sanipat \\
\hline 41[ & & ]-nynk ayıg \\
\hline 42[ & & ] türlüg iglär käm \\
\hline $43[-$ lär & & ] \\
\hline 44[ & & eligli]g bäglig \\
\hline
\end{tabular}

\footnotetext{
451 ayupa < skt. āyuhpati, presiding over longevity‘ (MW: 148c).

${ }^{452}$ Geschrieben: 'wl'dy.

${ }^{453}$ Geschrieben: 'wd'čy.
} 


\section{$J(\Theta)$}

\section{Übersetzung}

[Alter-0]

(01-18) [...] der Tat (?) eigenes und fremdes [...] zu erscheinen geruhend [...] un[ermeßlich] gutes [...] des samsāara [...] ihre Kräfte dem [...] Bäg [...] weinen lassend [...] emporgekommener wie ein weiß werden lassender Alter weiße [Zähne ] ausfallen lassend, (11) die starken und stolzen Glieder [und Knochen krumm] machend ${ }^{454}, \quad[\ldots]$ von allen geliebter, nützlicher [...] krümmend, hart werden lassend, [...] sehend,[...] wie ein [...] sehenden macht es. Besondere Redekraft [...] in der zukünftigen Zeit mit dem Schnee und Reif des Alterns auf den Kopf [fallend ...] - das ist die schreckliches Alter genannte abscheuliche Sache. [Mein Fürst!]

[Alter-1]

(19-23) Wenn die Majestät der Fürstlichen Prinz-[Hoheit], die unter allen tapferen und harten śākyahaften Kämpfer[n der herausragende] Meister ist, [es anzunehmen geruht, dann gibt es bei diesen Geschöpfen zwei Arten: des [Körpers Altern und] des Sinnes Altern. [Was das Altern] des Körpers [betrifft, ] der Kraft und Stärke [nehmen ab ].

(Lücke)

[Krankheit]

(24-31) [...] herausgekommen, [...] mit dem Wunsch [...] mit einem [...] Körper, das [...] Wort [...] sein schrecklicher, schlechter Sinn [...] sein Fuß (?). Die Ärzte, angefangen mit dem ayupa genanntes Leben [bringenden ...] Jivaka [sind ...] Geschöpfe. So ist es, mein Fürst!

[Krankheit]

[Wenn die ? ] siddha-[Kraft habende Majestät der] Fürstlichen [Prinz-Hoheit gnädig zu sein geruht, dann] ist es so: [Erstens ... ] innen befindliche [...], zweitens außen [befindliche ...] [in den] Frühlingszeiten ...] in den Herbstzeiten [...] in den [... Zeiten] zerstört ... vermischt, samnipata [...] schlechte [...] Arten von Krankheiten [...] König-[...]

In der Anordnung des Textes in dieser Handschrift gibt es gravierende Unterschiede zur Handschrift A.

${ }^{454}$ A012: „läßt ihre festen und stolzen Gebeine und Knochen krumm und gebückt werden“. 


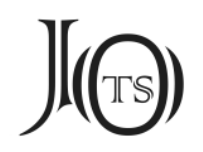

Der Abschnitt 19-23 ist mit Sicherheit dem Thema ,Alter` zuzuordnen und entspricht am ehesten Handschrift A, Abschnitt Alter-1, und zwar müßte er direkt an den Anfang gestellt werden, denn er handelt von den zwei Arten des Alterns, dem Altern des Körpers und dem Altern des Sinnes. Hier ist der Anfang vorhanden, in A fast nur der zweite Teil (Altern des Sinnes). Wenn dem so ist, sollten die Zeilen 01-18 vorangehen, doch in ihnen geht es ebenfalls um das Alter. Das bedeutet, daß am Anfang des Textes mehr Abschnitte zum ersten Thema Alter standen als die Handschrift A erkennen läßt.

Auf die größere Lücke folgen Abschnitte über die Krankheit. Auch in diesen kann man keine genauen Übereinstimmungen mit der Handschrift A feststellen.

\section{Handschrift G}

\section{Vorderseite}

Die drei Bruchstücke Ch/U 6834 + Ch/U 6087 (T II Y 39) + Ch/U 6864 (T II 740) können direkt zusammengesetzt werden, sie stammen aus einer Abschrift des chinesischen Mahāyāna Mahāparinirvāṇasūtra ${ }^{455}$.

\section{Rückseite}

Der Text der Rückseite enthält eine von A stark abweichende Version.

\section{Text}

Ch/U $6834+$ Ch/U 6087 (T II Y 59) + Ch/U 6864

01 šaki tözlüg altun-lug $\mathrm{t}[$

02 arslan hanı [tör]üyü b(ä)lgürü yarlıka[mıš ... täyrikän tegin]

03 t(ä)yrim kutı y[ar][[1kas]ar bo ärsär [ ]

04 küsänčig körklä kün ay t(ä)y[rilär ]

05 bätürdäči sudu hu-a-sıya okš[atı ]

06 -üg p(a)ramanu tözlüg kögüš öyl[üg ]

${ }^{455}$ T.XII.374.584a25-b15 // 375.831c21- $832 \mathrm{a} 15$. 


\section{J(G)}

07 <bürmäk-tä>>56 bašlap altı kačig-lar [

08 -ların tıdtačı särgürdäči . ölüm teg[mä törü alkuka käl] 09 -ü täginür $\mathrm{t}(a ̈)$ yrim ::

(09) kamag tınl(1)g [

10 -larınta äninlärintä kötürgäli elt[gäli

]

11 bodistv uguš-lug čintamani ärdini töz[lüg

]

12 yarlıkamıš täyrikän tegin $\mathrm{t}(a ̈) y r i m ~ k u t[1$ yarlıkasar]

13 bo anityat törü ärsär učmak kalımak-ta [ulatı küü]

14 kälig ädräm [är]k-lärin körkitmäk [

15 ašay köyül arvı bolgu täg äsrinü körk[ ]

16 -ları üzä kop-tın sıyar körgäli sä[//]g[ ]

17 ozmak kutrulmak küsüš-lüg tınl(1)g-1[ar ]

18 türlüg kalpavrkaš sögüt [ ]

19 bolsar [///] takı nä [ ]

20 [ ]ny-nynk ölüm [ ]

21 ] bo ölüm te[gmä ]

22 [ ]miš kälir '[ ]

$23[\text { ] }]^{457}$ kälü täg[inür ]

24 [nä]čük ol azmıš munm[ı̌

25 bodistv uguš-lug [ ]

$26 \mathrm{t}($ ä) yrikän tegin t[äyrim kutı yarlıkasar ]

27 tıkkın tügünkä okš[atı ]

${ }^{456}$ Getilgtes Wort.

${ }^{457}$ An dieser Stelle stehen Reste von Wörtern [ ] ] $k / /[\quad$ ]wr in kleinerer Schrift in zwei Kolumnen, oder liegt eine Textkorrektur vor? 


\section{$J(\Theta)$}

28 ärip tirig ät’özl[üg ]

29 titrü körgüsüz $z^{458}$ turu [ ]

30 1gač täg yagız ye[r ]

31 kamag šazın sav[ ]

$32[$ ]dači $[$ ]

$33[$ ]ny amirtg[ur ]

34 [ ] antirabav [ ]

35 [ ]ywn buyani [ ]

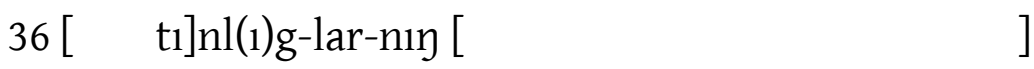

37 [ ] orun-larinta [ ]

$38[$ ]

\section{Übersetzung}

(01-09)

Wenn die Majestät der Fürstlichen Prinz-Hoheit, die als Löwenkönig auf dem goldenen Thron vom Śākya-Stamm zu erscheinen und aufzuscheinen geruhte, gnädig ist, dann ist es so.

[...] Die Tod genann[te Sache], die die wie Sonne und Mond aufwachsende sudu-Blume ${ }^{459}$ gleichende [... ] durch die - Atom (paramānu) -Natur gleich seienden - sechs Sinnesorgane, angefangen mit dem bläulichfarbenen [Auge ], behindert und anhält, [kommt zu allen], mein Fürst!

$(09-12)$

${ }^{458}$ Geschrieben: kwyrkwzwz.

${ }^{459}$ Vielleicht ist swdw Verkürzung für sudhādyā, einen der vielen Aliasnamen für Skt. sumanas ,Blume‘, vgl. BSJT Nr. 256 Sumanā. Letzterer Terminus ist auch im Stabreimgedicht der Bibliothek der İstanbul Üniversitesi (Nr. 20) belegt: sugandik mutugandik vasik malik suman čampak-ta ulatı. Hoffentlich wird dieses wunderbare Gedicht eine Bearbeiterin/einen Bearbeiter finden! 


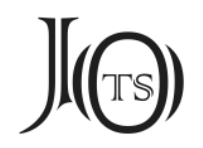

Wenn die Majestät der Fürstlichen Prinz-Hoheit von der Natur des cintāmaṇi-Juwels vom Stamm des alle Lebewesen auf seinen [...] und Schultern zu erheben und $\mathrm{zu}$ tragen geruhenden Bodhisattva [...] gnädig ist, [dann ist es so].

(13-21) Was das anityatā-Gesetz betrifft, so sind die Lebewesen, die Wünsche nach dem Zeigen der Zauber-Fähigkeiten, beginnend mit dem Fliegen und Sich-Erheben, nach dem Sehen-Können [...] in allen Himmelsrichtungen durch die verschiedenen Gestalt[en ] - solange man Zweifel in der Auffassungsgabe hat - und nach der Befreiung und Erlösung haben, wenn [ ]lei kalpavrkșa-Bäume sind, was soll man da [noch sagen ] des Todes [...]?

(21-23) Diese Tod genannte [verruchte Sache ] kommt [nicht zu einem], sie kommt [zu allen! Mein Fürst!]

$(24-26)$

Wenn die Majestät der Fürstlichen Prinz-Hoheit vom Stamm des Bodhisattva, der die verlorenen und irrenden Lebewesen [auf den rechten Weg führt] [...] gnädig ist, [dann ist es so].

(27-38) Einem zusammengepreßten ${ }^{460}$ Knoten gleich sind [die ], mit dem lebenden Körper [...] ohne genau zu sehen sind sie [...] wie Holz die braune Erde [...],

durch alle śāsana-Worte [...] die [...] beruhigend, [...] antaräbhava [...], durch das punya [der ] der [...] Lebewesen [...] an den Orten [der

].

\section{Handschrift H}

Eine weitere Abschrift ist nur durch ein Fragment aus Sängim vertreten: $\mathrm{Ch} / \mathrm{U} 6769$ (T II S 510).

\section{Vorderseite}

Die Vorderseite enthält einen Teil aus einer chinesischen Buchrolle des 大 方廣佛華嚴經 Huayanjing (T. 278) ${ }^{461}$.

\section{Rückseite}

Auf der Rückseite stehen Reste von sieben Zeilen vom unteren Ende des Blattes, sie sind in einer uigurischen Kursivschrift geschrieben, die sich von den

${ }^{460}$ ED 465a tık-, to squeeze؛

${ }^{461}$ T.IX.278.684a10-13. 


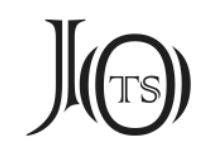

anderen Handschriften unterscheidet. Die Zuordnung gestaltet sich schwierig, weil viele Wörter keine deutliche Lösung zulassen, möglicherweise handelt es sich um Abschnitte, die in den anderen Handschriften nicht belegt sind.

$\begin{array}{lll}\text { Text } & \\ 01[ & \text { ] yavlakı[ } & \\ 02[ & \text { ]llg ya[g]ız yer-nin [ } & \text { ] } \\ 03[ & \text { ] ärig orn(a)g tutmı̌̌ ku[ } & \text { ] } \\ 04[ & \text { ] t (ä)yrikän tegin [täyrim kutı } & \text { ] } \\ 05[ & \text { a]yančan köyülin [ } & \text { ] } \\ 06[ & \text { ]č-lar-ka tamudu }{ }^{462}[ & \text { ] } \\ 07[ & \text { ]un yaltrı[ }\end{array}$

\section{Übersetzung}

(01-04) [Wenn die Majestät der] Fürstlichen Prinz-[Hoheit ], die das Böse der [...], [auf der Oberfläche] der braunen Erde Wohnstatt und Platz ergriffen und [ gnädig ist, dann ist es so.] (05-07) [...] in ehrfurchtsvollem Sinn [...] den [...] Höllen(?) [...] strahlen[d ].

\section{Handschrift I}

Die Wendung elig tägrim tegül kommt in A026 in einer längeren Variante vor: elig tänrim tegül šakimuni. Sie steht so auch in einem Text aus der Lujiang Caotang-Sammlung in Hangzhou: 未标尺寸/ Bild 5. Die Vorderseite enthält aus dem chinesischen Lotos-Sūtra (妙法蓮華經) den Abschnitt T.IX.262.4c06-28.

Unklar bleibt, ob für die Niederschrift des altuigurischen Textes die jetzt erhaltene halbe Blatthöhe genutzt wurde oder die volle. Unter der

${ }^{462}$ Wenn eine Wortform von tamu ,Hölle vorliegt, ist die labiale Endung du[?] kaum erklärlich. Dann wäre es vielleicht möglich, an eine labiale Variante des Verbs tamıt-, to blaze up (ED: 504a) zu denken: $t^{2} m w d t[$ ] $=\operatorname{tam} \imath t d[a \check{c} c]$ ? 


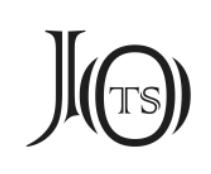

Voraussetzung, daß die erstere Annahme zutrifft, sollten zwischen den Zeilen nur kleine Lücken bestehen. Es könnte jedoch auch sein, daß die volle Höhe benutzt wurde, was bedeuten würde, daß die einzelnen Zeilen doppelt so lang waren.

Zeile 07 bildet das Ende des letzten Abschnitts über Krankheit, eine gewisse Annäherung besteht zum Abschnitt Krankheit-4 der Handschrift A. Mit dem Text nach Zeile 07 beginnt dann ein Abschnitt über den Tod, aber auch das ist bisher nur Spekulation.

\section{Text}

$01[$ ] ] ] sarati apay p-y

02 yakın kälir ök ärsär : alku üdü[n]

03 nägü ol asıg-1 tusu-s1 :: anın

04 käväl ak atım(1)z tı ordu-garu tägsä[r]

05 bügülärim näčük-in ärsär bulgay mu

06 nomug ::

07 elig täyrim tegül šakimu[ni]

08 a sarati a sarati a sarati

09 nä yalyuk ol bo sarati kötitmiš

10 -nin čökük-in bälgürtdäči kündülü

11 -lüg oyun-ug kügsirättäči ::

12 uyadmak sıkılmak-tın tünülmi[̌̌s]

13 öni tınl(1)g-lar-tın ıramıš .. ti[ši]

14 kiši-sinä ymä sav söslämä[z]

15 yıgıtın sıgıtın äšidmädäči : an[1]

16 ukmadačı . bodın sının ätin 


\section{Übersetzung}

(01-07) Wenn [...] Sārathi ${ }^{463}$ Apay ${ }^{464}$ p-y ${ }^{465}$ wirklich nahe kommt, wie soll alle Zeit sein Nutzen sein? Deshalb: wenn unser käväl ${ }^{466}$ weißes Pferd ${ }^{467}$ zum Palast gelangt, wird er, meine Weisen, wie es auch sei, den dharma erlangen $?^{468}$ O Herr König! Śākyamuni soll es sagen! (08-16) O Sārathi! O Sārathi! O Sārathi! Was für ein Geschöpf ist er? Dieser Sārathi läßt das Geheimnisvolle ${ }^{469}$ des Erhabenen ${ }^{470}$ erscheinen. Er läßt das kündül $\ddot{u ̈}^{471}$ Spiel melodielos ${ }^{472}$ sein. Er ist von Scham und Druck enttäuscht ${ }^{473}$. Von anderen Menschen ist er getrennt. Selbst Frauen sagt er kein Wort. Ihr Weinen und Klagen hört er nicht mehr. Er versteht sie nicht mehr. Ihren Körper, ihre Glieder, ihr Fleisch [fühlt er nicht mehr].

${ }^{463}$ SWTF IV: 371ab sārathi, Wagenlenker.

${ }^{464}$ Bisher ist im UW nur apa als Verwandtschaftsterminus belegt, UWN/1: 207-208: Großvater, Vorfahre, Titel. Doch vgl. Zieme 2017: 63. Man denke auch an den kazakischen Dichter Abay!

${ }^{465}$ Unklar.

466 Zu käväl vgl. Zieme 2014.

${ }^{467}$ In dem Bericht des Wagenlenkers Sārathi, der den Wagen Maitreyas zurückbringt, ist von einem Pferd keine Rede. Vielleicht darf man interpolieren, daß wie bei Siddhārtha auch ein weißes Pferd eine Rolle gespielt haben könnte. In der Biographie des Buddha wird diese Szene um das ,edle Roß` mit großer Emotion beschrieben. Ich zitiere hier aus Waldschmidts Buch: „Und unter Tränen begab sich Tschandaka [dem Pendant zu Maitreyas Sārathi], das edle Roß und die Schmucksachen mit sich führend, zu den Frauengemächern. Als Gopa ihn mit dem stolzen Renner kommen sah, fiel sie ohnmächtig zu Boden. (...) Als Gopa dann wieder zu sich gekommen war, umschlang sie betrübt den Hals des königlichen Rosses und gab, in Erinnerung an die einstigen Liebesspiele mit dem Gemahl, ihrem Jammer vielberedten Ausdruck.“ (Waldschmidt 1982: 113-114); „Und es bestieg der Sproß der Macht von hundert guten Taten den lotus-, den jasminweißen Renner. Die Erde erzitterte sechsfach, und die Gefilde der Buddhas gleißten." (Waldschmidt 1982: 115).

${ }^{468}$ Das ist eine rhetorische Frage.

${ }^{469}$ ED: 415a.

${ }^{470}$ Vgl. Zieme 2013: kökli yagızlı̌a köditmiš (besser: kötitmiš von köti-t-) kötrülmiš ,erhaben im Himmel und auf Erden'. G. CLAUSON nahm unter dem Lemma köti- eine Fehllesung an (ED: 702a), doch dürfte es sich um den Verbstamm köti- handeln, der neben köt- besteht.

${ }^{471}$ Das Wort kwyndwlw ist aus türkischen Sprachen nur schwer erklärlich, es erinnert an mongolisch kündüle-, respektieren, achten', vgl. Cleaves 1993: 32.

${ }^{472}$ Neues Wort küg+sirät-t-, melodielos machen'?

${ }_{473}$ ED: $521 \mathrm{a}$, to be disappointed, disillusioned; to despair, give up hope'. 


\section{$J(\Theta)$}

\section{Kommentar}

Eines der Epitheta des Buddhas ist purușadamyasārathi „Lenker der Menschen, die zu bekehren sind“474. Im altuigurischen Maitrisimit nom bitig ist Sārathi der Wagenlenker ${ }^{475}$, der nach Maitreyas Entschluß, Asket zu werden, dessen Wagen und Schmuck nach Ketumatī zurückbringt, ganz so wie Chandaka es der Legende nach tat. Im 13. Kapitel, das nur in der Tömürtü-Version vorhanden ist, lesen wir in Blatt 7 beginnend, wie der Bodhisattva seinen Wagenlenker Sārathi ruft, damit er seinen zuvor mit starker Intention entwickelten Gedanken, den Palast zu verlassen und nach der Erkenntnis zu streben, vollziehen kann. Als einziges Heilmittel gegen die Leiden des Alters, der Krankheit und des Todes sieht er nunmehr nur das Mönchsdasein. Nach der Begegnung mit einem Asketen übergibt der Bodhisattva Sārathi seinen Wagen und alles, was er bei sich hat, daß er es der Familie und den Freunden als Geschenke überreichen solle. Dann entspinnt sich eine rührende Szene zwischen dem Wagenlenker und dem Bodhisattva. Sārathi klagt, daß er bei seiner Rückkehr angeklagt werden könnte, weil er den Bodhisattva nicht von seinem Entschluß abgehalten habe. Doch dieser beruhigt den Wagenlenker, lobt ihn seiner treuen Dienste wegen und verspricht, die Übel des Samsāra zu beseitigen: „In ganz kurzer Zeit werde ich dein Leid des Getrenntwerdens bis in alle Ewigkeit beseitigen."

Voller Bange vernehmen die Menschen in Ketumatī den Bericht des Sārathi. Wir lesen im 14. Kapitel nach Taf. $146^{476}$ :

bodis(a)v(a)tda öyi bo ketumati känt uluš ymä čogsuz yalınsız bolmıš ärür .. ötrü ükkin terginin bodis(a)v(a)tnıy kälgüsin küdügli ketumati känt uluštakı bodun bokun bodis(a)v(a)tnı mingü kölükin tonın etigin körüp sarati tapa yakın barıp inčä tep teyürlär .. sözlä sözlä sarati basa basa yer täpräyür ${ }^{477}$.. kök kalıkda hua čäčäklig yagmur yagar .. t(ä)yrilärnin yokaru kudı yorımıš tavıš ünläri ištilür s(ä)n yenä yıglayu sıgtayu bodis(a)v(a)tnay mingüsin etigin yaratıgın tuta bodis(a)v(a)tta öni yorıyu kälir-s(ä)n ..

\footnotetext{
474 Nattier 2003.

475 In anderen Quellen der Maitreya-Literatur gibt es für Sārathi und seine Funktion als Maitreyas Wagenlenker keine Nachweise.

476 BT 9.

477 Den Satz sözlä sözlä sarati basa basa yer täpräyür zitiert J. WILKENS (2019), ohne Erläuterung.
} 
kanča bardı bizin balık uluš körki .. eliglär eligi bizin maitri bodis(a)v(a)t isig özdä öyi ödrülmiš ät’öz osuglug .. kurug kaylı birlä kanča barırs(ä)n ötrü yašlıg közin sariti inčä tep t(e)yür .. ölüm yagıka korkup y(a)rlıkančučı biliglig tözün tınl(1)g sizlärni ıdaladı titdi .. arıg semäkig sävdi .. kraža ton kädip toyın dentar törüsin tutdı .. kaylısın tonın etigin köligälikin ädgü ögliläriyä kasıya kadašına bäläk ıdtı .. isig özümtin ıdalamıš osuglug antada adrılıp bärü kältim .. amtı kanča bargumın ukmazm(ä)n .. ol savıg išidip ketumati känt uluštakı yalyuklar .. amarıları könülläri bärtinip ıglayu .. amarıları ulug tına muyadu adınu bir ikintiškä inčä tep tešürlär .. ančama y(a)rlıkančučı bilignin küči küsüni nnčama tınl(1)glarka asıg tusu kılmakı otguratı ol y(a)rlıknčučı biliglig ädgü tınl(1)g toyın dentar bolup asanke sanınča tınl(1)glarka asıg tusu kılgusın uktı ärki .. anın antag yigit antag oglagu antag mänin ulgadmıš antag čoglug yalıll(1)g ärip üč üdün olurguluk ärdnilig karšısın kudup t(ä)yri hatunları täg säkiz tümän tört min inčgä kızlarıg ıdalap titip arıg semäkig tapladı biz ymä amtı bükün ök ävig barkıg kudup anı̀ udu toyın bolalım .. inčip ymä arıg semäktä ınga bultı $\cdot$

„Getrennt vom Bodhisattva ist die Stadt Ketumatī ohne Glanz und Pracht. Da sahen die in Gruppen versammelten Leute in der Stadt Ketumatī, die auf das Kommen des Bodhisattva warteten, des Bodhisattva Reitpferd und seine Gewänder, gingen auf Sārathi zu und sprachen: 'Sprich, sprich, Sārathi! Ständig bebt die Erde, vom Himmel fällt Blumenregen, man hört die Geräusche, wie die Götter nach oben und nach unten wandeln. Und du hältst weinend und schluchzend des Bodhisattva Reittier und Ausrüstung und kommst vom Bodhisattva getrennt. Wohin ist gegangen die Schönheit unserer Stadt, der König der Könige, der Bodhisattva Maitreya, mit einem Körper, der von Leben getrennt ist? Wohin gehst du mit dem leeren Wagen?' Da spricht Sārathi mit tränendem Auge: 'Den Tod, den Feind, fürchtend hat das barmherzige edle Wesen euch verlassen. Er bevorzugt den Wald. Er zog das kāsạaya-Gewand an und nahm die Mönchsregeln auf sich. Seinen Wagen, seine Gewänder, seien Ausrüstungen und seine Schirme hat er als Geschenke Freunden und Familienangehörigen geschickt. Als ob ich mich von meinem Leben getrennt habe, bin ich von dort hierher gekommen. Jetzt weiß ich nicht, wohin ich gehen soll.' Als sie diese Worte gehört hatten, sprachen die Leute in der Stadt Ketumatī untereinander, einige, deren Herzen verletzt waren, schluchzend, einige, die tief seufzend sich wunderten: 'Dieses barmherzige und gütige Wesen, dessen Kraft der Barmherzigkeit wie auch das Nutzen-Bereiten für die Lebewesen sicher ist, ist Mönch geworden und hat wohl verstanden, den Lebewesen für asaṃkhyeyas Nutzen zu bereiten. Deshalb hat er, der so jung, so zart, so in Freuden aufgewachsen und so glanzvoll und prächtig ist, seinen Juwelenpalast, in dem er alle drei Zeiten ${ }^{478}$ wohnte, verlassen, die 84000 zarten Göttermädchen gleichenden Jungfrauen aufgegeben und den Wald bevorzugt. Auch wir wollen nun heute Haus und Hof aufgeben und ihm folgend Mönche werden, denn er fand das Wertlose (= Zuflucht) ${ }^{479} \mathrm{im}$ Wald.“

478 Ş. TeKIN wollte BT 9/I: 115 Fußn. 146 v 21 in üč üdün ,Morgen, Tag und Nacht‘ sehen und dachte an eine im Islam verbreitete Vorstellung, doch kommt wohl eher die vom Chin. her bestimmte Zeiteinteilung von ,dawn, daylight and sunset' in Betracht, die im Grunde genommen dasselbe bedeutet (SH 67b sub 三時).

${ }^{479}$ Das Wort inga übersetzt MK als, vile, worthless' (ED: 183a). 


\section{Indices}

\section{Chinesische Zeichen}

Zeichen(gruppen), die in der Handschrift A anstelle der altuigurischen Wörter verwendet werden. Wie man leicht erkennen kann, handelt es sich fast nur um einfache Zeichen. In Klammern steht die Häufigkeit des Vorkommens.

\begin{tabular}{||l||l||}
\hline \hline (4) & 八十 (1) \\
七 (1) & 六 (1) \\
\hline$三(8)$ & 十 (2) \\
三十 (1) & 十八 (1) \\
上 (2) & 四 (7) \\
下 (4) & 大 (3) \\
九 (1) & 天 (2) \\
九月 (1) & 火 (1) \\
\hline (5) & 生 (1) \\
五 (1) & 者 (4) \\
人 (1) & 八 (1) \\
\hline \hline
\end{tabular}

\section{Altuigurische Wortformen}

Der folgende Index enthält eine komplette Liste aller altuigurischen Wortformen aus der Handschrift A. Aus den anderen parallelen Handschriften werden vor allem die Belege aufgenommen, die in A nicht vorkommen. Die Kapitalbuchstaben B bis I sowie AppA und AppB sind den Zeilen vorangesetzt, Zahlen ohne einen vorgesetzten Buchstaben sind Angaben aus der Handschrift A. Hochgestelltes ${ }^{\mathrm{CH}}$ bedeutet, daß das Wort in der betreffenden Zeile durch ein chinesisches Zeichen repräsentiert ist. 
A

abayapur

a. 112

adak

iki a.+larnıy 76

[a]dak+1 F29

adasiz

a. $+\ln 80$

adin

a. $46,92,93,94,94$

adınčı

a. E07

adınsız

a. D13

adıril-

a.-miš 72

adirtla-

a.-matın 18

a.-yu 4

adirtlig

a. 105

adırtsız

a. 115

adruk

a. 119, F14 adruklug
a. 121

agllik

a. $+\operatorname{lar} 30$

ag1r

a. $60,127,129$, AppB14

agu

a. 118

agulug

a. E20

ak

a. $115, \mathrm{I} 04$

ak-

a. $-\mathrm{m}[1]$ š D01

akar-

a.-1p D14

akıt-

a.-tačllar 101

akla-

a.-p 112

aklančı

a. 112

aklatıl-

a.-miš 34

alk- 
a.-1p 118

alka-

a.-p 125

alkınčsız

a. 120

alkınču

a. 17

alku

a. $6,33,35,72,75,86, \mathrm{~B} 061$,

B063, D06, I02

a.+ka 18, 55, 95, 129

a.+ta 119

al-

a.-miš D18

almak

a.+1ntin 31

alp

a. 60

alt 1

a. 30,135, G07, AppA05

altin

a. $52,53^{\mathrm{CH}}, 101,129$, alt $[1 \mathrm{n}]$

B060

altun

a. AppA02

altunlayu a. 10

altunlug

a. G01

amanuši

a.+lar 31

amirtgur-

amirtg[ur ] G33

amrak

a. 115

amrilmak

a. + ta B005

amt1
a. AppB10

ana

a. 72

anča

a. 22

ančulayu

a. AppB18

a. ok 54

an1

a. AppB24

a. täg 22,65

an[1] I15

anın 
a. $85,95,103$

anityat

$$
\text { a.+ka 84, C42, G13 }
$$

anityatlig

a. 103

anta

\section{a. AppB14}

antag

$$
\text { a. 98, 122, AppA12 }
$$

antirabav
a. G34

ap

a. ... a. AppA09

apay

a. I01

ara

$$
\text { a.+sinta } 35,57,86
$$

arada

$$
\text { a. } 45,45
$$

arčune

a. 60, AppA18

arhant

$$
\text { a. } 102
$$

arit-

$$
\text { a.-mıšım(1)z AppB13 }
$$

arit1
a. 25,106

arslan

a. 57, E04, G02

art

a.+1g 102

artamak

$$
\text { a.+1ntın } 30
$$

arv1

a. $22,65, \mathrm{G} 15$

aryatan

a. 114

asig

a.+1 I03

asiglig

a. F12

asıgsiz

a. D23

asılmak

[a]s1l[mak1] AppB23

[asıl]makı AppB26

asure
a. 62

aš
a. 30,116 


\begin{tabular}{|c|c|}
\hline a.+lar1 B084 & a. H05 \\
\hline a.+ka 39 & ayaz \\
\hline aš- & a. $+l_{1} 36$ \\
\hline a.-1p 102 & ay1g \\
\hline ašay & a. F41, AppB12 \\
\hline a. G15 & a. +113 \\
\hline at & ayit- \\
\hline a.+1m(1)z I04 & a.-miš 94 \\
\hline at- & a.-sar 132 \\
\hline a.-sar 60 & ayupa \\
\hline ata & a. F29 \\
\hline a. 72 & $a z$ \\
\hline atl(1)g & a. 103 \\
\hline a. $34,50,55,75,85,88,95,110$ & az- \\
\hline 119, АppA14, AppA18 & a.-miš G24 \\
\hline ay & azig \\
\hline a. 79, 135, G04, AppA04 & a.+larin 10, a.+[larin] E19 \\
\hline a.+1n AppA15 & azu \\
\hline aya- & a.+ča 31 \\
\hline a.-guluk 129 & ažun \\
\hline a.-gulukı 16, 76 & a. 78 \\
\hline ayag & a. $+\mathrm{ka} 46,93,93,94$ \\
\hline a. 127,129 & \\
\hline a.tka 119, 130, 131 & $\ddot{\mathrm{A}}$ \\
\hline [a]yančan & $\begin{array}{l}\text { äd } \\
\text { ä. } 71\end{array}$ \\
\hline
\end{tabular}


ä.+in 74, 83, 125, B118

ädgü

ä. 55, D20

ä. + g 18

ä.+li 3

ädgülüg

ä. 120, 134, F03

ädräm

ä. 100, G14

ädrämlig

ä. 61

ägil-

ä.-miš D17

ägrildür-

ä.-täči 12, [ägril]dür-täči F12

äm

ä. 45,45

ämgäk

ä.+lärnin D22

ämgän-

[ä]mgän-ü D16

ämiz-

ä.-mäktä 81

än

ä. 21, AppA13 äybašlayu 122

äyilki $40^{\mathrm{CH}}$

äyin

ä.+lärintä G10

äninčig

ä.+lär 61, D13

äymıntın

ä. $18,89,99$

är

ä. E05

ä.+nin E17

är-

ä.-ür 2, AppB10

ä.-mäz D06, AppB03

ä.-ürlär 42

ä.-ti 133, E16

ä.-tilär AppA19

ä.-gäli 39

ä.-ip 104, D12, D17, G28

ä.-sär $2^{\mathrm{CH}}, 2,17,23,29,31,38$, $40^{\mathrm{CH}}, 41^{\mathrm{CH}}, \quad 42^{\mathrm{CH}}, 44,45,54,66,71$, 79, 81, 94, 111, 124, G03, G13, I02, I05, AppB18, AppB24

ärän

$$
\text { ä.+lärkä } 13
$$

ärdini 
ä. 27, 70, G11, AppB10

ä.+lär 20

ä.+lärkä AppB11

ä.+si 6

ärdni

ä.+n AppA01

ärig

ä. H03

äriglig

ä. E10, E16

ärk

ä.+i 22, 65, B094

ä.+in 74

ärkälän-

ä.-ü (?) D16

ärki

ä. 25, 67, 106

ärklig

ä. 20

ärksinmäk

ä. AppA17

ärksiz

ä.+in 74, 84

är[ksiz] 2

ärtmäk ä. 73

ärtür-

ä.-ü E16

ärük

ä. 11

äsän

ä. 80

äsri

ä. 22, 65

äsrinü

ä. G15

äšid-

ä.-gäli 34, 85

ä.-mädäči I15

äš(i)d-mäktin D21

ätin

ä. I16

ätöz

ä.+nün F26, AppB22

ä.+lärin 8

ä.+intin 100, 101

ät’özlüg

ä.+lär 62, F26

äymän-

ä.-ip 111, 125 
äv

ä.+in 83, 113, 125

ä.+tin 131

ävin

ä.+inčä AppA07

B

bagir

b. $+\ln 53$

baglig

b. 27

bahš1

b. F20

bal[1]k-

b.-miš E14

bar

b. 23, AppA19, АppB15, AppB15, AppB28

bar-

b.-1rlar 93

b.-dilar AppA18

b.-1p 130, 132

barča

b. 55

b.+n1 E12, AppA12

bark b. + in $83,113,125$

b.+tin 132

baš

b.+1ra 82, F16

b. $+1[$ ar] D01

bašla-

b.-p 19, G07

b.-yu AppA14

bašlag

b.+1ndak1 59

bašlayu

s. äyb.

bat-

b.-t1lar 103

b.-1p 3

bavagir

b.+lig 102

bay

b. 55, AppA09

bayagut

b. 122,126

bädük

b. $51^{\mathrm{CH}}, 62$

bäg

b. $63, \mathrm{~B} 130$ 
b.+kä F06

b.+lär AppB29

bäglig

b. F44

bälgür-

b.-di AppA15

b.-dilär 123

b.-ü 28, 49, 70, D19, F02, G02

b.-mištä AppA14

bälgürt-

b.-däči I10

bätür-

b.-däči G05

beš

b. $30^{\mathrm{CH}}$

bımsıramak

b.+1ntin 30

bilä

b. 52,53

bilgä

b.+lärkä AppA09

biliš

b. B133

bilmäksiz b. 5

bir

b. $54^{\mathrm{CH}}, 55,56^{\mathrm{CH}}, \mathrm{C} 30, \mathrm{D} 05$, AppA02, AppA06, AppA08

b. täg $14,18^{\mathrm{CH}}, 89,95$, [b.] täg

D07

birär

b. 124

b.+läri $79^{\mathrm{CH}}$

birk(i)yä

b. 104

birök

b. 78,80

biti-

b.-dim B134

bitig

b. 118, B131

bo

b. $3,7,17,29,35,37,40,44,46$, $50,54,59,63,71,76,78,82,85,87,93$, 107, 108, 120, 121, 122, 122, 123, 127, D05, D05, D23, E05, E16, E17, F17, F21, F31, G03, G13, I09, AppA13, AppA13, AppA16, АppB21

b. ok 88

b. $+\operatorname{lar} 42$

bod 
b.+1n I16

bodistv

b. $36,49,58,77$

boguz

b. 33

bol-

b.-ur AppB21, АppB24,

AppB27

b.-urlar $21,46,84,129$

b.-u $6,16,40,47,77,85,97,108$, 132, F20, F21

[bol]-u 44

b.-zun 134

b.-sar G19

b.-up 83,116

b.-gay 98

b.-gu G15

b.-gu täg 22, 65

b.-guča 94

b.-matač1 98

b.-magay mu 95

b.-miš 13, 78, D12, D13, D23

b.-mak1 2, b.-ma[k1] E17

[b]olmakta D22

boran

b.+1[ar] D02 braman

b. 122,126

buu

b. 31

bul-

b.-gay I05

b.-mıšča k(1)ya 116

b.-galı 112

bulgan-

b.-ur F40

bulganmak

b.+1ntin 29, 41, 43

bulitlig

b. 4

bulunčsuz

b. 6

burhan

b. AppB28

b.+nin AppB02

buti

b. 31

buyan

b. 86

b. $+1 \mathrm{G} 35$

buyanlig 
b. $87, \mathrm{AppB} 14$

buz

b. D02

bügü

b.+lärim I05

bükril-

b.-miš D17

bükrüldür-

b.-täči 12

bürmäk

b.+tä G07

$\check{C}$

čahšapt

č. 135, AppA08

čakir

č. 19

čakiravart

č. 20; [čakr]av(a)rt B020

čaru

č. 59

čäčäk

č.+i 11

Č.+lärin D03

čärlät-

č.-ü 114 čerlig

č. D13

čıgay

č. 55, AppA09

čınkoydu

č. 135

činratgu

č. 110

čintamani

č. 6, G11

čivake

č.+[d]a F30

čivšig

č. E03

čog

č. 86

č.+ka 102

čw'k'

č. 1

čök-

č.-üp 3

čöküg

č.+in I10

D

dartarašatiri 
d. 63

dentar

d. 110,119

d.+larnin 121

d.+larka 128

diravi

d. + ka 71

divip

d. B019

dyan

d. 90

E

ediš

e. 97

ediz

e. 102, F09

el

e. AppB20, AppB26

e.+intä (?) D18

elän-

e.-ti AppA16

elänmäk

e. AppA17

elig e. $26,68,106,133$, I07, AppA15, AppB06

e.+lär 20,60, AppB29

elt-

e.-[gäli] G10

enč

e. B117, AppA09

er-

e.-gülük 13

e.-ip 111,125

eritil-

e.-miš $33,37,46$

etig

$$
\text { e.+i } 69,97
$$

etiglig
e. 19

etilmäk

e. AppB08

eyin

e. AppA18

G

gavdam

g. 27

grah

g. 32 
gunačari

g. 99

$\mathrm{H}$

han

h. AppA15

h.+1 49, E04, G02

h.+1nča 57

h.+lar 20, 60

hansarača

h. 48

hua

h.+sina G05

h.+larin D03

I

1d-

1.-maz AppA09

1.-matin 39

1dala-

1.-p 74,84

ıdılmak

1. E08

1duk

1. 20

1gač
1. G30

1ra-

1.-miš D21, I13

I

i-ä

i. +[s]i-nin AppB20

i.+läri-ni[y] AppB26

ič

i.+indä 48, F15, ič+[intä] D08

i.+indäki 16

ičgäk

i.+lär 32

ičgü

i. 30

i.+1[äri] B084

i. $+k a ̈ 39$

ičtin

i. F35

ig

i. $41,42,43$

[ig] 42

i. + kä 2

i.+lär 42, F42

i.+lärdä 44

i. + ig 44 
igit

i. E17

igitmäk

i. 33

iglä-

i.-mägäy 67

i.-güčä 44

iglämäk

i. $34,37,40,47,50,54,83,111$, 125

i.+lig 64, 66, B062

iki

i. $4,19^{\mathrm{CH}}, 76^{\mathrm{CH}}, 99^{\mathrm{CH}}, \mathrm{D} 03, \mathrm{~F} 21$

ikinti

$$
\text { i. } 2^{\mathrm{CH}}, 41^{\mathrm{CH}}, \mathrm{F} 36, \text { AppA02 }
$$

ikšivaku

i. 69, [ikš] ivaku D26

ilgün-

i.-miš 33

ilgüntür-

i.-ür 81

ilki

s. äyi.

ilkisiz

i.+tinbärü 33 inčip

i. 63,67 , inči $[p]$ D10

in lan (?)

i. 1.83

intiri

i. $+\operatorname{lig}$ D03

intravar

i. AppA03

isig

i. 83, F29, AppB23, АppB30

iš

i. E09, E14

i.+lärig AppB14

išlä-

i.-mišim(i)z AppB15

K

ka

k.+sintin 72

kačig

k. D21

k.+lar G07

$\operatorname{kad}(?)$

k. D12

kadalur (?)

k. D12 
kadaš

k.+1ntın 72

kadgi

k. 99

kadig (?)

k. F19

kal-

k.-maz AppA07, AppA08

kalımak

k.+ta G13

kalısız

k. 54,56

kalpav(a)rkaš

k. G18

kalt1

k. 51

kalyani

k.+ta 59

kalık

k. 52,100

k.+ka 89

kamag

k. 6, 8, 14, 35, 72, 86, G09, G31,

AppA20

k.+ka F12 k.+ta 119, D11, D22

kamč

kamč[1+1]1g D18

kamı̌

k.+layu 9

kanlig

k. D11

kanımlıg

k. 116

kay

k. 1

k.+1m(1)z AppB28

k.+1n 113

kapig

k. 115

k.+152

kapilavastu

k. 48

kar

k. 82, D02, F10, F16

kara

k. 9,11

karak

k.+nın D12

karamuk 
k.+ča 67

karangu

k. D08

karar-

k.-1p 3

karaša

k. 126

kargat-

k.-mıš 14

kar1-

k.-magay 25

karımak

k. 7, 13, 17, 21, 24, 25, D05, F17

k.+ka 111, 124

k.+1 2, F22

k.+lig 82, E20, F16

karın

ög k.+ta 79, 80

karit-

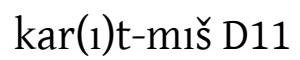

kart

k.+1 D12

kašınčıg

k. 8

kat k. AppA05

katkı

k. 12, E18, F11

katig

k. 13

katuru

k. F13

kavril-

k.-u D11

kaya

k. 52

kayu

k. 44, 124, АppB04, АppB29

kaz

k.+lar 48

käd-

k.-ärlär 126

kädimlig

k. 110, D14

käl-

k.-ir D06, G22, I02

k.-zün 134

k.-däči 15, 18, 56, 89, 96

k.-täči B059, C30

k.-dükdä 92 
k.-miš 51, 88, F09

k.-mištä 66

k.-sär 52, AppA06

k.-ü D07, D25, G23

[k](ä)l-ti AppA16

kälig

küü k. 99, G14

kälmädük

k. F15

käm

k.+[lär] F42

kämiš-

k.-ip 113, 126

käntlig

k. 48

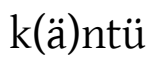

k.+nüy AppA20

k(ä)rgäk

k. AppB13

käv-

k.-ip 38

käväl

k. I04

käyik

k.+lär 57 käz-

k.-ä 115

kesari

k. 57, [k]esari E04

kenki

k. E11

kıdig

uč k. 116

k1l-

k.-ur AppA12

k.-urlar 128, 129

k.-dač1 5, 11, 39, F14

k.-gu ol 26, 133

kılık

k. E10

klliklig

kılıkl[1g] E15

k1lın-

k.-u E15

[k11]ın-magularıg E15

k1lınč

k. 42

k.+nın F01

[kılınč]-1m(1)znı AppB12

$[\mathrm{k} 1] \ln c ̌ l l g$ 
k. АppB07

kılınmak

k. E15

kıragu

k. F16, kır(a)gu D02

kırtıš

k.+ların 11

kiy

k. 115

$\mathrm{k}(1) \mathrm{ya}$

k. 116

k1z

k.+1n 114

k.+tın 72

kızl

k. 109

kičig

k. E09

kigür-

k.-[ü]p AppB30

kim

k. 3, 7, 37, 50, 71, 87, 108, 121,

D10, AppA01

kinšuk

k. 27,69 kir-

k.-dilär AppA20

kišadirik

k. D09

kiši

k. 72

k.+sinä I14

k.+lärkä 34, 71, [kiši]lärkä C30

kit-

k.-ip E18

kitär-

k.-mišim(i)z AppB13

k(i)yä

k. 136

kod-

k.-up 113, 125

kodur-

k.-up 136

kog

k. AppA06

kolu

k.+g E16

kolun-

k.-u B004

koptın 
k. G16

kork-

k.-up 111, 124

korku

k. E10

kögüš

k. G06

kök

k. kalık 52, 89, 100

köl

k.+üg 61

köni

k. 118

köyül

k. 3, 22, 65, G15

k.+nüy 2, F23

k.+in $\mathrm{H} 05$

köyl+i F28

kör-

k.-ür F14

k.-däči 115, F13

k.-güči 131

k.-gäli D12, G16

körgüsüz

k. G29 körk

k.+i 96, 107

körkitmäk

k. G14

körklä

k. 8, G04

körksüz

k. D12, D22

körünčlüg

k. 107

köšik

k.+ig B004

kötitmiš

k.+nin I09

kötür-

k.-gäli G10

kötürt-

k.-miš 71

köz

k. 22,65

közün-

k.-ü D19

kšan

k. k. 3

kšatirik 
k. 57, 69, 122, 127, 128

[kšatri]k 27

kudul-

k. -u 86

kugu

k.+layu 9

kulgak

k. D21

kulut

k. 135

k.+1 B094

kumut

k. 27

kurit-

k.-tačı D05

kurug

k.+1[ar] AppB16

kut

k. 86

$\mathrm{k} .+17,16,28,37,50,58,70,78$,

$87,98,104,109,121,130, \mathrm{~B} 130, \mathrm{D} 10$, G03

k.+1lig 102

k.+1nin 21, 64

kutlug

k. 87,119 kutrul-

k.-up 112

k.-miš 24

kutrulmak

k. G17

kuvrag

k.+nin 107

k.+1 57

kuzgun

k. 9

küü

k. 99

küč

k.+üg 38

k.+inin F23

k.+lärin F05

küč<s>irät-

k.-ip 38

küčlüg

k. 63, B018

kügsirät-

k.-täči I11

külä-

k.-p 120

kümüš 
k. AppA02

kün

k. 79, G04, AppA04

k.+i 92

kündülülüg

k. I10

küni

k. AppA16

küp

k. F09

küsänčig

k. G04

küsün

k.+üg 38

k.+i F23

küsünlüg

k.+lär 63

küsüšlüg

k. 96, G17

[kü]süšlüg F25

küvän-

k.-ü E13

küvänč

k.+i 96, 107

küväz k. 12, F11

küz

k[ü]z F38

L

lakšan

1.+lar 19

lenhua

1. 28

ligui

1. B094

M

mahabut

m. + lar $29^{\mathrm{CH}}$

m(a)ha[but]+lar 41

[maha]but+lar 43

m(a)hak(a)lp

m. 91

m(a)ha-sampadi

m. AppA14

m(a)ndakini

m. 48

män

m. 25, 67, D07, E12

mänin 
m. AppB29

mängü

m. 91

mäyi

m.+si 22, 65

m. $+\sin 112$

mänilig

m. E11

mäyiz

m.+lärin E03

m.+inä E13

mäyizlig

m. D13

$\min$

m. B018

$\mathrm{mu}$

m. 95, I05

mun-

m.-mi[̌̌s] G24

mun1

m. 46, 93, D23

muntag

m. 47,85

munaddınčıg

m. E07
$\mathbf{N}$

nayrag

n.+lar 19

nä

n. $94,98, \mathrm{G} 19$, I09

näčä

n. $23,64,66$, B085, АppB14, AppB15

n.+tä 78, 80

näčükin

n. I05

nägü

n. $\mathrm{I03}$

näy

n. 63,67, AppA17

nätäg

n. 51, B085, AppB23

nätägin

n. 104

nirvan

n. 112

n.+lig B117

nizvani

n. 104

n.+larig 101, 118 
nom

$$
\begin{aligned}
& \text { n.+ug I06 } \\
& \text { n.+larta } 118 \\
& \text { n.+larnin } 75 \\
& \text { n.+larig } 4
\end{aligned}
$$

nomlug

$$
\text { n. D04, AppB02, AppB30 }
$$

0

oglan

o. B018

o.+lar1 B061, o.+[lar1] B063

o.+larinin 6, 8, 14, 77

o.+larina 89, D06

ogul

o. 72

$0 .+1 n 114,115$

ok

o. 51, 80, E12, AppB21

bo 0.88

ančulayu 0.54

okšatı

o. 71

ol o. 22, 130, 131, 133 (Kopula), G24, I03, I09, AppA13, AppA01, AppA02, AppA08, AppA16

olur-
o.- ur 79
o.-galı 38
o.-up 117

on

o. $117^{\mathrm{CH}}$

säkiz o. $19^{\mathrm{CH}}$

o. kün $79^{\mathrm{CH}}$

tokuz o. säkiz $101^{\mathrm{CH}}$

oprak

o. D14

ordu

o.+garu I04

o.+sinta AppA04

$\operatorname{orn}(\mathrm{a}) \mathrm{g}$

o. H03

ot

o. äm 45,45

oot

o. 17

o. $100^{\mathrm{CH}}$

ordu

o.+lar 30 
ornan-

o.-dilar 103

orun

o.+nuy 107

o.+ta B117

o.+lartın 117

o.+larig 114

o.+larta 117

o.+larinta G37

osuglug

o. 46, D23

otač1

o.+lar F30

otgurak

o. 25,105

otuz

o. $19^{\mathrm{CH}}, \mathrm{D} 03$

oyun

o.+ug I11

OZ-

o.-matılar 64

o.-galı 105

o.-matuk 23

o.-miš 24

o.-up 112 ozmak
o. G17

Ö

öč

ö.+kä AppA19

ödrül-

ö.-miš 73

ö.-üp 117

ög

ö. karin 79, 80

ög.+in 113

ög-

ö.-üp 120

ögüz

ö. AppA07

ök

ö. $61,64,132$, I02

öl-

ö.-ürlär 80

ö.-mägäy 106

ö.-mäz 91

ölitil-

ö.-miš D15

ölmäk

ö. 105 
ö.+ig 111, 125

ölüm

ö. 75, 85, 87, 95, 104, G08, G21, AppA13, AppA16, AppA17

ö.+kä 98

öy

ö.+lärin 11

ö.+inä E13

öndün

ö. $51,82,131$

öni

ö. 73, 117, I13

öylüg

ö. D13

öysüz

ö. 92

örlät-

ö.-ü 114

öttürmäki (?)

ö. D16

öz

ö. F01

ö.+tä B085

tirig ö. 81

ö.+i 132 ö.+nüy AppB17, AppB23

ö.+ümin AppB30

özlüg

ö. 91, B071

P

p(a)dma-rog

p. AppA03

p(a)ramanu

p. G06

pramandal

sansara p. 15

praty(e)kasanbud

p.+lar 99

purvanandiniklp

p. 59

Q

qr'q AppA05

$\mathbf{R}$

rami

r. AppA18

ridi

r. 99

\section{S}

sač 
s.+larin 9, 126

sačlıg

s. 109, E02

sadu

s. 134

sakal

s.+larin 126

sakallig

s. 109, E02

sakın-

s. $-\mathrm{u} 67,106$

sakınčlıg

s. 92

sakı̌̌sı1z

s. AppA15

sana-

s.-yu 115

sanipat

s. F40

sanlig

s. $46,84,94,95,98$

sansar

s. + tin 112

s. + n1[y] F04

sansara pramandal
S. 15

$\operatorname{sans}(1) \mathrm{Z}$

s. AppA15

sarati

s. I01, I08, I08, I08, I09

sargart-

s.-dač1 10

sarig

S. 109

satı̌̌̌

s. $+\operatorname{lar} 5$

sav

s. F27, I14, s(a)V B071

s. + ka 39

s.+larig 131, D21

savlig

s. D17

sayu

S. 3

säkiz

s. D04

s. tümän 91

S. on $19^{\mathrm{CH}}$

särgür-

s.-däči G08 
säv-

s.-ä 114

sävi[ ]

s. E01

säviglig

s. F12

sävinčlig

s. D01

sezin-

s.-ü D25

sigtat-

s.-u 113

sigtatur-

s.-tač1 F08

sigit

s.+1n I15

s1k1l-

s. $-\mathrm{u} \mathrm{D16}$

sik1lmak

s.+tin I12

sin

s.+1n I16

s.+ların 12, F11

sin-

s.-miš D11 sinlig

s. D17

sinar

s. G16

sinark1

s. F35

sigšil

buu s. 31

sinirlig

s. D20

sinmämäk

s.+intin 31

sitilig

s. F32

sod-

s.-up 61

soka

s. 66

solan-

s. $-1 p 79$

sor-

s.-up 61,132

sögüt

s. $116, \mathrm{G} 18$

sörp 
F19

söz

s.+kä 39

sözlä-

s.-güči 82

s[özlä-yü] 26

s.-mä[z] I14

sözlämäk

s. B071

sözlüg

s. D17

sudu

s. G05

sugul-

s.-ur AppA08

sugur-

s.-dačılar 61

suv

s. 101, AppA13

s.tug 61

s.+1 AppA07

yer s. 15

$\mathrm{s}[\mathrm{u}] \mathrm{v}+1[\mathrm{ar}] \mathrm{D} 01$

sünük

s.+lärin 12 sünüklüg

s. D18, E04

sünüšč[i]

s. F19

süt

S. 81

$\check{S}$

šaki

š. G01

šakilıg

ร̌. F19

š.+larnıy 86

šakimuni

š. 26,133

šakimu[ni] I07

šazın

š. G31

Š.+1min AppB29

šäpgün

ร̌. 11

Šllatıl-

š.-mıš D15

šoban

Š.+1 108 
$\mathrm{T}$

tadu

t. 40

[tadu] 43

tag

t. 52,114

t.+1g 61, 61

t. + ta 103

tak1

t. $94, \mathrm{G} 19$

talačangini

t. 62

taluy

t. AppA07

tamaz

t. AppA08

tamudu

t. H06

tančula-

t.-p 61

tap-

t.-gal1 113

tapla-

t.-yu 114

tapsiz t. 39

tapig

t. udug 127,128

tarik-

t.-miš F 24

tarkar-

t.-1p 102, 118

t.-matuk 104

[tarkar]-guluk AppB12

tart-

t.-mıš D21

tartiglig

t. D20

tašıkar-

t.-u D19

taštın

t. F36

tavar

t.+1n 74, 84, 125, B118, AppA13

tay-

t.-1p AppB04

tayaklig

t. $110, \mathrm{D} 18$

t. $+\ln 90$

tayan- 
t.-miš 110

ta[ya]n-1p AppB05

tayanmak

t. AppB11

tašgar-

t.-1p 100

täg

t. $2,5,9,10,11,14,17,18,22$,

$22,46,56,62,63,65,65,89,93,95$, C30, D23, E04, F14, t(ä)g F09, F10, G30, AppB24

täg-

t.-däči B064

t.-miš 103

t.-sä[r] I04

t.-ip 61

tägimlig

t. 119

t.+nin 131

t.+kä 130

tägin-

t.-ür $5,15,18,35,40,40,44,47$, 56, 76, 85, 89, 96, 120, 122, B064, D07, D25, E16, F21, G09

t.-ürl[är] F34

t.-mäz 24, 51, 88, B059, B063 t.-tim 136

t.-äyin E12

t.-gäy 133

t.-miš 103

tägzin-

t.-ür AppA04

tälim

t. 23,66

tälmir-

t.-ip D19

täy

t.+tä D20

täylig

t. $45,79,81,94$,

täyri

t. 90, 90, 92, B060, АppA04, AppA05, AppB28

t.+kä 129

t.+lär $92,90^{\mathrm{CH}}, 93^{\mathrm{CH}}$

[täyri täyris]i AppB02

täyrikän

t. tegin täyrim 7, 16, 21, 28, 36, 49, 58, 64, 70, 77, 87, 97, 104, 108, 121, 130, D10, D24, F20, F31, G04, G12, G26, H04

täyrim 
t. $5,15,26,35,47,56,68,76,85$, 96, 106, 120, 133; D07, D19, t[äyrim] D24, G03, G09, I07

täyrikän tegin t. 7, 16, 21, 28, $37,50,58,64,70,78,87,98,104,108$, 121, 130, D10, G12, G26, H04

elig t. 26, 68, 106, 133 te-

$$
\text { t.-miš E12 }
$$

t.-gü 133

t.-gül 26, 68, I07

t.-p 25, 67, 106, AppB27

t.-mätin 55

tegin

täyrikän t. täyrim 7, 16, 21, 28, $37,49,58,64,70,77,87,97,104,108$, 121, 130, D10, D24, G12, G26

tegli

$$
\text { t. } 7,14,17,37, \text { D05, F17 }
$$

tegmä

t. E05, F29

tet-

$$
\text { t.-ir } 78
$$

t1

t. $78, \mathrm{I} 04$

tıd- t.-tačı G08

tigrak

t. 13

tıkkın

t. G27

tilayu

t. F14

tiltag

t.+1 121

t.+1g 132

t.+1nta AppB10

$\operatorname{tinl}(1) g$

t. 82, B06, D063, G09

t. oglanlarinıy $6,8,14,77,82$

t. + ka 51, 88, D05

t.+lar 94, 103, B061, G17

t.+larnin 16, 35

t.+larig 54

t.+lartın I13

tınsız

t. 71

tirig

t. G28

t. öz 81

tirilmäk 
t.+i AppB27

tirin

t. 107

tǐs

t.+lärin 10, E19

ti[ši]

t. I13

tit-

t.-ip 74, 84

titrü

t. D16, G29

tiz-

t.-miš 10

tok1

t. + s1 108

tokuz

t. $79^{\mathrm{CH}}, 101^{\mathrm{CH}}$

tokımak

t.+1ntin 32

tokit1l-

t.-1p 83

toli

t. 82

ton

t. 126 tonlug

t. 110, D14

tona

t. + S1 23, 65, B018, AppA18

tona

t.+ta 60, D19

tooš

t. $+\operatorname{lar} 29$

tošgur-

t.-dačilar 61

toylaš-

t.-miš 107

toyin

t.+larka 128

tökün-

t.-ü D02, D02

tönüt-

t.-gülüki 77

töpü

t.+rä 76

t.+sintä AppA05

törči-

t.-yür F39

tört 


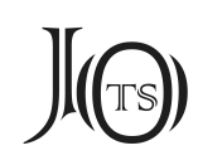
t. $29^{\mathrm{CH}}, 43^{\mathrm{CH}}, 43^{\mathrm{CH}}, 44^{\mathrm{CH}}, 44^{\mathrm{CH}}$,
t.-mıš 88

$71^{\mathrm{CH}}, 122,123^{\mathrm{CH}}$, B019, AppA01, AppA07, tö[rt] AppB21

törtünč

$$
\text { t. AppA03 }
$$

törü

t. $8,14,17,34,38,47,50,55,66$, 75, 78, 85, 88, 95, B062, D05, D24, E17, F17, G13

$$
\begin{aligned}
& \text { t.+kä B064 } \\
& \text { t.+tin 23, 24, 64, } 105
\end{aligned}
$$

törü-

$$
\begin{aligned}
& \text { t.-dilär } 123 \\
& \text { t.-gülük } 121 \\
& \text { t.-yü 28, 49, 70, D09 }
\end{aligned}
$$

törülüg

t. 25,105

$$
\text { töz }
$$

$$
\text { t.+intinbärü E18 }
$$

tözlüg

t. $27,41,42,57,123,123$, D09, G06, G11, töz[lüg] G11

tözün

$$
\text { t. } 117
$$

tug-

t.-guča 80

tugmak

t. $23,111,124$

tugr1

t. D17

tugum
t. $78^{\mathrm{CH}}$

tur-

t.-ur 87, D02, F23, F27, AppA06, tu[r-ur] B071

t.-urta B071

t.-miš 43, AppB05

$\mathrm{t}[\mathrm{ur}]-\mathrm{miš} 41$

t.-gali 38

t.-u G29

tusu

$$
\text { t.+S1 I03 }
$$

tusul-

t.-ur 45

t.-maz 45, 67

t.-mat1 AppA17

tuš

t. E09

t. + ta 79

t.+lar E14 
tut-

t.-ars[iz] AppB03

t.-mıš H03

t.-dum B094

t.-guča 79

t.-dačı AppA08

tutči

t. 52,53

tutun

t. $135, \mathrm{~B} 094$

tügün

t.+kä G27

tükätinčsiz

t. 120

tükät-

t.-ü 136

tülüg

t. 11

tüülüg

t. 76

tümän

t. 91

tün

t.+däki 4

tünär- t.-ip 3

tünül-

t.-mi[šs] I12

tüp

t.+i 53

t.+indä 116

äy t.+indä 21

türk

t. 13, E05, E17

t.+i 22,65

t.+in 74

türklüg

t. 20

türksüz

t.+in 84

türlüg

t. $4,40,42,43,44,99,117,123$, 123, 131, D04, F21, F42, G18, AppA01

tüš-

t.-är AppA06

t.-sär AppB09

tüšür-

t.-däči F11

t.-miš 109

tüz 


\section{t. 115}

tüzü

t.+kä 14, 89, C30

tüzügü

t.+kä D06

tüzüksirämäk

t.+intin 29

U

u-

u.-maz AppA10

u.-gay 105

u.-matın 4

uč

u. 116

uč-

u.-dačllar 100

u.-ugma 53

učık

u. 41

učmak

u. G13

udug

u. 127,128

uguš

u. 27, 77, 127, D08 u.+nuy 69

u. +tak1 124

u.+dak1lar 127

ugušlug

u. $36,49,58$, D26, G11

u. + lar 123,128

u.+larda 123

u.+larig 127

$\mathrm{uk}-$

u.-madač1 I16

uk1t-

u.-tač 75

ula-

u.-gay AppB30

ulatı

u. 60, D22, F30

u. +lar 81

ulug

u. $51^{\mathrm{CH}}, 60^{\mathrm{CH}}, 62, \mathrm{AppB} 14$

uluš

u.+nuy AppB19, AppB25

u.+ug AppB06

umuglug

u. 91

upačaru 


\section{$J(\Theta)$}

u. 59

ušat-

u.-tačılar 62

ut-

u.-t1lar AppA20

utun

u. $7,14,17,37,50,55,64,66$,

D05, F17

uyadmak

u. I12

uz

u. $122,127,132$, E08

uzun

u. 91, B071

Ü

üč

ü. $29^{\mathrm{CH}}, 40^{\mathrm{CH}}, 42^{\mathrm{CH}}, 118^{\mathrm{CH}}, 118^{\mathrm{CH}}$, $127^{\mathrm{CH}}, 131^{\mathrm{CH}}$, AppB08, АppB11

üčün

ü. 24

üčünč

ü. $42^{\mathrm{CH}}$, AppA03

üd

ü. F15

ü.+üg E16 ü.+i 92, AppA06

ü.+ün AppA19

ü..ü[n] I02

ü.+täki 17

ü.+lärtä F38, ü.+[lärtä] F37

üklimäk

ü.+i AppB25

üklimä[k+i] AppB22

üklitmäk

ü.+i AppB24

üküš

ü. 23, 66, AppA19

ülügsüz

ü. $75,88,95$

ün-

ü.-gülük 132

ü.-ä F09

ündür-

ü.-üp 101

ürlügsüz

ü.+in 75

üstün

ü. $52,53,100^{\mathrm{CH}}, 129^{\mathrm{CH}}$

üstünki

ü. 93, B084 
üšüt-

ü.-ü D02

üzä

ü. $19,20,32,33,73,81,82,83$,

86, 116, C42, D03, D15, F16, F19, G16, AppB23, АppB26

üzlünčülüg

ü. 21

V

varu

v. 59

Y

$y-a$

y. $6,15,35,48,57,69,76,86,96$,

107,120

yag

y. 81

yag1

y.+sin 115

yagilig

y. E09

yagiz

y. $53, \mathrm{G} 30$

ya[g]1z H02

y.+liča 36 yagmak

y.+1 D15

yagu-

y.-mıš 73

yakın

y. 66,130, D18, I02

yaktur-

y.-u E08

yalın

y.+ka 102

y.+lar 86

yalyuk

у. 73, 98, 111, 120, F31, F21, F31

y.+ka $129^{\mathrm{CH}}$, I09

yalyuz

y. 50,88

yam

y. 90

yamadevi

y.+ka 73

yamakalyan[ ]

y. E06

yana

y. $8,43,82,124,128$

yanč- 
y.-ar 54

y.-dač 19

yaya

a. AppA18

yay1-

y.-1p E06

yayılmak

y.+1n E06

yap

$\mathrm{y} \cdot+\operatorname{larin}$ D04

yapran-

[yap]ran-mıš D14

yar

y. D15

yar-

y.-1p B118

yarat-

y.-miš AppA01

yaratig

$y .+169,97$

yaratiglig

y. 19

yaratin-

y.-dačı 119

yarı̌ y.+ka AppA19

y(a)rlig

y. B131

y[arligin] AppB02

yarlıka-

y.-r 25, 105

y.-mazun $26,68,106$, yarl[1kamazun] D25

y.-sar 7, 17, 28, 37, 50, 58, 70, 78, 87, 98, 108,121, D10

y.-miš 7, 16, 28, 49, 70, 77, 97, 108, F20, G12

y(a)rlıka-mišı AppB28

yars1-

y.-guluk 13

yarsınčig

y. F28

yaruk

y. D09

yaškın-

y.-miš 109

yaš-

y.-maz 60

yaša-

y.-guluk1 73

yašamak 
$\mathrm{y} \cdot+1 \mathrm{AppB} 27$

yašlıg

y. 91, B071

yat

y. F01

yav1l-

y.-u E08

yavišgu

$\mathrm{y} \cdot+\operatorname{larin}$ D04

yavız

y. 34, 37, 46, 55, 85, B062, D11, F17, F28, y(a)v1z B071

y.+1g 18

yavlak

y(a)vlak AppB12

$\mathrm{y} .+1 \mathrm{H} 01$

yavrımak

у.+1 AppB19

[yavr1]mak1 AppB21

[yavr1]mak1 AppB17

yaz

y. F37

yägän

y(ä)gä[n]-lärig AppB08

yäk y. 32

yänä

y. AppB27

yedürmäk

y. 81

yeg

у. AppB03

yegäd-

y.-miš 36,58

yel

y. 34

yeel

y. 83

yelpik

y. 41

yelpikmäk

y.+intin 32

yenik

y. E10

yer

y. 116, AppA13

y.+kä AppB04, AppB05

y.+i AppA05

y. suv 15

y.+nin H02 
y.+indäki 90, 90, 92, y.+intäki B060

yertinčü

y. 15, B019, AppA13

y.+nün 96, 97

y.+tä 122

y.+dä AppA16

y.+sindäki 74

yertinčülüg

y. D04, D08

yeti

y. $20^{\mathrm{CH}}$

y1git

$y \cdot+1 n$ I15

yiglat-

y.-u 113

$\mathrm{y} 11$

y.+1n AppA15

yımrak

y. E02

yinak

$y \cdot+\operatorname{tin} 51$

y(i)g(i)rmi

y.+kä 136

yigit y. 13, E09, yigi[t] E05

yimir-

y.-däčilär 61

yimril-

y.-ür AppA06

yinčü

y. 10

yint-

y.-miš 36, 58

yinli[g]

y. D11

yipün

y. E03

yit-

y.-d[i]m[iz] AppB01

yitgün-

y.-äyin E11

yitlinmäk

$\mathrm{y} .+\mathrm{i}$ AppB17

ymä

y. $20,23,24,31,40,45,45,54$, $63,66,67,78,90,92,93,103,130$, F21, I14

yodun

y. AppA12

yok 
y. D06, AppA12

yol

y.+ta 118, AppB12

y.+larta AppB09

yonamat

y. E05

yor1-

y.-dač1 90, 118

y.-gma 53

y.-yu 52

yölän-

y.-miš 110

yörgän-

y.-miš 109

yuul

y. 48

y[uu $] 1+1[a r]$ D01

yula

y. D09

yumur- y.-ur 54

yülit-

y.-miš 109

y.-ip 126

yüp

y. E19

yürün

y. 10, E19, F10

yürüyädtür-

y.-täči F10

yürünärt-

y.-täči 9

yüz

y. 43,44

y.+i AppA02, AppA02, AppA03, AppA03

yüüz

y.+intä 100, E03

yüzsüz

y. AppA12 


\section{$J(\Theta)$}

\section{Abkürzungen}

ADAW $=$ Abhandlungen der Deutschen Akademie der Wissenschaften, Berlin .

Altuig. $=$ Altuigurisch .

AN = An்guttara Nikāya (Thanissaro Bhikkhus Internet translation).

APAW = Abhandlungen der Preussischen Akademie der Wissenschaften, Berlin.

ARIRIAB = Annual Report of the International Research Institute for Advanced Buddhology at Soka University.

AYS = Altun Yaruk Sudur (Suv.).

BSJT = Waku 1979 .

BT $=$ Berliner Turfantexte .

BT $3=$ Tezcan 1974.

BT 7 = Kara-Zieme 1975.

BT 13 = Zieme 1985

BT $20=$ Zieme 2000.

BT 25 = Wilkens 2007.

BT 34 = Shōgaito et al. 2015.

BT 37 = Wilkens 2016.

BT 43 = Vér 2019 .

BT 47 = Zieme 2021.

chin.$=$ chinesisch

DDB = Digital Dictionary of Buddhism (Charles Muller).

DKPAM = Daśakarmapathāvadānamālā.

DKPAM-H = Daśakarmapathāvadānamālā Tömürtü-Version (zuvor Hami-Version genannt).

DLT = Dīvān lugāt at-türk.

DTS = Nadeljaev et al. 1969 .

$\mathrm{ED}=$ Clauson 1972. 


\section{J(G)}

ETŞ = Arat 1965

GOT $=$ Erdal 2004

HT V = Dietz et al. 2015.

HT VII = Röhrborn 1991.

IDP = International Dunhuang Project.

IOM = Institute of Oriental Manuscripts of the Russian Academy of Sciences.

MK = Maḥmūd al-Kāšgarī (DLT).

MW = Monier-Williams 1899 .

OTWF = Erdal 1991

SH = Soothill-Hodous 1937

Skt. $=$ Sanskrit.

SN = Samyutta Nikāya.

SPAW = Sitzungsberichte der Preussischen Akademie der Wissenschaften, Berlin.

Suv. $=$ Radloff-Malov 1913-1917.

SWTF I-IV = Hartmann 1994-2019.

T. = Taishō shinshū daizōkyō.

TETTL = Tietze 2016-2019.

TT I = Bang-Gabain 1929.

TT VI = Bang et al. 1934 .

TT VII = Rachmati 1936.

TT X = Gabain-Kowalski 1958.

$\mathrm{UAJb}=$ Ural-Altaische Jahrbücher .

UWN/1 = Röhrborn 2015.

UWN/2 = Röhrborn 2017.

UWV/1 = Röhrborn 2010.

UWV/2 = Özertural-Röhrborn 2020.

VOHD $=$ Veröffentlichungen der Orientalischen Handschriften in Deutschland . 


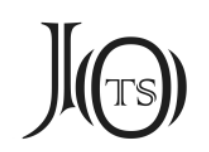

\section{Literaturverzeichnis}

AKANumA，C. (1967). 印度佛教固有名詞辞典 Indo bukkyō koyūmeishi jiten [Wörterbuch der indischen buddhistischen Namen], Kyoto: Hōzōkan.

Apple, J. B. (2008). Stairway to Nirvana, a Study of the Twenty Samghas Based on the Works of Tsong Kha Pa, New York: State University of New York Press.

ARAT, R. R. (1965). Eski Türk Şiiri, Ankara: Türk Tarih Kurumu Yayınları.

Aydemir, H. (2003). “Altaic etymologies: tōz, toprak, toyosun", Turkic Languages, 7: 105-143.

BANG, W. \& A. v. Gabain (1929). Türkische Turfan-Texte I: Bruchstücke eines Wahrsagebuches, Berlin. (SPAW. Phil.-hist. Kl. 1929: 15, 241-268)

BANG, W. et al. (1934). Türkische Turfan-Texte VI: das buddhistische Sūtra Säkiz yükmäk, Berlin. (SPAW. Phil.-hist. Kl. 1934: 10, 93-192)

BhiKKнu, T. (1997). Translation of Pabbatopama Sutta: The Simile of the Mountains. (Internet Version)

BURHÂN-I KATI (2009). Mütercim Âsım Efendi, Burhân-1 Katı, Haz. M. ÖztÜRK, Ankara: Türk Dil Kurumu Yayınları.

CicuzzA, C. (2011). A Mirror Reflecting the Entire World. The Pāli Buddhapādamanigala or "Auspicious Signs on the Buddha's Feet", Bangkok: Lumbini International Research Institute.

Clauson, Sir G. (1972). An Etymological Dictionary of Pre-Thirteenth Century Turkish, Oxford: Oxford University Press.

CleAves, F. W. (1993). "The Fifth Chapter of an Early Mongolian Version of the Hsiao Ching”, Mongolian Studies, 16: 19-40.

DanKoff, R. \& J. Kelly (1984). Maḥmūd al-Kāş̧arĩ: Compendium of the Turkic Dialects (Dīvān Luүāt at-Türk) II, Harvard: Harvard University Press.

DAYAL, H. (1932). The Bodhisattva Doctrine in Buddhist Sanskrit Literature, Delhi: Motilal Banarsidass.

DeEG, M. (2003). The Places Where Siddhārta Trod: Lumbinī and Kapilavastu, Lumbini: Lumbini International Research Institute.

DiETZ, S. (2003). "Kosmologie nach den buddhistischen Sanskrit-Texten aus Zentralasien”, Indien und Zentralasien, Sprach- und Kulturkontakt, Vorträge des 


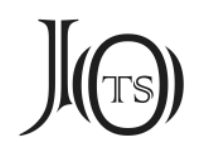

Göttinger Symposions vom 7. bis 10. Mai 2001, hrsg. von S. BRETFELD \& J. WiLKENS, Harrassowitz Verlag, Wiesbaden: 207-225.

DiETZ, S. (2004). "The Sanskrit Abhidharma Fragments from the Turfan Oasis", Turfan Revisited: the First Century of Research into the Arts and Cultures of the Silk Road, hrsg. von D. DURKIN-MEISTERERNST et al. Reimer, Berlin: 59-67.

DiETz, S. et al. (2015). Die alttürkische Xuanzang-Biographie, nach der Handschrift von Paris und St. Petersburg sowie nach dem Transkript von Annemarie v. GabAin, Wiesbaden: Harrassowitz Verlag.

DOERFER, G. (1993). Versuch einer linguistischen Datierung älterer osttürkischer Texte, Wiesbaden: Harrassowitz Verlag.

EHLERS, G. (1990). “Kurzfassungen buddhistischer Legenden im Alttürkischen”, Buddhistische Erzählliteratur und Hagiographie in türkischer Überlieferung, hrsg. von J. P. LAUT \& K. RÖHRBORN, Harrassowitz Verlag, Wiesbaden: 1-14.

ERDAL, M. (1991). Old Turkic Word Formation. A Functional Approach to the Lexicon I-II, Wiesbaden: Harrassowitz Verlag.

ERDAL, M. (2004). A Grammar of Old Turkic, Leiden-Boston: Brill.

GABAIN, A. von \& T. KowALSKI (1958). Türkische Turfan-Texte X: das Avadāna des Dämons Āṭavaka, Berlin: Akademie Verlag.

GENG, S. \& H. J. KLIMKEIT (1988). Das Zusammentreffen mit Maitreya, die ersten fünf Kapitel der Hami-Version der Maitrisimit I-II, Wiesbaden: Harrassowitz Verlag.

GENG, S. et al. (1992). "Der Gang zum Bodhi-Baum, das 14. Kapitel der HamiHandschrift der Maitrisimit”, Materialia Turcica, 16: 25-47.

GENG, S. et al. (1993). "Das Erlangen der unvergleichlichen Buddhawürde, das 15. Kapitel der Hami-Handschrift der Maitrisimit”, Altorientalische Forschungen, 20: 182234.

GENG, S. et al. (2005). "Fragmente der uigurischen Daśakarmapathāvadānamālā aus Hami (Teil 1)", UAJb Neue Folge, 19: 72-121.

GulCALI, Z. (2013). Eski Uygurca Altun Yaruk Sudur'dan “Aç Bars” Hikâyesi, Ankara: Türk Dil Kurumu Yayınları.

GulCALI, Z. (2019). “Altun Yaruk Sudur X. Kitaptaki Yazım Yanlışları Üzerine”, International Journal of Old Uyghur Studies, 1/1: 73-88. 


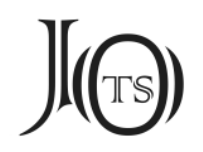

國家圖書館藏敦煌遺書 Guojia tushuguan cang Dunhuang yishu [DunhuangManuskripte der Nationalbibliothek Chinas] (2010). Bd. 135, Beijing tushuguan chubanshe, Beijing.

GüL, B. (2016). “Eski Türkçe Tarıgçı 〈Tarımçı Ekinci〉 Adı Üzerine”, Türkbilig, 32: 85-96.

HAHN, M. (2007). Vom rechten Leben. Buddhistische Lehren aus Indien und Tibet, Frankfurt am Main und Leipzig: Verlag der Weltreligionen im Insel Verlag.

HANSEN, V. (2020). The Year 1000. When Explorers connected the World and Globalization Began, New York London Toronto Sydney New Delhi: Penguin.

HARTMANN, J.-U. (1994-2019). Sanskrit-Wörterbuch der buddhistischen Texte aus den Turfan-Funden, Göttingen: Vandenhoeck \& Ruprecht.

HAUENSCHILD, I. (1994). "Botanica im Dīwān lugāt at-turk", Journal of Turkology, 2: $25-100$.

HōBōGIRIN (1929-1994). Dictionnaire Encyclopédique de Bouddhisme d'après les sources chinoises et japonaises, hrsg. von S. Levi et al. Tokyo: Maison Franco-Japonaise.

HŌBŌGIRIN (1978). Répertoire du canon bouddhique Sino-Japonais: édition de Taishō (Taishō Shinshū Daizōkyō), hrsg. von P. Demieville et al. Tokyo/Paris: Libraire d'Amérique et d'Orient.

HöKE, H. (1984). "Das P'u-sa pen-yüan ching (Frühere Leben des Bodhisattva). Eine Sammlung buddhistischer Geschichten”, Bochumer Jahrbuch zur Ostasienforschung, 7: 113-213.

HuANG, Z. (2005). 敦煌俗字典 Dunhuang su zidian [Dictionary of Vernacular Characters from Dunhuang], Shanghai: Shanghai jiaoyu chubanshe.

HUCKER, C. O. (1985). A Dictionary of Official Titles in Imperial China, Stanford: Stanford University Press.

ICHIMURA, S. (2015). The Canonical Book of the Buddha's Lengthy Discourses (Taishō Volume I, Number 1), Moraga/Calif.

INAGAKI, H. (1994). The Three Pure Land Sutras. A Study and Translation from Chinese, in collaboration with H. STEWART, Kyoto: Nagata Bunshodo.

IMIN, T. (2020). 吐峪沟 出土 回鹘文《土都木萨里修寺碑》研究 “Tuyugou chutu Huihuwen «Tudumu Sali xiusi bei» yanjiu", [Studie über die in Tuyuq entdeckte 


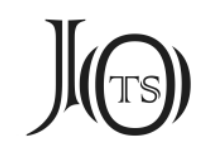

uigurische Inschrift über die Tempelrestaurierung durch Tudum Šäli], Hexi xueyuan xuebao [Zeitschrift der Hexi-Studien], 36/1, 1-7.

KAGAWA, M. (1915). 西域考古図譜 Saiiki kōko zufu I-II [Archäologische Funde der Westlande], Tokyo: Kokkasha.

KARA, G. \& P. ZIEME (1976). Fragmente tantrischer Werke in uigurischer Übersetzung, BT 7, Berlin: Akademie Verlag.

KARTtUnen, K. (2015). Yonas and Yavanas in Indian Literature, Helsinki: Finnish Oriental Society.

KASAI, Y. (2017). Die altuigurischen Fragmente mit Brāhmī-Elementen, unter Mitarbeit von H. OGIHARA, BT 38, Turnhout (Belgium): Brepols Publishers.

KAYA, C. (1994). Uygurca Altun Yaruk. Giriş, Metin ve Dizin, Ankara: Türk Dil Kurumu Yayınları.

Kirfel, W. (1920). Die Kosmographie der Inder nach den Quellen dargestellt, Hildesheim: Olms.

Kitsudō, K. (2013). Liao Influence on the Uighur Buddhism, Studies in Chinese Manuscripts: From the Warring States Period to the 20th Century, hrsg. von I. Galambos, Institute of East Asian Studies, Eötvös Loránd University Budapest: 226-247.

Kloppenborg, R. (1974). The Paccekabuddha. A Buddhist Ascetic. A Study of the concept of the paccekabuddha in Pāli canonical and commentarial Literature, Leiden: Brill.

LANGER, R. (2013). Sermon Studies and Buddhism. A Case Study of Sri Lankan Preaching, Tokyo: The International Institute for Buddhist Studies.

LAUT, J. P. \& K. RÖHRBORN (1990). Buddhistische Erzählliteratur und Hagiographie in türkischer Überlieferung, Wiesbaden: Harrassowitz Verlag.

LAUT, J. P. \& P. ZiEME (1990). “Ein zweisprachiger Lobpreis auf den Bäg von Kočo und seine Gemahlin", Buddhistische Erzählliteratur und Hagiographie in türkischer Überlieferung, hrsg. von J. P. LAUT \& K. RÖHRBORN, Harrassowitz Verlag, Wiesbaden: 1536.

LAUT, J. P. (1986). Der frühe türkische Buddhismus und seine literarischen Denkmäler, Wiesbaden: Harrassowitz Verlag. 


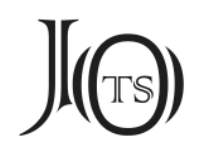

LAUT, J. P. (2017). “Tod im Buddhismus, eine systemimmanente Zwischenstation, Leben und Tod”. Akademie im Gespräch (Göttingen), 2: 79-90.

LIN, L.-K. (1949). L'aide-Mémoire de la Vraie Loi (Saddharma-smṛtyupasthānasūtra), Recherches sur un Sūtra Développé du Petit Véhicule, Paris: AdrienMaisonneuve.

MaGAIL, J. et al. (2010). "Découverte d'une inscription turque proche de Tsatsyn Ereg (Montagne de Khoyor Khavchig, Arkhangaï, Mongolie)", Bulletin du Musée d'Anthropologie Préhistorique de Monaco, 50: 115-119.

Malalasekera, G. P. (1960). Dictionary of Pali Proper Names I-II, London: Luzac.

Mathew, R. M. (1963). Chinese-English Dictionary (A Chinese-English Dictionary Compiled for the China Inland Mission): Revised American Edition, Cambridge: Harvard University Press.

MATSUI, D. (2004). シヴシドゥ・ヤクシドゥ關係文書とトヨク石窟の佛教教 團: ペテルブルク所藏ウイグル語世俗文書笭記 Shivushido, Yakushido kankei bunsho to Toyoku sekkutsu no bukkyō kyōdan -Peteruburuku shozō Uigurugo sezoku monjō sakki- [Notes on the Uigur Secular Documents from the St. Petersburg Collection: Buddhist Monastery of the Toyoq Caves as Revealed from the Texts Related to Monks Sivšidu and Yaqšidu], Papers on the Pre-Islamic Documents and Other Materials Unearthed from Central Asia, hrsg. von T. MoRIYASU, Hōyū Shoten, Kyoto: 4170.

MAUE, D. (1996). Alttürkische Handschriften, Teil 1: Dokumente in Brāhmī und tibetischer Schrift, VOHD XIII,9, Stuttgart: Franz Steiner Verlag.

MAUE, D. (2002). "Altbekanntes und Neues. Bruchstücke des uigurischen Almanachs von 1277/78", Nairiku Ajia gengo no kenkyū [Studies on the Inner Asian Languages], 17: 77-115.

MAUE, D. (2016). “Im Tode endet ja das Leben”, (www.academia.edu, 16.9.2016).

MeIER, F. J. [1988]. Die Mythologie des chinesischen Buddhismus, Klett-Cotta [1988] (Wörterbuch der Mythologie. I. Abteilung Die alten Kulturvölker 23. + 24. Lieferung).

Mirkamal, A. \& P. Zieme (2021). New Texts from Beijing. (im Druck)

MIRKAMAL, A. (2015). 回鹘文诗体注疏和新发现敦煌本韵文研究 Huihu wen shi ti zhushu he xin faxian Dunhuang ben yunwen yanjiu [Alliterative Verse Commentaries 


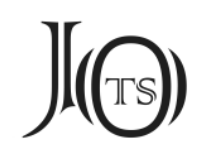

in Old Uyghur and Newly Unearthed Verses from Dunhuang], Shanghai: Chinese Classics Publishing House.

MitANI, M. (2018). 大谷隊ドイッ隊収集漢字仏典断片目録 Ōtani-tai Doitsu-tai shūshū kanji butten dampen mokuroku [A Catalogue of Chinese Buddhist Fragments Collected by Otani and German Turfan Expedition], Ryūkoku Daigaku.

MonieR-Williams, M. (1899). A Sanskrit-English Dictionary, Etymologically and Philologically Arranged with Special Reference to Cognate Indo-European Languages, Oxford.

Mus, P. (1939). La lumière sur les six voies. Tableau de la transmigration bouddhique d'après des sources sanskrites, pāli, tibétaines et chinois en majeure partie inédites, Paris: Institut d'Ethnologie.

MYLIUS, K. (1975). Wörterbuch Sanskrit-Deutsch, Leipzig: Verlag Enzyklopädie.

NADELJAEv, V. M. et al. (1969). Drevnetyurkskiy Slovar', Leningrad: İzdatel'stvo "Nauka" Leningradskoye Otdeleniye Leningrad.

NAKAMURA，H. (1975). 仏教語大辞典 I-III Bukkyō go daijiten I-III [Großes Buddhistisches Wörterbuch I-III], Tokyo: Tokyo Shoseki.

NatTiER, J. (1991). Once upon a future time. Studies in a prophecy of decline. Nanzan Insitute for Religion and Culture, California: Asian Humanities Press.

NATTIER, J. (2003). "The Ten Epithets of the Buddha in the Translations of Zhi Qian 支謙”, Annual Report of the International Research Institute for Advanced Buddhology at Soka University, 6: 207-250.

NoBeL, J. (1958). Suvarṇaprabhāsottamasūtra, das Goldglanz-Sūtra. Ein Sanskrittext des Mahāyāna-Buddhismus, I-Tsing's chinesische Version und ihre tibetische Übersetzung I-II, Leiden: Brill.

ODA, J. (1996). "A Fragment of the Uighur Avalokiteśvara-Sūtra with Notes", Turfan, Khotan und Dunhuang, Vorträge der Tagung "Annemarie v. Gabain und die Turfanforschung", veranstaltet von der Berlin-Brandenburgischen Akademie der Wissenschaften in Berlin (9. - 12. 12. 1994), hrsg. von R. E. EMMERICK et al. Akademie Verlag, Berlin, 229-243.

ODA, J. (2003). "Indian Buddhist Missions to Uighuristan, based on Chinese sources", Indien und Zentralasien, Vorträge des Göttinger Symposions vom 7. bis 10. Mai 2001, hrsg. von S. BRETFELD \& J. WiLKENS, Harrassowitz Verlag, Wiesbaden: 25-43. 


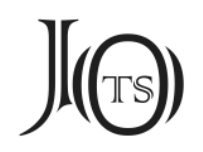

ODA, J. (2009). "«Reasons and motives for meritorious deeds» (Skt. Punyakriyāvastu), written in Turkic and Sanskrit, transcribed and translated in collaboration with Professor Shunkan Murakami”, Studies in Turkic Philology, Festschrift in honour of the 80th birthday of Professor Geng SHIMIN, hrsg. von D. ZHANG \& A. YAKUP, Beijing: 358-376.

ODA, J. (2015). A Study of the Buddhist Sūtra called Säkiz Yükmäk Yaruq or Säkiz Törlügin Yarumiš Yaltrïmǐs in Old Turkic, BT 33, Turnhout (Belgium): Brepols Publishers.

ORZECH, C. D. (1998). Politics and Transcendent Wisdom: The Scripture for Humane Kings in the Creation of Chinese Buddhism, Pennsylvania: Pennsylvania State University.

ÖZERTURAL, Z. \& K. RÖHRBORN (2020). Uigurisches Wörterbuch, Sprachmaterial der vorislamischen türkischen Texte aus Zentralasien I/2: edäd- - iztä-, Stuttgart: Franz Steiner Verlag.

Poppe, N. (1967). The Twelve Deeds of Buddha, a Mongolian Version of the Lalitavistara. Mongolian Text, Notes, and English Translation, Wiesbaden: Harrassowitz Verlag.

Pulleyblank, E. G. (1991). Lexicon of Reconstructed Pronunciation in Early Middle Chinese, Late Middle Chinese, and Early Mandarin, Vancouver: UBC Press.

Rachmati, G. R. (1936). Türkische Turfan-Texte VII, Berlin (APAW 1936, Nr. 12).

Rachmeti, G. R. (1932). Zur Heilkunde der Uiguren II, Berlin (SPAW. Phil.-hist. Kl. 1932/22: 401-448).

RadLov, V. \& S. E. MALov (1913-1917). Suvarṇaprabhāsa (Sutra zolotogo bleska), Tekst' uygurskoy redaktsii I-IV, Bibliotheca Buddhica: XVII, Sanktpeterburg.

RAschmann, S.-CH. \& O. F. SeRTKAyA (2016). Alttürkische Handschriften, Teil 20: Alttürkische Texte aus der Berliner Turfansammlung im Nachlass Reşid Rahmeti Arat, VOHD XIII,28, Stuttgart: Franz Steiner Verlag.

RÁSONYI, L. \& İ. BASKi (2007). Onomasticon Turcicum. Turkic Personal Names I-II, Bloomington: Indiana University Press.

RÖHRBORN, K. (1988). "Zur Darstellung der Gutturale in den indischen Fremdwörtern des Uigurischen", Central Asiatic Journal, 32: 232-243. 


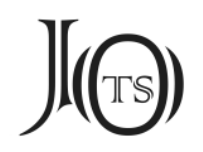

RöHRBORN, K. (1991). Die alttürkische Xuanzang-Biographie VII, nach der Handschrift von Paris, Peking und St. Petersburg sowie nach dem Transkript von Annemarie v. Gabain, Wiesbaden: Harrassowitz Verlag.

RÖHRBORN, K. (2010). Uigurisches Wörterbuch, Sprachmaterial der vorislamischen türkischen Texte aus Zentralasien I/1: ab- - äzüglä-, Stuttgart: Franz Steiner Verlag.

RÖHRBORN, K. (2015). Uigurisches Wörterbuch, Sprachmaterial der vorislamischen türkischen Texte aus Zentralasie II/1: a - asvık, Stuttgart: Franz Steiner Verlag.

RÖHRBORN, K. (2017). Uigurisches Wörterbuch, Sprachmaterial der vorislamischen türkischen Texte aus Zentralasie II/2: aš - äžük, Stuttgart: Franz Steiner Verlag.

RyBAtzKi, V. (2008). "Farbigkeit und Vielfalt. Einiges zum Pfau und seinen Bezeichnungen in den zentralasiatischen Sprachen", Nairiku Ajia gengo no kenkyū [Studies on the Inner Asian Languages], 23: 187-207.

SAlguero, C. P. (2017a). Buddhism and Medicine, an Anthology of Premodern Sources, New York: Columbia University Press.

Salguero, C. P. et al. (2017b). "Medicine in the Chinese Buddhist Canon, Selected Translations", Asian Medicine, 12: 279-294.

SAlomon, R. \& S. BAums (2007). "Sanskrit Ikṣvāku, Pāli Okkāka, and Gāndhārī Ișmaho", Journal of the Pali Text Society, 29: 201-227.

Schlingloff, D. (1962). Die Religion des Buddhismus, I. Der Heilsweg des Mönchtums (Göschen 174), Berlin: de Gruyter.

Schlingloff, D. (1963). Die Religion des Buddhismus, II. Der Heilsweg für die Welt (Göschen 770), Berlin: de Gruyter.

Schlingloff, D. (1977). “Zwei Anatiden-Geschichten im alten Indien”, Zeitschrift der Deutschen Morgenländischen Gesellschaft, 127: 370-397.

Schlingloff, D. (2015). Die übermenschlichen Phänomene, Visuelle Meditation und Wundererscheinung in buddhistischer Literatur und Kunst, ein religionsgeschichtlicher Versuch, Düsseldorf: EKO Haus der japanischen Kultur.

SERTKAyA, P. (2011). Türk Tarihinde Terkenler, Selçuk Üniversitesi, Sosyal Bilimler Enstitüsü, Tarih Anabilim Dalı, Ortaçă̆ Tarihi Bilim Dalı, Konya. (Unveröffentlichte Masterarbeit) 


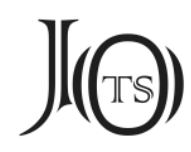

ShōGAITo, M. (1978). "On the routes of the loan words of Indic origin in The Old Uigur language”, Journal of Asian and African Studies, 15: 79-110.

SHōGAITo, M. (1988). “Drei zum Avalokiteśvara-sūtra passende Avadānas”, Der türkische Buddhismus in der japanischen Forschung, hrsg. von J. P. LAUT \& K. RÖHRBORN, Harrassowitz Verlag, Wiesbaden: 56-119.

SHōGAITO, M. et al. (2015). The Berlin Chinese text U 5335 written in Uighur script. A reconstruction of the Inherited Uighur Pronunciation of Chinese, BT 34, Turnhout (Belgium): Brepols Publishers.

Skilling, P. (2012)." Discourse on the Tenty-Two Daculties. Translated from Śamathadeva's Upāyikā-Ṭīkā", Dharmapravicaya, Aspects of Buddhist Studies. Essays in Honour of Professor Narayan Hemandas SAMTANI, Delhi, 399-434.

SoothiLL, W. E. \& L. Hodous (1937). A Dictionary of Chinese Buddhist Terms with Sanskrit and English Equivalents and a Sanskrit-Pali Index, London: Kegan Paul, Trench, Trübner \& Co.

StachowsKi, M. (2019). Kurzgefaßes etymologisches Wörterbuch der türkischen Sprache, Kraków: Księgarnia Akademicka.

STEINGASS, F. (1892). A Comprehensive Persian-English Dictionary, Including the Arabic Words and Phrases to be Met with in Persian Literature, Second Impression, London: Kegan Paul, Trench, Trübner \& Co. Ltd.

TEZCAN, S. \& P. ZIEME (1994). “Alttürkische Reimsprüche, ein neuer Text”, Journal of Turkology, 2: 259-271.

TEZCAN, S. (1974). Das uigurische Insadi-Sutra, BT 3, Berlin: Akademie Verlag.

TIETZE, A. (2016-2019). Tarihi ve Etimolojik Türkiye Türkçesi Lugati I-VIII, Ankara: Türkiye Bilimler Akademisi Yayınları.

VAn Tongerloo, A. \& M. KnÜPPel (2011-2012). “Die Briefe von E. Ritter von Zach an W. Bang Kaup", Nachrichten der Ost-Asiatischen Gesellschaft, 187-188: 293-317.

VÉR, M. (2019). Old Uyghur Documents Concerning the Postal System of the Mongol Empire, BT 43, Turnhout (Belgium): Brepols Publishers.

Vovin, A. (2019a.) "A Sketch of the Earliest Mongolic Language: the Brāhmī Bugut and Khüis Tolgoi Inscriptions”, International Journal of Eurasian Linguistics, 1: 162-197. 


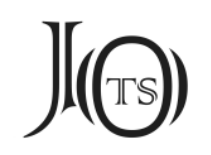

Vovin, A. (2019b). "Röhrborn, Klaus: Uigurisches Wörterbuch. Sprachmaterial der vorislamischen türkischen Texte aus Zentralasien. Neubearbeitung. II. Nomina Pronomina - Partikeln. Band 1: a - asvık. Stuttgart: Franz Steiner 2015", Orientalistische Literaturzeitung, 114: 169-170. (Rezension)

WAKU, H. (1979). 仏教植物辞典 Bukkyō shokubutsu jiten [Wörterbuch der buddhistischen Flora], Tokyo: Kokusho Kankōkai.

WALDSChmidT, E. (1929). Die Legende vom Leben des Buddha, in Auszügen aus den heiligen Texten, Berlin: Wegweiser Verlag.

WALDSCHMIDT, E. (1953-1956). Das Mahāvadāna-sūtra, ein kanonischer Text über die sieben letzten Buddhas I-III, Berlin: Akademie Verlag.

WeBER, C. (1999). Buddhistische Sutras, das Leben des Buddha in Quellentexten, Kreuzlingen/München: Hugendubel.

Weltsch, U. (2011). Das Mahabharata, deutsche Komplettübersetzung aus den englischen Versionen von Kisari Mohan Ganguli (1883-1896) und Manmatha Nath Dutt (1895-1905) III: Buch - Vana Parva - Das Buch des Waldes. (Internet-Ausgabe)

WilKENS, J. (2007). Das Buch von der Sündentilgung. Edition des alttürkischbuddhistischen Kšanti Kilguluk Nom Bitig I-II, BT 25, Turnhout (Belgium): Brepols Publishers.

WiLKENS, J. (2016a). Buddhistische Erzählungen aus dem alten Zentralasien. Edition der altuigurischen Daśakarmapathāvadānamālā, I-III, BT 37, Turnhout (Belgium): Brepols Publishers.

WilKENS, J. (2016b). "Buddhism in the West Uyghur Kingdom and Beyond", Transfer of Buddhism across Central Asian Networks (7th to 13th Centuries), hrsg. von C. MEINERT, Brill, Leiden/Boston: 191-249.

WiLKENS, J. (2017). "The Old Uyghur translation of the Bieyi za ahanjing (1935.52.0012-0015)", The Old Uyghur Ägama fragments preserved in the Sven Hedin collection, Stockholm, hrsg. von Y. KASAI et al. Brepols Publishers, Turnhout (Belgium): 197-280.

Wogihara, U. (1979). Sanskrit-Chinese-Japanese Dictionary, Tokyo: Suzuki Research Foundation.

YAKUP, A. (2019). “An Old Uyghur Appeal to T(ä)ngrikän Tegin T(ä)ngrim to Renounce Secular Life", Turkic Languages, 23: 6-30. 


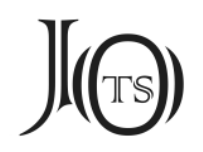

YАмамото, K. (2007). The Mahayana Mahaparinirvana Sutra. (Internet-Version).

YÜsüP, I. (2004). "Die uigurische Übersetzung des Bhaișajyagurusūtra nach einem Blockdruck aus Turfan", Turfan Revisited: the First Century of Research into the Arts and Cultures of the Silk Road, hrsgg. von D. DuRKIN-MeIsterernst et al. Reimer, Berlin: 411-415.

ZHANG, T. \& P. Zieme (2011). "A memorandum about the King of the On Uygur and his Realm”, Acta Orientalia Academiae Scientiarum Hungaricae, 64: 129-159.

ZIEME, P. (1981). “Ein Hochzeitssegen uigurischer Christen”, Scholia, Beiträge zur Turkologie und Zentralasienkunde, Annemarie von Gabain zum 80. Geburtstag am 4. Juli 1981 dargebracht von Kollegen, Freunden und Schülern, hrsg. von K. RöHRBORN, Harrassowitz Verlag, Wiesbaden: 221-232.

ZIEME, P. (1989). "Die Vorrede zum alttürkischen Goldglanz-Sūtra von 1022", Journal of Turkish Studies, 13: 237-243.

ZIEME, P. (1992). Religion und Gesellschaft im Uigurischen Königreich von Qočo, Kolophone und Stifter des alttürkischen buddhistischen Schrifttums aus Zentralasien, Opladen: Westdeutscher Verlag.

ZIEME, P. (2000). Vimalakīrtinirdeśasūtra, Edition alttürkischer Übersetzungen nach Handschrift-fragmenten von Berlin und Kyoto, mit einem Appendix von Jorinde Ebert: ein Vimalakirti-Bildfragment aus Turfan, BT 20, Turnhout (Belgium): Brepols Publishers.

ZIEME, P. (2002). "Ein weiteres alttürkisches Fragment des «Sūtras von der Vollkommenen Erleuchtung»”, Acta Orientalia Academiae Scientiarum Hungaricae, 55: 281-295.

ZIEME, P. (2005). Magische Texte des uigurischen Buddhismus, BT 23, Turnhout (Belgium): Brepols Publishers.

ZIEME, P. (2013). "Das Muschelhorn, eine chinesisch-altuigurische Erklärung", Yalım Kaya Bitigi: Osman Fikri SERTKAYA Armağanı, hrsg. von H. Ş. UsER \& B. GÜL, Türk Kültürünü Araştırma Enstitüsü Yayınları, Ankara: 673-680.

ZIEME, P. (2014). “Altuigurische Wörter (2)”. (www.academia.edu 2014)

ZIEME, P. (2015). Altuigurische Texte der Kirche des Ostens, Piscataway: Gorgias Press Llc. 


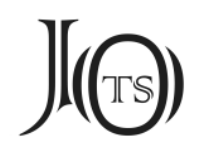

ZiEME, P. (2016). “An Old Uighur Fictional Letter Supposedly Written by Prince Gautama from a Fragment in the Serindia Collection at the IOM, RAS", Written Monuments of the Orient, 2016/1: 64-72.

ZIEME, P. (2016). “Rezension von BT 37”. (www.academia.edu 2016)

ZIEME, P. (2017a). "Premières notes sur quelques fragments vieux-ouïgours de Paul Pelliot". (www.academia.edu 2017)

ZiEME, P. (2017b). "Manichaean Turkic texts in the Ōtani Collection of the Library of Ryūkoku University", Essays on the Manuscripts written in Central Asian Languages in the Otani Collection, Buddhism, Manichaeism, and Christianity, Kyoto, Research Institute for Buddhist Culture, Ryūkoku University; Research Center for World Buddhist Cultures, Eds. by T. IRISAWA \& K. KITSUDO, 45-70. Online (augmented version).

ZIEME, P. (2020a). "Buddhist Pāramitās as Seen from Old Uygur Texts", Annual Report of the International Research Institute for Advanced Buddhology at Soka University, 23: 147-165.

ZiEME, P. (2020b). “Notes on the Toyok inscription”, Nairiku Ajia gengo no kenkyu [Studies on the Inner Asian Languages]. (im Druck)

ZIEME, P. (2021). Minora fragmenta veterorvm vigvrorvm, BT 47, Turnhout (Belgium): Brepols Publishers. (im Druck).

Zieme, P. \& G. KARA (1978). Ein uigurisches Totenbuch, Nāropas Lehre in uigurischer Übersetzung von vier tibetischen Traktaten nach der Sammelhandschrift aus Dunhuang British Museum Or. 8212 (109), Wiesbaden: Harrassowitz Verlag.

Zieme, P. \& K. KudARA (1985). Guanwuliangshoujing in Uigur, Kyoto: Nagata Bunshōdō.

Zin, M. \& D. Schlingloff (2007). Saṃsāracakra, das Rad der Wiedergeburten in der indischen Überlieferung, Düsseldorf: EKO Haus der Japanischen Kultur. 


\section{J(৫)}

\section{Tafeln}

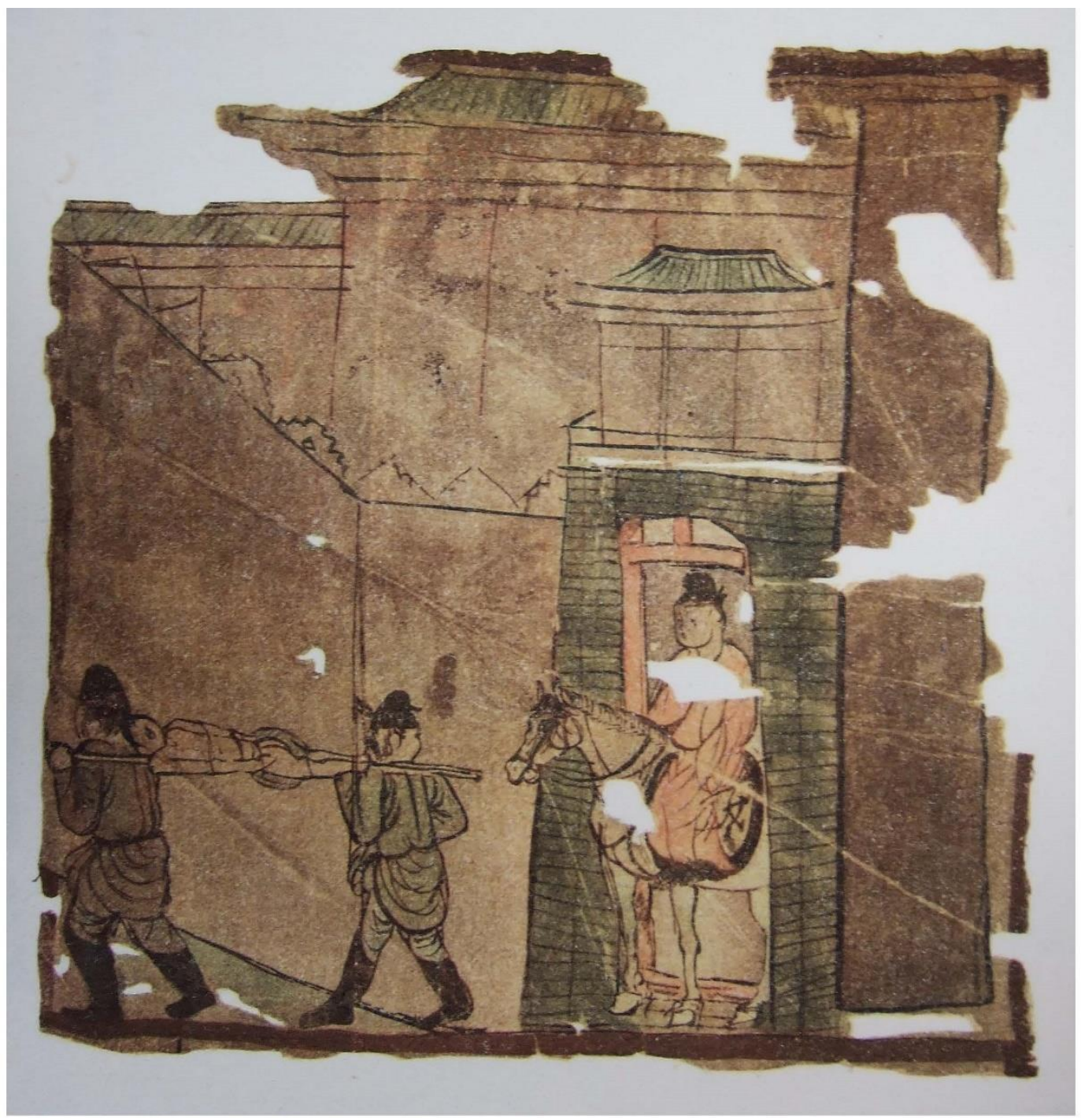

Abb. I

Nach Kagawa 1915, Tafel 37: Aus Toyok stammendes Fragment, heute vermißt. Es handelt sich um ein Seidenbild aus einem Buch, das vermutlich eine Buddhavita enthielt. Man sieht den Prinzen beim Ausritt, wie er einem Toten begegnet. "Zu wieder einer anderen Zeit zog der Bodhisattva mit großem Pomp zum westlichen Tore der Stadt hinaus, um die Parkanlagen zu besuchen. Und da sah er, wie man einen Toten dahertrug, dessen Leichnam auf ein Tragbett gelegt und mit einem Gewande zugedeckt war." (Waldschmidt 1929: 87). 


\section{J(৫)}

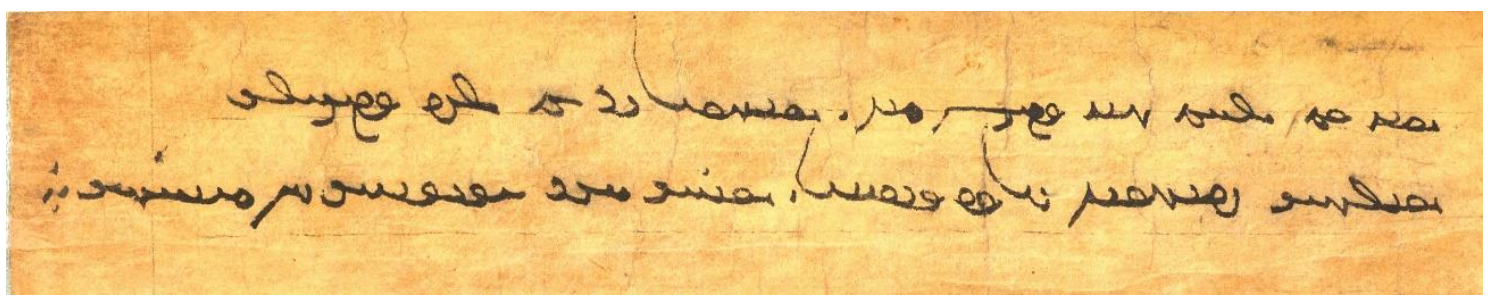

Abb. II: BD 14940 (Gedicht)

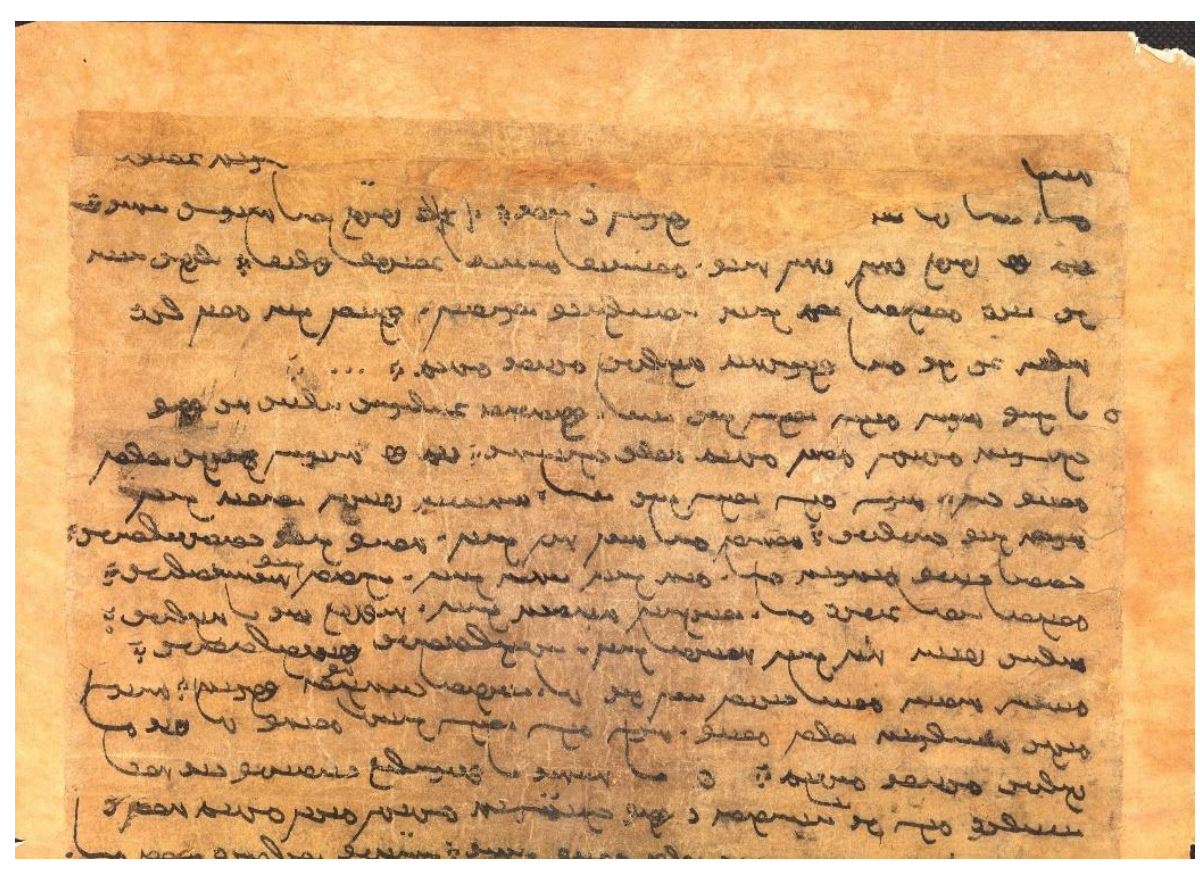

Abb. III: BD 14941 (ZZ. 001-016) 


\section{$\mathrm{J}(\mathrm{G})$}

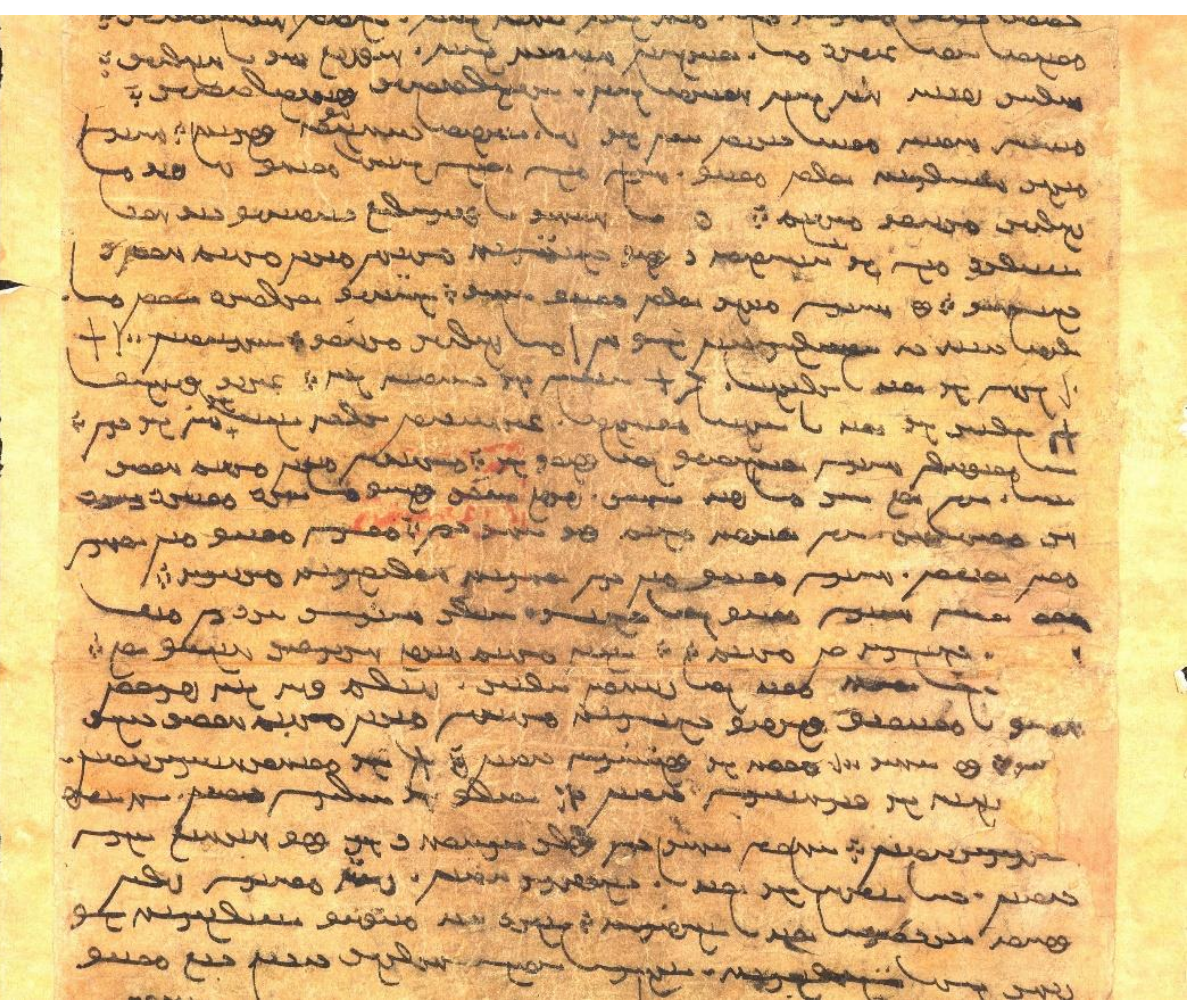

Abb. IV: BD 14941 (ZZ. 011-034)

- Hew

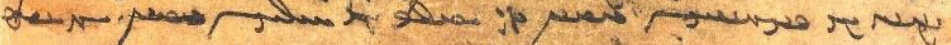

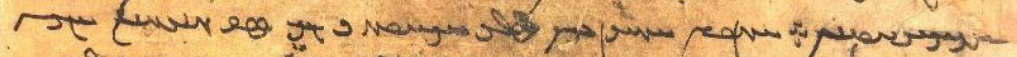

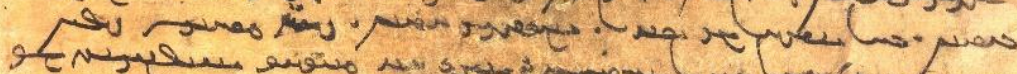
हN, 2no

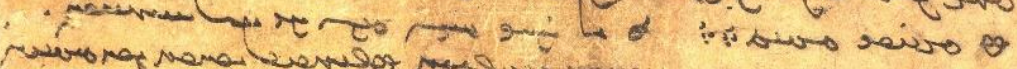

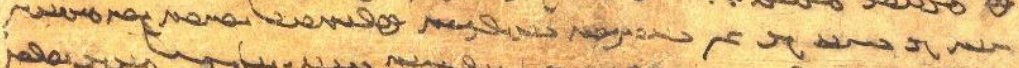

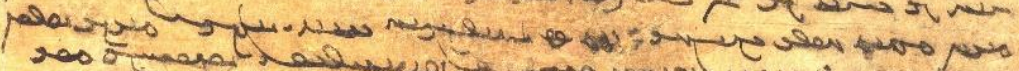

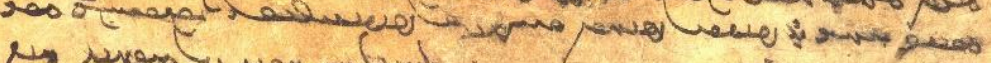

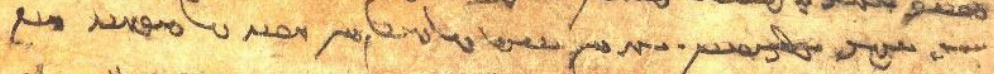

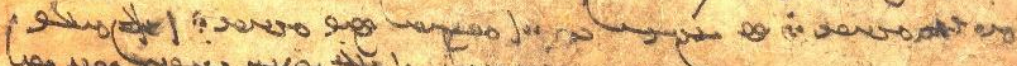

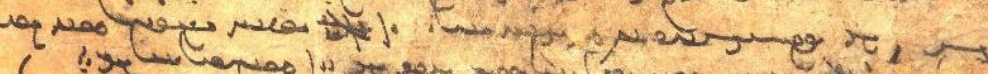

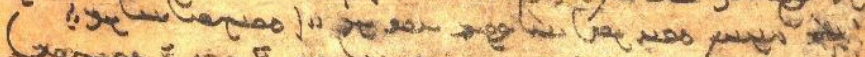

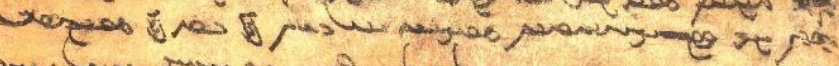

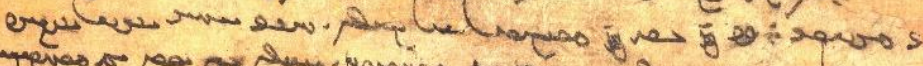

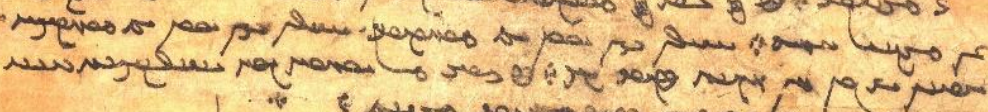

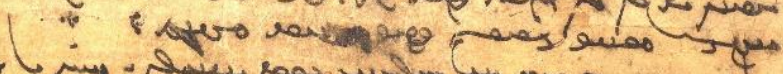

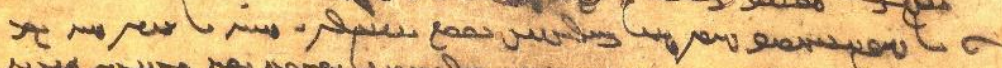

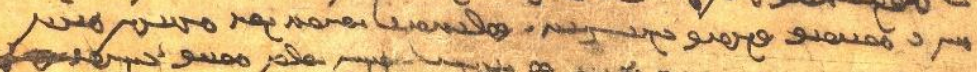

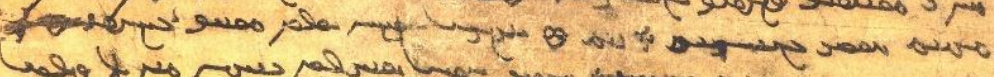

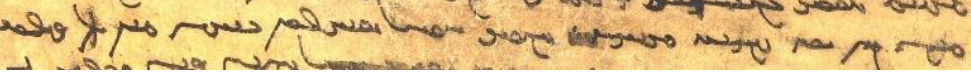

Abb. V: BD 14941 (ZZ. 029-051) 


\section{$\mathrm{J}(\mathrm{G})$}

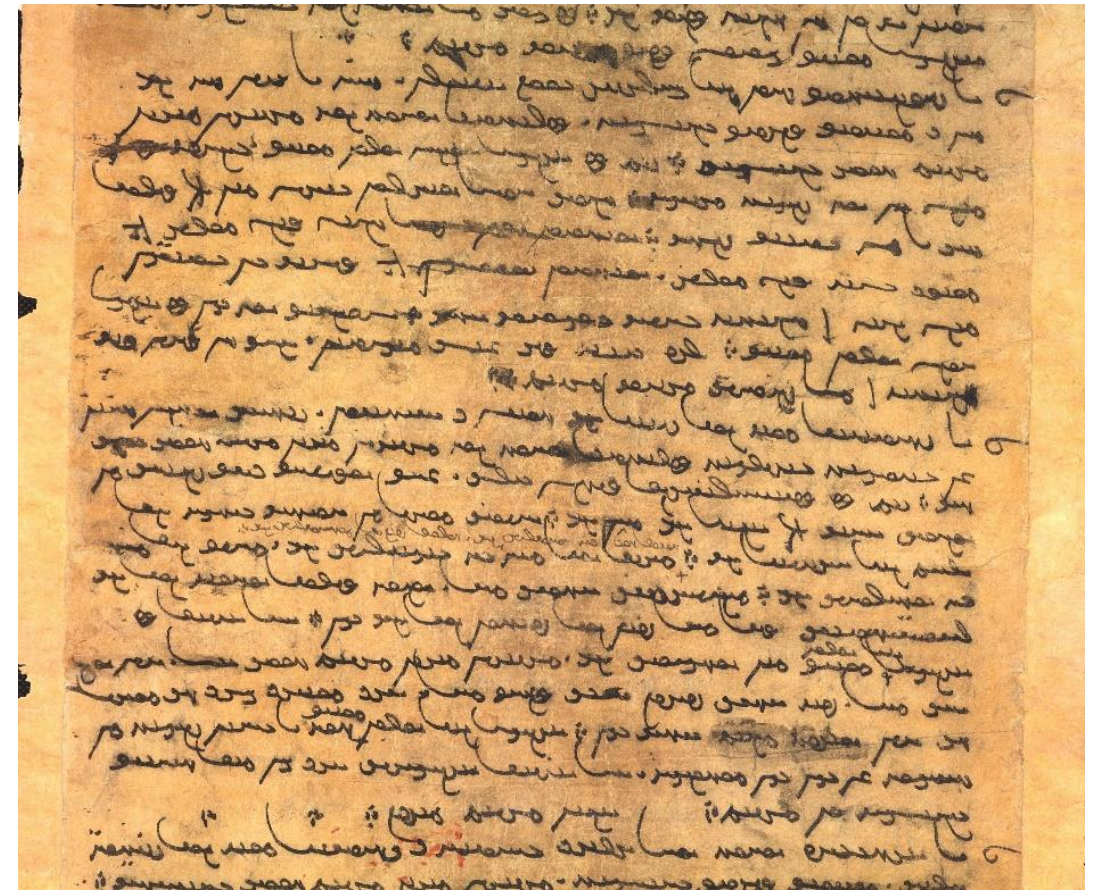

Abb. VI: BD 14941 (ZZ. 047-069)

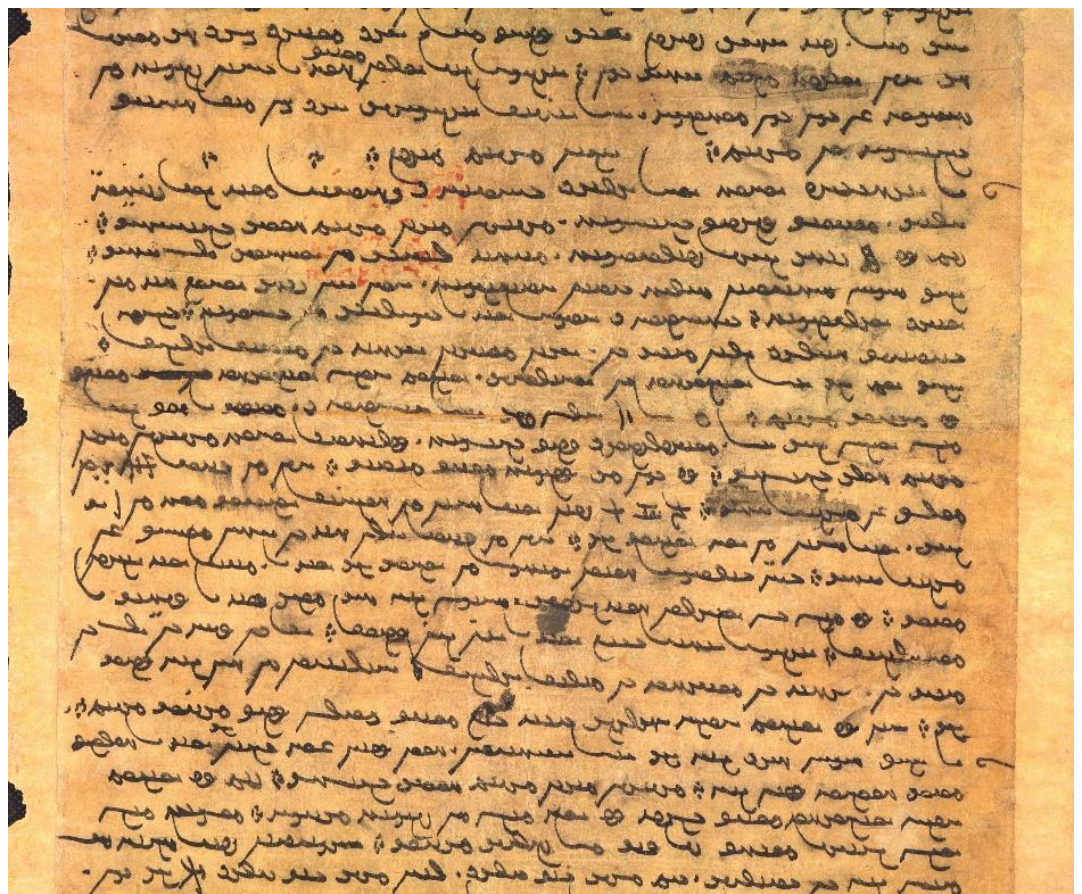

Abb. VII: BD 14941 (ZZ. 065-090) 


\section{J(G)}

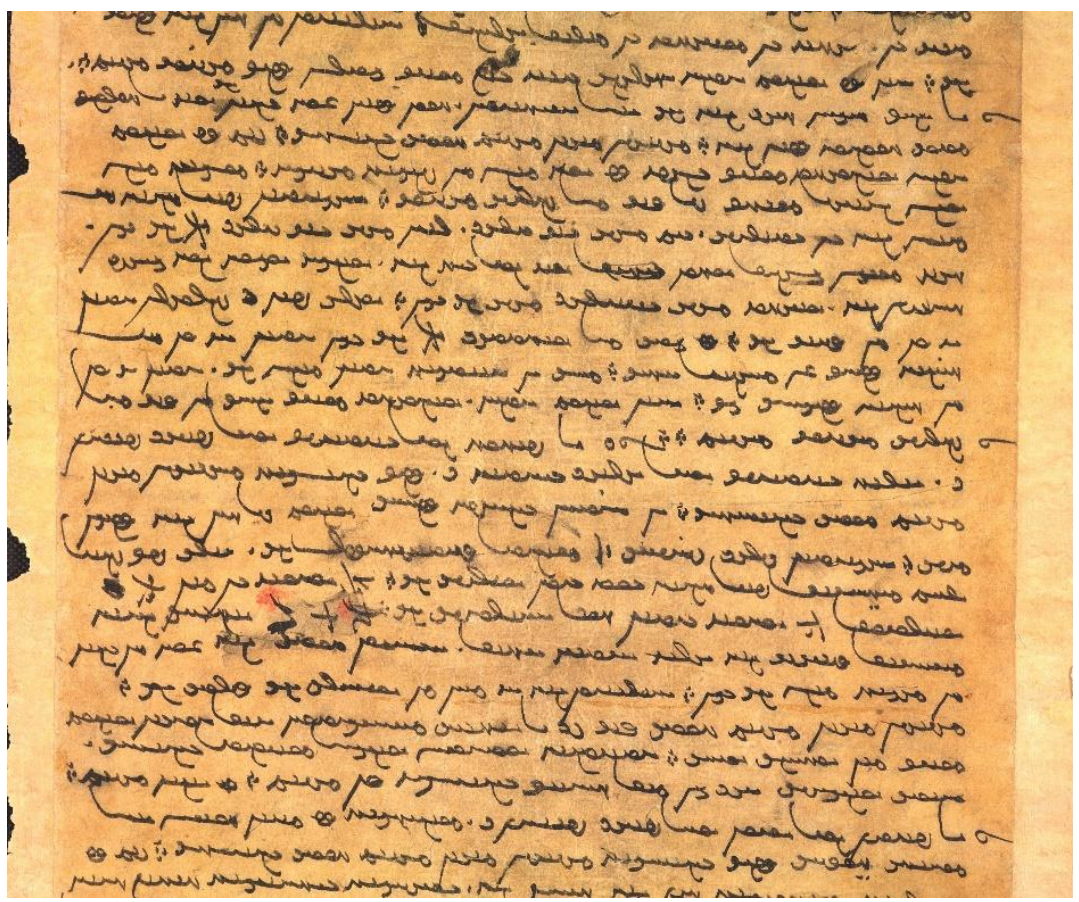

Abb. VIII: BD 14941 (ZZ. 085-107)

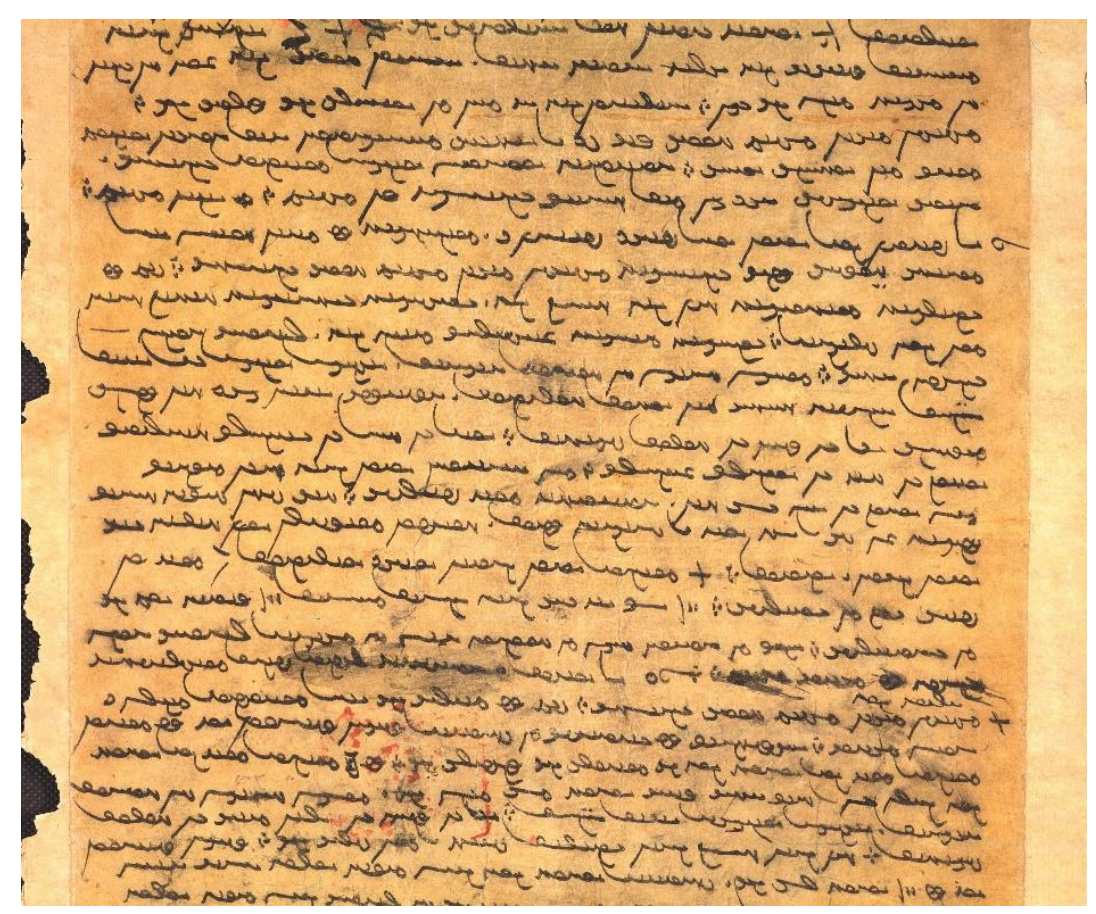

Abb. IX: BD 14941 (ZZ. 103-126) 


\section{J(G)}

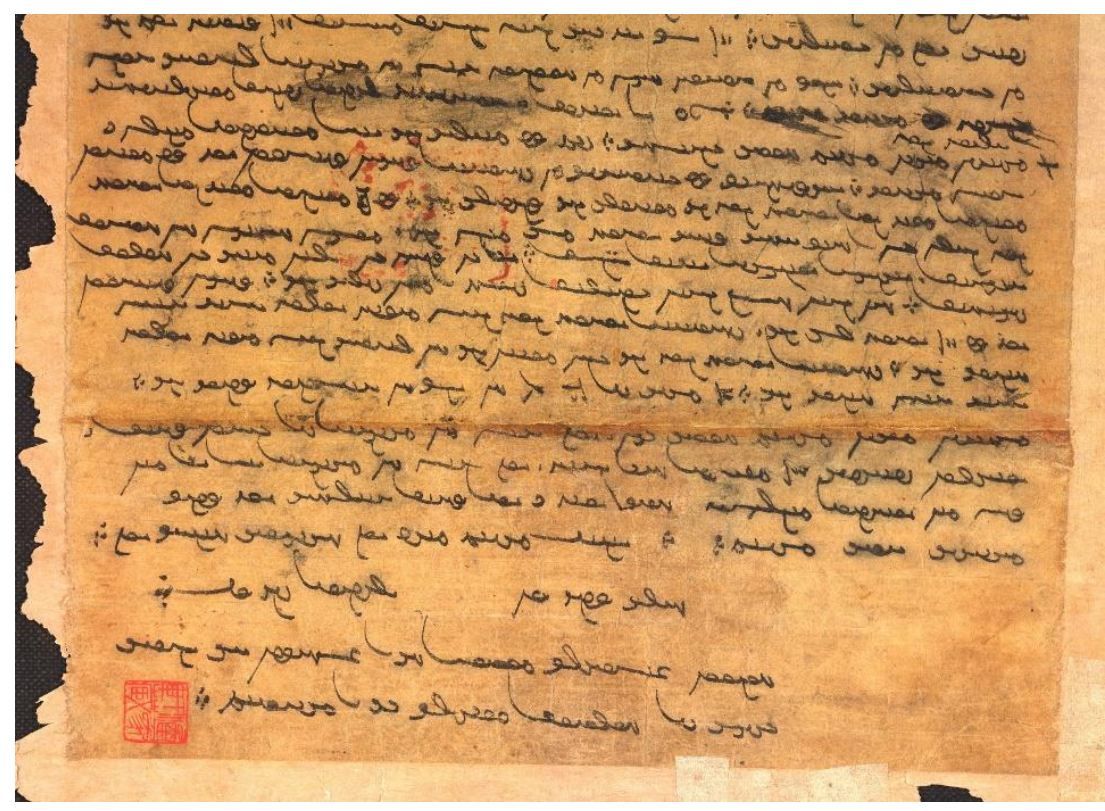

Abb. X: BD 14941 (ZZ. 119-Ende)

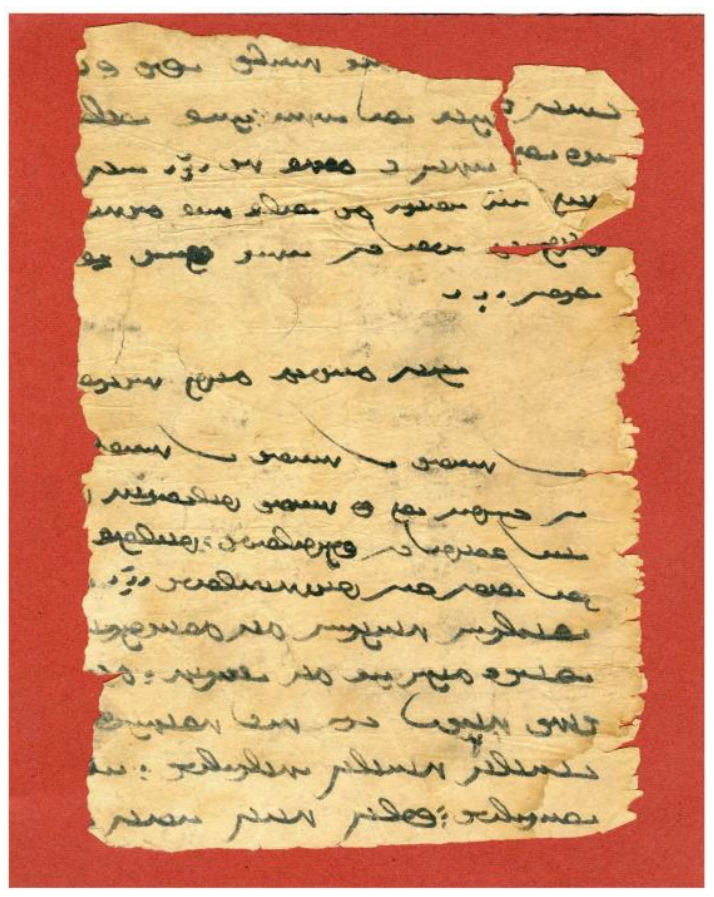

Abb. XI: Fragment der Lujiang Caotang-Sammlung in Hangzhou. 